\title{
Interventions for promoting habitual exercise in people living with and beyond cancer (Review)
}

Turner RR, Steed L, Quirk H, Greasley RU, Saxton JM, Taylor SJC, Rosario DJ, Thaha MA, Bourke L

Turner RR, Steed L, Quirk H, Greasley RU, Saxton JM, Taylor SJC, Rosario DJ, Thaha MA, Bourke L.

Interventions for promoting habitual exercise in people living with and beyond cancer.

Cochrane Database of Systematic Reviews 2018, Issue 9. Art. No.: CD010192.

DOI: 10.1002/14651858.CD010192.pub3.

www.cochranelibrary.com 
TABLE OF CONTENTS

ABSTRACT 1

PLAIN LANGUAGE SUMMARY

SUMMARY OF FINDINGS

BACKGROUND

OBJECTIVES

METHODS

RESULTS

Figure 1.

Figure 2.

Figure 3.

DISCUSSION

AUTHORS' CONCLUSIONS

ACKNOWLEDGEMENTS

REFERENCES

CHARACTERISTICS OF STUDIES

DATA AND ANALYSES

Analysis 1.1. Comparison 1 Aerobic exercise tolerance, Outcome 1 Aerobic exercise tolerance (all cancers: 8 to 12 weeks of follow-up).

Analysis 1.2. Comparison 1 Aerobic exercise tolerance, Outcome 2 Aerobic exercise tolerance (all cancers: 8 to 12 weeks of follow-up sensitivity analysis).

Analysis 1.3. Comparison 1 Aerobic exercise tolerance, Outcome 3 Aerobic exercise tolerance (all cancers: 6 months of followup).

Analysis 1.4. Comparison 1 Aerobic exercise tolerance, Outcome 4 Aerobic exercise tolerance (breast cancer: 8-12 weeks of follow-up).

Analysis 1.5. Comparison 1 Aerobic exercise tolerance, Outcome 5 Aerobic exercise tolerance (all cancers: combination of supervised and home-based exercise: 8 to 12 weeks of follow-up).

Analysis 1.6. Comparison 1 Aerobic exercise tolerance, Outcome 6 Aerobic exercise tolerance (all cancers: home-based exercise: 8 to 12 weeks of follow-up).

Analysis 1.7. Comparison 1 Aerobic exercise tolerance, Outcome 7 Aerobic exercise tolerance (all cancers:supervised exercise: 8 to 12 weeks of follow-up).

Analysis 1.8. Comparison 1 Aerobic exercise tolerance, Outcome 8 Aerobic exercise tolerance (all cancers: undergoing active treatment: 8 to 12 weeks follow-up).

Analysis 1.9. Comparison 1 Aerobic exercise tolerance, Outcome 9 Aerobic exercise tolerance (all cancers: no active treatment: 8 to 12 weeks follow-up.

Analysis 2.1. Comparison 2 Strength tests (all cancers), Outcome 1 Strength tests (all cancers, 12 weeks of follow-up). ........... Analysis 2.2. Comparison 2 Strength tests (all cancers), Outcome 2 Strength tests (all cancers: 12 weeks of follow-up: sensitivity analysis).

ADDITIONAL TABLES

APPENDICES

WHAT'S NEW

HISTORY

CONTRIBUTIONS OF AUTHORS

DECLARATIONS OF INTEREST

SOURCES OF SUPPORT

DIFFERENCES BETWEEN PROTOCOL AND REVIEW

INDEX TERMS 
[Intervention Review]

\section{Interventions for promoting habitual exercise in people living with and beyond cancer}

Rebecca R Turner ${ }^{1}$, Liz Steed², Helen Quirk ${ }^{1}$, Rosa U Greasley¹, John M Saxton ${ }^{3}$, Stephanie JC Taylor ${ }^{4}$, Derek J Rosario ${ }^{5}$, Mohamed A Thaha6, Liam Bourke ${ }^{7}$

${ }^{1}$ Centre for Sport and Exercise Science, Sheffield Hallam University, Sheffield, UK. ${ }^{2}$ Centre for Primary Care and Public Health, Barts and The London School of Medicine and Dentistry, Queen Mary University of London, London, UK. ${ }^{3}$ Department of Sport, Exercise, and Rehabilitation, Northumbria University, Newcastle-upon-Tyne, UK. ${ }^{4}$ Centre for Primary Care and Public Health and Asthma UK Centre for Applied Research, Barts and The London School of Medicine and Dentistry, Queen Mary University of London, London, UK. 5 Department of Oncology, University of Sheffield, Sheffield, UK. ${ }^{6}$ Academic Surgical Unit, National Centre for Bowel Research \& Surgical Innovation, Centre for Digestive Diseases, Blizard Institute, Barts \& The London School of Medicine \& Dentistry, Queen Mary University London, London, UK. 7Health and Wellbeing Research Institute, Sheffield Hallam University, Sheffield, UK

Contact: Liam Bourke, Health and Wellbeing Research Institute, Sheffield Hallam University, Sheffield, S10 2BP, UK. l.bourke@shu.ac.uk.

Editorial group: Cochrane Gynaecological, Neuro-oncology and Orphan Cancer Group.

Publication status and date: Edited (no change to conclusions), published in Issue 9, 2018.

Citation: Turner RR, Steed L, Quirk H, Greasley RU, Saxton JM, Taylor SJC, Rosario DJ, Thaha MA, Bourke L. Interventions for promoting habitual exercise in people living with and beyond cancer. Cochrane Database of Systematic Reviews 2018, Issue 9. Art. No.: CD010192. DOI: 10.1002/14651858.CD010192.pub3.

Copyright () 2018 The Cochrane Collaboration. Published by John Wiley \& Sons, Ltd.

\section{A B S T R A C T}

\section{Background}

This is an updated version of the original Cochrane Review published in the Cochrane Library 2013, Issue 9. Despite good evidence for the health benefits of regular exercise for people living with or beyond cancer, understanding how to promote sustainable exercise behaviour change in sedentary cancer survivors, particularly over the long term, is not as well understood. A large majority of people living with or recovering from cancer do not meet current exercise recommendations. Hence, reviewing the evidence on how to promote and sustain exercise behaviour is important for understanding the most effective strategies to ensure benefit in the patient population and identify research gaps.

\section{Objectives}

To assess the effects of interventions designed to promote exercise behaviour in sedentary people living with and beyond cancer and to address the following secondary questions: Which interventions are most effective in improving aerobic fitness and skeletal muscle strength and endurance? Which interventions are most effective in improving exercise behaviour amongst patients with different cancers? Which interventions are most likely to promote long-term (12 months or longer) exercise behaviour? What frequency of contact with exercise professionals and/or healthcare professionals is associated with increased exercise behaviour? What theoretical basis is most often associated with better behavioural outcomes? What behaviour change techniques (BCTs) are most often associated with increased exercise behaviour? What adverse effects are attributed to different exercise interventions?

\section{Search methods}

We used standard methodological procedures expected by Cochrane. We updated our 2013 Cochrane systematic review by updating the searches of the following electronic databases: Cochrane Central Register of Controlled Trials (CENTRAL) in The Cochrane Library, MEDLINE, Embase, AMED, CINAHL, PsycLIT/PsycINFO, SportDiscus and PEDro up to May 2018. We also searched the grey literature, trial registries, wrote to leading experts in the field and searched reference lists of included studies and other related recent systematic reviews. 


\section{Selection criteria}

We included only randomised controlled trials (RCTs) that compared an exercise intervention with usual care or 'waiting list' control in sedentary people over the age of 18 with a homogenous primary cancer diagnosis.

\section{Data collection and analysis}

In the update, review authors independently screened all titles and abstracts to identify studies that might meet the inclusion criteria, or that could not be safely excluded without assessment of the full text (e.g. when no abstract is available). We extracted data from all eligible papers with at least two members of the author team working independently (RT, LS and RG). We coded BCTs according to the CALO-RE taxonomy. Risk of bias was assessed using the Cochrane's tool for assessing risk of bias. When possible, and if appropriate, we performed a fixed-effect meta-analysis of study outcomes. If statistical heterogeneity was noted, a meta-analysis was performed using a random-effects model. For continuous outcomes (e.g. cardiorespiratory fitness), we extracted the final value, the standard deviation (SD) of the outcome of interest and the number of participants assessed at follow-up in each treatment arm, to estimate the standardised mean difference (SMD) between treatment arms. SMD was used, as investigators used heterogeneous methods to assess individual outcomes. If a meta-analysis was not possible or was not appropriate, we narratively synthesised studies. The quality of the evidence was assessed using the GRADE approach with the GRADE profiler.

\section{Main results}

We included 23 studies in this review, involving a total of 1372 participants (an addition of 10 studies, 724 participants from the original review); 227 full texts were screened in the update and 377 full texts were screened in the original review leaving 35 publications from a total of 23 unique studies included in the review. We planned to include all cancers, but only studies involving breast, prostate, colorectal and lung cancer met the inclusion criteria. Thirteen studies incorporated a target level of exercise that could meet current recommendations for moderate-intensity aerobic exercise (i.e.150 minutes per week); or resistance exercise (i.e. strength training exercises at least two days per week).

Adherence to exercise interventions, which is crucial for understanding treatment dose, is still reported inconsistently. Eight studies reported intervention adherence of $75 \%$ or greater to an exercise prescription that met current guidelines. These studies all included a component of supervision: in our analysis of BCTs we designated these studies as 'Tier 1 trials'. Six studies reported intervention adherence of $75 \%$ or greater to an aerobic exercise goal that was less than the current guideline recommendations: in our analysis of BCTs we designated these studies as 'Tier 2 trials.' A hierarchy of BCTs was developed for Tier 1 and Tier 2 trials, with programme goal setting, setting of graded tasks and instruction of how to perform behaviour being amongst the most frequent BCTs. Despite the uncertainty surrounding adherence in some of the included studies, interventions resulted in improvements in aerobic exercise tolerance at eight to 12 weeks (SMD $0.54,95 \% \mathrm{Cl} 0.37$ to $0.70 ; 604$ participants, 10 studies; low-quality evidence) versus usual care. At six months, aerobic exercise tolerance was also improved (SMD 0.56, 95\% Cl 0.39 to 0.72; 591 participants; 7 studies; low-quality evidence).

\section{Authors' conclusions}

Since the last version of this review, none of the new relevant studies have provided additional information to change the conclusions. We have found some improved understanding of how to encourage previously inactive cancer survivors to achieve international physical activity guidelines. Goal setting, setting of graded tasks and instruction of how to perform behaviour, feature in interventions that meet recommendations targets and report adherence of $75 \%$ or more. However, long-term follow-up data are still limited, and the majority of studies are in white women with breast cancer. There are still a considerable number of published studies with numerous and varied issues related to high risk of bias and poor reporting standards. Additionally, the meta-analyses were often graded as consisting of low- to very low-certainty evidence. A very small number of serious adverse effects were reported amongst the studies, providing reassurance exercise is safe for this population.

\section{PLAIN LANGUAGE SUMMARY}

\section{Interventions for promoting habitual exercise in people living with and beyond cancer}

\section{The issue}

Being regularly active can bring a range of health benefits for people living with and beyond cancer, including improved quality of life and physical function. Being physically active might also reduce the risk of cancer recurrence and of dying from cancer. Because most cancer survivors are not regularly physically active, there is a need to understand how best to promote and sustain physical activity in this population.

\section{The aim of the review}

To understand what are the most effective ways to improve and sustain exercise behaviour in people living with and beyond cancer.

\section{Study characteristics}

We included only studies that compared an exercise intervention with a usual care comparison or 'waiting list' control. Only studies that included sedentary people over the age of 18 with the same cancer diagnosis were eligible. Participants must have been allocated to exercise or usual care at random. We searched for evidence from research databases from 1946 to May 2018. 
What are the main findings?

We included 23 studies involving 1372 participants in total. Evidence suggests that exercise studies that incorporate an element of supervision can help cancer survivors. However, we still have a poor understanding of how to promote exercise long term (over six months). There is some concern that research is not being reported as clearly as it should be. We found that setting goals, graded physical activity tasks and providing instructions on how to perform the exercises could help people to do beneficial amounts of exercise. In addition, we found some evidence that in people who do meet recommended exercise levels, get fitter for up to six months.

\section{Quality of the evidence}

The main problems that we found regarding the quality of studies in this review included: not knowing how study investigators conducted randomisation for the trials and not knowing whether investigators who were doing trial assessments knew to which group the person they were assessing had been randomly assigned. The quality of the evidence from these studies was found to be low due to the majority of the trials often containing a low number of participants.

\section{What are the conclusions?}

The main conclusions from this review are that exercise is generally safe for cancer survivors. We have a better understanding of how to encourage cancer survivors to meet current exercise recommendations. However, there is still a lack of evidence of how to encourage exercise in cancer survivors over six months. 


\section{SUMMARY OF FINDINGS}

\section{Summary of findings for the main comparison. Exercise interventions compared to usual care for promoting habitual exercise in people living with and beyond cancer to improve aerobic exercise tolerance}

Exercise interventions compared to usual care for promoting habitual exercise in people living with and beyond cancer to improve aerobic exercise tolerance

\begin{tabular}{|c|c|c|c|c|}
\hline \multirow[t]{2}{*}{ Outcomes } & \multirow{2}{*}{$\begin{array}{l}\text { № of partici- } \\
\text { pants } \\
\text { (studies) } \\
\text { Follow-up }\end{array}$} & \multirow{2}{*}{$\begin{array}{l}\text { Certainty of the } \\
\text { evidence } \\
\text { (GRADE) }\end{array}$} & \multicolumn{2}{|l|}{ Anticipated absolute effects ${ }^{*}(95 \% \mathrm{CI})$} \\
\hline & & & Risk with usual care & $\begin{array}{l}\text { Risk difference } \\
\text { with exercise in- } \\
\text { terventions }\end{array}$ \\
\hline $\begin{array}{l}\text { Aerobic exercise tolerance } \\
\text { (all cancers: } 8 \text { to } 12 \text { weeks of } \\
\text { follow-up) }\end{array}$ & $\begin{array}{l}604 \\
\text { (10 RCTs) }\end{array}$ & $\begin{array}{l}\oplus \oplus \ominus \ominus \\
\text { LOW } 12\end{array}$ & $\begin{array}{l}\text { The mean aerobic exercise toler- } \\
\text { ance (all cancers: } 8 \text { to } 12 \text { weeks of } \\
\text { follow-up) was } 0\end{array}$ & $\begin{array}{l}\text { SMD } 0.54 \text { higher } \\
\text { ( } 0.37 \text { higher to } 0.70 \\
\text { higher) }\end{array}$ \\
\hline $\begin{array}{l}\text { Aerobic exercise tolerance } \\
\text { (all cancers: } 8 \text { to } 12 \text { weeks of } \\
\text { follow-up sensitivity analysis) }\end{array}$ & $\begin{array}{l}201 \\
\text { (4 RCTs) }\end{array}$ & $\begin{array}{l}\oplus \oplus \Theta \ominus \\
\text { LOW } 23\end{array}$ & $\begin{array}{l}\text { The mean aerobic exercise toler- } \\
\text { ance (all cancers: } 8 \text { to } 12 \text { weeks of } \\
\text { follow-up sensitivity analysis) was } 0\end{array}$ & $\begin{array}{l}\text { SMD } 0.85 \text { higher } \\
\text { ( } 0.56 \text { higher to } 1.14 \\
\text { higher) }\end{array}$ \\
\hline $\begin{array}{l}\text { Aerobic exercise tolerance } \\
\text { (all cancers: } 6 \text { months) }\end{array}$ & $\begin{array}{l}591 \\
\text { (7 RCTs) }\end{array}$ & $\begin{array}{l}\oplus \oplus \ominus \ominus \\
\text { LOW } 12\end{array}$ & $\begin{array}{l}\text { The mean aerobic exercise toler- } \\
\text { ance (all cancers: } 6 \text { months) was } 0\end{array}$ & $\begin{array}{l}\text { SMD } 0.56 \text { higher } \\
\text { ( } 0.39 \text { higher to } 0.72 \\
\text { higher) }\end{array}$ \\
\hline $\begin{array}{l}\text { Aerobic exercise tolerance } \\
\text { (breast cancer: } 8-12 \text { weeks of } \\
\text { follow-up) }\end{array}$ & $\begin{array}{l}441 \\
\text { (6 RCTs) }\end{array}$ & $\begin{array}{l}\oplus \ominus \ominus \odot \\
\text { VERY LOW } 124\end{array}$ & $\begin{array}{l}\text { The mean aerobic exercise toler- } \\
\text { ance (breast cancer: 8-12 weeks of } \\
\text { follow-up) was } 0\end{array}$ & $\begin{array}{l}\text { SMD } 0.57 \text { higher } \\
\text { ( } 0.22 \text { higher to } 0.93 \\
\text { higher) }\end{array}$ \\
\hline $\begin{array}{l}\text { Aerobic exercise tolerance } \\
\text { (all cancers: combination of } \\
\text { supervised and home-based } \\
\text { exercise: } 8 \text { to } 12 \text { weeks of fol- } \\
\text { low-up) }\end{array}$ & $\begin{array}{l}357 \\
\text { (4 RCTs) }\end{array}$ & $\begin{array}{l}\oplus \odot \ominus \odot \\
\text { VERY LOW } 234\end{array}$ & $\begin{array}{l}\text { The mean aerobic exercise toler- } \\
\text { ance (all cancers: combination of } \\
\text { supervised and home-based exer- } \\
\text { cise: } 8 \text { to } 12 \text { weeks of follow-up) was } \\
0\end{array}$ & $\begin{array}{l}\text { SMD } 0.53 \text { higher } \\
\text { ( } 0.01 \text { higher to } 1.04 \\
\text { higher) }\end{array}$ \\
\hline $\begin{array}{l}\text { Aerobic exercise tolerance } \\
\text { (all cancers: home-based ex- } \\
\text { ercise: } 8 \text { to } 12 \text { weeks of fol- } \\
\text { low-up) }\end{array}$ & $\begin{array}{l}155 \\
\text { (3 RCTs) }\end{array}$ & $\begin{array}{l}\oplus \odot \ominus \odot \\
\text { VERY LOW } 123\end{array}$ & $\begin{array}{l}\text { The mean aerobic exercise toler- } \\
\text { ance (all cancers: home-based exer- } \\
\text { cise: } 8 \text { to } 12 \text { weeks of follow-up) was } \\
0\end{array}$ & $\begin{array}{l}\text { SMD } 0.70 \text { higher } \\
\text { ( } 0.37 \text { higher to } 1.03 \\
\text { higher) }\end{array}$ \\
\hline $\begin{array}{l}\text { Aerobic exercise tolerance } \\
\text { (all cancers:supervised ex- } \\
\text { ercise: } 8 \text { to } 12 \text { weeks of fol- } \\
\text { low-up) }\end{array}$ & $\begin{array}{l}92 \\
\text { (3 RCTs) }\end{array}$ & $\begin{array}{l}\oplus \odot \odot \odot \\
\text { VERY LOW } 235\end{array}$ & $\begin{array}{l}\text { The mean aerobic exercise toler- } \\
\text { ance (all cancers:supervised exer- } \\
\text { cise: } 8 \text { to } 12 \text { weeks of follow-up) was } \\
0\end{array}$ & $\begin{array}{l}\text { SMD } 1.07 \text { higher } \\
\text { ( } 0.26 \text { higher to } 1.89 \\
\text { higher) }\end{array}$ \\
\hline
\end{tabular}

*The risk in the intervention group (and its 95\% confidence interval) is based on the assumed risk in the comparison group and the relative effect of the intervention (and its $95 \% \mathrm{Cl}$ ).

CI: Confidence interval; SMD: standarised mean difference

\section{GRADE Working Group grades of evidence}

High-certainty: We are very confident that the true effect lies close to that of the estimate of the effect

Moderate-certainty: We are moderately confident in the effect estimate: The true effect is likely to be close to the estimate of the effect, but there is a possibility that it is substantially different

Low-certainty: Our confidence in the effect estimate is limited: The true effect may be substantially different from the estimate of the effect 
Very low-certainty: We have very little confidence in the effect estimate: The true effect is likely to be substantially different from the estimate of effect

1 Some concerns with high number of participants lost to follow-up, selective reporting of data and other risks of bias

2 Concerns over number of small studies included with positive results

3 Low number of participants in the studies overall and large confidence intervals

4 Some concerns over variations in effect sizes, the test for heterogeneity is significant and $\mathrm{I}^{2}$ value is high (> 50)

5 Some concerns over the variations in effect sizes. 


\section{B A C K G R O U N D}

This review is an update of a previously published review in the Cochrane Database of Systematic Reviews (2013, Issue 9) Bourke 2013.

\section{Description of the condition}

Cancer is a major public health issue. In 2015, there were 17.5 million cases of cancer globally, 8.7 million deaths and the disease is estimated to be responsible for 208 million disability adjusted life years (Global Burden of Disease Cancer Collaboration 2017). Age-standardised cancer mortality rates are decreasing (in the Western hemisphere), which is encouraging progress (Hashim 2016). However, although increasing numbers of cancer survivors live longer, this does not equate to living well. Survivors face a multitude of unique, debilitating health problems, even after treatment with curative intent. These range from an increased risk of recurrent cancers (Low 2014), persistent symptoms such as fatigue (Low 2014), ongoing poor health and well-being (Elliott 2011), and mental health comorbidity (Nakash 2014). The burden of these problems can lead to negative impacts on health-related quality of life (HRQoL) (Corner 2013). Throughout this review, the term we define as 'cancer survivor' is synonymous with someone 'living with and beyond cancer', in accordance with the Macmillan Cancer Support definition (Macmillan Cancer Support 2011).

\section{Description of the intervention}

The goal of any exercise intervention is to offer a sustained physiological challenge that, over time, will induce a spectrum of beneficial cardiovascular, respiratory, musculoskeletal, neurological, metabolic adaptations as well as bringing a host of psychosocial benefits. In the context of living with and beyond cancer, such adaptations underpin improvements in cancer-related fatigue, HRQoL and physical function (Mishra 2014; Stout 2017). The UK Chief Medical Officer recommends that in adults, weekly activity should add up to at least 150 minutes of moderate intensity aerobic activity, performed in bouts of 10 minutes or longer (Department of Health 2011), with similar international recommendations for cancer survivors (Rock 2012). For example, this could translate to 30 minutes of aerobic activity that raises heart rate and breathing rate, five times per week. Alternatively, 75 minutes of vigorous intensity aerobic activity spread across the week has been suggested to confer similar benefit (Schmitz 2010a).

We have deliberately chosen the term 'habitual' over 'regular' to reflect the intention to assess which interventions could both A) improve and B) sustain exercise behaviour. 'Regular exercise' can be applied to both short-term and long-term contexts, where as a 'habitual' exerciser indicates a sustained and regular pattern of behaviour. Whilst 'habitual' refers to the process of behavioural 'habit forming' and an automaticity of behaviour (Gardner 2011; Verplanken 2009), we recognise there are other theoretical principals underpinning physical activity behaviour (Kwasnica 2016).

\section{How the intervention might work}

Encouraging people to participate in regular exercise from a background of an inactive lifestyle is difficult, requiring attention to important psychosocial and behavioural influences (Kampshoff 2014; Ormel 2017). A major challenge is to provide a support structure for physical activity until it becomes a pattern of sustained healthy behaviour. Randomised controlled trials (RCTs) in cancer survivors have assessed a number of exercise interventions, with the aim of promoting short- and long-term habitual exercise. A wide range of approaches have been investigated; including supervised exercise and home-based exercise (Bourke 2014), and inclusive of group counselling sessions, (Rogers 2015). Tailored exercise interventions commonly comprise aerobic exercise training, strength training or a combination of both, with or without behaviour change support. Behaviour change theory within exercise interventions is often viewed as essential, with the UK Medical Research Council (MRC) recommending the use of theory in intervention development for complex interventions to help improve behaviour change (Craig 2008). However, the application of behaviour change theory or specific behaviour change techniques is often generally poor, unclear and not clearly examined for impact of effectiveness.

\section{Why it is important to do this review}

The majority of people living with and beyond cancer are not regularly active, with estimates ranging from less than $10 \%$ to $20 \%$ to $30 \%$ of cancer survivors meeting the physical activity guidelines (Garcia 2014). There are a number of important beneficial effects of exercise participation in cancer survivors reported from RCTs including improved HRQoL, reduced fatigue and improved physical function, (Bourke 2014; Dittus 2017; Meneses-Echavez 2015; Mishra 2012a; Mishra 2012b; Stout 2017). However, the original review (Bourke 2013) found that most of the current evidence comes from studies with short-term interventions and followup. Understanding which interventions are most efficacious in supporting the maintenance of long-term exercise behaviour is critical not just because of the HRQoL benefits (Bourke 2012a), but multiple observational reports link being regularly active to reduced chances of dying from cancer after diagnosis (Li 2016).

The original review showed that there is a poor understanding of how to encourage people living with and beyond cancer to meet current exercise recommendations (Bourke 2013). Poor study reporting standards was a pervasive issue e.g. failure to report adherence data. However, there were some useful data regarding the use of behaviour change techniques (BCTs). An updated review can firstly, offer insight as to whether interventions being tested in contemporary studies are mapping to the existing international recommendations i.e. the American Cancer Society (ACS) guidance (i.e. provided by Rock 2012). Secondly, this will allow us to evaluate if there have been any improvements in the quality of intervention reporting around specifics of set prescriptions (i.e. frequency, intensity, duration etc). Thirdly, and critically, we can use a larger data set from our updated searches to assess if both the quality of reporting of exercise adherence has improved and if there is more to learn about how to promote and sustain better adherence to exercise behaviour interventions in previously inactive cancer survivors.

In the UK, the Independent Cancer Taskforce strategy document sets out a number of initiatives to achieve world class outcomes in cancer; ensuring survivors have the best possible quality of life and improving rates of mortality. Promoting habitual exercise participation could help to accomplish these high priority agendas within the UK. 


\section{O B J E C T I VES}

\section{Primary objective}

To assess the effects of interventions designed to promote exercise behaviour in sedentary people living with and beyond cancer.

\section{Secondary objectives}

To address the following questions.

- Which interventions are most effective in improving aerobic fitness and skeletal muscle strength and endurance?

- What adverse effects are attributed to different exercise interventions?

- Which interventions are most effective in improving exercise behaviour amongst patients with different cancers?

- Which interventions are most likely to promote long-term (12 months or longer) exercise behaviour?

- What frequency of contact with exercise professionals and/or healthcare professionals is associated with increased exercise behaviour?

- What theoretical basis is most often associated with increased exercise behaviour?

- What behaviour change techniques are most often associated with increased exercise behaviour?

\section{METHODS}

\section{Criteria for considering studies for this review}

\section{Types of studies}

Randomised controlled trials (RCTs) that allocated participants or clusters of participants by a random method to an exercisepromoting intervention compared with usual care or 'waiting list' control. We included studies conducted both during and after primary treatment or during active monitoring. Only interventions that included a component targeted at increasing aerobic exercise and/or resistance exercise behaviour were included in this review. We did not include studies of heterogeneous cancer cohorts (i.e. participants with different primary cancer sites). We did not include studies in 'at risk' populations (i.e. studies involving individuals who have risk factors for cancer but who have not yet been diagnosed with the disease) that addressed primary prevention research questions.

\section{Types of participants}

We included only studies involving adults (18 years of age or older) who had a sedentary lifestyle or physically inactive at baseline (i.e. not undertaking 30 minutes or more of exercise of at least moderate intensity, three days per week, or 90 minutes in total of moderate intensity exercise per week). Participants must have been histologically or clinically diagnosed with cancer regardless of sex, tumour site, tumour type, tumour stage and type of anticancer treatment received. We excluded studies directed specifically at end-of-life-care patients and individuals who were currently hospital inpatients.

\section{Types of interventions}

For the purposes of this review, the phrases 'exercise' and 'physical activity' were used interchangeably. Definitions of exercise, related terms and nomenclature that describe the performance of exercise must adhere to principles of science and must satisfy the Système International d'Unités (SI), which was adopted universally in 1960. Hence, we referred to the appropriate, combined definition that applies to all situations: 'A potential disruption to homeostasis by muscle activity that is either exclusively or in combination, concentric, eccentric or isometric' (Winter 2009). Investigators must have reported the frequency, duration and intensity of aerobic exercise behaviour or frequency, intensity, type, sets and repetitions of resistance exercise behaviour that was prescribed in the intervention.

We acknowledge that the maximal aerobic capacity $\left(\mathrm{V}_{2}\right.$ max $) /$ peak is often the most informative metric for setting aerobic exercise intensity; however, given the nature of the population involved (elderly, potentially with multiple comorbidities), it is often difficult to conduct maximal testing protocols to prescribe intensity on the basis of this measures because of the requirements for medically qualified staff to be present during assessment. As such, for reasons of pragmatism, we accepted that exercise intensity is more frequently reported in cancer the cohorts in terms of age-predicted maximum heart rate $\left(\mathrm{HR}_{\max }\right)$ or Borg Rating of Perceived Exertion (RPE) (Borg 1982). The interventions in this review were categorised as achieving a mild (less than $60 \% \mathrm{HR}_{\max } / 10 \mathrm{RPE}$ or less), moderate $\left(60 \%\right.$ to $84 \% \mathrm{HR}_{\max } / 11$ to $14 \mathrm{RPE}$ ) or vigorous $\left(85 \% \mathrm{HR}_{\max }\right.$ or more/15 RPE or more) exercise intensity.

\section{Types of outcome measures}

\section{Primary outcomes}

Aerobic exercise behaviour as measured by:

- exercise frequency (number of bouts per week);

- exercise duration (total minutes of exercise achieved);

- exercise intensity (e.g. \% $\mathrm{HR}_{\max }, \mathrm{RPE}$ );

- estimated energy expenditure from free-living physical activity (e.g. from accelerometer readings (where available));

- adherence to the exercise intervention (\% of exercise sessions completed/attended); total duration of intervention when $\geq 75 \%$ adherence is achieved (in weeks);

- total duration of sustained exercise behaviour meeting American Cancer Society guidelines for exercise in people living with and beyond cancer (Rock 2012; i.e. aim to exercise at least 150 minutes per week, with at least two days per week of strength training).

Resistance exercise behaviour as measured by:

- exercise frequency (number of bouts per week);

- exercise intensity (e.g. \% of 1 repetition max or \% of body mass);

- type of exercise (e.g. free weights, body weight exercise);

- repetitions;

- sets.

\section{Secondary outcomes}

- Change in aerobic fitness or exercise tolerance (maximal or submaximal when measured directly or by a standard field test).

- Change in skeletal muscle strength and endurance.

- Adverse effects. 
- study recruitment rate.

- Intervention attrition rate.

Interventions were judged as successful in achieving exercise goals if investigators reported at least $75 \%$ adherence over a given followup period as done in the original review (Bourke 2013). Data on compliance with the intervention were quantified in terms of number of prescribed exercise sessions completed as a proportion of the total set. The intervention must have included at least six weeks of follow-up. Interventions were described according to whether they reported being based on a behaviour change theory e.g. control theory, social cognitive theory; (Bandura 2000; Bandura 2002; Carver 1982. This relates to the National Institute for Health and Clinical Excellence (NICE) guidance for behaviour change, which recommends that clinicians should be explicit about the theoretical constructs on which interventions are based (NICE 2007). Interventions were also coded using the 'Coventry, Aberdeen \& London-Refined' (CALO-RE) taxonomy (Michie 2011). This is a validated taxonomy of behaviour change techniques (BCTs) that can be used to help people change their exercise behaviour. Coding interventions according to this taxonomy allows for a better understanding of which techniques are employed by current interventions and how they are related to short- and longer-term exercise behaviour change.

\section{Search methods for identification of studies}

\section{Electronic searches}

The searches were run for the original review from inception to August 2012. The subsequent searches from the following electronic databases were run from August 2012 up to 3 May 2018. We carried out the following searches:

- the Cochrane Central Register of Controlled Trials (CENTRAL; 2018, Issue 5) in The Cochrane Library;

- MEDLINE via OVID August 2012 to April week 4 2018;

- Embase via OVID August 2012 to 2018 week 18;

- AMED (Allied and Alternative Medicine Database; covers occupational therapy, physiotherapy and complementary medicine) August 2012 to May 2018;

- CINAHL (Cumulative Index to Nursing and Allied Health Literature) August 2012 to May 2018;

- PsycINFO (Database of the American Psychological Association) August 2012 to May 2018;

- SportDiscus (Sports Evidence Database) August 2012 to April 2017;

- PEDro (Physiotherapy Evidence Database) August 2012 to April 2017.

The search strategies are presented in the Appendices, with both the 2018 updated strategy and previous 2012 strategy reported. CENTRAL search strategy is presented in Appendix 1 and the MEDLINE search strategy in Appendix 2. For databases other than MEDLINE, we adapted the search strategy accordingly: Embase (Appendix 3), AMED (Appendix 4), CINAHL (Appendix 5) PsycINFO (Appendix 6) PEDro (Appendix 7) SportsDiscus (Appendix 8).

The search strategies were developed with the Cochrane Gynaecological Cancer Group Information Specialist and included $\mathrm{MeSH}$ and text word terms as appropriate.

\section{Searching other resources}

We used snowballing, by searching reference lists of retrieved articles and published reviews on the topic.

We expanded the database search by identifying additional relevant studies for this review, including unpublished studies and references in the grey literature. This was done by searching the OpenGrey database (www.opengrey.eu/), which includes technical or research reports, doctoral dissertations, conference papers and other types of grey literature. We also searched the following clinical trials web pages.

- World Health Organisation apps.who.int/trialsearch/ Default.aspx

- National cancer institute www.cancer.gov/about-cancer/ treatment/clinical-trials/search

Furthermore, we wrote to Cancer Research UK (CRUK), Macmillan Cancer Support, the World Cancer Research Fund (WCRF), Worldwide Cancer Research , the American Association for Cancer Research (AACR), the American Cancer Society (ACS) and the American Society of Clinical Oncology (ASCO) to enquire about relevant unpublished papers.

\section{Data collection and analysis}

Since publication of the previous version of this review, we have included the use of the GRADE assessment to assess the quality of the evidence and produced a Summary of findings for the main comparison.

\section{Selection of studies}

We imported results from each database into the reference management software package Endnote, from which we removed duplicates. After training on the first 100 references retrieved from two different databases to ensure a consistent approach, two review authors (RT and $\mathrm{HQ}$ ) worked independently to screen all titles and abstracts to identify studies that met the inclusion criteria, or that could not be safely excluded without assessment of the full text (e.g. when no abstract was available). Disagreements were resolved by discussion with another review author (LB). Full texts were retrieved for these articles.

After training was provided to ensure a consistent approach to study assessment and data abstraction, two review authors worked independently to assess the retrieved full texts (RT and HQ). We linked together multiple publications and reports on the same study. Studies that appeared to be relevant but were excluded at this stage are listed in the 'Characteristics of excluded studies' table. We resolved disagreements by discussion with other group members. We attempted to contact study corresponding authors if we could not access a full text (e.g. if only an abstract was available), if we required more information to determine whether a study could be included (e.g. to determine baseline exercise behaviour of a cohort), or if we required supplementary information about an already eligible study (please also see Excluded studies).

\section{Data extraction and management}

Review authors (RT and LB) extracted the following data using the same data extraction form used in the original review and entered data into RevMan 5.3 (Review Manager 2014). 
- Study details: author; year; title; journal; research question/ study aim; country where the research was carried out; funding source; recruitment source (e.g. consecutive sampling from outpatient appointments; advertising in the community; convenient sample from support groups); inclusion and exclusion criteria; study design (cluster RCT, non-cluster RCT, single centre or multi-centre); sample size; number of participants per arm; length of follow-up; description of usual care.

- Intervention details: categorisation of intervention (e.g. supervised, independent, educational); setting (e.g. dedicated exercise facility, community, home); exercise prescription components (e.g. aerobic exercise, resistance exercise, stretching); theoretical basis, behaviour change techniques (using CALO-RE taxonomy), frequency of contact with an exercise professional and or healthcare professional; instructions to controls.

- Participant characteristics: primary cancer diagnosis; any cancer treatment currently undertaken; metastatic disease status; age; sex; body mass index (BMI); ethnicity; reported comorbidities.

- Resulting exercise behaviour: method of measuring exercise (e.g. self-report questionnaire). Numbers of participants randomly assigned and assessed at specified follow-up points. Frequency, duration, intensity of aerobic exercise achieved; frequency, intensity, type, sets and repetitions of resistance exercise achieved; total duration of the intervention; total duration of sustained meaningful exercise behaviour as a result of the intervention and whether the Rock 2012 guidelines were met, adherence to the intervention; rate of attrition and adverse effects reported.

- Resulting change in other outcomes: changes in aerobic fitness and estimated energy expenditure from free-living physical activity.

Three members of the group worked independently (RT, RG and LS) to extract data from all eligible papers using the data collection form. Data were entered into the Cochrane's statistical software, Review Manager 2014, by one review author and checked by a second review author.

\section{Assessment of risk of bias in included studies}

Risk of bias and methodological quality were assessed in accordance with Cochrane's tool for assessing risk of bias (Higgins 2011). The tool includes the following seven domains:

- sequence generation (method of randomisation);

- allocation concealment (selection bias);

- blinding (masking) of participants and personnel (detections bias);

- blinding (masking) of outcome assessors (detection bias);

- incomplete outcome data;

- selective outcome reporting;

- other sources of bias.

However, we did not include blinding to group allocation, as it is not possible (e.g. in a supervised exercise setting) to blind participants to an intervention while promoting exercise behaviour. Two review authors (RT and RG) independently applied the 'Risk of bias' tool, and differences were resolved by discussion with a third review author (LB). We summarised results in both a 'Risk of bias' graph and a 'Risk of bias' summary. Results of meta-analyses were interpreted in light of the findings with respect to risk of bias. We contacted study authors to ask for additional information or for further clarification of study methods if any doubt surrounded potential sources of bias. Individual 'Risk of bias' items can be seen in Appendix 9.

\section{Measures of treatment effect}

For the purposes of this review, all exercise behaviour was synthesised as specified in the primary outcomes. For comparison of measures of change in fitness levels or estimated energy expenditure from free-living physical activity, please see the section on 'Continuous data' in Data synthesis.

\section{Unit of analysis issues}

We did not include any cross-over trials in this review because of the high risk of contamination. It can be very difficult to "wash out" exercise behaviour. Cancer survivors in particular can be a highlymotivated cohort, and significant contamination has been reported even in conventional RCT settings (Courneya 2003; Mock 2005). Hence this learning effect distorts results. Furthermore, asking individuals to revert to sedentary behaviour could be considered unethical (Das 2012). Therefore, any cross-over trials identified were rejected at the title and abstract screening stage.

\section{Dealing with missing data}

We assessed missing data and dropout rates for each of the included studies and reported the numbers of participants included in the final analysis as a proportion of all participants included in the study. We assessed the extent to which studies conformed to an intention-to-treat analysis.

\section{Assessment of heterogeneity}

Consistency of results was assessed visually and through examination of the $1^{2}$ statistic, a quantity that describes approximately the proportion of variation in point estimates that is due to heterogeneity rather than sampling error.An 12 greater than or equal to $50 \%$ was considered significant heterogeneity. We addressed this by performing a sensitivity analysis that excluded any heterogeneous trials. We supplemented this with a test of homogeneity to determine the strength of evidence that the heterogeneity was genuine. When significant statistical heterogeneity was detected, differences in characteristics of the studies or other factors were explored as possible sources of explanation. Any differences were summarised in a narrative synthesis.

\section{Assessment of reporting biases}

\section{Publication bias}

We intended to examine funnel plots corresponding to metaanalysis of the primary outcomes to assess the potential for small study effects such as publication bias if a sufficient number of studies (i.e. more than 10) was identified. However, this was not the case; therefore this step was not included in the analysis. 


\section{Data synthesis}

\section{Continuous data}

For continuous outcomes (e.g. cardiorespiratory fitness), we extracted the final value, the standard deviation (SD) of the outcome of interest and the number of participants assessed at endpoint for each treatment arm at the end of follow-up, to estimate standardised mean differences (SMD) between treatment arms.

\section{Dichotomous outcomes}

For dichotomous outcomes (e.g. adverse effects, deaths), if it was not possible to use a hazard ratio (HR), we extracted the number of participants in each treatment arm who experienced the outcome of interest and the number of participants assessed at endpoint, to estimate a risk ratio (RR).

\section{Meta-analysis}

When possible, and if appropriate, we performed a meta-analysis of review outcomes. If statistical heterogeneity was noted, a metaanalysis was performed using a random-effects model. We planned to use a fixed-effect model if no significant statistical heterogeneity was observed.

When possible, all data extracted were those relevant to an intention-to-treat analysis in which participants were analysed in groups to which they were assigned. We noted the time points at which outcomes were collected and reported.

\section{Subgroup analysis and investigation of heterogeneity}

If a sufficient number of studies were identified, we performed subgroup analyses for the following.

- Cancer site.

- Type of intervention (i.e. supervised, home-based, etc).

- Age of individuals (i.e. elderly versus non-elderly).

- Current treatment (currently undergoing treatment versus not currently undergoing treatment).

- Participants with metastatic disease (metastatic cohort versus non-metastatic cohort).

- Accordance with behaviour change theory.

- Interventions in obese individuals (mean body mass index (BMI) of intervention group $>30 \mathrm{~kg} / \mathrm{m}^{2}$ versus mean BMI of intervention group $<30 \mathrm{~kg} / \mathrm{m}^{2}$ ).

\section{Sensitivity analysis}

Methodological strength was judged using Cochrane's tool for assessing risk of bias to identify studies of high and low quality (Higgins 2011). Sensitivity analyses were performed with the studies of low quality excluded.

\section{Summary of findings}

To assess the overall quality of the evidence for each outcome of the meta-analysis, we employed the GRADE approach. The GRADE profile (https://gradepro.org) enabled us to import data directly from Review Manager 5.3 to create Summary of findings for the main comparison. These tables provide outcome-specific information concerning the overall certainty of the evidence from studies included in the meta-analysis. Risk of bias, inconsistency of the data, the preciseness of the data publication bias and the indirectness of the data were all considered in assessing the quality of the data.

We downgraded the evidence from 'high' certainty by one level for serious (or by two for very serious) concerns for each limitation.

- High certainty: we are very confident that the true effect lies close to that of the estimate of the effect.

- Moderate certainty: we are moderately confident in the effect estimate: the true effect is likely to be close to the estimate of the effect, but there is a possibility that it is substantially different.

- Low certainty: our confidence in the effect estimate is limited: the true effect may be substantially different from the estimate of the effect.

- Very low certainty: we have very little confidence in the effect estimate: the true effect is likely to be substantially different from the estimate of effect.

The following outcomes were included in the 'Summary of findings' table.

- Aerobic exercise tolerance (all cancers: eight to 12 weeks of follow-up)

- Aerobic exercise tolerance (all cancers: eight to 12 weeks of follow-up sensitivity analysis)

- Aerobic exercise tolerance (all cancers: six months of follow-up)

- Aerobic exercise tolerance (breast cancer: eight to 12 weeks of follow-up)

- Aerobic exercise tolerance (all cancers: combination of supervised and home-based exercise: eight to 12 weeks of follow-up)

- Aerobic exercise tolerance (all cancers: supervised exercise: eight to 12 weeks of follow-up)

- Aerobic exercise tolerance (all cancers: home-based exercise: eight to 12 weeks of follow-up)

\section{RE S U L T S}

\section{Description of studies}

Please see Table 1, 'Summary of included studies'. See 'Characteristics of included studies'; 'Characteristics of excluded studies'; 'Characteristics of studies awaiting classification'; and 'Characteristics of ongoing studies'.

\section{Results of the search}

Figure 1 illustrates the process of the literature search and study selection for the review. The updated search identified 5442 unique records from databases searched. In addition, we identified 2750 records from grey literature and 'snowballing' techniques for this update. Given that the details of prescribed exercise are rarely reported in manuscript abstracts (e.g. frequency, intensity, duration of exercise prescription), this led to evaluation of a large number of manuscripts at full text stage $(n=227)$. From these full-text articles, 212 manuscripts were excluded, leaving 15 publications from 10 unique studies included in the review (total unique studies $=23$ ). Reasons for excluding these 212 publications and a subset of the original review total $(n=377)$ are covered in the Excluded studies section below. 
Figure 1. PRISMA flow diagram.

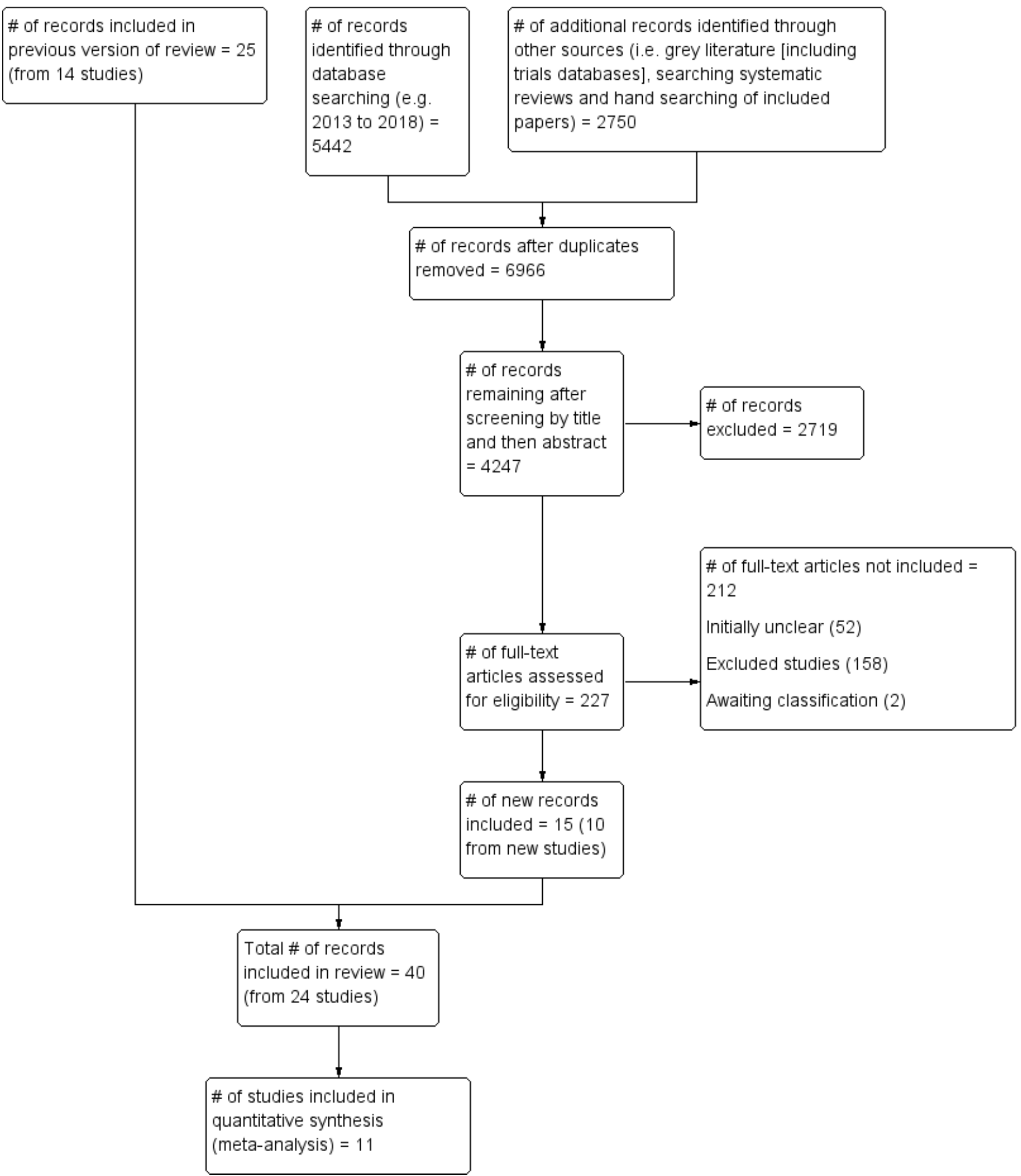

\section{Included studies}

This update identified 15 publications from 10 new studies, which when combined with the studies from the original review equates to 40 publications in total from 23 studies. (al-Majid 2015; Bourke 2014; Cadmus 2009; Campbell 2017; Cantarero-Villanueva 2012b; Cavalheri 2017; Daley 2007a; Drouin 2005; Hayes 2009; Irwin 2015;
Kaltsatou 2011; Kim 2006; Kim 2017; McKenzie 2003; Mohamady 2017; Musanti 2012; Perna 2010; Pinto 2003; Pinto 2005; Pinto 2011; Rogers 2015; Scott 2013; Thomas 2013). One study (Bourke 2014) was a efficacy study, following on from a previous feasibility study (Bourke 2011a) from the original review. 
For the 2018 update, we sent an additional 112 emails to request unpublished information for manuscripts that were unclear in reporting relative to our inclusion and exclusion criteria. We were able to include an additional seven published manuscripts and to exclude an additional eight published manuscripts on the basis of information received in correspondence from authors.

Only randomised controlled trials (RCTs) were included in the review. All included studies used a parallel-group design with baseline assessment and follow-up of 12 months maximum. All included studies were conducted using participant-level randomisation. The format of reporting precluded data extraction for meta-analytical combination in two studies (Drouin 2005; Pinto 2003). Sample size ranged from 14 to 222, with a total of 1372 participants included in this review (mean age range 51 to 72 ).

\section{Participants}

Twenty of the included trials were on breast cancer survivors (alMajid 2015; Cadmus 2009; Campbell 2017; Cantarero-Villanueva 2012b; Daley 2007a; Drouin 2005; Hayes 2009; Irwin 2015; Kaltsatou 2011; Kim 2006; Kim 2017; McKenzie 2003; Mohamady 2017; Musanti 2012; Perna 2010; Pinto 2003; Pinto 2005; Rogers 2015; Scott 2013; Thomas 2013); only two studies involved colorectal cancer (Bourke 2011a; Pinto 2011), one prostate cancer (Bourke 2014,) and one lung cancer (Cavalheri 2017). Of these studies, 12 included participants who were currently undergoing active treatment inclusive of hormone-based therapy (al-Majid 2015; Bourke 2014; Cadmus 2009; Daley 2007a; Drouin 2005; Irwin 2015; Kim 2006; Mohamady 2017; Musanti 2012; Perna 2010; Pinto 2005; Scott 2013). We found only one study that reported data from participants with metastatic disease (Bourke 2014), and six studies that were conducted in obese cohorts (i.e. mean BMI > $30 \mathrm{~kg} / \mathrm{m}^{2}$; (Cadmus 2009; Drouin 2005; Mohamady 2017; Rogers 2015; Scott 2013; Thomas 2013). The majority of participants were white, and only five studies reported data from an ethnically diverse sample (al-Majid 2015; Irwin 2015; Perna 2010; Rogers 2015; Thomas 2013). Comorbidities at baseline were largely unclear or unreported.

\section{Interventions}

\section{Type of exercise}

Fourteen studies prescribed exclusively aerobic exercise (alMajid 2015; Cadmus 2009; Campbell 2017; Cantarero-Villanueva 2012b; Daley 2007a; Drouin 2005; Kaltsatou 2011; Kim 2006; Mohamady 2017; Pinto 2003; Pinto 2005; Pinto 2011; Rogers 2015; Thomas 2013); the remaining RCTs used a mix of aerobic and resistance training (no exclusively resistance training studies met our inclusion criteria). Ten studies used a combination of supervised and home-based exercise (Bourke 2011a; Bourke 2014; Cadmus 2009; Campbell 2017; Hayes 2009; Irwin 2015; Kim 2006; Perna 2010; Pinto 2003; Rogers 2015), four studies opted to use an exclusively home-based design (Drouin 2005; Musanti 2012; Pinto 2005; Pinto 2011), and 10 studies were exclusively supervised studies (al-Majid 2015; Cantarero-Villanueva 2012b; Cavalheri 2017; Daley 2007a; Kaltsatou 2011; Kim 2017; McKenzie 2003; Mohamady 2017; Scott 2013; Thomas 2013).

\section{Exercise sessions and the role of exercise professionals and healthcare} professionals

Contact with exercise professionals or study researchers ranged from two to three weekly supervised sessions (Rogers 2015), to weekly phone calls after an initial one-to-one exercise consultation
(Pinto 2005; Pinto 2011). Most commonly however, supervised sessions were offered two to three times per week. Of note, seven studies (Drouin 2005; Kaltsatou 2011; Kim 2006; McKenzie 2003; Pinto 2003; Pinto 2005; Pinto 2011), placed restrictions on the control group regarding exercise behaviour during the course of the study, usually taking the form of direct instruction to refrain from changing exercise behaviour. However, the 2018 update found no additional studies that placed restrictions on the control group, usual activities were encouraged. Contact with healthcare professionals was not frequent amongst the studies, with three studies having healthcare professionals carry out medical assessments for eligibility (Cantarero-Villanueva 2012b; Kim 2017; Mohamady 2017), two studies having oncologists refer the participants onto the study, but it was not stated explicitly if they delivered any aspects of the intervention (al-Majid 2015; Campbell 2017).

\section{Level of exercise and adherence}

Thirteen studies incorporated prescriptions that would meet the Rock 2012 recommendations for aerobic exercise (i.e.150 minutes per week); (Cadmus 2009; Campbell 2017; CantareroVillanueva 2012b; Pinto 2011; Rogers 2015) or resistance exercise (i.e. resistance training strength training exercises at least two days per week); (Bourke 2011a; Bourke 2014; Cavalheri 2017; Irwin 2015; Kim 2017; Musanti 2012; Perna 2010; Scott 2013). However, only eight of these studies reported $75 \%$ adherence to these guidelines, (Bourke 2011a; Bourke 2014; Campbell 2017; Cantarero-Villanueva 2012b; Irwin 2015; Kim 2017; Rogers 2015; Scott 2013).

\section{Theoretical basis}

Of the interventions provided, only six were explicitly based on a theoretical model (Daley 2007a; Musanti 2012; Perna 2010; Pinto 2005; Pinto 2011; Rogers 2015); the trans-theoretical model was most common, followed by social cognitive theory and exercise, and self-esteem theory. Only one intervention from the 2018 update was found to be based on a theoretical model (Rogers 2015).

\section{Behaviour change techniques (BCT) and adherence}

Full details of intervention BCT coding according to the CALORE taxonomy for the previous review (Bourke 2013) and the 2018 update can be seen in Table 2 and Table 3 (respectively). In the previous review, there was a lack of identified studies that met the Rock 2012 guidelines. For this updated version of the review, our searches found more instances of studies (eight in total) that meet the 150 minutes per week or two strength sessions per week Rock 2012 target. Also, there were other studies with lower exercise targets but good adherence (i.e. over 75\%). Hence, we presented BCTs in a hierarchy format: Tier 1 and Tier 2. Tier 1 BCTs are presented from interventions that set prescriptions which meet the Rock 2012 target and achieved $75 \%$ or more adherence. Tier 2 BCTs are presented from interventions that reported good adherence (i.e. $75 \%$ or more) but set prescriptions that are below the 150 minutes per week Rock 2012 target. BCTs reported in the eight Tier 1 trials are presented in Table 4. It is notable that four of these studies incorporated both a supervised and an independent exercise component as part of their intervention and four were exclusively supervised, with all placing no restrictions on the control group in terms of exercise behaviour. Six studies were included in Tier 2 BCTs and reported adherence of $75 \%$ or greater to a specified exercise aerobic prescription which was lower than the targets set in the Rock 2012 guidelines (al-Majid 2015; Bourke 
2011a; Bourke 2014; Cadmus 2009; Kim 2017; Scott 2013). BCTs reported in Tier 2 studies are presented in Table 5.

Few interventions (Bourke 2014; Cadmus 2009; Daley 2007a; Kim 2006; Perna 2010; Rogers 2015) reported providing information on the consequences of behaviour (BCT \#1). All interventions had programme set goals, which we have highlighted as being different for the purpose of this review to goal setting (behaviour) and goal setting (outcome). Only seven studies set exercise goals in conjunction with participants (BCT \# 5) (Bourke 2014; Cadmus 2009; Daley 2007a; Perna 2010; Pinto 2005; Pinto 2011; Rogers 2015). These same seven studies also reported problemsolving with barriers identified (BCT \#8) and solutions facilitated. Three interventions (Daley 2007a; Perna 2010; Rogers 2015) which participants had some input into setting of goals were these reviewed (BCT \#10). When monitoring did occur (BCT \#16) or monitoring of outcome behaviour occurred (BCT \#17), feedback on performance (BCT \#19) was provided in only five out of 10 (Cadmus 2009; Perna 2010; Pinto 2005; Pinto 2011; Rogers 2015), which is important to note. Fourteen studies (Bourke 2011a; Bourke 2014; Cadmus 2009; Daley 2007a; Drouin 2005; Hayes 2009; Kaltsatou 2011; Kim 2006; Musanti 2012; Perna 2010; Pinto 2003; Pinto 2011; Rogers 2015; Scott 2013) reported providing instruction on how to perform the behaviour (BCT \#21), although it may be anticipated that this did occur but just was not reported. In addition, 15 studies prompted practise of the behaviour (BCT \#26) (Bourke 2011a; Bourke 2014; Cadmus 2009; Daley 2007a; Drouin 2005; Hayes 2009; Kaltsatou 2011; Kim 2006; McKenzie 2003; Musanti 2012; Perna 2010; Pinto 2003; Pinto 2005; Pinto 2011; Rogers 2015), Only four studies used techniques to increase social support (BCT \#29); (Bourke 2014; Cadmus 2009; Daley 2007a; Perna 2010). Other common BCTs included setting of graded tasks (i.e. increased exercise duration or intensity over time) and self-monitoring of behaviour (exercise) and outcomes of behaviour (e.g. heart rate), although it is not clear for all interventions whether this was done primarily for data collection or as a mechanism of behaviour change.. Only three studies reported relapse prevention (BCT \#35) (Daley 2007a; Perna 2010; Rogers 2015).

\section{Measurement of exercise behaviour}

Ten studies were identified that attempted to objectively validate independent exercise behaviour with accelerometers or heart rate monitoring (al-Majid 2015; Bourke 2014; Cadmus 2009; Irwin 2015; Mohamady 2017; Pinto 2005; Pinto 2011; Rogers 2015; Scott 2013; Thomas 2013). Seven of these studies attempted to validate selfreported independent exercise behaviour by using accelerometers or heart rate monitors (al-Majid 2015; Bourke 2014; Irwin 2015; Pinto 2005; Pinto 2011; Rogers 2015; Thomas 2013), however in three studies (Pinto 2005; Pinto 2011; Rogers 2015), data either were not supportive of exercise behaviour recorded by participants or were not reported in their entirety.

\section{Excluded studies}

Reasons for excluding published studies included the following.

- Non-RCTs (e.g. review manuscripts, comment/editorial articles).

- Mixed cancer cohorts or cohorts that included non-cancer populations.

- Studies that failed to describe essential metrics of exercise prescription used in the intervention (e.g. frequency, intensity, duration).

- Studies involving active participants at baseline.

- Studies involving hospital inpatients.

- Interventions that provided follow-up of less than 6 weeks.

- Studies involving participants younger than 18 years of age.

All excluded studies ( $\mathrm{N}=180$ ) for the 2018 update, are presented in the Characteristics of excluded studies. However for the original review only a subset of excluded studies could be included in the 'Characteristics of excluded studies' section. This is a result of the large volume of studies that had to be full text screened ( $N=$ 402) and the high proportion (around 90\%) that were excluded. In accordance with editorial advice, we divided this large number $(\mathrm{N}=$ 365) into initially unclear studies that required further investigation $(\mathrm{N}=76)$ and those that clearly were not eligible after full text had been retrieved $(N=289)$. This approach is analogous to the approach adopted in recent reviews (Galway 2012), and is detailed in the existing PRISMA diagram (Figure 1).

For the 2018 update, we sent an additional 101 emails to corresponding authors to request additional information (regarding included studies, excluded studies and studies that we could not access) to determine eligibility and to supplement published data for this review.

\section{Risk of bias in included studies}

Only seven studies were judged not to include a high risk of bias (al-Majid 2015; Bourke 2011a; Cadmus 2009; Cantarero-Villanueva 2012b; Drouin 2005; Irwin 2015; Scott 2013). Full results of the methodological quality assessment for allocation bias, blinding, incomplete data outcome and selective reporting (along with justifications) are covered in the 'Risk of bias' tables for each study and are illustrated in Figure 2; Figure 3. Twelve studies stated that an intention-to-treat analysis was used (Bourke 2011a; Bourke 2014; Cadmus 2009; Cantarero-Villanueva 2012b; Cavalheri 2017; Daley 2007a; Irwin 2015; Perna 2010; Pinto 2005; Rogers 2015; Scott 2013; Thomas 2013). 
Figure 2. 'Risk of bias' summary: review authors' judgements about each risk of bias item for each included study.

\begin{tabular}{|c|c|c|c|c|c|c|}
\hline & 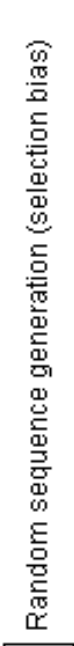 & 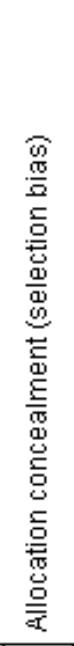 & 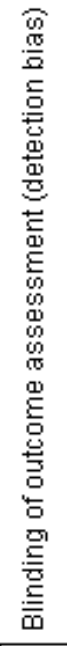 & 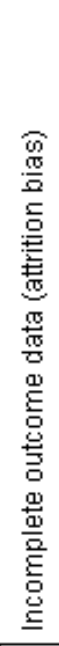 & 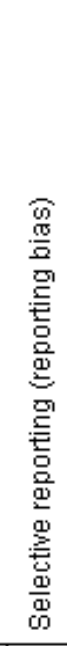 & 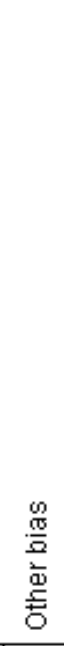 \\
\hline al-Majid 2015 & $?$ & $?$ & $?$ & $?$ & + & $?$ \\
\hline Bourke 2011a & + & + & + & + & + & $?$ \\
\hline Bourke 2014 & 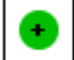 & + & + & $\odot$ & + & + \\
\hline Cadmus 2009 & + & + & $?$ & + & + & + \\
\hline Campbell 2017 & + & $?$ & $?$ & + & + & - \\
\hline Cantarero-Villanueva 2012b & + & + & + & + & + & + \\
\hline Cavalheri 2017 & + & + & + & - & + & $\Theta$ \\
\hline Daley 2007a & + & + & $\theta$ & + & + & + \\
\hline Drouin 2005 & + & $?$ & $?$ & + & + & + \\
\hline Hayes 2009 & + & $?$ & $\odot$ & + & + & - \\
\hline Irwin 2015 & + & $?$ & $?$ & + & + & + \\
\hline Kaltsatou 2011 & ? & ? & $?$ & ? & + & $\Theta$ \\
\hline Kim 2006 & + & $?$ & $?$ & - & + & - \\
\hline Kim 2017 & + & + & + & + & + & - \\
\hline McKenzie 2003 & $?$ & $?$ & $?$ & ? & + & \\
\hline Mohamady 2017 & + & $\odot$ & $?$ & $?$ & + & \\
\hline Musanti 2012 & + & $\odot$ & + & 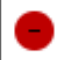 & 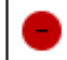 & $\odot$ \\
\hline Perna 2010 & + & $\odot$ & + & + & + & $\odot$ \\
\hline Pinto 2003 & $?$ & ? & $?$ & $\theta$ & $\theta$ & - \\
\hline \multirow{3}{*}{ Pinto 2011} & $?$ & $?$ & ? & + & + & \\
\hline & $?$ & $?$ & $?$ & + & $\Theta$ & \\
\hline & P & 10 & 19 & $\theta$ & 8 & \\
\hline
\end{tabular}


Figure 2. (Continued)

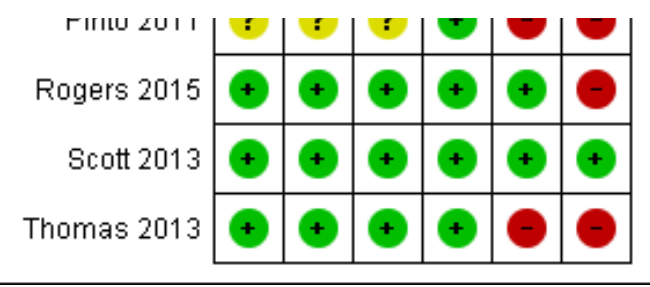

Figure 3. 'Risk of bias' graph: review authors' judgements about each risk of bias item presented as percentages across all included studies.

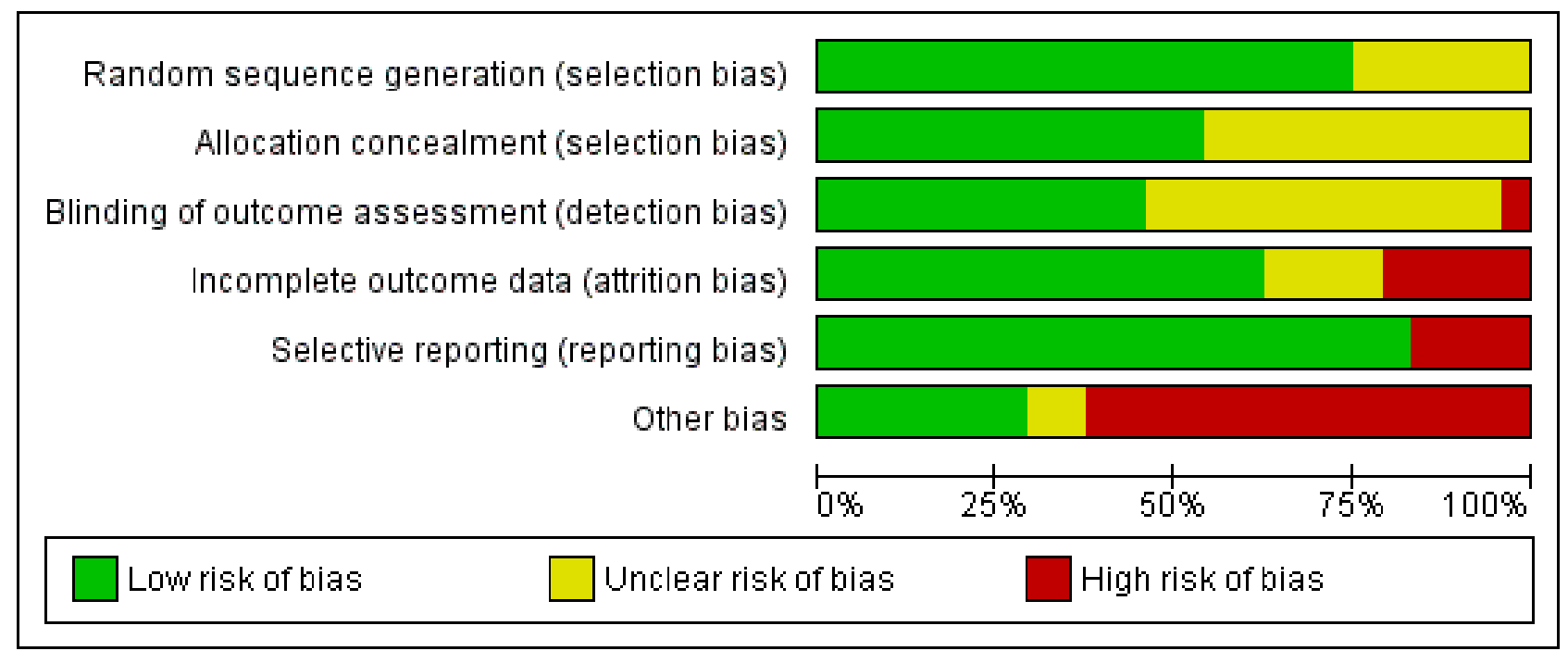

\section{Allocation}

Eleven studies had an unclear risk in their description of concealment in randomisation allocation. However, no study was judged to have a high risk of bias in this respect.

\section{Blinding}

Eleven studies had undertaken the blinding of study assessors (Bourke 2011a; Bourke 2014; Cantarero-Villanueva 2012b; Cavalheri 2017; Hayes 2009; Kim 2017; Musanti 2012; Perna 2010; Rogers 2015; Scott 2013; Thomas 2013). The remaining studies did not include enough information for the review authors to make a definitive judgement on this criterion.

\section{Incomplete outcome data}

Five studies were judged to have been subject to incomplete data outcome bias: Kim 2006 reported data from only 41 of 74 participants randomly assigned; Musanti 2012 reported that 13 women (24\%) did not complete their assigned 12-week programme; and Pinto 2003 did not report control group data for the exercise tolerance test. Bourke 2014 had incomplete outcome data at six months follow-up. Cavalheri 2017 reported missing patient data in both arms with no reasons given.

\section{Selective reporting}

Most studies reported all listed outcomes; however, four studies were judged to omit outcomes from their results reporting. Musanti 2012 did not report waist and upper, mid and lower arm circumference outcomes; Pinto 2003 reported none of the physiological assessments in the control group at 12 weeks of follow-up; Pinto 2011 did not report data derived from the use of accelerometers; and Thomas 2013 did not report on body fat or lean mass values and no data were given from food frequency questionnaire.

\section{Other potential sources of bias}

Other sources of bias found in the included studies that are worth highlighting include adherence data missing or not clear (Cavalheri 2017; Hayes 2009; Kaltsatou 2011; Kim 2017; McKenzie 2003; Mohamady 2017; Musanti 2012); high attrition at follow-up (Pinto 2003); low recruitment rate (Bourke 2011a; Campbell 2017; Thomas 2013); Significant differences in participants excluded from study analysis/dropouts (Kim 2006; Musanti 2012; Pinto 2003); numbers randomly assigned to study arms with study completion rate unclear (Perna 2010); significant differences in cohorts at baseline (Kim 2017; Musanti 2012; Pinto 2003; Pinto 2005); and inconsistencies between objective and subjective measures of exercise behaviour (Pinto 2005; Pinto 2011; Rogers 2015). Insufficient information was reported to permit a judgement about any single element of bias because of lack of data (al-Majid 2015; Bourke 2011a; Cadmus 2009; Campbell 2017; Drouin 2005; Hayes 2009; Irwin 2015; Kaltsatou 2011; Kim 2006; McKenzie 2003; Mohamady 2017; Pinto 2003; Pinto 2005; Pinto 2011). 


\section{Effects of interventions}

See: Summary of findings for the main comparison Exercise interventions compared to usual care for promoting habitual exercise in people living with and beyond cancer to improve aerobic exercise tolerance

\section{Primary outcome}

\section{To assess the effects of interventions designed to promote exercise behaviour in sedentary people living with and beyond cancer}

Please see Table 1, 'Summary of included studies'. As it is not meaningful to interpret individually the component metrics of aerobic (frequency, intensity and duration) or resistance exercise (frequency, intensity, type of exercise, sets and repetitions) behaviour, these primary outcomes are presented in the narrative synthesis below of interventions achieving $75 \%$ or greater adherence.

In Rogers 2015, adherence to planned intervention components was $98 \%$ for supervised exercise sessions, $96 \%$ for update sessions, and $91 \%$ for discussion group sessions. Only five participants did not receive the allocated intervention (i.e. did not complete $75 \%$ of all intervention components combined). With the intervention group reporting an average of 169 minutes of moderate intensity exercise per week at 12 weeks, and 137 minutes of moderate intensity exercise per week at six months. Although, there is a high risk of bias around how 'in-active' the recruited participants were at baseline, as baseline accelerometer recordings are incongruent with the inclusion criteria.

Four of the studies included in this review reported that $75 \%$ or more of the intervention group met the (Rock 2012) aerobic exercise guidelines at any given follow-up (Campbell 2017; Cantarero-Villanueva 2012b; Irwin 2015; Rogers 2015). Four studies reported that $75 \%$ or more of the intervention group met the (Rock 2012) resistance exercise guidelines. (Bourke 2011a; Bourke 2014; Kim 2017; Scott 2013). Behaviour change techniques (BCTs) reported in these eight studies are presented in Table 4. Of these studies, only one study explicitly stated it had theoretical basis (Rogers 2015).

Due to of unclear reporting it was not possible to make a judgement on whether some trials achieved adherence of $75 \%$ or greater . Reasons for an unclear judgement or unsuccessful adherence are detailed below.

- Daley 2007a: judgement unclear; adherence reported as a proportion of participants attending a proportion of set exercise sessions (i.e. $77 \%$ of the intervention group attending $70 \%$ of sessions).

- Drouin 2005: judgement unclear; adherence reported as mean number of days per week when exercise was undertaken, relative to a range within the prescription (i.e. 3.6 days per week, when the prescription was for three to five days per week).

- Kaltsatou 2011: judgement unclear; no adherence data reported.

- Kim 2006: judgement unclear; high adherence was reported $(78 \%)$, but in tandem with substantial attrition (i.e. data missing for $45 \%$ of the cohort).
- Pinto 2003: judgement unclear; high adherence was reported $(88 \%)$ but in tandem with substantial attrition (i.e. $25 \%$ of the intervention group dropped out over the intervention period).

- Pinto 2005: judgement unsuccessful; $75 \%$ adherence threshold was not met after week four.

- Pinto 2011: judgement unsuccessful; three-day Physical Activity Recall (PAR) questionnaire indicates that $64.7 \%$ of the intervention group and $40.9 \%$ of controls were adhering to the exercise guidelines at three months.

- Hayes 2009: judgement unclear; adherence reported as a proportion of participants attending a proportion of set exercise sessions (i.e. $88 \%$ allocated to the intervention group participated in $70 \%$ or more of scheduled supervised exercise sessions). Further, adherence from the unsupervised aspect is not reported.

- McKenzie 2003: judgement unclear; no adherence data reported.

- Musanti 2012: judgement unclear; high adherence reported but only $50 \%$ of activity logs returned.

- Perna 2010: judgment unclear; women assigned to the structured intervention completed an average of $83 \%$ of their scheduled hospital-based exercise sessions (four weeks in total). Home-based adherence is not clear.

- Mohamady 2017: judgement unclear; no adherence data reported.

- Thomas 2013: judgement unsuccessful; the goal of the intervention was for participants to achieve 150 minutes of moderate intensity exercise per week; $33 \%$ of the intervention group achieved 150 minutes per week, $56 \%$ of the intervention group achieved 120 minutes per week and $75 \%$ achieved 90 minutes per week.

- Irwin 2015: judgement unsuccessful; resistance exercise - an average of $70 \%$ of strength-training sessions completed.

- Cavalheri 2017: judgement unsuccessful; of the nine participants randomised to the exercise intervention, four (44\%) adhered to exercise training by completing 15 or more training sessions (i.e. $\geq 60 \%$ ).

Ideally, a meta-analysis of objectively verified (e.g. using accelerometers or heart rate monitoring) minutes per week of moderate intensity aerobic exercise achieved in an intervention group, compared with controls, for whom the exercise prescription adherence is at least $75 \%$, would be most informative. However, due to variation in measurement and reporting amongst included studies, this was not possible. Insufficient data were available for a synthesis of evidence to be conducted around free-living energy expenditure.

\section{Secondary outcomes}

\section{Aerobic exercise tolerance}

\subsection{All cancers: eight to 12 weeks of follow-up}

A meta-analysis of change in aerobic exercise tolerance was carried out on 10 studies that reported these outcomes and also reported means for final value scores. Standardised mean differences (SMDs) were used to produce effect estimates as variation in how studies assessed this outcome was evident. Standard deviations (SDs) were calculated from 95\% confidence intervals (Cls) using the formula in the Cochrane Handbook for Systematic Reviews of Interventions (Higgins 2011) (i.e. SD $=\sqrt{ } N^{*}$ (upper limit-lower limit)/(t distribution 
${ }^{*} 2$ ), and from standard errors (SES) using $S D=S E^{\star} \sqrt{ } N$, when they were not reported. Length of follow-up ranged from eight (Cavalheri 2017; Daley 2007a; Kim 2006), to 12 weeks (al-Majid 2015; Bourke 2011a; Bourke 2014; Musanti 2012; Pinto 2005; Pinto 2011; Rogers 2015) . Aerobic exercise tolerance was significantly better in intervention versus control groups in 604 participants: (SMD $0.54,95 \% \mathrm{Cl} 0.37$ to $0.70 ; 10$ studies, 604 participants: low-certainty evidence; Analysis 1.1). Results were analysed using a fixed-effect model. Certainty of the evidence assessed using GRADE and was graded as low. As there was some serious concerns over risk of bias and concerns over the number of small studies with positive results (please see Summary of findings for the main comparison).

\subsection{All cancers: eight to 12 weeks of follow-up (sensitivity analysis)}

We then removed studies with a high risk of bias relative to this outcome and repeated the analysis with the four remaining studies (al-Majid 2015; Bourke 2011a; Bourke 2014; Pinto 2005), and aerobic exercise tolerance was better in intervention versus control groups (SMD 0.85, 95\% Cl 0.56 to 1.14; 4 studies, 201 participants; low-certainty evidence; Analysis 1.2). The certainty of the evidence was graded as low using GRADE as there were concerns imprecision as there were variations in effect sizes and concerns over the low number of participants in the studies (please see Summary of findings for the main comparison).

\subsection{All cancers: six months of follow-up}

Seven studies included data from a follow-up of six months (Bourke 2014; Daley 2007a; Kaltsatou 2011; Pinto 2005; Pinto 2011; Rogers 2015; Scott 2013) showing that aerobic exercise tolerance was significantly better at six months in intervention versus control groups (SMD 0.56, 95\% Cl 0.39 to 0.72; 7 studies; 591 participants: low-certainty evidence; Analysis 1.3). It should be highlighted that six of these studies have a high risk of bias, which could affect this outcome at six months; specifically, Bourke 2014 had high attrition at six months follow-up; no adherence data in the Kaltsatou 2011 study; substantial contamination among controls in the Pinto 2011 study; Rogers 2015 objective and subjective measures of exercise results varied greatly and non-blinded assessors in the Daley 2007a study. Note that in all meta-analyses, data from Pinto 2005 have been multiplied by -1 to control for direction of effect (i.e. lower values in a timed test indicate a better outcome). Brief narrative descriptions of studies not suitable for meta-analyses include the following: Drouin $2005 \mathrm{VO}_{2}$ peak data are reported as medians and interquartile ranges; for Pinto 2003, no control group data are presented for the exercise tests; for Campbell 2017, no means or SDs present at baseline and follow-up. For grading of data please see Summary of findings for the main comparison.

\subsection{Breast cancers: eight to 12 weeks of follow-up}

We were able to carry out one subgroup analysis in breast cancer patients This was a meta-analysis of change in aerobic exercise tolerance carried out on six studies (al-Majid 2015; Daley 2007a; Kim 2006; Musanti 2012; Pinto 2005; Rogers 2015), showing that aerobic exercise tolerance was significant (SMD $0.57,95 \% \mathrm{Cl} 0.22$ to 0.93 ; 6 studies, 441 participants; very low-certainty evidence; Analysis 1.4). However, it should be noted that four of the studies were considered to have high risk of bias (Daley 2007a; Kim 2006; Musanti 2012; Rogers 2015). The certainty of the evidence was graded as very low as there was high risk of bias, concerns over the precision of the data as the confidence intervals were wide and there were serious concerns over the heterogeneity of the data (please see Summary of findings for the main comparison).

\subsection{All cancers: combination of supervised and home-based exercise:} eight to 12 weeks of follow-up

A meta-analysis of aerobic exercise tolerance was carried out in the following subgroups: supervised exercise interventions, homebased interventions, and a combination of both. In a combination of home-based and supervised exercise interventions (Bourke 2014; Bourke 2011a; Kim 2006; Rogers 2015), aerobic exercise tolerance was better in the intervention than the control: (SMD $0.53,95 \% \mathrm{Cl} 0.01$ to $1.04 ; 4$ studies, 357 participants; very lowcertainty evidence; Analysis 1.5). The certainty of the evidence was graded as very low as there were concerns over the precision of the data as the confidence intervals were wide and there were very serious concerns over inconsistency due to the heterogeneity of the data and variations in effect sizes (please see Summary of findings for the main comparison).

\subsection{All cancers: home-based exercise: eight to $\mathbf{1 2}$ weeks of follow-up}

In home-based interventions (Musanti 2012; Pinto 2005; Pinto 2011), aerobic exercise tolerance was better in the intervention than the control (SMD $0.70,95 \% \mathrm{Cl} 0.37$ to $1.03: 3$ studies, 155 participants; very low-certainty evidence; Analysis 1.6). The certainty of the evidence was graded as very low due to high risk of bias, low number of participants within the studies and wide confidence intervals (please see Summary of findings for the main comparison).

\subsection{All cancers: supervised exercise: eight to 12 weeks of follow-up}

In supervised interventions (al-Majid 2015; Cavalheri 2017; Daley 2007a), aerobic exercise tolerance was better in the intervention group versus control (SMD 1.07, 95\% $\mathrm{Cl} 0.26$ to 1.89 ; 3 studies, 92 participants; very low-certainty evidence; Analysis 1.7$)$. Serious concerns with inconsistency and imprecision were presented due to wide variations in effect sizes and wide confidence intervals. Therefore the certainty of evidence was classed as very low (please see Summary of findings for the main comparison).

\subsection{All cancers: undergoing active treatment: eight to 12 weeks of follow-up}

A meta-analysis of active treatment and no current treatment for aerobic exercise tolerance was carried out. For participants undergoing active treatment in six studies, (al-Majid 2015; Bourke 2014; Daley 2007a; Kim 2006; Musanti 2012; Pinto 2005), demonstrated aerobic exercise tolerance was better in the intervention than the control (SMD $0.72,95 \% \mathrm{Cl} 0.49$ to 0.95 ; 6 studies, 313 participants; Analysis 1.8). However, five of these studies had a high risk of bias so interpretation of these results should be done with caution.

\subsection{All cancers: no active treatment: eight to 12 weeks of follow-up}

A meta-analysis of aerobic exercise tolerance in participants not undergoing active treatment was carried out in four studies (Bourke 2011a; Cavalheri 2017; Pinto 2011; Rogers 2015), showing that aerobic exercise tolerance was better in the intervention than the control (SMD 0.61, 95\% Cl 0.10 to 1.12; 4 studies, 291 participants: Analysis 1.9). 


\section{Sketal muscle strength}

\subsection{All cancers: eight to 12 weeks of follow-up}

Four studies that used resistance exercise as a component of the intervention reported changes in lower- (Bourke 2011a; Rogers 2015 ) and upper limb (Musanti 2012; Kim 2017) strength. All four studies had reported strength changes at 12 weeks of follow-up. No significant improvement in strength was found (SMD 0.20, 95\% Cl -0.03 to $0.44 ; 4$ studies, 278 participants: Analysis 2.1).

\subsection{All cancers: eight to 12 weeks of follow-up}

After two studies was removed for high risk of bias (Kim 2017; Musanti 2012), effect estimates remained non-significant (SMD $0.17,95 \% \mathrm{Cl}-0.09$ to $0.43 ; 2$ studies, 231 participants; Analysis 2.2).

Planned subgroup analysis was not possible according to participant age, presence of metastatic disease, theoretical underpinning of interventions or participant body mass index (BMI).

\section{Adverse effects}

Thirteen studies reported adverse effects (Bourke 2011a; Bourke 2014; Cadmus 2009; Cantarero-Villanueva 2012b; Cavalheri 2017; Daley 2007a; Irwin 2015; Kim 2006; Musanti 2012; Pinto 2005; Pinto 2011; Rogers 2015; Thomas 2013); these ranged from minor (e.g. musculoskeletal problems; Musanti 2012; Rogers 2015), to major events (e.g. death; Kim 2006). However, only five studies (Cadmus 2009; Cantarero-Villanueva 2012b; Irwin 2015; Rogers 2015; Thomas 2013) were explicit as to which of these adverse effects were caused by inclusion of the participant in the intervention group (two instances of plantar fasciitis).

\section{Study recruitment rate}

Study recruitment rate ranged from $9.5 \%$ (Thomas 2013) to $94 \%$ (Thomas 2013, Cantarero-Villanueva 2012b, respectively). Eleven studies reported a priori sample size estimates (Bourke 2014; Cadmus 2009; Campbell 2017; Daley 2007a; Hayes 2009; Kaltsatou 2011; Musanti 2012; Perna 2010; Pinto 2003; Pinto 2011; Scott 2013), and seven (Bourke 2014; Cadmus 2009; Cantarero-Villanueva 2012b; Hayes 2009; Perna 2010; Rogers 2015; Scott 2013) met their recruitment target.

\section{Intervention attrition rate}

Fifteen studies produced CONSORT diagrams (al-Majid 2015; Bourke 2011a; Bourke 2014; Cadmus 2009; Campbell 2017; Cantarero-Villanueva 2012b; Cavalheri 2017; Daley 2007a; Irwin 2015; Kim 2017; Pinto 2005; Pinto 2011; Rogers 2015; Scott 2013; Thomas 2013). Intervention attrition rates from the included studies ranged from $0 \%$ to $25 \%$ (Campbell 2017, Pinto 2003) ,respectively, with seven studies not clearly reporting attrition in the intervention arm (Cavalheri 2017; Kaltsatou 2011; Kim 2006; McKenzie 2003; Mohamady 2017; Musanti 2012; Perna 2010).

\section{DISCUSSION}

\section{Summary of main results}

In this review update we have found more evidence that there are interventions that meet the Rock 2012 guidelines for aerobic (Campbell 2017; Cantarero-Villanueva 2012b; Irwin 2015; Rogers 2015) and resistance (Bourke 2011a; Bourke 2014; Kim 2017; Scott
2013) exercise with $75 \%$ adherence in previously inactive cancer cohorts. We have identified a hierarchy of the most common behaviour change techniques (BCTs) that feature in these studies (Table 4). The most frequent of these interventions were setting of graded tasks (\#BCT 9), programme set goal and instruction of how to perform behaviour (\#21). These studies were predominantly exclusively supervised studies or a combination of supervised and home-based studies. Supervision usually consisted of contact with the exercise professional or research team at least twice weekly. However, from our review of studies at full-text screening stage, it is still true that adherence to exercise interventions, which is crucial for understanding treatment dose, is frequently either poorly reported or not reported at all in randomised controlled trials (RCTs).

Despite the uncertainty surrounding adherence in many of the included studies, interventions caused improvement in aerobic exercise tolerance at eight to 12 weeks (Analysis 1.1) in intervention participants compared with controls. There is also evidence that this can be sustained at six months of follow-up, but owing to potential high risk of bias, this should be viewed with caution (Analysis 1.3). We were able to carry out one cancer subgroup analysis in breast cancer patients, showing that aerobic exercise tolerance was significantly improved up to 12 weeks (Analysis 1.4), however caution is again warranted when interpreting the result, due to frequent high risk of bias.

Adverse effects these ranged from minor e.g. musculoskeletal problems ( Musanti 2012; Rogers 2015) to major events e.g. death (Kim 2006). However, only five studies were explicit as to which of these adverse effects were caused by inclusion of the participant in the intervention group (two instances of plantar fasciitis) (Cadmus 2009; Cantarero-Villanueva 2012b; Irwin 2015; Rogers 2015; Thomas 2013).

\section{Overall completeness and applicability of evidence}

We included 23 studies in this systematic review, all of which were RCTs. These studies randomly assigned 1372 participants to exercise or comparison groups. A large majority of these studies included women with breast cancer, two involved colorectal cancer survivors, one involved men with advanced prostate cancer, and one involved lung cancer survivors. As found in the original review (Bourke 2013), although these four primary cancers account for most of the population living with and beyond cancer, other common cancers such as lymphoma do not appear at all in this review and less common cancers also are not represented in the evidence base.

Furthermore, an overwhelming majority of participants were white, and only five studies included an ethnically diverse population. As such, other ethnicities are still substantially underrepresented, as found previously (Bourke 2013). Comorbidities were rarely reported at baseline and only six studies were carried out in obese cohorts. Although we set a limit in this review of 90 minutes per week of moderate-intensity exercise at baseline as the criterion for categorising participants as 'sedentary' or 'physically inactive', we did not specify any threshold for vigorous exercisers. It is possible that we could have included individuals who were performing as much as 90 minutes per week of vigorous intensity exercise. However, it is important to note that baseline reporting of behaviour in terms of how much 'vigorous' exercise these cohorts were undertaking was rare. 
Nineteen of the included studies were conducted in Northern America or Western Europe, and two studies were completed in Australia, one in Egypt and one in North Korea. The majority all are considered high-income nations according to the World Health Organization (WHO) taxonomy. Very little evidence was derived from developing countries, and it is uncertain whether the resources, infrastructure or both required for some of the interventions included in this review would be applicable in these parts of the world.

Although no single tool for measuring physical activity is infallible (Warren 2010), when possible it is desirable to have self-reported exercise behaviour supported by objective measurements such as accelerometers or heart rate data. Ten studies were identified that attempted to objectively validate independent exercise behaviour with accelerometers or heart rate monitoring (al-Majid 2015; Bourke 2014; Cadmus 2009; Irwin 2015; Mohamady 2017; Pinto 2005; Pinto 2011; Rogers 2015; Scott 2013; Thomas 2013). Seven studies of these studies attempted to validate self-reported independent exercise behaviour by using accelerometers or heart rate monitors (al-Majid 2015; Bourke 2014; Irwin 2015; Pinto 2005; Pinto 2011; Rogers 2015; Thomas 2013), however in three studies, data either were not supportive of exercise behaviour recorded by participants or were not reported in their entirety (Pinto 2005; Pinto 2011; Rogers 2015). Still a number of studies evaluated non-supervised exercise behaviour by using self-report logs or seven-day physical activity questionnaires. Whilst these tools are relatively non-complex and affordable for implementation in study design, they are prone to well-established bias, including difficulties in ascertaining the frequency, duration and intensity of physical activity; social desirability bias; the cognitive demands of recall and overestimation of behaviour, particularly when such data are used to extrapolate MET/hours of exercise per week performed, or kcal/week of energy expenditure.

Analysis by behaviour change techniques as it relates to any given outcome (e.g. aerobic exercise tolerance) was not possible given that few studies stated a theoretical basis for their intervention, and only one study in this update being based on theory i.e. the trans theoretical model in Rogers 2015. It is worthy of note, however, that interventions frequently consisted of little more than telling people how to exercise and providing opportunities for this to occur, with little consideration of the psychological aspects of changing behaviour. A number of interventions were excluded at full-text screening stage, that had a theoretical basis but did not meet our inclusion criteria. Whilst, the use of theory is variable amongst behaviour change interventions generally, the lack of interventions based on a theoretical model in this review is a concern.

It is also acknowledged that although coding of BCTs was done primarily on the basis of study reports, it is possible that some BCTs may have been implemented but not reported. To overcome this possibility and enhance understanding of the techniques important for changing behaviour in cancer patients, adoption of the CALO-RE taxonomy or the broader BCT V1 taxonomy is recommended.

We acknowledge that in this review, we have undertaken a synthesis of RCTs that represent a combination of exercise efficacy and behaviour change studies (Courneya 2010), we recognise the distinction and this is reflected in the literature. During the screening process, there were a number of behaviour change studies based on theory that we excluded as they did not meet our inclusion criteria. However, it should be noted by the reader that all eight studies that we judged as successful (i.e. reported $75 \%$ or greater adherence over the intervention period to the Rock 2012 guidelines) incorporated intervention elements that were designed to promote independent exercise behaviour and did not place any restrictions on the control group in terms of the exercise they were permitted to undertake during the study.

Finally, we stated in the justification for this review that a better understanding of the types of interventions that could promote long-term, habitual physical activity (i.e. 12 months or longer) in people living with and beyond cancer was a valuable addition to our knowledge due to the original review not being able to address this issue. Unfortunately, because of limitations in the evidence that we identified, we have not been able to address this issue. As such, this is an area of uncertainty that represents an important research gap. Whilst there is more research available of how to promote exercise behaviour at around eight to 12 weeks up until six months, there is still a lack of long-term follow-up of anything beyond this amongst these studies.

\section{Quality of the evidence}

Most of the uncertainty in judging study bias came from lack of clarity around randomisation procedures, allocation concealment and blinding of study outcome assessors. Most of the studies in this review were judged to include at least one element of high risk of non-standard bias, as described in the 'Other potential sources of bias outcome. Of note, we chose to refrain from judging studies according to the performance bias criterion because we considered it not possible to realistically blind intervention participants to 'sham' conditions. Public health guidelines (e.g. the UK CMO report) for aerobic and resistance exercise (which are identical to the Rock 2012 recommendations) are freely available to the public, and given their ease of access via the Internet, the validity of a 'sham' condition is highly dubious. The Summary of findings for the main comparison and 'Risk of bias' tables and Figure 2 and Figure 3 provide a summary of the certainty of evidence. Reporting of adherence of exercise behaviour within the studies was infrequent, which impacted upon the certainty of evidence.

We found the certainty of evidence assessed using the GRADE methodology for the majority of the outcomes to be low to very low; this was mainly due to high risk of bias, inconsistency of the results and imprecise results. One of the main reasons for a very lowcertainty of evidence grading was due to the high number of studies presenting a low number of participants in their study. Concerns over inconsistency were present due to variations in effect sizes and heterogeneity. Additionally, the serious concerns were present with the imprecision of the data due to wide confidence intervals and overall low numbers of participants in each study.

Additionally, attrition ranged from $0 \%$ to $25 \%$, some studies with longer term follow-up (post six months) demonstrated poorer attrition rates, but reasons for this were seldom explained. Ensuring reasons for dropout is reported in future studies is important.

\section{Potential biases in the review process}

We were not able to translate all non-English language studies identified through our database, grey literature and snowballing searches, due to not having access to or resources for translation services. However, a huge effort was made to identify all 
relevant RCTs in this field. To the review authors' knowledge, we have identified and evaluated more RCTs involving exercise interventions in sedentary people living with or beyond cancer than any other systematic review in this field. More than 190 papers were screened at full-text stage for eligibility for this update, in addition to the 400 papers screen at full text for the original review. For this 2018 update, we sent 112 emails in addition to the 116 emails to request data to inform the screening and data extraction process, so that the conclusions of the review would be as accurate and informative as possible. Dual data extraction was used throughout the review, except for study characteristics.

\section{Agreements and disagreements with other studies or reviews}

To the review authors' knowledge, this is still the most comprehensive systematic review of exercise behaviour interventions in sedentary cancer cohorts. A recent systematic review of predictors of adherence to exercise in people living with and beyond cancer found that the trans-theoretical model of behaviour change and the theory of planned behaviour were significantly associated with better exercise adherence (Husebø 2013). The current review does not explicitly support such conclusions: mainly due to reporting in the included studies.

Howlett 2018 conducted a systematic review and meta-analysis that aimed to evaluate physical activity interventions for healthy inactive adults. The BCT analysis found that interventions that included 'biofeedback', 'demonstration of the behaviour', 'behaviour practice/rehearsal' and 'setting of graded tasks' showed larger effect sizes for physical activity outcomes than studies that did not include these BCTs. Our review also found 'setting of graded tasks' to be common amongst the studies with higher adherence rates. Additionally, this review reported a number of studies that were judged as having high risk of bias or were judged as being unclear due to the lack of clear reporting. A suggestion was for future studies to use the TIDieR (Template for Intervention Description and Rreplication) framework (Hoffman 2014), particularly around the description of intervention content. Our review findings support this recommendation, as a number of exercise studies appear to display problems with reporting and are often judged with high risk of bias.

Ormel 2017 carried out a recent systematic review of predictors of adherence and identified the issues with low adherence to exercise interventions for people with cancer. Home-based interventions were found to possibly address the issue of time and travelling to a location, which was identified as a potential barrier. Our review found that interventions that incorporated an element of supervision have better adherence rates to the set exercise target than home-based interventions. However, as previously stated adherence was infrequently reported amongst the studies.

\section{AUTHORS' CONCLUSIONS}

\section{Implications for practice}

Since the last version of this review none of the new relevant studies have provided additional information to change the conclusions. Service provision to promote exercise in sedentary people living with and beyond cancer could incorporate components of both supervised and independent exercise requirements, with supervision being most important for adherence. The majority of the studies in this review were undertaken in breast cancer cohorts and included mainly white females: these limitations to generalisability that were also present in our 2013 review (Bourke 2013). A number of behaviour change techniques (BCTs) were identified in studies which achieved $75 \%$ adherence to the aerobic or resistance guidelines (Rock 2012). Most commonly reported BCTs were goal setting, instruction on how to perform behaviour, and setting graded tasks. In the original review, we argued that expecting the most sedentary survivors to achieve at least 150 minutes per week of aerobic exercise is likely to be unrealistic. This review update has found studies that can achieve these guidelines, but only for limited follow-up. Exercise interventions were found to significantly improve aerobic exercise tolerance compared to usual care at eight to 12 weeks and six months followup. However, there is low to very low-certainty evidence according to the GRADE methodology to suggest this is due to issues of high risk of bias, inconsistency and imprecision. So caution is warranted when interpreting these results for future practice. A very small number of serious adverse effects were reported amongst the studies, ensuring researchers, clinicians and guideline developers that these aerobic and resistance exercise studies are safe in cancer survivors. The role of healthcare professionals involved in cancer care is still unclear from the studies we synthesised.

\section{Implications for research}

The majority of cancer survivors are not regularly active. Future research needs to address the following issues.

- How to promote and sustain exercise behaviour in other cancer survivorship cohorts who are inactive.

- Studies need to improve the standards of reporting adverse effects and if they are related or unrelated to the intervention or study participation.

- Studies need to be explicit about baseline exercise behaviour and about how it was assessed.

- Studies should attempt to use objective measures of exercise, which may be supported with the use of subjective measures.

- Studies should clearly state reasons for drop out.

- Studies need to report as standard frequency, intensity and duration of aerobic exercise, as well as repetitions, sets and intensity of resistance exercise used in intervention prescriptions.

- There needs to be a standardisation of adherence reporting in clinical studies investigating the effects of exercise in cancer survivors. We still recommend that adherence is reported as a single proportion of the cohort who attended/performed exercise according to the set prescription. If adherence were to be clearly reported, there is a much better chance of understanding which factors improve adherence.

- Reporting of BCTS used in such interventions should be standardised. Adoption of the CALO-RE taxonomy or the broader BCT V1 taxonomy is recommended.

- Future interventions should use the TIDieR (Template for Intervention Description and Rreplication) checklist as a guide when designing and when reporting interventions.

By achieving these standards, researchers and clinicians can aim to have an acceptable level of rigour that will demonstrate dose response relationship between exercise and given clinically relevant outcomes. Such rigor can underpin clinical exercise 
guidelines and so that practitioners are able to communicate achievable exercise recommendations for sedentary people living with and beyond cancer.

\section{ACKN OWLEDGEMENTS}

We thank the editorial team Jo Morrison, Clare Jess, Gail Quinn, Jo Platt and Tracey Harrsion for their kind and helpful support during the review process. We also wish to acknowledge the hard work that went in to the original version of the review by Kate Holmer and Karen Robb.

This project was supported by the National Institute for Health Research, via Cochrane Infrastructure funding to the Cochrane Gynaecological, Neuro-oncology and Orphan Cancer Group. The views and opinions expressed therein are those of the authors and do not necessarily reflect those of the Systematic Reviews Programme, NIHR, NHS or the Department of Health. 


\section{R E F E R E N C E S}

\section{References to studies included in this review}

al-Majid 2015 \{published data only\}

Al-Majid S, Wilson LD, Rakovski C, Coburn JW. Effects of exercise on biobehavioral outcomes of fatigue during cancer treatment: results of a feasibility study. Biological Research for Nursing 2015;17:40-8.

\section{Bourke 2011a \{published data only\}}

Bourke L, Thompson G, Gibson DJ, Daley A, Crank H, Adam I, et al. Pragmatic lifestyle intervention in patients recovering from colon cancer: a randomized controlled pilot study. Archives of Physical Medicine \& Rehabilitation 2011;92:749-55.

Bourke 2014 \{published data only\}

* Bourke L, Gilbert S, Hooper R, Steed LA, Joshi M, Catto JW, et al. Lifestyle changes for improving disease-specific quality of life in sedentary men on long-term androgen-deprivation therapy for advanced prostate cancer: a randomised controlled trial. European Urology 2014;65:865-72.

Gilbert SE, Tew GA, Fairhurst C, Bourke L, Saxton JM, Winter EM, et al. Effects of a lifestyle intervention on endothelial function in men on long-term androgen deprivation therapy for prostate cancer. British Journal of Cancer 2016;114:401-8.

\section{Cadmus 2009 \{published data only\}}

* Cadmus LA, Salovey P, Yu H, Chung G, Kasl S, Irwin ML. Exercise and quality of life during and after treatment for breast cancer: results of two randomized controlled trials. PsychoOncology 2009;18:343-52.

Irwin ML, Alvarez-Reeves M, Cadmus L, Mierzejewski E, Mayne ST, Yu H, et al. Exercise improves body fat, lean mass and bone mass in breast cancer survivors. Obesity (Silver Spring) 2009;17:1534-41.

Irwin ML, Cadmus L, Alvarez-Reeves M, O'Neil M, Mierzejewski E, Latka $R$, et al. Recruiting and retaining breast cancer survivors into a randomized controlled exercise trial: the Yale Exercise and Survivorship Study. Cancer 2008;112:2593-606.

Irwin ML, Varma K, Alvarez-Reeves M, Cadmus L, Wiley A, Chung GG, et al. Randomized controlled trial of aerobic exercise on insulin and insulin-like growth factors in breast cancer survivors: the Yale Exercise and Survivorship study. Cancer Epidemiology Biomarkers and Prevention 2009;18:306-13.

Latka RN, Alvarez-Reeves M, Cadmus L, Irwin ML. Adherence to a randomized controlled trial of aerobic exercise in breast cancer survivors: the Yale exercise and survivorship study. Journal of Cancer Survivorship 2009;3:148-57.

\section{Campbell 2017 \{published data only\}}

Campbell KL, Kam JW, Neil-Sztramko SE, Lliu Ambrose T, Handy TC, Lim HJ, et al. Effect of aerobic exercise on cancerassociated cognitive impairment: A proof-of-concept RCT. Psycho-Oncology 2017;27(1):53-60.

\section{Cantarero-Villanueva 2012b \{published data only\}}

Cantarero-Villanueva I, Fernandez-Lao C, Fernandez-De-LasPenas C, Lopez-Barajas IB, Del-Moral-Avila R, De La-llaveRincon, et al. Effectiveness of water physical therapy on pain, pressure pain sensitivity, and myofascial trigger points in breast cancer survivors: a randomized, controlled clinical trial. Pain Medicine 2012;13:1509-19.

\section{Cavalheri 2017 \{published data only\}}

Cavalheri V, Jenkins S, Cecins N, Gain K, Phillips MJ, Sanders LH, et al. Exercise training for people following curative intent treatment for non-small cell lung cancer: a randomized controlled trial. Brazilian Journal of Physical Therapy 2017;21:58-68

Daley 2007a \{published and unpublished data\}

Daley AJ, Crank H, Mutrie N, Saxton JM, Coleman R. Determinants of adherence to exercise in women treated for breast cancer. European Journal of Oncology Nursing 2007;11:392-9.

* Daley AJ, Crank H, Saxton JM, Mutrie N, Coleman R, Roalfe A. Randomized trial of exercise therapy in women treated for breast cancer. Journal of Clinical Oncology 2007;25:1713-21.

Drouin 2005 \{published and unpublished data\}

* Drouin JS, Armstrong H, Krause S, Orr J, Birk TJ, Hryniuk WM, et al. Effects of aerobic exercise training on peak aerobic capacity, fatigue, and psychological factors during radiation for breast cancer. Rehabilitation Oncology 2005;23:11-7.

Drouin JS, Birk TJ, Wirth JC. Random control clinical trial on effect of aerobic exercise training on weight management during radiation treatment for breast cancer. Rehabilitation Oncology 2006;24:6-10.

Drouin JS, Young TJ, Beeler J, Byrne K, Birk TJ, Hryniuk WM, et al. Random control clinical trial on the effects of aerobic exercise training on erythrocyte levels during radiation treatment for breast cancer. Cancer 2006;107:2490-5.

Hayes 2009 \{published and unpublished data\}

Hayes SC, Reul-Hirche H, Turner J. Exercise and secondary lymphedema: safety, potential benefits, and research issues. Medicine and Science in Sports and Exercise 2009;41:483-9.

Irwin 2015 \{published data only\}

* Irwin ML, Cartmel B, Gross CP, Ercolano E, Li P, Yao X, et al. Randomized exercise trial of aromatase inhibitor-induced arthralgia in breast cancer survivors. Journal of Clinical Oncology 2015;33(10):1104-11.

Thomas GA, Cartmel B, Harrigan M, Fiellin M, Capozza S, Zhou Y, et al. The effect of exercise on body composition and bone mineral density in breast cancer survivors taking aromatase inhibitors. Obesity (Silver spring) 2017;25(2):346-51.

Kaltsatou 2011 \{published and unpublished data\}

Kaltsatou A, Mameletzi D, Douka S. Physical and psychological benefits of a 24-week traditional dance program in breast 
cancer survivors. Journal of Bodywork \& Movement Therapies 2011;15:162-7.

\section{Kim 2006 \{published and unpublished data\}}

Kim CJ, Kang DH, Smith BA, Landers KA. Cardiopulmonary responses and adherence to exercise in women newly diagnosed with breast cancer undergoing adjuvant therapy. Cancer Nursing 2006;29:156-65.

\section{Kim 2017 \{published data only\}}

Kim TH, Chang JS, Park KS, Park J, Kim N, Lee JI, et al. Effects of exercise training on circulating levels of Dickkpof- 1 and secreted frizzled-related protein-1 in breast cancer survivors: A pilot single-blind randomized controlled trial. PLOS One 2017;8:e0171771.

\section{McKenzie 2003 \{published and unpublished data\}}

McKenzie DC, Kalda AL. Effect of upper extremity exercise on secondary lymphedema in breast cancer patients: a pilot study. Journal of Clinical Oncology 2003;21:463-6.

\section{Mohamady 2017 \{published data only\}}

Mohamady HM, Elsisi HF, Aneis YM. Impact of moderate intensity aerobic exercise on chemotherapy-induced anemia in elderly women with breast cancer: A randomized controlled clinical trial. Journal of Advanced Research 2017;8:7-12.

\section{Musanti 2012 \{published data only\}}

Musanti R. A study of exercise modality and physical self-esteem in breast cancer survivors. Medicine and Science in Sports and Exercise 2012;44:352-61.

\section{Perna 2010 \{published and unpublished data\}}

Perna FM, Craft L, Freund KM, Skrinar G, Stone M, Kachnic L, et al. The effect of a cognitive behavioral exercise intervention on clinical depression in a multiethnic sample of women with breast cancer: a randomized controlled trial. International Journal of Sport and Exercise Psychology 2010;8:36-47.

\section{Pinto 2003 \{published data only\}}

Pinto BM, Clark MM, Maruyama NC, Feder SI. Psychological and fitness changes associated with exercise participation among women with breast cancer. Psycho-Oncology 2003;12:118-26.

\section{Pinto 2005 \{published and unpublished data\}}

* Pinto BM, Frierson GM, Rabin C, Trunzo JJ, Marcus BH. Homebased physical activity intervention for breast cancer patients. Journal of Clinical Oncology 2005;23:3577-87.

Pinto BM, Rabin C, Dunsiger S. Home-based exercise among cancer survivors: adherence and its predictors. Psycho-Oncology 2009;18:369-76.

Pinto BM, Rabin C, Papandonatos GD, Frierson GM, Trunzo JJ, Marcus BH. Maintenance of effects of a home-based physical activity program among breast cancer survivors. Support Care Cancer 2008;16:1279-89.

Pinto BM, Trunzo JJ, Rabin C, Cady B, Fenton MA, Herman A, et al. Random control clinical trial on effect of aerobic exercise training on weight management during radiation treatment for breast cancer. Journal of Clinical Psychology in Medical Settings 2004;11:171-8.

Rabin C, Pinto BM, Frierson G. Mediators of a randomized controlled physical activity intervention for breast cancer survivors. Journal of Sport and Exercise Psychology 2006;28:269-84.

\section{Pinto 2011 \{published and unpublished data\}}

Pinto BM, Papandonatos GD, Goldstein MG, Marcus BH, Farrell N. Home-based physical activity intervention for colorectal cancer survivors. Psycho-Oncology Epub 2011; Vol. 22, issue 1:54-64

\section{Rogers 2015 \{published data only\}}

Rogers LQ, Courneya KS, Anton PM, Hopkins-Price P, Verhulst S, Robbs RS, et al. Social cognitive constructs did not mediate the BEAT cancer intervention effects on objective physical activity behavior based on multivariable path analysis. Annals of Behavioral Medicine 2017;51:321-6.

* Rogers LQ, Courneya KS, Anton PM, Hopkins-Price P, Verhulst S, Vicari SK, et al. Effects of the BEAT Cancer physical activity behavior change intervention on physical activity, aerobic fitness, and quality of life in breast cancer survivors: a multicenter randomized controlled trial. Breast Cancer Research and Treatment 2015;149:109-19.

Rogers LQ, Courneya KS, Carter SJ, Anton PM, Verhulst S, Vicari SK, et al. Effects of a multicomponent physical activity behavior change intervention on breast cancer survivor health status outcomes in a randomized controlled trial. Breast Cancer Research and Treatment 2016;159:283-91.

Rogers LQ, McAuley E, Anton PM, Courneya KS, Vicari S, Hopkins-Price $P$, et al. Better exercise adherence after treatment for cancer (BEATCancer) study: rationale, design, and methods. Contemporary Clinical Trials 2012;33(1):124-37.

\section{Scott 2013 \{published data only\}}

Saxton JM, Scott EJ, Daley AJ, Woodroofe MN, Mutrie N, Crank $\mathrm{H}$, et al. Effects of an exercise and hypocaloric healthy eating intervention on indices of psychological health status, hypothalamic-pituitary-adrenal axis regulation and immune function after early-stage breast cancer: a randomised controlled trial. Breast Cancer Research and Treatment 2014;16(2):R39.

* Scott E, Daley AJ, Doll H, Woodroofe N, Coleman RE, Mutrie N, et al. Effects of an exercise and hypocaloric healthy eating program on biomarkers associated with long-term prognosis after early-stage breast cancer: a randomized controlled trial. Cancer Causes \& Control 2013;24:181-91.

\section{Thomas 2013 \{published data only\}}

Irwin ML, Cadmus L, Alvarez-Reeves M, O'Neil M, Mierzejewski E, Latka $R$, et al. Recruiting and retaining breast cancer survivors into a randomized controlled exercise trial: the Yale Exercise and Survivorship Study. Cancer 2008;112:2593-606.

* Thomas GA, Alvarez-Reeves M, Lu L, Yu H, Irwin ML. Effect of Exercise on Metabolic Syndrome Variables in Breast Cancer 
Survivors. International Journal of Endocrinology 2013;Volume 2013:168797.

\section{References to studies excluded from this review}

\section{Adams 2016 \{published data only\}}

Adams SC, Segal RJ, McKenzie DC, Morielli AR, Mackey JR, Gelmon K, et al. Impact of resistance and aerobic exercise on sarcopenia and dynapenia in breast cancer patients receiving adjuvant chemotherapy: a multicenter randomized controlled trial. Breast Cancer Research and Treatment 2016 Aug;158(3):497-507.

\section{Ahmed 2006 \{published data only\}}

Ahmed RL, Thomas W, Yee D, Schmitz KH. Randomized controlled trial of weight training and lymphedema in breast cancer survivors. Journal of Clinical Oncology 2006;24:2765-72.

\section{Alibhai 2014 \{published data only\}}

Alibhai SM, O'Neill S, Fisher-Schlombs K, Breunis H, Timilshina N, Brandwein JM, et al. A pilot phase II RCT of a home-based exercise intervention for survivors of AML. Supportive Care in Cancer 2014;22(4):881-9.

\section{Ames 2011 \{published data only\}}

Ames SC, Tan WW, Ames GE, Stone RL, Rizzo TD Jr, Crook JE, et al. A pilot investigation of a multidisciplinary quality of life intervention for men with biochemical recurrence of prostate cancer. Psycho-Oncology 2011;20:435-40.

\section{Anderson 2012 \{published data only\}}

Anderson RT, Kimmick GG, McCoy TP, Hopkins J, Levine E, Miller $\mathrm{G}$, et al. A randomized trial of exercise on well-being and function following breast cancer surgery: the RESTORE trial. Journal of Cancer Survivorship 2012;6:172-81.

\section{Anderson 2013 \{published data only\}}

Andersen C, Rørth M, Ejlertsen B, Stage M, Møller T, Midtgaard J, et al. The effects of a six-week supervised multimodal exercise intervention during chemotherapy on cancer-related fatigue. European Journal of Oncology Nursing 2013;17(3):331-9.

\section{Anderson 2015 \{published data only\}}

Anderson DJ, Seib C, McCarthy AL, Yates P, Porter-Steele J, McGuire A, et al. Facilitating lifestyle changes to manage menopausal symptoms in women with breast cancer: A randomized controlled pilot trial of The Pink Women's Wellness Program. Menopause (New York) 2015;22(9):937-45.

\section{Anulika 2015 \{published data only\}}

Anulika Aweto H, Akinbo SRA, Olawale OA. Effects of combined aerobic and stretching exercises on the cardiopulmonary parameters of premenopausal and postmenopausal breast cancer survivors. Nigerian Quarterly Journal of Hospital Medicine 2015;25(3):177-83.

\section{Arbane 2011 \{published and unpublished data\}}

Arbane G, Tropman D, Jackson D, Garrod R. Evaluation of an early exercise intervention after thoracotomy for non-small cell lung cancer (NSCLC), effects on quality of life, muscle strength and exercise tolerance: randomised controlled trial. Lung Cancer 2011;71:229-34.

\section{Arbane 2014 \{published data only\}}

Arbane G, Douiri A, Hart N, Hopkinson NS, Singh S, Speed C, et al. Effect of postoperative physical training on activity after curative surgery for non-small cell lung cancer: a multicentre randomised controlled trial. Physiotherapy 2014;100(2):100-7.

\section{Arikawa 2013 \{published data only\}}

Arikawa AY, Thomas W, Patel SR, Kurzer MS. No effect of exercise on urinary 6 -sulfatoxymelatonin and catecholamines in young women participating in a 16-week randomized controlled trial. Cancer Epidemiology, Biomarkers \& Prevention 2013;22(9):1634-6

Banerjee 2013 \{published data only\} Banerjee S, Manley K, Thomas L, Shaw B, Saxton J, Mills R, et al. Preoperative exercise protocol to aid recovery of radical cystectomy: Results of a feasibility study. European Urology, Supplements 2013;12(6):125-6.

\section{Baruth 2015 \{published data only\}}

Baruth M, Wilcox S, Der Ananian C, Heiney S. Effects of homebased walking on quality of life and fatigue outcomes in early stage breast cancer survivors: a 12-week pilot study. Journal of Physical Activity \& Health 2015;12(1):110-8.

\section{Battaglini 2007 \{published and unpublished data\}}

Battaglini C, Bottaro M, Dennehy C, Rae L, Shields E, Kirk D, et al. The effects of an individualized exercise intervention on body composition in breast cancer patients undergoing treatment. Sao Paulo Medical Journal 2007;125:22-8.

\section{Battaglini 2008 \{published and unpublished data\}}

Battaglini CL, Mihalik JP, Bottaro M, Dennehy C, Petschauer MA, Hairston LS, et al. Effect of exercise on the caloric intake of breast cancer patients undergoing treatment. Brazilian Journal of Medical and Biological Research 2008;41:709-15.

\section{Bloom 2013 \{published data only\}}

Bloom J, Stewart S, Oakley-Girvan I, Luce J, Sellmeyer D. Bone health for younger women with breast cancer: effects of a YMCA-based intervention on exercise, bone density, body mass, and physical and mental health in a multi-ethnic sample. Psycho-Oncology 2013;22:81-2.

\section{Bracha 2012 \{published data only\}}

Bracha J, Katz-Leurer M. The immediate effect of upper arm exercise compared with lower or combined upper and lower arm exercise on arm volume reduction in women with breast cancer related lymphedema: A randomized preliminary study. Rehabilitation Oncology 2012;30:3-8.

\section{Brdareski 2012 \{published data only\}}

Brdareski Z, Djurovic A, Susnjar S, Zivotic-Vanovic M, Ristic A, Konstantinovic $L$, et al. Effects of a short-term differently dosed aerobic exercise on maximum aerobic capacity in breast cancer survivors: a pilot study. Vojnosanitetski Pregled [Military Medical and Pharmaceutical Review] 2012;69(3):237-42. 
Brown 2012 \{published data only\}

Brown JC, Troxel AB, Schmitz K. Safety of weightlifting among women with or at risk for breast cancer-related lymphedema: musculoskeletal injuries and health care use in a weightlifting rehabilitation trial. Oncologist 2012;17(8):1120-8.

\section{Bruno 2018 \{published data only\}}

Bruno E, Roveda E, Vitale J, Montaruli A, Berrino F, Villarini A, et al. Effect of aerobic exercise intervention on markers of insulin resistance in breast cancer women. European Journal of Cancer Care 2018;27(2):e12617.

\section{Buchan 2016 \{published data only\}}

Buchan J, Janda M, Box R, Schmitz K, Hayes S. A randomized trial on the effect of exercise mode on breast cancer-related lymphedema. Medicine and Science in Sports and Exercise 2016;48(10):1866-74.

\section{Buffart 2013 \{published data only\}}

Buffart L, Galvao D, Paw M, Brug CA, Taaffe J, Spry D, et al. How does a resistance and aerobic exercise program improve physical and general health in men undergoing androgen deprivation therapy for prostate cancer?. Psycho-Oncology 2013;22:28-9.

\section{Buffart 2014a \{published data only\}}

Buffart LM, Galvão DA, Chinapaw MJ, Brug J, Taaffe DR, Spry Nigel, et al. Mediators of the resistance and aerobic exercise intervention effect on physical and general health in men undergoing androgen deprivation therapy for prostate cancer. Cancer 2014;120:294-301.

\section{Buffart 2014b \{published data only\}}

Buffart LM, Ros WJG, Chinapaw MJ, Brug J, Knol DL, Korstjens I, et al. Mediators of physical exercise for improvement in cancer survivors' quality of life. Psycho-Oncology 2014;23:330-8.

\section{Campbell 2005 \{published data only\}}

Campbell A, Mutrie N, White F, McGuire F, Kearney N. A pilot study of a supervised group exercise programme as a rehabilitation treatment for women with breast cancer receiving adjuvant treatment. European Journal of Oncology Nursing 2005;9:56-63.

\section{Cantaero-Villanueva 2013 \{published data only\}}

Cantarero-Villanueva I, Fernández-Lao C, Cuesta-Vargas A, Del Moral-Avila R, Fernández-de-las-Peñas C, Arroyo-Morales M. The effectiveness of a deep water aquatic exercise program in cancer-related fatigue in breastcancer survivors: a randomized controlled trial. Archives of Physical Medicine \& Rehabilitation 2013;94(2):221-30

\section{Cantaero-Villanueva 2016 \{published data only\}}

Cantarero-Villanueva I, Sanchez-Jimenez A, Galiano-Castillo N, Diaz-Rodriguez L, Martin-Martin L, Arroyo-Morales M.

Effectiveness of lumbopelvic exercise in colon cancer survivors: a randomized controlled clinical. Medicine \& Science in Sports \& Exercise 2016;48(8):1438-46.

\section{Cantarero-Villanueva 2011 \{published and unpublished data\}}

Cantarero-Villanueva I, Fernández-Lao C, Díaz-Rodriguez L, Fernández-de-las-Peñas C, del Moral-Avila R, Arroyo-Morales M. A multimodal exercise program and multimedia support reduce cancer-related fatigue in breast cancer survivors: a randomised controlled clinical trial. European Journal of Integrative Medicine 2011;3:e189-e200.

\section{Cantarero-Villanueva 2012a \{published and unpublished data}

Cantarero-Villanueva I, Fernández-Lao C, Del Moral-Avila R, Fernández-de-Las-Peñas C, Feriche-Fernández-Castanys MB, Arroyo-Morales M. Effectiveness of core stability exercises and recovery myofascial release massage on fatigue in breast cancer survivors: a randomized controlled clinical trial. EvidenceBased Complementary and Alternative Medicine 2012; Vol. 2012:620619. [DOI: 10.1155/2012/620619]

\section{Carmack Taylor 2004 \{published data only\}}

Carmack Taylor CL, Smith MA, de Moor C, Dunn AL, Pettaway C, Sellin R, et al. Quality of life intervention for prostate cancer patients: design and baseline characteristics of the Active for Life After Cancer trial. Controlled Clinical Trials 2004;25:265-85.

\section{Carmack Taylor 2006 \{published data only\}}

Carmack Taylor CL, Demoor C, Smith MA, Dunn AL, BasenEngquist K, Nielsen I, et al. Active for Life After Cancer: a randomized trial examining a lifestyle physical activity program for prostate cancer patients. Psycho-oncology 2006;15:847-62.

\section{Carmack Taylor 2007 \{published data only\}}

Carmack Taylor CL, de Moor C, Basen-Engquist K, Smith MA, Dunn AL, Badr H, et al. Moderator analyses of participants in the Active for Life After Cancer trial: implications for physical activity group intervention studies. Annals of Behavioral Medicine 2007;33:99-104.

\section{Carson 2009 \{published and unpublished data\}}

Carson JW, Carson KM, Porter LS, Keefe FJ, Seewaldt VL. Yoga of Awareness program for menopausal symptoms in breast cancer survivors: results from a randomized trial. Supportive Care in Cancer 2009;17(10):1301-9.

\section{Casla 2015 \{published data only\}}

Casla S, Lopez-Tarruella S, Jerez Y, Marquez-Rodas I, Galvao DA, Newton RU, et al. Supervised physical exercise improves VO2max, quality of life, and health in early stage breast cancer patients: a randomized controlled trial. Breast Cancer Research and Treatment 2015;153(2):371-82.

\section{Cerulli 2014 \{published data only\}}

Cerulli C, Minganti C, De Santis C, Tranchita E, Quaranta F, Parisi A. Therapeutic horseback riding in breast cancer survivors: a pilot study. Journal of Alternative and Complementary Medicine (New York, N.Y.) 2014;20(8):632-9.

\section{Chen 2015 \{published data only\}}

Chen HM, Tsai CM, Wu YC, Lin KC, Lin CC. Randomised controlled trial on the effectiveness of home-based walking exercise on anxiety, depression and cancer-related symptoms in patients with lung cancer. British Journal of Cancer 2015;112:438-45. 
Chen 2016 \{published data only\}

Chen HM, Tsai CM, Wu YC, Lin KC, Lin CC. Effect of walking on circadian rhythms and sleep quality of patients with lung cancer: a randomised controlled trial. British Journal of Cancer 2016;115(11):1304-12.

\section{Cho 2006 \{published data only\}}

Cho OH, Yoo YS, Kim NC. Efficacy of comprehensive group rehabilitation for women with early breast cancer in South Korea. Nursing and Health Sciences 2006;8:140-6.

\section{Christensen 2014 \{published data only\}}

Christensen JF, Jones LW, Tolver A, Jørgensen LW, Andersen JL, Adamsen $L$, et al. Safety and efficacy of resistance training in germ cell cancer patients undergoing chemotherapy: a randomized controlled trial. British Journal of Cancer 2014;111(1):8-16.

\section{Chuang 2017 \{published data only\}}

Chuang TY, Yeh ML, Chung YC. A nurse facilitated mind-body interactive exercise (Chan-Chuang qigong) improves the health status of non-Hodgkin lymphoma patients receiving chemotherapy: randomised controlled trial. International Journal of Nursing Studies 2017;69:25-33.

\section{Coleman 2003 \{published data only\}}

Coleman EA, Hall-Barrow J, Coon S, Stewart CB. Facilitating exercise adherence for patients with multiple myeloma. Clinical Journal of Oncology Nursing 2003;7:529-34.

\section{Cornette 2016 \{published data only\}}

Cornette T, Vincent F, Mandigout S, Antonini MT, Leobon S, Labrunie A, et al. Effects of home-based exercise training on VO2 in breast cancer patients under adjuvant or neoadjuvant chemotherapy (SAPA): a randomized controlled trial. European Journal of Physical and Rehabilitation Medicine 2016;52(2):223-32.

\section{Cornie 2013a \{published data only\}}

Cormie P, Newton R, Spry N, Joseph D, Taaffe DR, Galvao DA. Safety and efficacy of resistance exercise in prostate cancer patients with bone metastases. Prostate Cancer \& Prostatic Diseases 2013;16(4):328-35.

\section{Cornie 2013b \{published data only\}}

Cormie P, Newton RU, Taaffe DR, Spry N, Joseph D, Akhlil Hamid $M$, et al. Exercise maintains sexual activity in men undergoing androgen suppression for prostate cancer: a randomized controlled trial. Prostate Cancer \& Prostatic Diseases 2013;16(2):170-5.

\section{Cornie 2014 \{published data only\}}

Cormie P, Chambers SK, Newton RU, Gardiner RA, Spry N, Taaffe DR, et al. Improving sexual health in men with prostate cancer: randomised controlled trial of exercise and psychosexual therapies. BMC Cancer 2014;14(1):14-199.

\section{Cornie 2015 \{published data only\}}

Cormie P, Galvao DA, Spry N, Joseph D, Chee R, Taaffe DR, et al. Can supervised exercise prevent treatment toxicity in patients with prostate cancer initiating androgen-deprivation therapy: a randomised controlled trial. BJU International 2015;115(2):256-66.

\section{Courneya 2012 \{published data only\}}

Courneya KS, Sellar CM, Trinh L, Forbes CC, Stevinson C, McNeely ML, et al. A randomized trial of aerobic exercise and sleep quality in lymphoma patients receiving chemotherapy or no treatments. Cancer Epidemiology, Biomarkers \& Prevention 2012;21(6):887-94

\section{Courneya 2013 \{published data only\}}

Courneya KS, Forbes CC, Trinh L, Sellar CM, Friedenreich CM, Reiman T. Patient satisfaction with participation in a randomized exercise trial: effects of randomization and a usual care posttrial exercise program. Clinical Trials (London, England) 2013;10(6):959-66.

\section{Courneya 2014a \{published data only\}}

Courneya K, Segal R, Mackey J, Gelmon K, Friedenreich C, Yasui $Y$, et al. Effects of exercise dose and type on sleep quality during breast cancer chemotherapy: a multicenter randomized trial. Psycho-Oncology 2014;23:57-8.

Courneya 2014b \{published data only\}

Courneya KS, Segal RJ, McKenzie DC, Dong H, Gelmon K, Friedenreich CM, et al. Effects of exercise during adjuvant chemotherapy on breast cancer outcomes. Medicine and Science in Sports and Exercise 2014;46(9):1744-51.

\section{Courneya 2015 \{published data only\}}

Courneya KS, Friedenreich CM, Franco-Villalobos C, Crawford JJ, Chua N, Basi S, et al. Effects of supervised exercise on progression-free survival in lymphoma patients: an exploratory follow-up of the HELP Trial. Cancer Causes \& Control 2015;26(2):269-72.

\section{Courneya 2016a \{published data only\}}

Courneya KS, Vardy JL, O'Callaghan CJ, Friedenreich CM, Campbell KL, Prapavessis $\mathrm{H}$, et al. Effects of a structured exercise program on physical activity and fitness in colon cancer survivors: one year feasibility results from the CHALLENGE trial. Cancer Epidemiology, Biomarkers \& Prevention 2016;25(6):969-77.

\section{Courneya 2016b \{published data only\}}

Courneya KS, Segal RJ, Vallerand JR, Forbes CC, Crawford JJ, Dolan LB, et al. Motivation for different types and doses of exercise during breast cancer chemotherapy: a randomized controlled trial. Annals of Behavioral Medicine 2016;50(4):554-63.

\section{Culos Reed 2010 \{published data only\}}

Culos-Reed SN, Robinson JW, Lau H, Stephenson L, Keats M, Norris $\mathrm{S}$, et al. Physical activity for men receiving androgen deprivation therapy for prostate cancer: benefits from a 16week intervention. Supportive Care in Cancer 2010;18:591-9.

Danhauer 2009 \{published data only\}

Danhauer SC, Mihalko SL, Russell GB, Campbell CR, Felder L, Daley $\mathrm{K}$, et al. Restorative yoga for women with breast cancer: 
finding from a randomized pilot study. Psycho-Oncology 2009;18:360-8.

\section{Daubenmier 2006 \{published data only\}}

Daubenmier JJ, Weidner G, Marlin R, Crutchfield L, DunnEmke S, Chi C, et al. Lifestyle and health-related quality of life of men with prostate cancer managed with active surveillance. Urology 2006;67:125-30.

\section{De Jesus 2013 \{published data only\}}

De Jesus S, Fitzgeorge L, Massel D, Prapavessis H, Sanatani M, Suskin, et al. Community-based exercise intervention for oncology patients suffering from fatigue: effects on symptoms, psychosocial health, aerobic fitness and body composition: a pilot study. Psycho-Oncology 2013;22:48.

\section{Demark-Wahnefried 2015 \{published data only\}}

Demark-Wahnefried W, Colditz GA, Rock CL, Sedjo RL, Liu J, Wolin KY, et al. Quality of life outcomes from the Exercise and Nutrition Enhance Recovery and Good health for You (ENERGY) - randomized weight loss trial among breast cancer survivors. Breast Cancer Research and Treatment 2015;154(2):329-37.

\section{DeNysschen 2011 \{published data only\}}

DeNysschen CA, Brown JK, Cho MH, Dodd MJ. Nutritional symptom and body composition outcomes of aerobic exercise in women with breast cancer. Clinical Nursing Research 2011;20:29-46

\section{Dieli-Conwright 2014 \{published data only\}}

Dieli-Conwright CM, Mortimer JE, Schroeder ET, Courneya K, Demark-Wahnefried W, Buchanan TA, et al. Randomized controlled trial to evaluate the effects of combined progressive exercise on metabolic syndrome in breast cancer survivors: rationale, design, and methods. BMC Cancer 2014;14(1):doi: 10.1186/1471-2407-14-238.

\section{Dieperink 2017 \{published data only\}}

Dieperink KB, Johansen C, Hansen S, Wagner LK, Andersen K, Minet LR, et al. Male coping through a long-term cancer trajectory. Secondary outcomes from a RTC examining the effect of a multidisciplinary rehabilitation program (RePCa) among radiated men with prostate cancer. Acta Oncologica 2017;56(2):254-61.

\section{Diepold 2016 \{published data only\}}

Diepold C, Wiskemann J, Hummler S, Steins M, Thomas M. Physical exercise program in non-operable lung cancer patients undergoing palliative treatment-preliminary report of recruitment rates and feasibility of the POSITIVE study (part III). Oncology Research and Treatment 2016;16:10.1186/ s12885-016-2561-1.

\section{Do 2015 \{published data only\}}

Do J, Cho Y, Jeon J. Effects of a 4-week multimodal rehabilitation program on quality of life, cardiopulmonary function, and fatigue in breast cancer patients. Journal of Breast Cancer 2015;18(1):87-9.
Dolan 2010 \{published data only\}

Dolan LB, Gelmon K, Courneya KS, Mackey JR, Segal RJ, Lane $\mathrm{K}$, et al. Hemoglobin and aerobic fitness changes with supervised exercise training in breast cancer patients receiving chemotherapy. Cancer Epidemiology Biomarkers \& Prevention 2010;19:2826-32.

\section{Dolan 2014 \{published data only\}}

Dolan LB, Campbell K, Neil S, McKenzie D. The influence of exercise intensity on health-related outcomes in breast cancer survivors. Archives of Physical Medicine and Rehabilitation 2014;95(10):E43-4.

\section{Dolan 2016 \{published data only\}}

Dolan LB, Campbell K, Gelmon K, Neil-Sztramko S, Holmes D, McKenzie DC. Interval versus continuous aerobic exercise training in breast cancer survivors - a pilot RCT. Supportive Care in Cancer 2016;24(1):119-27.

\section{Donmez 2017 \{published data only\}}

Donmez A, ArikanKapucu Sevgisun RTY. The effectiveness of a clinical and home-based physical activity program and simple lymphatic drainage in the prevention of breast cancer-related lymphedema: a prospective randomized controlled study. European Journal of Oncology Nursing 2017;31:12-21.

\section{Donnelly 2011 \{published and unpublished data\}}

Donnelly CM, Blaney JM, Lowe-Strong A, Rankin JP, Campbell A, McCrum-Gardner E, et al. A randomised controlled trial testing the feasibility and efficacy of a physical activity behavioural change intervention in managing fatigue with gynaecological cancer survivors. Gynecologic Oncology 2011;122:618-24.

\section{Edvarsen 2015 \{published data only\}}

Edvardsen E, Skjønsberg OH, Holme I, Nordsletten L, Borchsenius F, Anderssen SA. High-intensity training following lung cancer surgery: a randomised controlled trial. Thorax 2015;70(3):244-50.

\section{Emslie 2007 \{published data only\}}

Emslie C, Whyte F, Campbell A, Mutrie N, Lee L, Ritchie D, et al. 'I wouldn't have been interested in just sitting round a table talking about cancer'; exploring the experiences of women with breast cancer in a group exercise trial. Health Education Research 2007;22:827-38.

\section{Eriksen 2017 \{published data only\}}

Eriksen AK, Hansen RD, Larsen RG, Jensen JM, Overgaard K, Borre $\mathrm{M}$, et al. A lifestyle intervention among elderly men on active surveillance for non-aggressive prostate cancer: a randomised feasibility study with whole-grain rye and exercise. Trials 2017;18(20):doi: 10.1186/s13063-016-1734-1.

\section{Fan-Ko 2017 \{published data only\}}

Fan-Ko S, Chao-Ming H, YuChun Y, Chu-Yun L, Chun-Ying C. The effects of muscle relaxation and therapeutic walking on depression, suicidal ideation, and quality of life in breast cancer patients receiving chemotherapy. Cancer Nursing 2017;40:E39-48. 
Fernandez-Lao 2012 \{published and unpublished data\}

Fernández-Lao C, Cantarero-Villanueva I, Fernández-deLas-Peñas C, del Moral-Ávila R, Castro-Sánchez AM, ArroyoMorales M. Effectiveness of a multidimensional physical therapy program on pain, pressure hypersensitivity, and trigger points in breast cancer survivors: a randomized controlled clinical trial. Clinical Journal of Pain 2012;28:113-21.

\section{Fields 2015 \{published data only\}}

Fields J, Richardson A, Fenlon D. Nordic walking as a physical activity intervention for aromatase inhibitor associated arthralgia: a feasibility study. European Journal of Surgical Oncology 2015;41(6):s76-7.

\section{Fields 2017 \{published data only\}}

Fields J, Richardson A, Hopkinson J, Fenlon D. Nordic walking as an exercise intervention to reduce pain in women with aromatase inhibitor-associated arthralgia: a feasibility study. Journal of Pain and Symptom Management 2017;52(4):548-59.

Forbes 2017 \{published data only\}

Forbes CC, Blanchard CM, Mummery K, Courneya K. A pilot study on the motivational effects of an internet-delivered physical activity behaviour change programme in Nova Scotian cancer survivors. Psychology, Health \& Medicine 2017;32(2):234-52.

\section{Frattaroli 2008 \{published data only\}}

Frattaroli J, Weidner G, Dnistrian AM, Kemp C, Daubenmier JJ, Marlin RO, et al. Clinical events in prostate cancer lifestyle trial: results from two years of follow-up. Urology 2008;72:1319-23.

\section{Friedenrich 2016 \{published data only\}}

Friedenreich CM, Pialoux V, Wang Q, Shaw E, Brenner DR, Waltz $X$, et al. Effects of exercise on markers of oxidative stress: an ancillary analysis of the Alberta Physical Activity and Breast Cancer Prevention trial [with consumer summary]. BMJ Open Sport \& Exercise Medicine 2016;2(1):e000171.

\section{Furzer 2016 \{published data only\}}

Furzer BJ, Ackland TR, Wallman KE, Petterson AS, Gordon SM, Wright $K E$, et al. A randomised controlled trial comparing the effects of a 12-week supervised exercise versus usual care on outcomes in haematological cancer patients. Supportive Care in Cancer 2016;24(4):1697-707.

\section{Galiano-Castillo 2017 \{published data only\}}

Galiano-Castillo N, Arroyo-Morales M, Fernandez-Lao C, Cantarero-Villanueva I, Lozano-Lozano M, Martin-Martin L, et al. Effect of an Internet-based telehealth system on functional capacity and cognition in breast cancer survivors: a secondary analysis of a randomized controlled trial. Supportive Care in Cancer 2017;25(11):3351-559.

\section{Galvão 2010 \{published data only\}}

Galvão DA, Taaffe DR, Spry N, Joseph D, Newton RU. Combined resistance and aerobic exercise program reverses muscle loss in men undergoing androgen suppression therapy for prostate cancer without bone metastases: a randomized controlled trial. Journal of Clinical Oncology 2010;28:340-7.

\section{Galvão 2011 \{published data only\}}

Galvão DA, Taaffe DR, Spry N, Joseph D, Newton RU. Acute versus chronic exposure to androgen suppression for prostate cancer: impact on the exercise response. Journal of Urology 2011;186:1291-7.

\section{Galvão 2017 \{published data only\}}

Galvao DA, Newton RU, Girgis A, Lepore SJ, Stiller A, Mihalopoulos C, et al. Randomized controlled trial of a peer led multimodal intervention for men with prostate cancer to increase exercise participation. Psycho-Oncology 2017;27(1):199-207.

\section{Gaskin 2016 \{published data only\}}

Gaskin CJ, Fraser SF, Owen PJ, Craike M, Orellana L, Livingston PM. Fitness outcomes from a randomised controlled trial of exercise training for men with prostate cancer: the ENGAGE study. Journal of Cancer Survivorship 2016;10(6):972-80.

\section{Gehring 2014 \{published data only\}}

Gehring K, Stuiver M, Rutten GJ, Taphoorn M, Aaronson N, Sitskoorn M. A pilot RCT on the efficacy of home-based exercise to improve cognitive functioning in grade II and III glioma patients. Neuro-Oncology 2014;16:v185.

\section{Gehring 2015 \{published data only\}}

Gehring K, Stuiver M, Rutten GJ, Taphoorn M, Aaronson N, Sitskoorn M. A pilot RCT on the efficacy of E-health supported physical exercise to improve cognitive functioning in glioma patients. Neuro-oncology 2015;17:v146-7.

\section{Gehring 2018 \{published data only\}}

Gehring K, Kloek C, Aaronson NK, Janssen KW, Jones LW, Sitskoorn MM, et al. Feasibility of a home-based exercise intervention with remote guidance for patients with stable grade II and III gliomas: a pilot randomized controlled trial. Clinical Rehabilitation 2018;32(8):352-66.

\section{Gerland 2012 \{published data only\}}

Gerland L, Frisse S, Latta S, Bloch W, Harbeck N, Baumann FT. Evaluation of the impact of a 3-month strength training on strength parameters, EMG and oxidative stress of breast cancer patients during chemotherapy. Journal of Cancer Research and Clinical Oncology 2012;1:133-8.

\section{Giallauria 2014 \{published data only\}}

Giallauria F, Gentile M, Chiodini P, Mattiello A, Maresca L, Vitelli $A$, et al. Exercise training reduces high mobility group box-1 levels in women with breast cancer: the DIANA (diet and androgens)-5 project. European Journal of Preventive Cardiology 2014;21(1):61-7.

\section{Gokal 2016 \{published data only\}}

Gokal K, Wallis D, Ahmed S, Boiangiu I, Kancherla K, Munir F. Effects of a self-managed home-based walking intervention on psychosocial health outcomes for breast cancer patients receiving chemotherapy: a randomised controlled trial. Supportive Care in Cancer 2016;24(3):1139. 
Gómez 2011 \{published data only\}

Gómez AM, Martínez C, Fiuza-Luces C, Herrero F, Pérez M, Madero L, et al. Exercise training and cytokines in breast cancer survivors. International Journal of Sports Medicine 2011;32:461-7.

\section{Granger 2013 \{published data only\}}

Granger CL, Chao C, McDonald CF, Berney S, Denehy L. Safety and feasibility of an exercise intervention for patients following lung resection: a pilot randomized controlled trial. Integrative Cancer Therapies 2013;12(3):213-24.

\section{Greenlee 2013 \{published data only\}}

Greenlee HA, Crew KD, Mata JM, McKinley PS, Rundle AG, Zhang W, et al. A pilot randomized controlled trial of a commercial diet and exercise weight loss program in minority breast cancer survivors. Obesity (19307381) 2013;21(1):65-76.

\section{Gruenigen 2012a \{published data only\}}

Gruenigen V, Frasure H, Kavanagh MB, Janata J, Waggoner S, Rose $P$, et al. Survivors of uterine cancer empowered by exercise and healthy diet (SUCCEED): a randomized controlled trial. Gynecologic Oncology 2012;125(3):699-704.

\section{Gruenigen 2012b \{published data only\}}

Gruenigen VE, Gibbons HE, Kavanagh MB, Janata JW, Lerner E, Courneya KS. A randomized trial of a lifestyle intervention in obese endometrial cancer survivors: quality of life outcomes and mediators of behavior change. Health and Quality of Life Outcomes 2012;7:doi: 10.1186/1477-7525-7-17.

\section{Guinan 2013 \{published data only\}}

Guinan E, Hussey J, Broderick JM, Lithander FE, O'Donnell D, Kennedy MJ, et al. The effect of aerobic exercise on metabolic and inflammatory markers in breast cancer survivors - a pilot study. Supportive Care in Cancer 2013;21(7):1983-92.

\section{Guinan 2017 \{published data only\}}

Guinan E, Doyle SL, O'Neill L, Dunne MR, Foley EK, O'Sullivan J, et al. Effects of a multimodal rehabilitation programme on inflammation and oxidative stress in oesophageal cancer survivors: the ReStOre feasibility study. Supportive Care in Cancer 2017;25(3):749-56.

\section{Haines 2010 \{published data only\}}

Haines TP, Sinnamon P, Wetzig NG, Lehman M, Walpole E, Pratt T, et al. Multimodal exercise improves quality of life of women being treated for breast cancer, but at what cost? Randomized trial with economic evaluation. Breast Cancer Research and Treatment 2010;124:163-75.

\section{Hanssens 2012 \{published data only\}}

Hanssens S, Fontaine C, Decoster L, Schallier DCC, Luyten R, Watthy $C$, et al. The effect of a varied exercise program (VEP) on shoulder function and lymphedema (LE) in breast cancer survivors (BCs): a pilot study. Journal of Clinical Oncology 2012;30:DOI: 10.1200/jco.2012.30.27_suppl.82.

\section{Hartman 2015 \{published data only\}}

Hartman SJ, Natarajan L, Palmer BW, Parker B, Patterson RE, Sears DD. Impact of increasing physical activity on cognitive functioning in breast cancer survivors: Rationale and study design of Memory \& Motion. Contemporary Clinical Trials 2015;45:371-6.

\section{Hatchett 2013 \{published data only\}}

Hatchett A, Hallam JS, Ford MA. Evaluation of a social cognitive theory-based email intervention designed to influence the physical activity of survivors of breast cancer. Psycho-Oncology 2013;22(4):829-36

\section{Hayes 2011 \{published and unpublished data\}}

Hayes S, Rye S, Battistutta D, Yates P, Pyke C, Bashford J, et al. Design and implementation of the Exercise for Health trial-a pragmatic exercise intervention for women with breast cancer. Contemporary Clinical Trials 2011;32:577-85.

Hayes 2012 \{published and unpublished data\} Hayes S, Battistutta D, Eakin E. Evaluating telephone versus face-to-face modes of exercise intervention delivery to women during and following treatment for breast cancer. Asia-Pacific Journal of Clinical Oncology 2012;8:117-8.

Hayes 2013 \{published and unpublished data\} Hayes SC, Rye S, Disipio T, Yates P, Bashford J, Pyke C, et al. Exercise for health: a randomized, controlled trial evaluating the impact of a pragmatic, translational exercise intervention on the quality of life, function and treatment-related side effects following breast cancer. Breast Cancer Research and Treatment 2013;137(1):175-86.

\section{Hayes 2014 \{published and unpublished data\}}

Hayes S, Friedlander M, Obermair A, Mileshkin L, Janda M, Gordon L, et al. Exercise during chemotherapy for ovarian cancer (ECHO): study design features and outcomes of a cancer Australia and cancer council australia funded randomised, controlled trial. International Journal of Gynecological Cancer 2014;24:200-1.

\section{Headley 2004 \{published data only\}}

Headley JA, Ownby KK, John LD. The effect of seated exercise on fatigue and quality of life in women with advanced breast cancer. Oncology Nursing Forum 2004;31:977-83.

\section{Heim 2007 \{published data only\}}

Heim ME, v d Malsburg ML, Niklas A. Randomized controlled trial of a structured training program in breast cancer patients with tumor-related chronic fatigue. Onkologie 2007;30(8-9):429-34.

\section{Herbert 2012 \{published data only\}}

Hebert JR, Hurley TG, Harmon BE, Heiney S, Hebert CJ, Steck SE. A diet, physical activity, and stress reduction intervention in men with rising prostate-specific antigen after treatment for prostate cancer. Cancer Epidemiology 2012;36(2):e128-36

\section{Herrero 2006 \{published data only\}}

Herrero F, San Juan AF, Fleck SJ, Balmer J, Pérez M, Cañete S, et al. Combined aerobic and resistance training in breast cancer survivors: a randomized, controlled pilot trial. International Journal of Sports Medicine 2006;27:573-80. 
Ho 2016 \{published data only\}

Ho RT, Fong TC, Cheung IK, Yip PS, Luk MY. Effects of a shortterm dance movement therapy program on symptoms and stress in patients with breast cancer undergoing radiotherapy: a randomized, controlled, single-blind trial. Journal of Pain and Symptom Management 2016;51(5):824-31.

\section{Hoffman 2013 \{published data only\}}

Hoffmann R. The impact of exercise on hematopoietic stem cell transplant patients. Biology of Blood and Marrow Transplantation 2013;19:S370-80.

\section{Hoffman 2017 \{published data only\}}

Hoffman AS, Lowenstein LM, Kamath GR, Housten AJ, Leal VB, Linder SK, et al. An entertainment-education colorectal cancer screening decision aid for African American patients: a randomized controlled trial. Cancer 2017;123(8):1401-8.

\section{Hojan 2016 \{published data only\}}

Hojan K, Kwiatkowska-Borowczyk E, Leporowska E, Gorecki M, Ozga-Majchrzak O, Milecki T, et al. Physical exercise for functional capacity, blood immune function, fatigue, and quality of life in high-risk prostate cancer patients during radiotherapy: a prospective, randomized clinical study. European Journal of Physical and Rehabilitation Medicine 2016;52(4):489-501.

\section{Hojan 2017 \{published data only\}}

Hojan K, Kwiatkowska-Borowczyk E, Leporowska E, Milecki P. Inflammation, cardiometabolic markers, and functional changes in men with prostate cancer: a randomized controlled trial of a 12-month exercise program. Polskie Archiwum Medycyny Wewnetrznej 2017;127(1):25-35.

\section{Huang 2015 \{published data only\}}

Huang HP, Wen FH, Tsai JC, Lin YC, Shun SC, Chang HK, et al. Adherence to prescribed exercise time and intensity declines as the exercise program proceeds: findings from women under treatment for breast cancer. Supportive Care in Cancer 2015;23(7):2061-71.

\section{Hubbard 2016 \{published data only\}}

Hubbard G, O'Carroll R, Munro J, Mutrie N, Haw S, Mason H, et al. The feasibility and acceptability of trial procedures for a pragmatic randomised controlled trial of a structured physical activity intervention for people diagnosed with colorectal cancer: findings from a pilot trial of cardiac rehabilitation versus usual care (no rehabilitation) with an embedded qualitative study. Pilot and Feasibility Studies 2016;2(51).

\section{Husebo 2014 \{published data only\}}

Husebo AML, Dyrstad SM, Mjaaland I, Soreide JA, Bru E. Effects of scheduled exercise on cancer-related fatigue in women with early breast cancer. Scientific World Journal 2014;19((271828)):Epub.

\section{Hwang 2012 \{published data only\}}

Hwang CL, Yu CJ, Shih JY, Yang PC, Wu YT. Effects of exercise training on exercise capacity in patients with non-small cell lung cancer receiving targeted therapy. Supportive Care in Cancer 2012;20(12):3169-77.

\section{James 2012 \{published data only\}}

James E, Boyes A, Courbeya K, Lubans D, Stacey F, Morgan P, et al. A home-based resistance training program for survivors of prostate cancer: a pilot randomized controlled trial. Journal of Science and Medicine in Sport 2012;15:DOI: https:// doi.org/10.1016/j.jsams.2012.11.809.

\section{Jarden 2013 \{published data only\}}

Jarden M, Moller T, Kjeldsen L, Birgens H, Christensen JF, Christensen KB, et al. Patient Activation through Counseling and Exercise - Acute Leukemia (PACE-AL) - a randomized controlled trial. BMC Cancer 2013;13:https:// doi.org/10.1186/1471-2407-13-446.

\section{Jeffs 2013 \{published data only\}}

Jeffs E, Wiseman T. Randomised controlled trial to determine the benefit of daily home-based exercise in addition to self-care in the management of breast cancer-related lymphoedema: a feasibility study. Supportive Care in Cancer 2013;21(4):1013-23.

\section{Jensen 2015a \{published data only\}}

Jensen BT, Jensen JB, Borre M, Laustsen S, Petersen AK. Physical prehabilitation is feasible and effective in patients with advanced bladder cancer. Cancer Nursing 2015;38(4):S5.

\section{Jensen 2015b \{published data only\}}

Jensen BT, Petersen AK, Jensen JB, Laustsen S, Borre M. Efficacy of a multiprofessional rehabilitation programme in radical cystectomy pathways: a prospective randomized controlled trial. Scandinavian Journal of Urology and Nephrology 2015;49(2):133-41.

\section{Jensen 2016 \{published data only\}}

Jensen JD, Yale RN, Krakow M, John K, King AJ. Theorizing foreshadowed death narratives: examining the impact of character death on narrative processing and skin self-exam intentions. Journal of Health Communication 2017;22(1):84-93.

\section{Jones 2014a \{published data only\}}

Jones LW, Douglas PS, Khouri MG, Mackey JR, Wojdyla D, Kraus WE, et al. Safety and efficacy of aerobic training in patients with cancer who have heart failure: an analysis of the HF-ACTION randomized trial. Journal of Clinical Oncology 2014;32(23):2496-502.

\section{Jones 2014b \{published data only\}}

Jones LW, Hornsby WE, Freedland SJ, Lane A, West MJ, Moul JW, et al. Effects of nonlinear aerobic training on erectile dysfunction and cardiovascular function following radical prostatectomy for clinically localized prostate cancer. European Urology 2014;65(5):852-5.

\section{Kalter 2015 \{published data only\}}

Kalter J, Buffart LM, Korstjens I, van Weert E, Brug J, Verdonckde Leeuw IM, et al. Moderators of the effects of group-based physical exercise on cancer survivors' quality of life. Supportive Care in Cancer 2015;23(9):2623-31.

\section{Kampshoff 2015 \{published data only\}}

Kampshoff CS, Chinapaw MJ, Brug J, Twisk JW, Schep G, Nijziel MR, et al. Randomized controlled trial of the effects 
of high intensity and low-to-moderate intensity exercise on physical fitness and fatigue in cancer survivors: results of the Resistance and Endurance exercise After ChemoTherapy (REACT) study. BMC Medicine 2015;29(13):275.

\section{Kampshoff 2016 \{published data only\}}

Kampshoff CS, van Mechelen W, Schep G, Nijziel MR, Witlox L, Bosman L, et al. Participation in and adherence to physical exercise after completion of primary cancer treatment. International Journal of Behavioral Nutrition and Physical Activity 2016;13(1):100.

\section{Kanera 2016 \{published data only\}}

Kanera IM, Bolman CA, Willems RA, Mesters I, Lechner L. Lifestyle-related effects of the web-based Kanker Nazorg Wijzer (Cancer Aftercare Guide) intervention for cancer survivors: a randomized controlled trial. Journal of Cancer Survivorship 2016;10(5):883-97.

\section{Kanera 2017 \{published data only\}}

Kanera IM, Willems RA, Bolman CAW, Mesters I, Verboon P, Lechner L. Long-term effects of a web-based cancer aftercare intervention on moderate physical activity and vegetable consumption among early cancer survivors: a randomized controlled trial. International Journal of Behavioral Nutrition and Physical Activity 2017;14(1):19.

\section{Kavanagh 2009 \{published data only\}}

Kavanagh MB, von Gruenigen VE, Courneya KS, Gibbons HE, Waggoner SE, Lerner E. Effects of a lifestyle intervention on nutrient intake in overweight/obese endometrial cancer survivors. European e-Journal of Clinical Nutrition and Metabolism 2009;4:e143-e147.

\section{Kilbreath 2006 \{published data only\}}

Kilbreath S, Refshauge K, Beith J, Lee M. Resistance and stretching shoulder exercises early following axillary surgery for breast cancer. Rehabilitation Oncology 2006;24:9-14.

\section{Kilbreath 2012 \{published data only\}}

Kilbreath SL, Refshauge KM, Beith JM, Ward LC, Lee M, Simpson JM, et al. Upper limb progressive resistance training and stretching exercises following surgery for early breast cancer: a randomized controlled trial. Breast Cancer Research and Treatment 2012;133:667-76.

\section{Kim 2010 \{published data only\}}

Kim do S, Sim YJ, Jeong HJ, Kim GC. Effect of active resistive exercise on breast cancer-related lymphedema: a randomized controlled trial. Archives of Physical Medicine and Rehabilitation 2010;91:1844-8.

\section{Klepin 2015 \{published data only\}}

Klepin HD, Tooze J, Pardee T, Renee EL, Berenzon D, Howard D, et al. Feasibility of a symptom-adapted physical activity intervention during induction chemotherapy for older adults with acute myeloid leukemia (AML). Blood 2015;126(23):2012.

\section{Klinkhammer-Schalke 2012 \{published data only\}}

Klinkhammer-Schalke M, Koller M, Steinger B, Ehret C, Ernst B, Wyatt JC, et al. Regensburg QoL Study Group. Direct improvement of quality of life using a tailored quality of life diagnosis and therapy pathway: randomised trial in 200 women with breast cancer. British Journal of Cancer 2012;106:826-38.

Kwiatkowski 2013 \{published data only\}

Kwiatkowski F, Mouret-Reynier MA, Duclos M, Leger-Enreille A, Bridon F, Hahn T, et al. Long term improved quality of life by a 2-week group physical and educational intervention shortly after breast cancer chemotherapy completion. Results of the 'Programme of Accompanying women after breast Cancer treatment completion in Thermal resorts' (PACThe) randomised clinical trial of 251 patients. European Journal of Cancer 2013;49(7):1530-8.

\section{Lahart 2016 \{published data only\}}

Lahart IM, Metsios GS, Nevill AM, Kitas GD, Carmichael AR. Randomised controlled trial of a home-based physical activity intervention in breast cancer survivors. BMC Cancer 2016;17(16):234.

\section{Lai 2017 \{published data only\}}

Lai Y, Huang J, Yang M, Su J, Liu J, Che G. Seven-day intensive preoperative rehabilitation for elderly patients with lung cancer: a randomized controlled trial. Journal of Surgical Research 2017;209:30-6.

\section{Lee 2012a \{published data only\}}

Lee CE, Kilgour A, Lau YK. Efficacy of walking exercise in promoting cognitive-psychosocial functions in men with prostate cancer receiving androgen deprivation therapy. BMC Cancer 2012;12:324.

\section{Lee 2012b \{published data only\}}

Lee CE, Leslie WD, Lau YK. A pilot study of exercise in men with prostate cancer receiving androgen deprivation therapy. $B M C$ Cancer 2012;12(103):doi:10.1186/1471-2407-12-103.

\section{Lee 2014 \{published data only\}}

Lee MK, Yun YH, Park HA, Lee ES, Jung KH, Noh DY. A webbased self-management exercise and diet intervention for breast cancer survivors: pilot randomized controlled trial [with consumer summary]. International Journal of Nursing Studies 2014;51(12):1557-67.

\section{Leone 2016 \{published data only\}}

Leone LA, Allicock M, Pignone MP, Walsh JF, Johnson L, Armstrong-Brown J, et al. C Cluster randomized trial of a church-based peer counselor and tailored newsletter intervention to promote colorectal cancer screening and physical activity among older African Americans. Health Education \& Behavior 2016;43(5):568-76.

Ligibel 2008 \{published and unpublished data\}

Ligibel JA, Campbell N, Partridge A, Chen WY, Salinardi T, Chen $\mathrm{H}$, et al. Impact of a mixed strength and endurance exercise intervention on insulin levels in breast cancer survivors. Journal of Clinical Oncology 2008;26:907-12.

Ligibel 2009 \{published and unpublished data\}

Ligibel JA, Giobbie-Hurder A, Olenczuk D, Campbell N, Salinardi T, Winer EP, et al. Impact of a mixed strength and 
endurance exercise intervention on levels of adiponectin, high molecular weight adiponectin and leptin in breast cancer survivors. Cancer Causes \& Control 2009;20:1523-8.

\section{Ligibel 2016 \{published data only\}}

Ligibel JA, Giobbie-Hurder A, Shockro L, Campbell N, Partridge AH, Tolaney S, et al. Randomized trial of a physical activity intervention in women with metastatic breast cancer. Cancer 2016;112(8):1169-77.

\section{Lin 2014 \{published data only\}}

Lin KY, Shun SC, Lai YH, Liang JT, Tsauo JY. Comparison of the effects of a supervised exercise program and usual care in patients with colorectal cancer undergoing chemotherapy. Cancer Nursing 2014;37:E21.

\section{Litterini 2013 \{published data only\}}

Litterini AJ, Fieler VK, Cavanaugh JT, Lee JQ. Differential effects of cardiovascular and resistance exercise on functional mobility in individuals with advanced cancer: a randomized trial. Archives of Physical Medicine \& Rehabilitation 2013;94(12):2329-35.

\section{Livingston 2015 \{published data only\}}

Livingston PM, Craike MJ, Salmon J, Courneya KS, Gaskin CJ, Fraser SF, et al. Effects of a clinician referral and exercise program for men who have completed active treatment for prostate cancer: A multicenter cluster randomized controlled trial (ENGAGE). Cancer 2015;121(15):2646-54

\section{Lynch 2014 \{published data only\}}

Lynch BM, Courneya KS, Sethi P, Patrao TA, Hawkes AL. A randomized controlled trial of a multiple health behavior change intervention delivered to colorectal cancer survivors: effects on sedentary behavior. Cancer 2014;120(17):2665-72.

\section{Lyons 2016 \{published data only\}}

Lyons KS, Winters-Stone KM, Bennett JA, Beer TM. The effects of partnered exercise on physical intimacy in couples coping with prostate cancer. Health Psychology 2016;35(5):509-13.

\section{MacVicar 1989 \{published data only\}}

MacVicar MG, Winningham ML, Nickel JL. Effects of aerobic interval training on cancer patients' functional capacity. Nursing Research 1989;38:348-51.

\section{Manassero 2007 \{published data only\}}

Manassero F, Traversi C, Ales V, Pistolesi D, Panicucci E, Valent $\mathrm{F}$, et al. Contribution of early intensive prolonged pelvic floor exercises on urinary continence recovery after bladder neck-sparing radical prostatectomy: results of a prospective controlled randomized trial. Neurourology and Urodynamics 2007;26:985-9.

\section{Martin 2013 \{published data only\}}

Martin E, Battaglini C, Groff D, Naumann F. Improving muscular endurance with the MVe Fitness Chair ${ }^{\mathrm{TM}}$ in breast cancer survivors: a feasibility and efficacy. Journal of Science and Medicine in Sport 2013;16(4):372-6.

\section{Mayo 2014 \{published data only\}}

Mayo NE, Moriello C, Scott SC, Dawes D, Auais M, Chasen M. Pedometer-facilitated walking intervention shows promising effectiveness for reducing cancer fatigue: a pilot randomized trial. Clinical Rehabilitation 2014;28:1198-209.

McClure 2010 \{published data only\} McClure MK, McClure RJ, Day R, Brufsky AM. Randomized controlled trial of the Breast Cancer Recovery Program for women with breast cancer-related lymphedema. American Journal of Occupational Therapy 2010;64:59-72.

McGowan 2013 \{published data only\}

McGowan EL, North S, Courneya KS. Randomized controlled trial of a behavior change intervention to increase physical activity and quality of life in prostate cancer survivors. Annals of Behavioral Medicine 2013;46(3):382-93.

\section{McGuire 2011 \{published data only\}}

McGuire R, Waltman N, Zimmerman L. Intervention components promoting adherence to strength training exercise in breast cancer survivors with bone loss. Western Journal of Nursing Research 2011;33:671-89.

\section{McNeely 2004 \{published and unpublished data\}}

McNeely ML, Parliament M, Courneya KS, Seikaly H, Jha N, Scrimger $\mathrm{R}$, et al. A pilot study of a randomized controlled trial to evaluate the effects of progressive resistance exercise training on shoulder dysfunction caused by spinal accessory neurapraxia/neurectomy in head and neck cancer survivors. Head and Neck 2004;26:518-30.

\section{Milecki 2013 \{published data only\}}

Milecki P, Hojan K, Ozga-Majchrzak O, Molinska-Glura M. Exercise tolerance in breast cancer patients during radiotherapy after aerobic training. Wspolczesna Onkologia [Contemporary Oncology] 2013;17(2):205-9.

\section{Mina 2013 \{published data only\}}

Mina DS, Connor MK, Alibhai SMH, Toren P, Guglietti C, Matthew AG, et al. Exercise effects on adipokines and the IGF axis in men with prostate cancer treated with androgen deprivation: a randomized study. Canadian Urological Association Journal [Journal de l'Association des Urologues du Canada] 2013;7:E692-8.

\section{Mock 1994 \{published data only\}}

Mock V, Burke MB, Sheehan P, Creaton EM, Winningham ML, McKenney-Tedder $S$, et al. A nursing rehabilitation program for women with breast cancer receiving adjuvant chemotherapy. Oncology Nursing Forum 1994;21:899-907.

\section{Mock 1997 \{published data only\}}

Mock V, Dow KH, Meares CJ, Grimm PM, Dienemann JA, Haisfield-Wolfe ME, et al. Effects of exercise on fatigue, physical functioning, and emotional distress during radiation therapy for breast cancer. Oncology Nursing Forum 1997;24:991-1000.

Mock 2005 \{published data only\}

Mock V, Frangakis C, Davidson NE, Ropka ME, Pickett M, Poniatowski B, et al. Exercise manages fatigue during breast 
cancer treatment: a randomized controlled trial. PsychoOncology 2005;14:464-77.

\section{Molassiotis 2015 \{published data only\}}

Molassiotis A, Charalambous A, Taylor P, Stamataki Z, Summers $Y$. The effect of resistance inspiratory muscle training in the management of breathlessness in patients with thoracic malignancies: a feasibility randomised trial. Supportive Care in Cancer 2015;23(6):1637-45.

\section{Moller 2015 \{published data only\}}

Moller T, Lillelund C, Andersen C, Bloomquist K, Christensen K, Ejlertsen $\mathrm{B}$, et al. Use of exercise in patients with breast cancer. Supportive Care in Cancer 2015;30:406-11.

\section{Monga 2007 \{published data only\}}

Monga U, Garber SL, Thornby J, Vallbona C, Kerrigan AJ, Monga TN, et al. Exercise prevents fatigue and improves quality of life in prostate cancer patients undergoing radiotherapy. Archives of Physical Medicine and Rehabilitation 2007;88:1416-22.

\section{Morielli 2018 \{published data only\}}

Morielli AR, Boule NG, Usmani N, Kurian J, Tankel K, Severin $D$, et al. Predictors of adherence to aerobic exercise in rectal cancer patients during and after neoadjuvant chemoradiotherapy. Psychology, Health \& Medicine 2018;23(2):224-31.

\section{Mustian 2008 \{published data only\}}

Mustian KM, Palesh OG, Flecksteiner SA. Tai Chi Chuan for breast cancer survivors. Medicine and Sport Science 2008;52:209-17.

\section{Mustian 2015 \{published data only\}}

Mustian K, Janelsins M, Peppone L, Kamen C, Heckler C. Exercise effects on muscular strength, cancer-related fatigue, and mitochondrial and nuclear gene expression in skeletal muscle among older prostate cancer patients. Supportive Care in Cancer 2015;23:s89-90.

\section{Mutrie 2007 \{published and unpublished data\}}

Mutrie N, Campbell AM, Whyte F, McConnachie A, Emslie C, Lee $\mathrm{L}$, et al. Benefits of supervised group exercise programme for women being treated for early stage breast cancer: pragmatic randomised controlled trial. BMJ 2007;334:517.

\section{Naumann 2012 \{published data only\}}

Naumann F, Martin E, Philpott M, Smith C, Groff D, Battaglini C. Can counseling add value to an exercise intervention for improving quality of life in breast cancer survivors? A feasibility study. Journal of Supportive Oncology 2012;10(5):188-94.

\section{Newton 2014 \{published data only\}}

Newton RU, Galvao DA, Spry N, Cormie P, Chambers SK, Gardiner RA, et al. Musculoskeletal effects of exercise in men with prostate cancer initiating androgen deprivation therapy. Asia-Pacific Journal of Clinical Oncology 2014;10:206-7.

\section{Nieman 1995 \{published data only\}}

Nieman DC, Cook VD, Henson DA, Suttles J, Rejeski WJ, Ribisl PM, et al. Moderate exercise training and natural killer cell cytotoxic activity in breast cancer patients. International Journal of Sports Medicine 1995;16:334-7.

Nikander 2007 \{published data only\}

Nikander R, Sievänen H, Ojala K, Oivanen T, KellokumpuLehtinen PL, Saarto T. Effect of a vigorous aerobic regimen on physical performance in breast cancer patients - a randomized controlled pilot trial. Acta Oncologica 2007;46:181-6.

Nikander 2012 \{published data only\}

Nikander R, Sievanen H, Ojala K, Kellokumpu-Lehtinen PL, Palva T, Blomqvist $\mathrm{C}$, et al. Effect of exercise on bone structural traits, physical performance and body composition in breast cancer patients - a 12-month RCT. Journal of Musculoskeletal \& Neuronal Interactions 2012;12(3):127-35.

Nilsen 2015 \{published data only\}

Nilsen TS, Raastad T, Skovlund E, Courneya KS, Langberg CW, Lilleby W, et al. Effects of strength training on body composition, physical functioning, and quality of life in prostate cancer patients during androgen deprivation therapy. Acta Oncologica 2015;54(10):1805-13.

\section{Nobes 2012 \{published data only\}}

Nobes JP, Langley SEM, Klopper T, Russell-Jones D, Laing RW. A prospective, randomized pilot study evaluating the effects of metformin and lifestyle intervention on patients with prostate cancer receiving androgen deprivation therapy [with consumer summary]. BJU International 2012;109(10):1495-502.

\section{Nuri 2012 \{published data only\}}

Nuri R, Kordi MR, Moghaddasi M, Rahnama N, Damirchi A, Rahmani-Nia F, et al. Effect of combination exercise training on metabolic syndrome parameters in postmenopausal women with breast cancer. Journal of Cancer Research \& Therapeutics 2012;8(2):238-42.

\section{Nuri 2016 \{published data only\}}

Nuri R, Moghaddasi M, Darvishi H, Izadpanah A. Effect of aerobic exercise on leptin and ghrelin in patients with colorectal cancer. Journal of Cancer Research \& Therapeutics 2016;12(1):169-74.

\section{Nyrop 2017 \{published data only\}}

Nyrop KA, Callahan LF, Cleveland RJ, Arbeeva LL, Hackney BS, Muss HB. Randomized controlled trial of a home-basedwalking program to reducemoderate to severe aromatase inhibitorassociated arthralgia in breast cancer survivors. Oncologist 2017;22(10):1238-48.

\section{O'Neil 2015 \{published data only\}}

O'Neill RF, Haseen F, Murray LJ, O'Sullivan JM, Cantwell MM. A randomised controlled trial to evaluate the efficacy of a 6month dietary and physical activity intervention for patients receiving androgen deprivation therapy for prostate cancer. Journal of Cancer Survivorship 2015;9(3):431-40.

\section{Ohira 2006 \{published data only\}}

Ohira T, Schmitz KH, Ahmed RL, Yee D. Effects of weight training on quality of life in recent breast cancer survivors: the Weight Training for Breast Cancer Survivors (WTBS) study. Cancer 2006;106:2076-83. 


\section{Ornish 2005 \{published data only\}}

Ornish D, Weidner G, Fair WR, Marlin R, Pettengill EB, Raisin CJ, et al. Intensive lifestyle changes may affect the progression of prostate cancer. Journal of Urology 2005;174:1065-9.

\section{Ornish 2008a \{published data only\}}

Ornish D, Magbanua MJ, Weidner G, Weinberg V, Kemp C, Green $C$, et al. Changes in prostate gene expression in men undergoing an intensive nutrition and lifestyle intervention. Proceedings of the National Academy of Sciences in the United States of America 2008a;105:8369-74.

Ornish 2008b \{published data only\}

Ornish D, Lin J, Daubenmier J, Weidner G, Epel E, Kemp C, et al. Increased telomerase activity and comprehensive lifestyle changes: a pilot study. Lancet Oncology 2008;9:1048-57.

\section{Park 2012 \{published data only\}}

Park SW, Kim TN, Nam JK, Ha HK, Shin DG, Lee W, et al. Recovery of overall exercise ability, quality of life, and continence after 12-week combined exercise intervention in elderly patients who underwent radical prostatectomy: a randomized controlled study. Urology 2012;80:299-305.

Park 2016 \{published data only\}

Park CL, Cho D, Salner A, Dornelas E. A randomized controlled trial of two mail-based lifestyle interventions for breast cancer survivors. Supportive Care in Cancer 2016;24(7):3037-46.

\section{Payne 2008 \{published data only\}}

Payne JK, Held J, Thorpe J, Shaw H. Effect of exercise on biomarkers, fatigue, sleep disturbances, and depressive symptoms in older women with breast cancer receiving hormonal therapy. Oncology Nursing Forum 2008;35:635-42.

\section{Philips 2012 \{published data only\}}

Phillips KM, Jim HS, Small BJ, Tanvetyanon T, Roberts WS, Jacobsen PB. Effects of self-directed stress management training and home-based exercise on stress management skills in cancer patients receiving chemotherapy. Stress and Health 2012;25(5):368-75.

\section{Pickett 2002 \{published data only\}}

Pickett M, Mock V, Ropka ME, Cameron L, Coleman M, Podewils L. Adherence to moderate-intensity exercise during breast cancer therapy. Cancer Practice 2002;10:284-92.

\section{Pinto 2013a \{published data only\}}

Pinto BM, Papandonatos GD, Goldstein MG. A randomized trial to promote physical activity among breast cancer patients. Health Psychology 2013;32:616-26.

\section{Pinto 2013b \{published data only\}}

Pinto BM, Papandonatos GD, Goldstein MG, Marcus BH, Farrell N. Home-based physical activity intervention for colorectal cancer survivors. Psycho-Oncology 2013;22(1):54-64.

\section{Pinto 2015 \{published data only\}}

Pinto BM, Stein K, Dunsiger S. Peers promoting physical activity among breast cancer survivors: a randomized controlled trial. Health Psychology 2015;34(5):463-72.

\section{Porserud 2014 \{published data only\}}

Porserud A, Sherif A, Tollbäck A. The effects of a physical exercise programme after radical cystectomy for urinary bladder cancer. A pilot randomized controlled trial. Clinical Rehabilitation 2014;28(5):451-9.

Portela 2008 \{published and unpublished data\} Portela ALM, Santaella CL, Gómez CC, Burch A. Feasibility of an exercise program for Puerto Rican women who are breast cancer survivors. Rehabilitation Oncology 2008;26(2):20-31.

\section{Rabin 2016 \{published data only\}}

Rabin C, Pinto B, Fava J. Randomized trial of a physical activity and meditation intervention for young adult cancer survivors. Journal of Adolescent and Young Adult Oncology 2016;5(1):41-7.

Rahnama 2010 \{published and unpublished data\}

Rahnama N, Nouri R, Rahmaninia F, Damirchi A, Emami H. The effects of exercise training on maximum aerobic capacity, resting heart rate, blood pressure and anthropometric variables of postmenopausal women with breast cancer. Journal of Research in Medical Sciences 2010;15:78-83.

\section{Rao 2012 \{published data only\}}

Rao R, Cruz V, Peng Y, Harker-Murray A, Haley BB, Zhao H, et al. Bootcamp during neoadjuvant chemotherapy for breast cancer: a randomized pilot trial. Breast Cancer 2012;6(1):39-46.

Reis 2013 \{published and unpublished data\}

Reis D, Walsh E, Young-McCaughan S, Jones T. Effects of Nia exercise in women receiving radiation therapy for breast cancer. Oncology Nursing Forum 2013;40(5):E374-81.

Rogers 2009 \{published and unpublished data\}

Rogers LQ, Hopkins-Price P, Vicari S, Pamenter R, Courneya KS, Markwell S, et al. A randomized trial to increase physical activity in breast cancer survivors. Medicine and Science in Sports and Exercise 2009;41:935-46.

\section{Rogers 2012 \{published and unpublished data\}}

Rogers LQ, Fogleman A, Trammell R, Hopkins-Price P, Vicari S, Rao K, et al. Effects of a physical activity behavior change intervention on inflammation and related health outcomes in breast cancer survivors: pilot randomized trial. Integrative Cancer Therapies 2012;4(2013):323-35. [DOI: 10.1177/1534735412449687]

\section{Rogers 2013a \{published data only\}}

Rogers LQ, Anton PM, Fogleman A, Hopkins-Price P, Verhulst S, Rao K, et al. Pilot, randomized trial of resistance exercise during radiation therapy for head and neck cancer. Head \& Neck 2013;35(8):1178-88.

\section{Rogers 2013b \{published data only\}}

Rogers LQ, Fogleman A, Trammell R, Hopkins-Price P, Vicari S, Rao K, et al. Effects of a physical activity behavior change intervention on inflammation and related health outcomes in breast cancer survivors: pilot randomized trial. Integrative Cancer Therapies 2013;12(4):323-35. 


\section{Rogers 2014 \{published data only\}}

Rogers LQ, Vicari S, Trammell R, Hopkins-Price P, Fogleman A, Spenner A, et al. Biobehavioral factors mediate exercise effects on fatigue in breast cancer survivors. Medicine \& Science in Sports \& Exercise 2014;46(6):1077-88.

\section{Rogers 2015b \{published data only\}}

Rogers LQ, Fogleman A, Trammell R, Hopkins-Price P, Spenner A, Vicari S, et al. Inflammation and psychosocial factors mediate exercise effects on sleep quality in breast cancer survivors: pilot randomized controlled trial. Psycho-Oncology 2015;24(3):302-10.

\section{Saarto 2012a \{published data only\}}

Saarto T, Penttinen HM, Sievanen H, Kellokumpu-Lehtinen PL, Hakamies-Blomqvist L, Nikander R, et al. Effectiveness of a 12-month exercise program on physical performance and quality of life of breast cancer survivors. Anticancer Research 2012;32(9):3875-84

\section{Saarto 2012b \{published data only\}}

Saarto T, Sievanen H, Kellokumpu-Lehtinen P, Nikander R, Vehmanen L, Huovinen R, et al. Effect of supervised and home exercise training on bone mineral density among breast cancer patients. A 12-month randomised controlled trial. Osteoporosis International 2012;23(5):1601-12.

\section{Sajid 2013 \{published data only\}}

Sajid S, Dale W, Mustian K, Kotwal A, Heckler C, Porto M, et al. Novel physical activity interventions for older patients with prostate cancer on hormone therapy: a pilot randomized study. Journal of Geriatric Oncology 2016;7(2):71-80.

\section{Samuel 2013 \{published data only\}}

Samuel SR, Maiya GA, Babu AS, Vidyasagar MS. Effect of exercise training on functional capacity and quality of life in head and neck cancer patients receiving chemoradiotherapy. Indian Journal of Medical Research 2013;137(3):515-20.

\section{Sandel 2005 \{published data only\}}

Sandel SL, Judge JO, Landry N, Faria L, Ouellette R, Majczak M. Dance and movement program improves quality-oflife measures in breast cancer survivors. Cancer Nursing 2005;28:301-9.

\section{Schmidt 2015 \{published data only\}}

Shmidt ME, Wiskemann J, Armburst P, Schneeweiss A, Ulrich C, Steindorf K. Effects of resistance exercise on fatigue and quality of life in breast cancer patients undergoing adjuvant chemotherapy: A randomized controlled trial. International Journal of Cancer 2015;35(10):5623-9.

\section{Schmidt 2017a \{published data only\}}

Schmidt ME, Wiskemann J, Ulrich CM, Schneeweiss A, Steindorf K. Self-reported physical activity behavior of breast cancer survivors during and after adjuvant therapy: 12 months follow-up of two randomized exercise intervention trials. Acta Oncologica 2017;56(4):618-27.

\section{Schmidt 2017b \{published data only\}}

Schmidt T, Berner J, Jonat W, Weisser B, Rocken C, van Mackelenbergh $\mathrm{M}$, et al. Influence of arm crank ergometry on development of lymphoedema in breast cancer patients after axillary dissection: a randomized controlled trial. Journal of Rehabilitation Medicine 2017;49(1):78-83.

Schmitz 2009 \{published and unpublished data\}

Schmitz KH, Ahmed RL, Troxel A, Cheville A, Smith R, LewisGrant $L$, et al. Weight lifting in women with breast-cancerrelated lymphedema. New England Journal of Medicine 2009;361:664-73.

Schmitz 2010 \{published and unpublished data\} Schmitz KH, Ahmed RL, Troxel AB, Cheville A, Lewis-Grant L, Smith $\mathrm{R}$, et al. Weight lifting for women at risk for breast cancer-related lymphedema: a randomized trial. JAMA 2010;304:2699-705.

\section{Schmitz 2015a \{published data only\}}

Schmitz KH, Williams NI, Kontos D, Domchek S, Morales KH, Hwang WT, et al. Dose-response effects of aerobic exercise on estrogen among women at high risk for breast cancer: a randomized controlled trial. Breast Cancer Research and Treatment 2015;154(2):309-18.

\section{Schmitz 2015b \{published data only\}}

Schmitz KH, Williams NI, Kontos D, Kurzer MS, Schnall M, Domchek S, et al. Women In Steady Exercise Research (WISER) Sister: study design and methods. Contemporary Clinical Trials 2015;41:17-30.

\section{Schuler 2017 \{published data only\}}

Schuler MK, Hentschel L, Kisel W, Kramer M, Lenz F, Hornemann B, et al. Impact of different exercise programs on severe fatigue in patients undergoing anticancer treatment a randomized controlled trial. Journal of Pain and Symptom Management 2017;53(1):57-66.

\section{Schwartz 2015 \{published data only\}}

Schwartz AL, Biddle-Newberry M, de Heer HD. Randomized trial of exercise and an online recovery tool to improve rehabilitation outcomes of cancer survivors. Physician and Sportsmedicine 2015;43(2):143-9.

\section{Scruggs 2018 \{published data only\}}

Scruggs S, Mama SK, Carmack CL, Douglas T, Diamond P, Basen-Engquist K. Randomized trial of a lifestyle physical activity intervention for breast cancer survivors: effects on transtheoretical model variables. Health Promotion Practice 2018;19(1):134-44.

\section{Sebio Garcia 2017 \{published data only\}}

Sebio Garcia R, Yanez-Brage MI, Gimenez Moolhuyzen E, Salorio Riobo M, Lista Paz A, Borro Mate JM. Preoperative exercise training prevents functional decline after lung resection surgery: a randomized, single-blind controlled trial. Clinical Rehabilitation 2017;31(8):1057-67. 
Segal 2001 \{published and unpublished data\}

Segal R, Evans W, Johnson D, Smith J, Colletta S, Gayton J, et al. Structured exercise improves physical functioning in women with stages I and II breast cancer: results of a randomized controlled trial. Journal of Clinical Oncology 2001;19:657-65.

Segal 2003 \{published and unpublished data\}

Segal RJ, Reid RD, Courneya KS, Malone SC, Parliament MB, Scott CG, et al. Resistance exercise in men receiving androgen deprivation therapy for prostate cancer. Journal of Clinical Oncology 2003;21:1653-9.

Segal 2009 \{published and unpublished data\}

Segal RJ, Reid RD, Courneya KS, Sigal RJ, Kenny GP, Prud'Homme DG, et al. Randomized controlled trial of resistance or aerobic exercise in men receiving radiation therapy for prostate cancer. Journal of Clinical Oncology 2009;27:344-51.

\section{Sener 2017 \{published data only\}}

Sener HO, Malkoc M, Ergin G, Karadibak D, Yavuzsen T. Effects of clinical pilates exercises on patients developing lymphedema after breast cancer treatment: a randomized clinical trial. Journal of Breast Health 2017;13(1):16-22.

\section{Sheppard 2016 \{published data only\}}

Sheppard VB, Hicks J, Makambi K, Hurtado-de-Mendoza A, Demark-Wahnefried W, Adams-Campbell L. The feasibility and acceptability of a diet and exercise trial in overweight and obese black breast cancer survivors: The Stepping STONE study. Contemporary Clinical Trials 2016;46:106-13.

\section{Shobeiri 2016 \{published data only\}}

Shobeiri F, Masoumi SZ, Nikravesh A, Heidari Moghadam R, Karami M. The impact of aerobic exercise on quality of life in women with breast cancer: a randomized controlled trial [with consumer summary]. Journal of Research in Health Sciences 2016;16(3):127-32.

\section{Short 2012 \{published data only\}}

Short C, James E, Girgis A, McElduff P, Plotnikoff R. The efficacy of two theoretically-based print interventions for promoting PA behaviour among post-treatment breast cancer survivors: a nationally-based 3-arm RCT. Journal of Science and Medicine in Sport 2012;15:S175-6.

\section{Short 2017a \{published data only\}}

Short CE, James EL, Girgis A, D'Souza MI, Plotnikoff RC. Main outcomes of the Move More for Life Trial: A randomised controlled trial examining the effects of tailored-print and targeted-print materials for promoting physical activity among post-treatment breast cancer survivors. Psycho-Oncology 2017;24(7):771-8.

\section{Short 2017b \{published data only\}}

Short CE, Rebar A, James EL, Duncan MJ, Courneya KS, Plotnikoff RC, et al. How do different delivery schedules of tailored web-based physical activity advice for breast cancer survivors influence intervention use and efficacy?. Journal of Cancer Survivorship 2017;11(1):80-91.
Singh 2015 \{published data only\}

Singh B, Newton RU, Cormie P, Galvao DA, Cornish B, ReulHirche $\mathrm{H}$, et al. Effects of compression on lymphedema during resistance exercise in women with breast cancer-related lymphedema: A randomized, cross-over trial. Lymphology 2015;48(2):80-92.

\section{Skinner 2016 \{published data only\}}

Skinner TL, Peeters G, Croci I, Bell KR, Burton NW, Chambers SK, et al. Impact of a brief exercise program on the physical and psychosocial health of prostate cancer survivors: a pilot study. Asia-Pacific Journal of Clinical Oncology 2016;12(3):225-34.

\section{Sohl 2016 \{published data only\}}

Sohl SJ, Danhauer SC, Birdee GS, Nicklas BJ, Yacoub G, Aklilu M, et al. A brief yoga intervention implemented during chemotherapy: a randomized controlled pilot study. Complementary Therapies in Medicine 2016;25:139-42.

\section{Spahn 2013 \{published data only\}}

Spahn G, Choi KE, Kennemann C, Ludtke R, Franken U, Langhorst J, et al. Can a multimodal mind-body program enhance the treatment effects of physical activity in breast cancer survivors with chronic tumor-associated fatigue? A randomized controlled trial. Integrative Cancer Therapies 2013;12(4):291-300.

\section{Stacey 2016 \{published data only\}}

Stacey FG, James EL, Chapman K, Lubans DR. Social cognitive theory mediators of physical activity in a lifestyle program for cancer survivors and carers: findings from the ENRICH randomized controlled trial. International Journal of Behavioral Nutrition and Physical Activity 2016;13:49.

\section{Stefanelli 2013 \{published data only\}}

Stefanelli F, Meoli I, Cobuccio R, Curcio C, Amore D, Casazza D, et al. High-intensity training and cardiopulmonary exercise testing in patients with chronic obstructive pulmonary disease and non-small-cell lung cancer undergoing lobectomy. European Journal of Cardio-thoracic Surgery 2013;44(4):e260-5.

\section{Stolley 2017 \{published data only\}}

Stolley M, Sheean PM, Gerber B, Arroyo C, Schiffer L, Banerjee A, et al. Efficacy of a weight loss intervention for African American breast cancer survivors. Journal of Clinical Oncology 2017;35(24):2820-30.

\section{Streckman 2014 \{published data only\}}

Streckmann F, Kneis S, Leifert JA, Baumann FT, Kleber M, Ihorst $\mathrm{G}$, et al. Exercise program improves therapy-related sideeffects and quality of life in lymphoma patients undergoing therapy. Annals of Oncology 2014;25(2):493-9.

\section{Sturgeon 2017 \{published data only\}}

Sturgeon KM, Dean LT, Heroux M, Kane J, Bauer T, Palmer E, et al. Commercially available lifestyle modification program: randomized controlled trial addressing heart and bone health in BRCA1/2+ breast cancer survivors after risk-reducing salpingo-oophorectomy. Journal of Cancer Survivorship 2017;11(2):246-55. 
Swisher 2015 \{published data only\}

Swisher AK, Abraham J, Bonner D, Gilleland D, Hobbs G, Kurian S, et al. Exercise and dietary advice intervention for survivors of triple-negative breast cancer: effects on body fat, physical function, quality of life, and adipokine profile. Supportive Care in Cancer 2015;23(10):2995-3003.

Taafe 2017 \{published data only\}

Taaffe DR, Newton RU, Spry N, Joseph D, Chambers SK, Gardiner RA, et al. Effects of different exercise modalities on fatigue in prostate cancer patients undergoing androgen deprivation therapy: a year-long randomised controlled trial. European Urology 2017;72(2):293-9.

Taleghani 2012 \{published data only\}

Taleghani F, Karimain J, Babazadeh S, Mokarian F, Tabatabaiyan M, Samimi MA, et al. The effect of combined aerobic and resistance exercises on quality of life of women surviving breast cancer. Iranian Journal of Nursing and Midwifery Research 2012;17(1):47-51.

\section{Taso 2014 \{published data only\}}

Taso CJ, Lin HS, Lin WL, Chen SM, Huang WT, Chen SW. The effect of yoga exercise on improving depression, anxiety, and fatigue in women with breast cancer: a randomized controlled trial. Journal of Nursing Research 2014;22(3):155-64.

\section{Terranova 2017 \{published data only\}}

Terranova CO, Lawler SP, Spathonis K, Eakin EG, Reeves MM. Breast cancer survivors' experience of making weight, dietary and physical activity changes during participation in a weight loss intervention. Supportive Care in Cancer 2017;25(5):1455-63.

\section{Tomasello 2017 \{published data only\}}

Tomasello B, Malfa GA, Strazzanti A, Gangi S, Di Giacomo C, Basile $F$, et al. Effects of physical activity on systemic oxidative/ DNA status in breast cancer survivors. Oncology Letters 2017;13(1):441-8.

\section{Tometich 2017 \{published data only\}}

Tometich DB, Mosher CE, Winger JG, Badr HJ, Snyder DC, Sloane RJ, et al. Effects of diet and exercise on weight-related outcomes for breast cancer survivors and their adult daughters: an analysis of the DAMES trial. Supportive Care in Cancer 2017;25(8):2559-68.

\section{Travier 2015 \{published data only\}}

Travier N, Velthuis MJ, Steins Bisschop CN, van den Buijs B, Monninkhof EM, Backx F, et al. Effects of an 18-week exercise programme started early during breast cancer treatment: a randomised controlled trial. BMC Medicine 2015;13(121):Epub.

\section{Trinh 2014 \{published data only\}}

Trinh L, Mutrie N, Campbell AM, Crawford JJ, Courneya KS. Effects of supervised exercise on motivational outcomes in breast cancer survivors at 5-year follow-up. European Journal of Oncology Nursing 18;6:557-63.

\section{Uth 2014 \{published data only\}}

Uth J, Hornstrup T, Schmidt JF, Christensen JF, Frandsen C, Christensen KB, et al. Football training improves lean body mass in men with prostate cancer undergoing androgen deprivation therapy. Scandinavian Journal of Medicine \& Science in Sports 2014;24:105-12.

\section{Uth 2016 \{published data only\}}

Uth J, Hornstrup T, Christensen JF, Christensen KB, Jørgensen NR, Schmidt JF, et al. Efficacy of recreational football on bone health, body composition, and physical functioning in men with prostate cancer undergoing androgen deprivation therapy: 32-week follow-up of the FC prostate randomised controlled trial. Osteoporosis International 2016;27(4):1507-18.

\section{Van Vulpen 2016 \{published data only\}}

Van Vulpen JK, Velthuis MJ, Steins Bisschop CN, Travier N, Van Den Buijs BJ, Backx FJ, et al. Effects of an exercise program in colon cancer patients undergoing chemotherapy. Medicine \& Science in Sports \& Exercise 2016;48(5):767-75.

\section{van Waart 2015 \{published data only\}}

van Waart H, Stuiver MM, van Harten WH, Geleijn E, Kieffer JM, Buffart LM, et al. Effect of low-intensity physical activity and moderate- to high-intensity physical exercise during adjuvant chemotherapy on physical fitness, fatigue, and chemotherapy completion rates: results of the PACES randomized clinical trial. Journal of Clinical Oncology 2015;33(17):1918-27.

\section{von Gruenigen 2008 \{published and unpublished data\}} von Gruenigen VE, Courneya KS, Gibbons HE, Kavanagh MB, Waggoner SE, Lerner E. Feasibility and effectiveness of a lifestyle intervention program in obese endometrial cancer patients: a randomized trial. Gynecologic Oncology 2008;109:19-26.

\section{von Gruenigen 2009 \{published and unpublished data\}}

von Gruenigen VE, Gibbons HE, Kavanagh MB, Janata JW, Lerner E, Courneya KS. A randomized trial of a lifestyle intervention in obese endometrial cancer survivors: quality of life outcomes and mediators of behavior change. Health and Quality of Life Outcomes 2009;7:17.

\section{von Gruenigen 2012 \{published and unpublished data\}} von Gruenigen V, Frasure H, Kavanagh MB, Janata J, Waggoner S, Rose P, et al. Survivors of uterine cancer empowered by exercise and healthy diet (SUCCEED): a randomized controlled trial. Gynecologic Oncology 2012;125:699-704.

\section{Waltman 2010 \{published and unpublished data\}}

Waltman NL, Twiss JJ, Ott CD, Gross GJ, Lindsey AM, Moore TE, et al. The effect of weight training on bone mineral density and bone turnover in post menopausal breast cancer survivors with bone loss: a 24-month randomized controlled trial. Osteoporosis International 2010;21:1361-9.

\section{Wang 2012 \{published data only\}}

Wang Q, Suo J, Jiang J, Wang C, Zhao YQ, Cao X. Effectiveness of fast-track rehabilitation vs conventional care in laparoscopic colorectal resection for elderly patients: a randomized trial. Colorectal Disease 2012;14:1009-13. 
Wasley 2018 \{published data only\}

Wasley D, Gale N, Roberts S, Backx K, Nelson A, Deursen R, et al. Patients with established cancer cachexia lack the motivation and self-efficacy to undertake regular structured exercise. Psycho-Oncology 2018;27(2):458-64.

Wiskemann 2017 \{published data only\}

Wiskemann J, Schmidt M, Klassen O, Debus J, Ulrich CM, Potthoff $\mathrm{K}$, et al. Effects of 12 -week resistance training during radiotherapy in breast cancer patients. Scandinavian Journal of Medicine \& Science in Sports 2017;27(11):1500-10.

\section{Xu 2015 \{published data only\}}

Xu Y, Cheng C. Effects of a walk-and-eat intervention for patients with esophageal cancer undergoing neoadjuvant chemoradiation. Supportive Care in Cancer 2015;23:1216-22.

Yang 2011 \{published data only\}

Yang CY, Tsai JC, Huang YC, Lin CC. Effects of a home-based walking program on perceived symptom and mood status in postoperative breast cancer women receiving adjuvant chemotherapy. Journal of Advanced Nursing 2011;67:158-68.

Yeo 2012 \{published and unpublished data\}

Yeo TP, Burrell SA, Sauter PK, Kennedy EP, Lavu H, Leiby BE, et al. A progressive postresection walking program significantly improves fatigue and health-related quality of life in pancreas and periampullary cancer patients. Journal of the American College of Surgeons 2012;214:463-75.

Yuen 2007 \{published and unpublished data\}

Yuen HK, Sword D. Home-based exercise to alleviate fatigue and improve functional capacity among breast cancer survivors. Journal of Allied Health 2007;36:e257-75.

Yun 2013 \{published data only\}

Yun YH, Lee MK, Bae Y, Shon EJ, Shin BR, Ko H, et al. Efficacy of a training program for long-term disease- free cancer survivors as health partners: a randomized controlled trial in Korea. Asian Pacific Journal of Cancer Prevention 2013;14(12):7229-35.

\section{Zhang 2018 \{published data only\}}

Zhang Q, Li F, Zhang H, Yu X, Cong Y. Effects of nurse-led homebased exercise \& cognitive behavioral therapy on reducing cancer-related fatigue in patients with ovarian cancer during and after chemotherapy: a randomized controlled trial. International Journal of Nursing Studies 2018;78:52-60.

\section{Zhao 2016 \{published data only\}}

Zhao SG, Alexander NB, Djuric Z, Zhou J, Tao Y, Schipper M, et al. Maintaining physical activity during head and neck cancer treatment: results of a pilot controlled trial. Head \& Neck 2016;38 (supp 1):E1086-96.

\section{Zhou 2015 \{published data only\}}

Zhou Y, Gottlieb L, Cartmel B, Li F, Ercolano EA, Harrigan M, et al. Randomized trial of exercise on quality of life and fatigue in women diagnosed with ovarian cancer: the women's activity and lifestyle study in connecticut (WALC). Journal of Clinical Oncology 2015;33:9505.
Zimmer 2014 \{published data only\}

Zimmer P, Baumann FT, Bloch W, Schenk A, Koliamitra C, Jensen $P$, et al. Impact of exercise on pro inflammatory cytokine levels and epigenetic modulations of tumorcompetitive lymphocytes in Non-Hodgkin-Lymphoma patientsrandomized controlled trial. European Journal of Haematology 2014;93(6):527-32.

\section{Zimmer 2016 \{published data only\}}

Zimmer P, Oberste M, Bloch W, Schenk A, Joisten N, Hartig P, et al. Impact of aerobic exercise training during chemotherapy on cancer related cognitive impairments in patients suffering from acute myeloid leukemia or myelodysplastic syndrome - study protocol of a randomized placebo-controlled trial. Contemporary Clinical Trials 2016;49:1-5.

Zopf 2012 \{published data only\}

Zopf EM, Braun M, Machtens S, Zumbe J, Bloch W, Baumann F. Effects of a 15-month rehabilitative exercise program in prostate cancer patients following a radical prostatectomy-first results of the ProRehab Study. Journal of Cancer Research and Clinical Oncology 2012;138:409-18.

\section{References to studies awaiting assessment}

\section{Bai 2004 \{published data only\}}

Bai S-M, Ma C, Liu Y-M, Xue W-P, Luo M, Ou Z-H. Effects of cognitive behavior intervention and cinesiateics on the quality of life of patients with nasopharyngeal carcinoma after radiotherapy. Chinese Journal of Clinical Rehabilitation 2004;8(29):6312-3.

\section{Chen 2010 \{published data only\}}

Chen J, Luo A, He Y. Influence of postoperative rehabilitation exercises on functional recovery of ill limb of breast cancer patients. Chinese Nursing Research 2010;24(4A):875-7.

\section{Cho 2004 \{published data only\}}

$\mathrm{Cho} \mathrm{OH}$. Effects of a comprehensive rehabilitation programme for mastectomy patients. Taehan Kanho Hakhoe Chi 2004;34(5):809-19.

\section{Choi 2012 \{published data only\}}

Choi J Y, Kang H S. Effects of a home-based exercise program for patients with stomach cancer receiving oral chemotherapy after surgery. Journal of Korean Academy of Nursing 2012;42(1):95-104.

\section{Dong 2006 \{published data only\}}

Dong HY, Wang ZF, Cai L. Correlation between quality of life and rehabilitative guidance education in the postoperative patients with breast cancer. Chinese Journal of Clinical Rehabilitation 2006;10(42):28-30.

\section{Guo 2004 \{published data only\}}

Guo Y-M. Effects of moderate strength and endurance exercise on emotion and quality of sleep in patients with malignant tumor. Chinese Journal of Clinical Rehabilitation 2004;8(35):7896-7. 
Hu 2013 \{published data only\}

Hu HF, Li TC, Liu LC, Wu CT, Wang Y J. Effects of a walking program on fatigue and exercise capacity in post-surgery breast cancer women. Hu li za zhi [Journal of nursing] 2013;60(5):53-63.

\section{LeVu 1997 \{published data only\}}

Le Vu B, Dumortier A, Guillaume MV, Mouriesse H, BarreauPouhaer L. Efficacy of massage and mobilization of the upper limb after surgical treatment of breast cancer. Bulletin du Cancer 1997;80(10):957-61.

\section{Oliveira 2010 \{published data only\}}

Oliveira MM, Souza GA, Miranda Mde S, Okubo MA, Amaral MT, Silva MP, Gurgel MS. Upper limb exercises during radiotherapy for breast cancer and quality of life. Revista Brasileira de Ginecologia e Obstetrícia 2010;32(3):133-8.

\section{Park 2006 \{published data only\}}

Park HS, Cho GY, Park KY. The effects of a rehabilitation program on physical health, physiological indicator and quality of life in breast cancer mastectomy patients. Taehan Kanho Hakhoe Chi 2006;36(2):310-20.

\section{Wang 2005 \{published data only\}}

Wang Y, Yao J-F, Yang J-Y. Effect of rehabilitation exercises on the recovery outcomes of lung function in postoperative patients with lung cancer. Zhongguo Linchuang Kangfu (Chinese Journal of Clinical Rehabilitation) 2005;9(39):14-6.

\section{Zhang 2005 \{published data only\}}

Effects of rehabilitation therapy in relieving pain and improving quality of life in patients with advanced cancer. Zhongguo Linchuang Kangfu (Chinese Journal of Clinical Rehabilitation) 2005, (40):59-61.

\section{Additional references}

\section{Bandura 2000}

Bandura A. Exercise of human agency through collective efficacy. Current Directions in Psychological Science 2000;9(3):75-8.

\section{Bandura 2002}

Bandura A. Social cognitive theory in cultural context. Applied Psychology: An International Review 2002;51:269-90.

\section{Borg 1982}

Borg GA. Psychophysical bases of perceived exertion. Medicine and Science in Sports and Exercise 1982;14(5):377-81.

\section{Bourke 2012a}

Bourke L, Rosario D, Copeland R, Taylor S. Physical activity for cancer survivors. BMJ 2012;344:d7998.

\section{Carver 1982}

Carver CS, Scheier MF. Control theory: a useful conceptual framework for personality-social, clinical, and health psychology. Psychological Bulletin 1982;92:111-35.

\section{Corner 2013}

Corner J, Wagland R, Glaser A, Richards SM. Qualitative analysis of patients' feedback from a PROMs survey of cancer patients in England. BMJ Open 2013;3(4):e002316.

\section{Courneya 2003}

Courneya KS, Friedenreich CM, Quinney HA, Fields AL, Jones LW, Fairey AS. A randomized trial of exercise and quality of life in colorectal cancer survivors. European Journal of Cancer Care 2003;12(4):347-57.

\section{Courneya 2010}

Courneya KS. Efficacy, effectiveness, and behavior change trials in exercise research. International Journal of Behavioural Nutrition and Physical Activity 2010;7:81.

\section{Craig 2008}

Craig P, Dieppe P, Macintyre S, Michie S, Nazareth I, Petticrew M. Developing and evaluating complex interventions: the new Medical Research Council guidance. BMJ 2008;337:a1655.

\section{Das 2012}

Das P, Horton R. Rethinking our approach to physical activity. Lancet 2012;380(9838):189-90.

\section{Department of Health 2011}

Department of Health Physical Activity Health Improvement and Protection. Start Active, Stay Active: A report on physical activity from the four home countries' Chief Medical Officers. http://www.dh.gov.uk/prod_consum_dh/groups/dh digitalassets/documents/digitalasset/dh_128210.pdf [accessed 4 January 2012].

\section{Dittus 2017}

Dittus KL, Gramling RE, Ades PA. Exercise interventions for individuals with advanced cancer: A systematic review. Preventive Medicine 2017;104:124-32.

\section{Elliott 2011}

Elliott J, Fallows A, Staetsky L, Smith PWF, Foster CL, Maher EJ, et al. The health and well-being of cancer survivors in the UK: findings from a population-based survey. British Journal of Cancer 2011;105(Supp 1):S11-S20. doi:10.1038/bjc.2011.418.

\section{Galway 2012}

Galway K, Black A, Cantwell M, Cardwell CR, Mills M, Donnelly M. Psychosocial interventions to improve quality of life and emotional well being for recently diagnosed cancer patients. Cochrane Database of Systematic Reviews 2012, Issue 11. [DOI: 10.1002/14651858.CD007064.pub2]

\section{Garcia 2014}

Garcia DO, Thomson CA. Physical activity and cancer survivorship. Nutrition in Clinical Practice 2014;29(6):768-79.

\section{Gardner 2011}

Gardner B, de Bruijn GJ, Lally P. A systematic review and metaanalysis of applications of the Self-Report Habit Index to nutrition and physical activity behaviours. Annals of Behavioral Medicine 2011;42:174-87. 


\section{Global Burden of Disease Cancer Collaboration 2017}

Global Burden of Disease Cancer Collaboration. Global, regional, and national cancer incidence, mortality, years of life lost, years lived with disability, and disability-adjusted life-years for 32 cancer groups, 1990 to 2015: A systematic analysis for the global burden of disease study. JAMA Oncology 2017;3(4):524-48.

\section{Godin 1986}

Godin G, Jobin J, Bouillon J. Assessment of leisure time exercise behavior by self-report: a concurrent validity study. Canadian Journal of Public Health 1986;77:359-62.

\section{Hashim 2016}

Hashim D, Boffetta P, La Vecchia C, Rota M, Bertuccio P, Malvezzi M, et al. The global decrease in cancer mortality: trends and disparities. Annals of Oncology 2016;27(5):926-33.

\section{Higgins 2011}

Higgins JPT, Green S (Editors). Cochrane Handbook for Systematic Reviews of Interventions Version 5.1.0 [updated March 2011]. The Cochrane Collaboration, 2011. www.cochranehandboook.org.

\section{Hoffman 2014}

Hoffmann TC, Glasziou P, Boutron I, Milne R, Perera R, Moher D, et al. Better reporting of interventions: template for intervention description and replication (TIDieR) checklist and guide. British Journal of Medicine 2014;348:g1687.

\section{Howlett 2018}

Howlett N, Trivedi D, Troop NA, Chater AM. Are physical activity interventions for healthy inactive adults effective in promoting behavior change and maintenance, and which behavior change techniques are effective? A systematic review and metaanalysis. Translational Behavioural Medicine 2018;28:iby010, https://doi.org/10.1093/tbm/iby010.

\section{Husebø 2013}

Husebø AM, Dyrstad SM, Søreide JA, Bru E. Predicting exercise adherence in cancer patients and survivors: a systematic review and meta-analysis of motivational and behavioural factors. Journal of Clinical Nursing 2013;22:4-21.

\section{Independent Cancer Taskforce}

Independent Cancer Taskforce. ACHIEVING WORLDCLASSCANCER OUTCOMESA STRATEGY FOR ENGLAND 2015-2020. https://www.cancerresearchuk.org/sites/default/ files/achieving_world-class_cancer_outcomes_-_a_strategy_ for_england_2015-2020.pdf.

\section{Kampshoff 2014}

Kampshoff CS, Jansen F, van Mechelen W, May AM, Brug J, Chinapaw MJ, et al. Determinants of exercise adherence and maintenance among cancer survivors: a systematic review. International Journal of Behavioral Nutrition and Physical Activity 2014;11(1):doi:10.1186/1479-5868-11-80.

\section{Kwasnica 2016}

Kwasnicka D, Dombrowski SU, White M, Sniehotta F. Theoretical explanations for maintenance of behaviour change: a systematic review of behaviour theories. Health Psychology Review 2016;10(3):277-96.

\section{Li 2016}

Li T, Wei S, Yun S, Pang S, Qin Q, Yin J, et al. The dose-response effect of physical activity on cancer mortality: findings from 71 prospective cohort studies. British Journal of Sports Medicine 2016;50:339.

\section{Low 2014}

Low CA, Beckjord E, Bovbjerg DH, Dew MA, Posluszny DM, Schmidt JE, et al. Correlates of positive health behaviors in cancer survivors: results from the 2010 LIVESTRONGsurvey. Journal of Psychosocial Oncology 2014;32(6):678-95.

\section{Macmillan Cancer Support 2011}

Macmillan Cancer Support. Move More. http:// www.macmillan.org.uk/Cancerinformation/ Livingwithandaftercancer/Physicalactivity/Physicalactivity.aspx (accessed 4 January 2012).

\section{Meneses-Echavez 2015}

Meneses-Echavez JF, Gonzalez-Jimenez E, Ramirez-Velez R. Supervised exercise reduces cancer-related fatigue: a systematic review. Journal of Physiotherapy 2015;61(1):3-9.

\section{Michie 2011}

Michie S, Ashford S, Sniehotta FF, Dombrowski SU, Bishop A, French DP. A refined taxonomy of behaviour change techniques to help people change their physical activity and healthy eating behaviours: the CALO-RE taxonomy. Psychology \& Health 2011;26(11):1479-98.

\section{Mishra 2012a}

Mishra SI, Scherer RW, Snyder C, Geigle PM, Berlanstein DR, Topaloglu O. Exercise interventions on health-related quality of life for people with cancer during active treatment. Cochrane Database of Systematic Reviews 2012, Issue 8. [DOI: 10.1002/14651858.CD008465.pub2]

\section{Mishra 2012b}

Mishra SI, Scherer RW, Geigle PM, Berlanstein DR, Topaloglu O, Gotay CC, et al. Exercise interventions on health-related quality of life for cancer survivors. Cochrane Database of Systematic Reviews 2012;8:CD007566.

\section{Mishra 2014}

Mishra SI, Scherer RW, Snyder C, Geigle P, Gotay C. Are exercise programs effective for improving health-related quality of life among cancer survivors? A systematic review and meta-analysis. Oncology Nursing Forum 2014;41(6):E326-42. doi:10.1188/14.ONF.

\section{Nakash 2014}

Nakash O, Levav I, Aguilar-Gaxiola S, Alonso J, Andrade L, Angermeyer M, et al. Comorbidity of common mental disorders with cancer and their treatment gap: findings from the World Mental Health Surveys. Psycho-Oncology 2014;23:40-51. 


\section{NICE 2007}

National Institute for Health and Clinical Excellence (NICE). NICE public health guidance 6 . Behaviour change at population, community and individual levels. October 2007. http:// www.nice.org.uk/PH6 (accessed 4 January 2012).

\section{Ormel 2017}

Ormel HL, van der Schoot GGF, Sluiter WJ, Jalving M, Gietema JA, Walenkamp AME. Predictors of adherence to exercise interventions during and after cancer treatment: $A$ systematic review. Psycho-Oncology 2017;27(3):713-24.

\section{Review Manager 2014 [Computer program]}

The Nordic Cochrane Centre, The Cochrane Collaboration. Review Manager (RevMan). Version 5.3. Copenhagen: The Nordic Cochrane Centre, The Cochrane Collaboration, 2014.

\section{Rock 2012}

Rock CL, Doyle C, Demark-Wahnefried W, Meyerhardt J, Courneya KS, Schwartz AL, et al. Nutrition and physical activity guidelines for cancer survivors. CA: A Cancer Journal for Clinicians 2012;62(4):242-74.

\section{Schmitz 2010a}

Schmitz KH, Courneya KS, Matthews C, Demark-Wahnefried W, Galvao DA, Pinto BM, et al. American College of Sports Medicine roundtable on exercise guidelines for cancer survivors. Medicine Science Sports Exercise 2010;43(1):195.

\section{Stout 2017}

Stout NL, Baima J, Swisher AK, Winters-Stone KM, Welsh J. A systematic review of exercise systematic reviews in the cancer literature (2005-2017). PM \& R: the Journal of Injury, Function, and Rehabilitation 2017;9(9 (supp 2)):S347-84.

\section{CHARACTERISTICS OF STUDIES}

Characteristics of included studies [ordered by study ID]

\section{Verplanken 2009}

Verplanken B, Melkelvik O. Predicting habit: the case of physical exercise. Psychology of Sport and Exercise 2009;9:15-26.

\section{Warren 2010}

Warren JM, Ekelund U, Besson H, Mezzani A, Geladas N, Vanhees L, Experts Panel. Assessment of physical activity a review of methodologies with reference to epidemiological research: a report of the exercise physiology section of the European Association of Cardiovascular Prevention and Rehabilitation. European Journal of Cardiovascular Prevention \& Rehabilitation 2010;17:127-39.

\section{Winter 2009}

Winter EM, Fowler N. Exercise defined and quantified according to the Systeme International d'Unites. Journal of Sports Sciences 2009;27(5):447-60.

\section{References to other published versions of this review}

\section{Bourke 2012b}

Bourke L, Homer KE, Thaha MA, Steed L, Rosario D, Robb KA, et al. Interventions for promoting habitual exercise in people living with and beyond cancer. Cochrane Database of Systematic Reviews 2012, Issue 11. [DOI: 10.1002/14651858.CD010192]

\section{Bourke 2013}

Bourke L, Homer KE, Thaha MA, Steed L, Rosario DJ, Robb KA, et al. Interventions for promoting habitual exercise in people living with and beyond cancer. Cochrane Database of Systematic Reviews 2013, Issue 9. [DOI: 10.1002/14651858.CD010192.pub2]

* Indicates the major publication for the study

al-Majid 2015

Methods

- Study design: RCT individual participant level randomisation.

- Study location: Central Virginia and Southern California, USA

- Funding source: Oncology Nursing Society Grant

- Inclusion criteria: patients eligible to participate included women aged 21 years or older diagnosed with Stage I or II breast cancer who were scheduled to receive chemotherapy, spoke and read English, and were willing to be randomly assigned to either group.

- Exclusion criteria: consistent with the exclusion criteria stipulated by the American College of Sports Medicine, patients who had recent or uncontrolled cardiac conditions were excluded. Other exclusion criteria included self-reported history of unstable or severe clinical depression, activity-limiting arthritis, having had joint surgery within the previous 3 months, and having been engaged in regular exercise ( 5 days per week) in the past 3 months.

- CONSORT diagram included: yes

- Number of participants in each arm: 7,7 (intervention vs control)

- Study recruitment rate: $16 / 35$

- Length of follow-up: length of intervention = 12 weeks, length of follow-up from baseline =15-16 weeks. 
al-Majid 2015 (Continued)

- Current cancer treatment: scheduled chemotherapy

- Metastatic disease: none

- Age, years, mean (SD): exercise group 47.9 +/- 10.4 \& control group 52.7 +/- 10.7

- Gender: female

- BMI: unknown

- Ethnicity: for both groups: Hispanic 29\%, Non Hispanic $71 \%$

- Comorbidities reported: unclear

- Group or individual intervention: individual
- Setting: rehabilitation suite
- Exercise prescription components: aerobic
- Theoretical basis: none
- Frequency of contact with researcher or exercise professional: every exercise session was supervised,
two to three times per week contact with exercise physiologist over nine to 12 weeks. 4 Assessments
over the intervention and follow-up period.
- Frequency of contact with healthcare professional: eligible participants were informed about the
study by referring oncologists and were approached by study staff who invited them to participate.
Instructions to controls: instructed to document and report any exercise activities they engaged in
while on the study.

Outcomes

- Change in fitness reported: aerobic exercise tolerance was measured using VO2 Max test.

- Free-living energy expenditure: unclear

Process measures

Compliance
- Method of measuring exercise behaviour: adherence to exercise protocol, and the amount (duration $\mathrm{HR}$ ) of exercise was achieved by participants during sessions was recorded using heart rate watch monitors.

- Aerobic exercise frequency: two to three times per week.

- Aerobic exercise duration: twenty to forty minutes.

- Aerobic exercise intensity: progression throughout the 12 -week period; from $40 \%$ heart rate reserve to $80 \%$ heart rate reserve.

- Description aerobic exercise mode: treadmills

- Resistance exercise frequency: N/A

- Resistance exercise sets: N/A

- Resistance exercise repetitions: N/A

- Resistance exercise intensity: N/A

- Description of resistance exercise: N/A

- Adherence: ranging between $95 \%$ and $97 \%$ to exercise protocol.

- Attrition: $12.5 \%$

- Adverse effects: none reported.

- Achieves Rock et al guidelines: no

Description of usual care

Participants in the usual-care group received usual care, which did not involve exercise, and were instructed to document and report any exercise activities they engaged in while on the study. Similarly, the exercise-group participants to report engagement in non-protocol exercise activities during the study.

Notes

\section{Risk of bias}


al-Majid 2015 (Continued)

Random sequence genera- Unclear risk Insufficient information to permit a 'low' or 'high' risk judgement. tion (selection bias)

Allocation concealment $\quad$ Unclear risk Insufficient information to permit a 'low' or 'high' risk judgement.
(selection bias)

(selection bias)

Blinding of outcome as-
sessment (detection bias)

Unclear risk

Insufficient information to permit a 'low' or 'high' risk judgement.

All outcomes

Incomplete outcome data Unclear risk Insufficient information to permit a 'low' or 'high' risk judgement.
(attrition bias)

All outcomes

Selective reporting (re- Low risk All outcomes reported.

porting bias)

Other bias Unclear risk None

Bourke 2011a

\begin{tabular}{|c|c|}
\hline Methods & $\begin{array}{l}\text { - Study design: RCT participant level randomisation } \\
\text { - Study location (WHO income taxonomy): Sheffield, UK (high) } \\
\text { - Funding source: Sheffield Hallam University } \\
\text { - Inclusion criteria: patients who had histologically-confirmed colon cancer (Dukes stages A to C) re- } \\
\text { spected } 6 \text { to } 24 \text { months previously } \\
\text { - Exclusion criteria: existing participation in regular physical activity (purposeful activity of at least } \\
\text { moderate intensity of } 30 \text { minutes or longer, three times a week), a Karnofsky rating of less than } 80 \text {, } \\
\text { - } \text { unstable angina, uncontrolled hypertension, recent myocardial infarction or a pacemaker } \\
\text { - Study recruitment rate: } 18 / 180 \\
\text { - Length of follow-up: length of intervention = } 12 \text { weeks, length of follow-up from baseline = } 12 \text { weeks }\end{array}$ \\
\hline Participants & $\begin{array}{l}\text { - Primary cancer diagnosis: histologically-confirmed colon cancer (Dukes stages A to C) } \\
\text { - Current cancer treatment: none } \\
\text { - Metastatic disease: none } \\
\text { - Age, years: mean (SD) = control: } 70.3 \text { (8.7), intervention: } 67.9(5.7) \\
\text { - Sex: } 12 \text { males, } 6 \text { females } \\
\text { - BMI: mean (SD): control: } 26.0 \text { (3.5), intervention: } 26.9(3.8) \\
\text { - Ethnicity: unclear } \\
\text { - Comorbidities reported: unclear }\end{array}$ \\
\hline Interventions & $\begin{array}{l}\text { - Sample size: intervention }(\mathrm{n}=9) \text {, control }(\mathrm{n}=9) \\
\text { - Group or individual intervention: group } \\
\text { - Setting: university rehabilitation suite } \\
\text { - Exercise prescription components: aerobic and resistance } \\
\text { - Theoretical basis: not stated } \\
\text { - CALO-RE taxonomy components: \#15, \#16, \#26, \#27 } \\
\text { - Frequency of contact with researchers or exercise professionals: } 18 \text { supervised exercise sessions } \\
\text { - Instructions to controls: continue behaviour as normal }\end{array}$ \\
\hline Outcomes & $\begin{array}{l}\text { - Change in fitness reported: aerobic-exercise tolerance using the Borg treadmill protocol. Resis- } \\
\text { tance-maximal voluntary torque of the knee extensors using isokinetic dynamometry }\end{array}$ \\
\hline
\end{tabular}


Bourke 2011a (Continued)

- Free-living energy expenditure: unclear

Process measures

- Method of measuring exercise behaviour: attendance at supervised session with HR monitors, exercise diaries and (Godin 1986) LSI at assessment points

- Aerobic exercise frequency: three or more times per week

- Aerobic exercise duration: 30 minutes per session or longer

- Aerobic exercise intensity: intensity of 55\% to $85 \%$ of age-predicted maximum heart rate and/or ratings of perceived exertion, 11 to 15/fairly light to hard, on the Borg Rating Perceived Exertion (RPE) scale

- Description aerobic exercise mode: cycle/rowing ergometers, treadmill work. Plus brisk walking, cycling or gym exercise, etc, during independent exercise sessions

- Resistance exercise frequency: three or more times per week

- Resistance exercise sets: between 2 and 4 sets of resistance exercises

- Resistance exercise repetitions: 8 to 12 repetitions

- Resistance exercise intensity: $60 \%$ of 1 repetition max

- Description of resistance exercise: large skeletal muscle groups (quadriceps, deltoids, pectorals, latissimus dorsi, hamstring muscles) were targeted using body weight resistance and free weights

- Intervention uptake: $9 / 9$
- Adherence: attendance was 146 of 162 of the supervised sessions attended ( $90 \%$ compliance). The
median (range) rating of perceived exertion (Borg RPE scale) during the exercise sessions was 12 (7 to
16). On average, $94 \%$ of the independent exercise sessions (i.e. participants reporting at least 25 to 30
minutes of aerobic exercise) were completed
- Attrition: one participant in the intervention arm was lost to follow-up. $89 \%$ completed final follow-up
in the intervention arm
- Adverse effects: one stroke in the intervention group occurred but was deemed unrelated to the study
- Achieves Rock et al guidelines: six weeks of resistance training

Description of usual care

Both groups had access to standard care, which consisted of a holistic nurse-led colorectal cancer follow-up service

Notes

\section{Risk of bias}

\begin{tabular}{lll}
\hline Bias & Authors' judgement & Support for judgement \\
\hline $\begin{array}{l}\text { Random sequence genera- } \\
\text { tion (selection bias) }\end{array}$ & Low risk & $\begin{array}{l}\text { Participants were randomly assigned by an independent researcher via code } \\
\text { numbers using nQuery statistical software }\end{array}$ \\
\hline $\begin{array}{l}\text { Allocation concealment } \\
\text { (selection bias) }\end{array}$ & Low risk & $\begin{array}{l}\text { Randomisation was undertaken by a senior academic who was not directly in- } \\
\text { volved in the recruitment or assessment of participants }\end{array}$ \\
\hline $\begin{array}{l}\text { Blinding of outcome as- } \\
\text { sessment (detection bias) } \\
\text { All outcomes }\end{array}$ & Low risk & $\begin{array}{l}\text { All outcomes were assessed by an experienced exercise physiologist, who was } \\
\text { blind to the group allocation }\end{array}$ \\
\hline $\begin{array}{l}\text { Incomplete outcome data } \\
\text { (attrition bias) }\end{array}$ & Low risk & $\begin{array}{l}\text { Intention-to-treat analysis was used to compare participants in the groups to } \\
\text { which they were randomly assigned, with data carried over from previous vis- } \\
\text { its in cases of participant withdrawal }\end{array}$ \\
\hline $\begin{array}{l}\text { Selective reporting (re- } \\
\text { porting bias) }\end{array}$ & Low risk & All outcomes reported \\
\hline \begin{tabular}{l} 
Other bias \\
\hline
\end{tabular} & Unclear risk & Low recruitment rate (18/180) could represent a biased sample
\end{tabular}


Bourke 2014

- Study design: RCT individual participant level randomisation
- Study location: Sheffield, UK
- Funding source: Sheffield Hallam University
- Inclusion criteria: eligible men were sedentary (i.e. exercising < 90 min per week at a moderate inten-
sity) and receiving continuous ADT for a minimum of 6 mo prior to recruitment, with planned long-
term retention on ADT.
- Exclusion criteria: Men with unstable angina, uncontrolled hypertension, recent myocardial infarc-
tion, pacemakers, and painful or unstable bony metastases were excluded.
- CONSORT diagram included: yes
- Study recruitment rate: $100 / 136$
- Length of follow-up: length of intervention = 12 weeks, length of follow-up from baseline $=6$ months.
- Primary cancer diagnosis: prostate cancer
- Current cancer treatment: androgen Deprivation Therapy
- Metastatic disease: $20 / 100$ men had metastatic disease
- Age, years, mean (SD): intervention: 71 (6), control: 71 (6)
- Gender: male
- BMI: Intervention: 29.3 (4.4), control: 28.1 (4.1)
- Ethnicity: unclear
- Comorbidities reported: $4 \%$ previous MI, $3 \%$ previous stroke, $5 \%$ angina, $7 \%$ diabetes, $27 \%$ hyperten-
sion, $5 \%$ hypertension diagnosed since ADT commencement * from linked paper Gilbert $2016{ }^{\star}$.

Interventions

- Sample size: intervention ( $n=25)$, control $(n=25)$

- Group or individual intervention: group

- Setting: dedicated rehabilitation suite plus home-based.

- Exercise prescription components: aerobic and resistance

- Theoretical basis: none

- CALO-RE taxonomy components: \#1 \#5 \#8 \#9 \#15 \#17 \#20 \#21 \#26 \#29

- Frequency of contact with researcher or exercise professional: men would be supervised by an exercise physiologist, this was undertaken twice a week from weeks 1-6, and once per week from weeks 7-12. Small-group healthy eating seminars, lasting approximately 20 minutes, were carried out every 2 week throughout the 12 -week intervention. Outcomes would be assessed by a trained technician at 3 points over the intervention.

- Frequency of contact with healthcare professional: men randomised to usual care were followed up in the urology clinic and seen by an oncology nurse specialist and urologist.

- Instructions to controls: no restrictions were placed on exercise/dietary behaviours over the period of the study.

Outcomes

- Change in fitness reported: aerobic exercise tolerance was tested using the Borg treadmill protocol

- Free-living energy expenditure: unclear

Process measures

- Method of measuring exercise behaviour: adherence to exercise protocol, Godin Questionnaire and Borg scales.

- Aerobic exercise frequency: supervised - twice a week from weeks 1-6, and once per week from weeks 7-12. Independent - once a week from weeks 1-6 and twice a week from weeks 7-12.

- Aerobic exercise duration: 30 minutes per supervised and independent exercise.

- Aerobic exercise intensity: the aerobic exercise prescription was 30 minutes at an intensity of $55 \%$ to $75 \%$ of age predicted maximum heart rate or 11-13 on the Borg Rating of Perceived Exertion scale.

- Description aerobic exercise mode: use of stationary cycles, rowing ergometers and treadmills. Independent - brisk walking, cycling and gym exercise.

- Resistance exercise frequency: supervised - twice a week from weeks 1-6, and once per week from weeks 7-12. 
Bourke 2014 (Continued)

- Resistance exercise sets: between 2-4 sets

- Resistance exercise repetitions: 8-12 reps

- Resistance exercise intensity: intensity of $60 \%$ of one repetition max with progression through increasing volume before weight was increased.

- Description of resistance exercise: body weight resistance and free weights targeting large skeletal muscle groups.

- Intervention uptake: 25.
- Adherence: adherence was $94 \%$ for the supervised and $82 \%$ of the prescribed independent exercise
sessions over the first 12 weeks.
- Attrition: $85 \%$ cohort completing 12 -week follow-up, $68 \%$ men attending 6 -month follow-up.
- Adverse effects: 2 unrelated deaths *from linked paper Gilbert $2016^{*}$
- Achieves Rock et al guidelines: yes, six weeks of resistance training

Description of usual care Men randomised to usual care were followed up in the urology clinic and seen by an oncology nurse specialist and urologist. The treating physicians were informed that the man was participating in a lifestyle intervention study and further information would be available on application. No restrictions were placed on exercise/dietary behaviours over the period of the study.

Notes

\section{Risk of bias}

\begin{tabular}{|c|c|c|}
\hline Bias & Authors' judgement & Support for judgement \\
\hline $\begin{array}{l}\text { Random sequence genera- } \\
\text { tion (selection bias) }\end{array}$ & Low risk & $\begin{array}{l}\text { Randomisation was undertaken ( } 1: 1) \text { by a senior academic independent of the } \\
\text { study, at the patient level using nQuery statistical software. }\end{array}$ \\
\hline $\begin{array}{l}\text { Allocation concealment } \\
\text { (selection bias) }\end{array}$ & Low risk & $\begin{array}{l}\text { Randomisation was undertaken (1:1) by a senior academic independent of the } \\
\text { study, at the patient level using nQuery statistical software. }\end{array}$ \\
\hline $\begin{array}{l}\text { Blinding of outcome as- } \\
\text { sessment (detection bias) } \\
\text { All outcomes }\end{array}$ & Low risk & $\begin{array}{l}\text { Randomisation was undertaken (1:1) by a senior academic independent of the } \\
\text { study, at the patient level using nQuery statistical software. }\end{array}$ \\
\hline $\begin{array}{l}\text { Incomplete outcome data } \\
\text { (attrition bias) } \\
\text { All outcomes }\end{array}$ & High risk & Incomplete outcome data at 6 months follow-up. \\
\hline $\begin{array}{l}\text { Selective reporting (re- } \\
\text { porting bias) }\end{array}$ & Low risk & All outcomes reported. \\
\hline Other bias & Low risk & None. \\
\hline
\end{tabular}

\section{Cadmus 2009}

$\begin{array}{ll}\text { Methods } & \text { Study design: RCT participant level randomisation } \\ \text { - Study location (WHO income taxonomy): USA, Connecticut (high) } \\ \text { - Funding source: supported in part by a General Clinical Research Center grant from the National Cen- } \\ \text { ter of Research Resources, National Institutes of Health (Grant \# M01-RR00125) awarded to Yale Uni- } \\ \text { versity School of Medicine } \\ \text { - Inclusion criteria: postmenopausal women, aged } 40 \text { to } 75 \text { years, AJCC Stages } 0 \text { to IIIa breast cancer, } 1 \\ \text { to } 10 \text { years post diagnosis, }>12 \text { months post completion of adjuvant treatment, physically able to ex- } \\ \text { ercise with physician consent to begin an exercise programme, sedentary activity pattern (<60 min- } \\ \text { utes/week) with physician consent to begin an exercise programme }\end{array}$


Cadmus 2009 (Continued)

- Exclusion criteria: diagnosis of recurrent or other primary cancer event. Current smoker, diabetes mellitus, current or planned enrolment in a structured weight-loss programme

- CONSORT diagram included: yes, in Irwin 2008

- Study recruitment rate: $75 / 88$

- Length of follow-up: length of intervention $=6$ months, length of follow-up from baseline $=6$ months

\begin{tabular}{|c|c|}
\hline Participants & $\begin{array}{l}\text { - Primary cancer diagnosis: AJCC Stages } 0 \text { to Illa breast cancer } \\
\text { - Current cancer treatment: completed adjuvant treatment (with the exception of hormonal therapy) } \\
\text { at least six months before enrolment. } 57 \% \text { versus } 70 \% \text { on hormone therapy in the intervention group } \\
\text { versus controls; } 30 \% \text { on tamoxifen in both arms; } 27 \text { versus } 40 \% \text { versus control on aromatase inhibitors } \\
\text { - Metastatic disease: none } \\
\text { - Age, years: mean (SD): intervention: } 56.5(9.5) \text {, control: } 55.1(7.7) \\
\text { - Sex: women } \\
\text { - BMI: mean (SD): intervention: } 30.4(6.0) \text {, control: } 30.1(7.4) \\
\text { - Ethnicity: } 84 \% \text { white in both groups } \\
\text { - Comorbidities reported: unclear }\end{array}$ \\
\hline Interventions & $\begin{array}{l}\text { - Sample size: intervention }(\mathrm{n}=37) \text {, control }(\mathrm{n}=38) \\
\text { - Group or individual intervention: supervised and home-based } \\
\text { - Setting: a supervised training programme at a local health club. Participants exercised at the club } \\
\text { during designated sessions } \\
\text { - Exercise prescription components: aerobic training } \\
\text { - Theoretical basis: not stated } \\
\text { - CALO-RE taxonomy components: } \# 1, \# 5, \# 8 . \# 9, \# 15, \# 16, \# 17, \# 19, \# 21, \# 26, \# 29, \# 35 \\
\text { - Frequency of contact with researchers or exercise professionals: unclear exactly how many exercise } \\
\text { sessions were supervised } \\
\text { - Instructions to controls: participants assigned to the usual care groups were told that they could ex- } \\
\text { ercise on their own if they chose, but that the study's physical activity programme would not be avail- } \\
\text { able to them. They received all exercise programme materials at six-month follow-up }\end{array}$ \\
\hline
\end{tabular}

Outcomes

- Change in fitness reported: not reported

- Free-living energy expenditure: unclear

Process measures

- Method of measuring exercise behaviour: heart rate monitors, physical activity questionnaire, a seven-day physical activity log and a seven-day pedometer log. Adherence to the intervention among exercise group participants was assessed by seven-day physical activity logs weekly

- Aerobic exercise frequency: three sessions per week supervised, two sessions per week at home or at a health club: total five days a week

- Aerobic exercise duration: participants were asked to perform three 15-minute sessions during week 1, building to five 30-minute moderate-intensity sessions by week 5

- Aerobic exercise intensity: $60 \%$ to $80 \%$ of maximal heart rate reserve

- Description aerobic exercise mode: from Irwin 2008: The intervention consisted primarily of walking, an activity preferred by most women and breast cancer survivors, although participants could choose to meet the exercise goal through swimming, aerobics, other forms of activity or a combination of different activities. Activities that did not involve sustained aerobic effort, such as weight lifting and yoga, could be performed but did not count toward the exercise goal for each week

- Resistance exercise frequency: N/A

- Resistance exercise sets: N/A

- Resistance exercise repetitions: N/A

- Resistance exercise intensity: N/A

- Description of resistance exercise: N/A

Compliance

- Intervention uptake: $37 / 37$

Adherence: 
- Cadmus 2009: regarding the weekly goals of thrice-weekly supervised exercise sessions at the health club and twice-weekly unsupervised sessions on their own, women participated in $67 \%$ of the supervised exercise sessions, and $96 \%$ of women reported exercising on their own two other days of the week and exercised on average at $76 \%$ of their maximal heart rate ( $82 \%$ as a mean over both supervised and unsupervised)

- Irwin 2008: 33\% reported 150 minutes/week of aerobic exercise at an average of $76 \%$ HR over the six-month intervention. Women randomly assigned to exercise chose weight-bearing activities most often, with $82 \%$ walking. Few women reported doing resistance training (3\%). $75 \%$ of women were doing between 90 and 119 minutes of moderate-intensity exercise per week, over six months

- Latka 2009: the variables that predict adherence were BMI and trans theoretical model stage of change. Specifically, a lower BMI and a higher degree of readiness to change physical activity behaviour were associated with better adherence

- Attrition: one participant lost to follow-up in the intervention group, five lost to follow-up in the control group. $97 \%$ completed final follow-up in the intervention group

- Adverse effects: five of the 37 women randomly assigned to exercise experienced an adverse effect; two were related to the study (plantar fascitis), and three were unrelated (swollen Achilles, stress fracture in foot and plantar fasciitis) to the study. No women developed lymphoedema during the study

- Achieves Rock et al guidelines: 33\% reported 150 minutes/week of moderate intensity aerobic exercise at an average of $76 \% \mathrm{HR}$ for six months

\begin{tabular}{ll} 
Description of usual care & Unclear \\
\hline Notes & $\begin{array}{l}\text { Only YES study included in the review because of the requirement that participants must be sedentary } \\
\text { at baseline }\end{array}$
\end{tabular}

\section{Risk of bias}

\begin{tabular}{|c|c|c|}
\hline Bias & Authors' judgement & Support for judgement \\
\hline $\begin{array}{l}\text { Random sequence genera- } \\
\text { tion (selection bias) }\end{array}$ & Low risk & $\begin{array}{l}\text { A computer programme randomly assigned each YES study participant with } \\
\text { equal probability to the exercise group or the usual care group }\end{array}$ \\
\hline $\begin{array}{l}\text { Allocation concealment } \\
\text { (selection bias) }\end{array}$ & Low risk & $\begin{array}{l}\text { The randomisation code for each participant was obtained by the principal in- } \\
\text { vestigator (who was not involved in recruitment or data collection) only after } \\
\text { baseline measures for that individual had been completed and staff conduct- } \\
\text { ing clinic visits did not have access to the randomisation programme }\end{array}$ \\
\hline $\begin{array}{l}\text { Blinding of outcome as- } \\
\text { sessment (detection bias) } \\
\text { All outcomes }\end{array}$ & Unclear risk & Insufficient information to permit a 'low' or 'high' risk judgement \\
\hline $\begin{array}{l}\text { Incomplete outcome data } \\
\text { (attrition bias) } \\
\text { All outcomes }\end{array}$ & Low risk & $\begin{array}{l}\text { Analyses were conducted according to the intention-to-treat principle. Base- } \\
\text { line QOL values were carried forward for the five IMPACT study participants } \\
\text { (three exercisers and two controls) and } 10 \text { YES study participants (five exercis- } \\
\text { ers and five controls) for whom six-month data were unavailable }\end{array}$ \\
\hline $\begin{array}{l}\text { Selective reporting (re- } \\
\text { porting bias) }\end{array}$ & Low risk & None, all outcomes reported \\
\hline Other bias & Low risk & None \\
\hline
\end{tabular}

\section{Campbell 2017}

\begin{tabular}{ll}
\hline Methods & - Study design: RCT individual participant level randomisation \\
& - Study location: Vancouver, BC, Canada \\
& - Funding source: Canadian Breast Cancer Foundation BC/Yukon. \\
\hline
\end{tabular}


- Inclusion criteria: all participants were $\geq 3$ months and up to 3 years post adjuvant treatment, physically able to undertake an exercise programme, postmenopausal (natural or chemotherapy induced) at time of enrolment, and receiving antihormonal treatment (i.e. aromatase inhibitor).

- Exclusion criteria: $>90$ minutes/week of self-reported moderate-vigorous physical activity (last 6 months); mini-mental status examination $<23$; comorbid conditions that could alter cognitive testing results, such as a psychiatric conditions, history of substance use disorder, or other neurological disorder (i.e., head injury, epilepsy, and neurodegenerative disease); and deemed unsafe for magnetic resonance imaging (MRI).

- CONSORT diagram included: yes

- Study recruitment rate:19/86

- Length of follow-up: length of intervention $=12$ weeks, length of follow-up from baseline $=24$ weeks.

- Primary cancer diagnosis: stages I to IIIA breast cancer
- Current cancer treatment: following chemotherapy
- Metastatic disease: unclear
- Age, years, mean (SD): intervention $=53.2(7.0)$, control $=51.4(5.1)$
- BMI: intervention $=26.1(5.5)$, control $=26.3(5.7)$
- Ethnicity: unclear
- Comorbidities reported: unclear
- Sample size: intervention ( $\mathrm{n}=10)$, control ( $\mathrm{n}=9)$
- Group or individual intervention: unclear
- Setting: research gym plus home-based
- Exercise prescription components: aerobic
- Theoretical basis: none
- CALO-RE taxonomy components: programme set goal, \#9
- Frequency of contact with researcher or exercise professional: two study visits at baseline and at 24
- Feeks with trained study staff. $2 \times 24$ sessions per week were supervised - unclear by whom.
- Instructions to controls: participants randomised to CON were asked to maintain usual lifestyle and
offered a 12 -week exercise programme upon study completion.

Outcomes

- Change in fitness reported: aerobic exercise tolerance using VO2 peak.

- Free-living energy expenditure: unclear

Process measures

- Method of measuring exercise behaviour: heart rate reserve, American College of Sports Medicine metabolic equation for treadmill walking

- Aerobic exercise frequency: supervised- twice per week and unsupervised - twice per week.

- Aerobic exercise duration: 30 to 45 minutes duration per session, 150 minutes per week of moderate-vigorous aerobic exercise for 24 weeks.

- Aerobic exercise intensity: the prescription began at $60 \%$ of HRR for 20 minutes, with a weekly increase in duration toward 45 minutes by week 6 , followed by a weekly increase in intensity toward $80 \%$ HRR by week 12 .

- Description aerobic exercise mode: independent walking or exercises of participants choice at home. Supervised sessions - treadmill walking.

- Resistance exercise frequency: N/A

- Resistance exercise sets: N/A

- Resistance exercise repetitions: N/A

- Resistance exercise intensity: N/A

- Description of resistance exercise: N/A

Compliance

- Intervention uptake: 19/19

- Adherence: participants attended $88 \%$ of supervised gym sessions (mean 1.8 sessions/ week and 87.5 minutes/week), and participants met $82 \%$ of the prescribed exercise targets (mean intensity $74.5 \%$ 
Campbell 2017 (Continued)

HRR). Home session completion was $87 \%$ (mean 2.4 sessions/week and 101.5 minutes/week), and participants met $87 \%$ of the prescribed exercise targets (mean intensity $73.5 \% \mathrm{HRR}$ ).

- Attrition: $100 \%$

- Adverse effects: none reported

- Achieves Rock et al guidelines: yes, 150 minutes of exercise per week.

Description of usual care

Participants randomised to the control were asked to maintain usual lifestyle and offered a 12-week exercise programme upon study completion.

\section{Notes}

\section{Risk of bias}

\begin{tabular}{lll}
\hline Bias & Authors' judgement & Support for judgement \\
\hline $\begin{array}{l}\text { Random sequence genera- } \\
\text { tion (selection bias) }\end{array}$ & Low risk & $\begin{array}{l}\text { Following completion of baseline measures, eligible participants were ran- } \\
\text { domised using permutated blocks of } 4 \text { to } 6 \text { in a 1:1 ratio to the aerobic exercise } \\
\text { intervention group or delayed exercise control. }\end{array}$ \\
\hline $\begin{array}{l}\text { Allocation concealment } \\
\text { (selection bias) }\end{array}$ & Unclear risk & Insufficient information to permit a 'low' or 'high' risk judgement. \\
\hline $\begin{array}{l}\text { Blinding of outcome as- } \\
\text { sessment (detection bias) } \\
\text { All outcomes }\end{array}$ & Unclear risk & Insufficient information to permit a 'low' or 'high' risk judgement. \\
\hline $\begin{array}{l}\text { Incomplete outcome data } \\
\text { (attrition bias) } \\
\text { All outcomes }\end{array}$ & Low risk & All data completed \\
\hline $\begin{array}{l}\text { Selective reporting (re- } \\
\text { porting bias) }\end{array}$ & Low risk & All outcomes reported \\
\hline \begin{tabular}{l} 
Other bias \\
\hline
\end{tabular} & High risk & Low study recruitment rate \\
\hline
\end{tabular}

- Study design: RCT individual participant level randomisation
- Study location: Granada, Spain
- Funding source: this study was funded by a research project grant (FISPI10/02749) from the Health
Institute Carlos III and PNI+D+I 2008-2011, Madrid, Spanish Government, and from a grant of Andalu-
sian Health Service, Junta de Andalucia.
- Inclusion criteria: participants were eligible if they: 1 ) had a diagnosis of breast cancer (stages I-IIIA);
2) had received a simple mastectomy or quadrantectomy with posterior breast reconstruction; 3) be-
tween 25 and 65 years; 4) finished their co-adjuvant treatment, except hormone therapy, at least 3
months before beginning the study; 5) not having an active cancer; and, 6) having neck and shoulder
pain that began after the breast cancer surgery assessed with a visual analogue scale (VAS) (0-100).
Neck pain was defined as pain from the occipital to C7 vertebra, not including the shoulder region,
whereas shoulder axillary pain was defined as pain experienced in the shoulder and/or the axillary
region, not including the cervical spine.
Exclusion criteria: participants were excluded if they: 1) were receiving chemotherapy or radiothera-
py at the time of the study; 2) suffer from an orthopaedic disease that limit to follow the water pro-
gramme; 3) had uncontrolled hypertension (diastolic pressure >95 mm Hg); 4) had presence of lym-
phoedema; 5) had recurrent cancer; or 6 ) had previous diagnosis of fibromyalgia.
CONSORT diagram included: yes


- Length of follow-up: length of intervention $=8$ weeks, length of follow-up from baseline $=8$ weeks.

\begin{tabular}{ll}
\hline Participants & Primary cancer diagnosis: bBreast cancer \\
& - Current cancer treatment: none \\
& - Mgetastatic disease: unclear \\
- Gears, mean (SD): intervention = 48 (8), control = 47 (9) \\
- BMl: unclear \\
- Ethnicity: unclear \\
- Comorbidities reported: unclear
\end{tabular}

Interventions

- Sample size: intervention $(n=33)$, control $(n=33)$

- Group or individual intervention: group

- Setting: a deep-water pool frequently used for swimming (water temperature: $28-31^{\circ} \mathrm{C}$; depth: $1.40 \mathrm{~m}$ in the lowest part and $1.80 \mathrm{~m}$ in the deepest part).

- Exercise prescription components: aerobic

- Theoretical basis: none

- CALO-RE taxonomy components: programme set goal, \#9

- Frequency of contact with researcher or exercise professional: initial telephone contact for recruitment with study researchers. Following that they attending the exercise sessions three per week for eight weeks, supervised by two physical therapists.

- Frequency of contact with healthcare professional: after inclusion criteria was met, they had a medical visit. Oncologist recommended a healthy lifestyle to patients as part of usual care.

- Instructions to controls: participants followed usual care recommendations by an oncologist in relation to a healthy lifestyle. Breast cancer survivors received a document printable dossier from the oncologist where they found recommendations related to nutrition, lifestyle behaviours, and exercise. A follow-up of the physical activity during the control period was used to control bias detected in previous studies with exercise in cancer survivors [35,36]. For that purpose, we used the Spanish version of the Minnesota Leisure Time Physical Activity Questionnaire [37]. Control group were offered the intervention after the 8 weeks.

Outcomes

- Change in fitness reported: unclear

- Free-living energy expenditure: assessed by the leisure time physical activity questionnaire.

Process measures

- Method of measuring exercise behaviour: Minnesota Leisure Time Physical Actiivty Questionnaire, adherence to exercise programme and the Borg scale

- Aerobic exercise frequency: three sessions per week for eight weeks.

- Aerobic exercise duration: 60 minutes per session.

- Aerobic exercise intensity: the intensity of the training was established following the recommendations of the American College of Sports Medicine and American Heart Association. Participants used the "Borg Rating of Perceived Exertion Scale" for rating their fatigue during the exercise. Progression in the aerobic training was performed throughout the 8 weeks by gradually increasing the intensity and the duration.

- Description aerobic exercise mode: swimming with use of pool noodles and swimming belts.

- Resistance exercise frequency: N/A

- Resistance exercise sets: N/A

- Resistance exercise repetitions: N/A

- Resistance exercise intensity: N/A

- Description of resistance exercise: N/A

Compliance

- Intervention uptake: 33

- Adherence: a checklist of all sessions was completed by the participants to determine adherence to the water exercise programme. One participant in the WATER programme dropped out due to a recurrence of breast cancer during the programme. All participants within the WATER group completed 
Cantarero-Villanueva 2012b (Continued)

more than $85 \%$ of the 24 water exercise sessions, showing a high adherence rate to the programme. Three women reported a transient increase of oedema, and four women noted an increase in fatigue immediately after the beginning of the first session, which improved in the next few days. These women did not dropout of the study.

- Attrition: 3\% drop out

- Adverse effects: one participant in the WATER programme dropped out due to a recurrence of breast cancer during the programme. All participants within the WATER group completed more than $85 \%$ of the 24 water exercise sessions, showing a high adherence rate to the programme. Three women reported a transient increase of oedema, and four women noted an increase in fatigue immediately after the beginning of the first session, which improved in the next few days. These women did not dropout of the study. No other adverse effects were reported.

- Achieves Rock et al guidelines: yes, aims to achieve 180 minutes of aerobic exercise per week.

Description of usual care

Participants followed usual care recommendations by an oncologist in relation to a healthy lifestyle. Breast cancer survivors received a document printable dossier from the oncologist where they found recommendations related to nutrition, lifestyle behaviours, and exercise. A follow-up of the physical activity during the control period was used to control bias detected in previous studies with exercise in cancer survivors $[35,36]$. For that purpose, we used the Spanish version of the Minnesota Leisure Time Physical Activity Questionnaire [37]. Control group were offered the intervention after the 8 weeks.

Notes

\section{Risk of bias}

\begin{tabular}{lll}
\hline Bias & Authors' judgement & Support for judgement \\
\hline $\begin{array}{ll}\text { Random sequence genera- } \\
\text { tion (selection bias) }\end{array}$ & Low risk & $\begin{array}{l}\text { A randomised, controlled clinical study was conducted. Eligible participants } \\
\text { who agreed to participate were randomly assigned into two groups: WATER } \\
\text { group who received the water exercise programme or CONTROL group who re- } \\
\text { ceived the usual care treatment for breast cancer. }\end{array}$
\end{tabular}

Allocation concealment Low risk
(selection bias)

We allocated patients to WATER or CONTROL groups into two randomisation (selection bias) cycles using a computer-generated numbers. The sequence was entered into numbered opaque envelopes by an external member, and they were opened after completion of the baseline assessment.

\begin{tabular}{|c|c|c|}
\hline $\begin{array}{l}\text { Blinding of outcome as- } \\
\text { sessment (detection bias) }\end{array}$ & Low risk & $\begin{array}{l}\text { Outcome measures were assessed } 1 \text { week before and after the intervention by } \\
\text { an individual blind to group assignment. }\end{array}$ \\
\hline
\end{tabular}
All outcomes

Outcome measures were assessed 1 week before and after the intervention by

\begin{tabular}{lll}
\hline $\begin{array}{l}\text { Incomplete outcome data } \\
\text { (attrition bias) } \\
\text { All outcomes }\end{array}$ & Low risk & All outcome data completed \\
\hline $\begin{array}{l}\text { Selective reporting (re- } \\
\text { porting bias) }\end{array}$ & Low risk & All outcomes reported. \\
\hline Other bias & Low risk & None \\
\hline
\end{tabular}

\section{Cavalheri 2017}

$\begin{array}{ll}\text { Methods } & \text { Study design: RCT individual participant level randomisation } \\ \text { - Study location: Perth, Australia } \\ \text { - Funding source: the study received funding from Sir Charles Gairdner Hospital Research Advisory } \\ \text { Committee (grant number: } 2011 / 12 / 013) .\end{array}$


- Inclusion criteria: measurements were collected in people 6-10 weeks after lobectomy for non-small cell lung cancer (stages I-IIIA) or, for those who required post-operative chemotherapy, 4-8 weeks after their last chemotherapy cycle. Participants were recruited from outpatient clinics and referrals to the pulmonary rehabilitation programs at two hospitals and a private thoracic surgery clinic.

- Exclusion criteria: Exclusion criteria comprised: presence of any comorbid condition that could compromise safety during assessments; severe neuro musculoskeletal limitations; participation in a program of supervised exercise training in the last 3 months; and inability to understand spoken or written English.

- CONSORT diagram included: yes

- Study recruitment rate: $17 / 50$

- Length of follow-up: length of intervention $=8$ weeks, length of follow-up from baseline $=8$ weeks.

\begin{tabular}{ll}
\hline Participants & Primary cancer diagnosis: non-small cell lung cancer \\
- Current cancer treatment: measurements were collected in people $6-10$ weeks after lobectomy for \\
NSCLC (stages I-IIIA) or, for those who required post-operative chemotherapy, 4-8 weeks after their \\
last chemotherapy cycle. \\
- Metastatic disease: unclear \\
- Age, years, mean (SD): intervention = $66(10)$, control = $68(9)$ \\
- Gender: female \\
- BMl: intervention $=25(5)$, control $=27(6)$ \\
- Ethnicity: unclear \\
- Comorbidities reported: unclear
\end{tabular}

Interventions

- Sample size: intervention $(n=9)$, control $(n=8)$

- Group or individual intervention: individual

- Setting: two hospital gyms

- Exercise prescription components: aerobic and resistance exercise

- Theoretical basis: none

- CALO-RE taxonomy components:programme set goal, \#9

- Frequency of contact with researcher or exercise professional: three weekly sessions for eight weeks ran by senior physical therapists. Three assessment points by an independent researcher at baseline, post baseline and 8 weeks.

- Frequency of contact with healthcare professional: patients were recruited from outpatient clinics but it is unclear by whom.

- Instructions to controls: participants in the control group were instructed to continue to perform their usual activities during the period of the study. They received weekly phone calls from a research assistant, which consisted of general conversation as well as standardised questions about their health and well-being. These phone calls allowed the investigators to maintain contact with those in the control group and optimise their retention in the study and also served to minimise bias resulting from differences in attention provided by the investigators to the participants during the intervention period.

Outcomes

- Change in fitness reported: aerobic exercise tolerance was measured using VO2 peak and the sixminute walk test.

- Free-living energy expenditure: yes, this was assessed using a step watch activity monitor.

Process measures

- Method of measuring exercise behaviour: activity monitors and adherence to exercise protocol.

- Aerobic exercise frequency: three times a week for eight weeks.

- Aerobic exercise duration: 60 minutes per session.

- Aerobic exercise intensity: for treadmill walking, the initial average speed was set at $70 \%$ of the average 6MWT speed. Average walking speed was increased if the participant was able to walk for 20 minutes continuously providing symptoms and $\mathrm{O} 2$ were within acceptable limits ( $\geq 88 \%)$. Cycling consisted of 10 minutes of endurance training (initial work rate was set at $60 \%$ of the max achieved during the CPET) and two periods of 2 minutes of power training (initial work rate was set at $80 \%$ of the max achieved during the CPET performed at the baseline assessment).

- Description aerobic exercise mode: walking or cycling

- Resistance exercise frequency: three times a week for eight weeks. 
- Resistance exercise sets: two sets for lower limbs and three sets for upper limb training

- Resistance exercise repetitions: 10 repetitions

- Resistance exercise intensity: lower limbs -In the last session, the number of step ups performed was $69 \pm 46 \%$ greater than in the first session $(P=0.004)$. Upper limbs In the last session, the product of weights lifted, number of sets and number of repetitions during the biceps brachii muscle training was $53 \pm 52 \%$ greater than in the first session $(P=0.02)$. There was no difference in the product of weights lifted, number of sets and number of repetitions during the deltoid muscle training $(P=0.08)$

- Description of resistance exercise: Step ups with parallel bars, hand weights for elbow flexion and shoulder abduction.

- Intervention uptake: 9
- Adherence: Adherence to exercise training was defined as a completion rate of $\geq 60 \%$ of training ses-
sions (i.e., $\geq 15$ training sessions) and reported by the senior physical therapists to the investigators.
Of the nine participants randomised to the EG, four (44\%) adhered to exercise training by completing
15 or more training sessions (i.e., $\geq 60 \%)$.
- Attrition: unclear
- Adverse effects: one participant completed four sessions and another completed six sessions. Both
stopped training as they felt unwell. They completed some of the post-intervention assessments and
were later diagnosed with a primary cancer other than lung cancer.
- Achieves Rock et al guidelines: yes; six weeks of resistance exercise training.

Description of usual care

Participants in the control group were instructed to continue to perform their usual activities during the period of the study. They received weekly phone calls from a research assistant, which consisted of general conversation as well as standardised questions about their health and well-being. These phone calls allowed the investigators to maintain contact with those in the control group and optimise their retention in the study and also served to minimise bias resulting from differences in attention provided by the investigators to the participants during the intervention period.

Notes

\section{Risk of bias}

\begin{tabular}{|c|c|c|}
\hline Bias & Authors' judgement & Support for judgement \\
\hline $\begin{array}{l}\text { Random sequence genera- } \\
\text { tion (selection bias) }\end{array}$ & Low risk & $\begin{array}{l}\text { The randomisation sequence was generated and man-aged by an independent } \\
\text { researcher using a computer. }\end{array}$ \\
\hline $\begin{array}{l}\text { Allocation concealment } \\
\text { (selection bias) }\end{array}$ & Low risk & $\begin{array}{l}\text { concealed using sequentially-numbered opaque envelopes. The sequence was } \\
\text { stratified according to the hospital from which the participant was recruited } \\
\text { and for the use (or not) of adjuvant chemotherapy. }\end{array}$ \\
\hline $\begin{array}{l}\text { Blinding of outcome as- } \\
\text { sessment (detection bias) } \\
\text { All outcomes }\end{array}$ & Low risk & $\begin{array}{l}\text { The primary investigator, who was responsible for the baseline and post-inter- } \\
\text { vention period assessments, was not aware of whether a participant had been } \\
\text { allocated control or intervention. }\end{array}$ \\
\hline $\begin{array}{l}\text { Incomplete outcome data } \\
\text { (attrition bias) } \\
\text { All outcomes }\end{array}$ & High risk & Missing patient data in both arms with reasons not given \\
\hline $\begin{array}{l}\text { Selective reporting (re- } \\
\text { porting bias) }\end{array}$ & Low risk & All outcomes reported. \\
\hline Other bias & High risk & Poor adherence rates $(44 \%)$ \\
\hline
\end{tabular}




\section{Methods}

- Study design: RCT individual participant level randomisation

- Study location (WHO income taxonomy): Sheffield, UK (high)

- Funding source: supported by Grant No. CE8304 from Cancer Research UK

- Inclusion criteria: women who were not regularly active (up to $2 \times 20$-minute sessions a week at moderate intensity (researcher had to gauge with client whether it was moderate intensity - fairly light to somewhat hard) RPE 11 to 13 were used); exercise 'pre-contemplators', 'contemplators' or 'prepares' as defined by the trans theoretical model, who had been treated for localised breast cancer 12 to 36 months previously, were eligible

- Exclusion criteria: women with metastases and inoperable or active locoregional disease were ineligible (clinician determined)

- CONSORT diagram included: yes

- Study recruitment rate: $108 / 273$

- Length of follow-up: length of intervention $=8$ weeks, length of follow-up from baseline $=24$ weeks

- Primary cancer diagnosis: breast cancer survivors without metastases (inoperable or active locoregional disease) were ineligible

- Current cancer treatment: $73.5 \%, 69.4 \%$ and $76.3 \%$ using hormone therapy in the intervention, placebo and usual care groups, respectively

- Metastatic disease: none

- Age, years, mean (SD): 51.6 (8.8); 50.6 (8.7); 51.1 (8.6) (intervention; sham; control, respectively)

- Gender: women

- BMI: mean (SD): 28.5 (4.4); 27.6 (4.1); 29.6 (5.1) (intervention; sham; control, respectively)

- Ethnicity: two of 108 non-white

- Comorbidities reported: 45/108 had lymphoedema

Interventions

- Sample size: intervention ( $n=34)$, sham $(n=36)$ control $(n=38)$

- Group or individual intervention: one-to-one supervised sessions

- Setting: university rehabilitation suite

- Exercise prescription components: aerobic

- Theoretical basis: trans theoretical model

- CALO-RE taxonomy components: \#1, \#5, \#8, \#9, \#10, \#13, \#16, \#17, \#18, \#20, \#21, \#23, \#26, \#29, \#35

- Frequency of contact with researchers or exercise professionals: every exercise session was supervised

- Instructions to controls: the usual-care group continued with their lives as usual. the exercise-placebo group attended 24 one-to-one 50-minute sessions during 8 weeks; however, instead of aerobic exercise, they performed light-intensity body conditioning/stretching (e.g. flexibility, passive stretching) exercises, during which HR was maintained below $40 \%$ heart rate reserve (HR typically was kept below 100 beats per minute). No exercise counselling or behavioural change advice was provided; instead, conversations were entered on topics of everyday life (i.e. weather, news items, and families). HR and RPE were assessed every 5 minutes

- Change in fitness reported: aerobic exercise tolerance was measured using the submaximal, 8-minute, single-stage walking test performed on a treadmill

- Free-living energy expenditure: unclear

Process measures

- Method of measuring exercise behaviour: adherence was calculated from session attendance, and the amount (duration, RPE, HR) of exercise achieved by participants during sessions was calculated by abstraction from physical activity logs maintained by the researcher

- Aerobic exercise frequency: three sessions per week

- Aerobic exercise duration: 27 minutes of exercise on average per session

- Aerobic exercise intensity: $65 \%$ to $85 \%$ of age-adjusted HR maximum and RPE of 12 to 13

- Description aerobic exercise mode: treadmills, rowing ergometers and cycling ergometers

- Resistance exercise frequency: N/A

- Resistance exercise sets: N/A 
Daley 2007a (Continued)

- Resistance exercise repetitions: N/A

- Resistance exercise intensity: N/A

- Description of resistance exercise: N/A

Compliance

- Intervention uptake: $34 / 34$

- Adherence: adherence to the interventions was excellent; $77 \%$ of exercise therapy and $88.9 \%$ of exercise-placebo groups, respectively, attended $70 \%$ (at least 17 of 24 sessions) or more of sessions. Mean HR for the exercise therapy group ranged from 117.4 (SD, 12.9) to 121.5 (SD, 13.4) throughout the weeks. Mean HR for exercise-placebo ranged from 92.5 (SD, 13.2) to 95.9 (SD, 9.5). Average durations of aerobic exercise achieved by exercise therapy ranged from 25.7 (SD, 6.3) to 27.4 (SD, 6.2) minutes. HR data indicated that both groups were exercising in accordance with the protocol

- Attrition: at 8 weeks, 1,0 and 5 women were lost to follow-up in the intervention, sham and control groups, respectively. At 24 weeks, 3, 2 and 7 women were lost to follow-up in the intervention, sham and control groups, respectively

- Adverse effects: three withdrawals in the intervention group: unclear as to why this occurred. Some withdrawals due to medical complications in placebo and control arms, but unclear if study related

- Achieves Rock et al guidelines: no

\begin{tabular}{ll}
\hline Description of usual care & All participants continue to receive usual care from their health team \\
\hline Notes & $\begin{array}{l}\text { Mean and SD data for aerobic exercise tolerance at } 8 \text { and } 24 \text { weeks provided by authors in response to } \\
\text { email request }\end{array}$
\end{tabular}

\section{Risk of bias}

\begin{tabular}{lll}
\hline Bias & Authors' judgement & Support for judgement \\
\hline $\begin{array}{l}\text { Random sequence genera- } \\
\text { tion (selection bias) }\end{array}$ & Low risk & $\begin{array}{l}\text { A telephone randomisation service was provided by an independent studies } \\
\text { unit. Randomisation to the three treatment arms was done on a 1:1:1 ratio and } \\
\text { was performed using stratified random permuted blocks (with block size of } \\
\text { six). Stratification factors were chemotherapy (yes/no) and tamoxifen (yes/no) }\end{array}$ \\
\hline $\begin{array}{l}\text { Allocation concealment } \\
\text { (selection bias) }\end{array}$ & Low risk & $\begin{array}{l}\text { Randomisation service was provided by an independent studies unit tele- } \\
\text { phone service }\end{array}$
\end{tabular}

Blinding of outcome as- High risk Outcome assessors were not blinded to participants' group allocation
sessment (detection bias) All outcomes

$\begin{array}{ll}\begin{array}{l}\text { Incomplete outcome data } \\ \text { (attrition bias) }\end{array} & \text { Low risk } \\ \text { (ittle's } \mathrm{D} \text { test indicated that missing data were missing completely at random } \\ \text { (2 88.2; df } 1290 ; \mathrm{P}=0.99) \text {. Data were analysed on an intention-to-treat basis }\end{array}$

All outcomes (2 88.2; df 1290; $\mathrm{P}=0.99)$. Data were analysed on an intention-to-treat basis

Selective reporting (re- Low risk All outcomes reported
porting bias)

Other bias Low risk None

$\begin{array}{ll}\text { Methods } & \text { Study design: RCT individual participant level randomisation } \\ \text { - Study location (WHO income taxonomy): USA, Michigan (high) } \\ \text { - Funding source: this study was funded by grants from the Elsa U. Pardee Foundation in Midland, Michi- } \\ \text { gan, and the Max and Victoria Dreyfus Foundation in White Plains, New York }\end{array}$


Drouin 2005 (Continued)

- Inclusion criteria: sedentary females (less than 30 minutes of moderate intensity exercise three times per week), between 20 and 65 years of age, with histologically-established Stage 0 (ductal carcinoma in situ) to III breast cancer, with medical clearance and signed informed consent

- Exclusion criteria: uncontrolled cardiac or hypertensive disease, orthopaedic conditions that would limit exercise participation, refusal to accept randomisation or participation in aerobic exercise within three months before the start of the study. Medical clearance for this study was determined by the participant's oncologist, the results of a routine Multiple Uptake Gated Scan (MUGA) of heart function and a symptom limited graded exercise test

- CONSORT diagram included: no

- Study recruitment rate: $23 / 39$

- Length of follow-up: length of intervention $=8$ weeks, length of follow-up from baseline $=8$ weeks

- Primary cancer diagnosis: stage 0 (ductal carcinoma in situ) to III breast cancer
- Current cancer treatment: each participant was undergoing external beam radiation five days per
week for seven weeks. The affected breast and regional lymph nodes received a 4500 to 5000 cGy dose
in 200 cGy fractions with a boost of 1000 to 1600 cGy delivered to the primary tumour bed. Treatment
dosages were similar between groups
- Metastatic disease: no
- Age, years: mean (SD): intervention: 49.4 (7.0), controls: 51.9 (10.0)
- Sex: women
- BMl: unclear
- Ethnicity: 13 African American, 8 Caucasian
- Comorbidities reported: not clear
- Sample size: intervention ( $n=13)$, control ( $n=8)$
- Group or individual intervention: unsupervised-members of the aerobic exercise group were in-
structed to perform self-monitored walking in their neighbourhood or on a treadmill in their home
- Setting: home-based
- Exercise prescription components: aerobic
- Theoretical basis: not stated
- CALO-RE taxonomy components: \#16, \#17, \#21, \#26
- Instructions to controls: participants in the placebo stretching group were instructed to perform a gen-
eral stretching protocol three to five days per week during this same period. However, the control
group was told not to begin any new exercise activity other than a general flexibility programme that
they were given

Outcomes

- Change in fitness reported: $\mathrm{VO}_{2}$ peak assessed before and after intervention

- Free-living energy expenditure: unclear
Process measures
- Method of measuring exercise behaviour: all participants were provided a training diary to record their training adherence in days per week and minutes per day; members of the intervention group also recorded their training heart rate range. The principal investigator communicated with all participants weekly in person or by telephone. Participants in the intervention group wore heart rate monitors to record training time and time spent in the training heart rate range to improve reporting of data on exercise compliance, training intensity and training duration

- Aerobic exercise frequency: three to five times per week

- Aerobic exercise duration: 20 to 45 minutes

- Aerobic exercise intensity: exercise intensity was $50 \%$ to $70 \%$ of the maximal heart rate achieved by the participant during a symptom limited graded exercise test

- Description aerobic exercise mode: self-monitored walking in the neighbourhood or on a treadmill in the home

- Resistance exercise frequency: N/A

- Resistance exercise sets: N/A

- Resistance exercise repetitions: N/A 
Drouin 2005 (Continued)

- Resistance exercise intensity: N/A

- Description of resistance exercise: N/A

\section{Compliance}

- Intervention uptake: $13 / 13$

- Adherence: participants in the intervention group averaged 3.6 days per week of aerobic exercise over an 8-week period, and placebo stretching subjects averaged 3.9 days per week of participation during this same time period. No details are available on what 'participation' for the placebo stretching group constituted

- Attrition: two women were lost to follow-up in the placebo stretching arm. Data from one participant in the placebo stretching group were eliminated from the final analysis because of marked irregularities in pretest and post-test physical measures from moderate to severe fluid retention during the initial test session

- Adverse effects: none reported

- Achieves Rock et al guidelines: unclear

Description of usual care

Each participant was treated with external beam radiation five days per week for seven weeks. The affected breast and regional lymph nodes received a 4500 to 5000 cGy dose in 200c Gy fractions with a boost of 1000 to 1600 cGy delivered to the primary tumour bed. Treatment dosages were similar between groups

Notes

\section{Risk of bias}

\begin{tabular}{lll}
\hline Bias & Authors' judgement & Support for judgement \\
\hline $\begin{array}{l}\text { Random sequence genera- } \\
\text { tion (selection bias) }\end{array}$ & Low risk & A random number table was used \\
\hline $\begin{array}{l}\text { Allocation concealment } \\
\text { (selection bias) }\end{array}$ & Unclear risk & Insufficient information to permit a 'low' or 'high' risk judgement \\
\hline $\begin{array}{l}\text { Blinding of outcome as- } \\
\text { sessment (detection bias) } \\
\text { All outcomes }\end{array}$ & Unclear risk & Insufficient information to permit a 'low' or 'high' risk judgement \\
\hline $\begin{array}{l}\text { Incomplete outcome data } \\
\begin{array}{l}\text { (attrition bias) } \\
\text { All outcomes }\end{array}\end{array}$ & Low risk & 2 of 23 participants lost to follow-up \\
\hline $\begin{array}{l}\text { Selective reporting (re- } \\
\text { porting bias) }\end{array}$ & Low risk & \\
\hline \begin{tabular}{l} 
Other bias \\
\hline
\end{tabular} & Low risk & None \\
\hline
\end{tabular}

Hayes 2009

Methods

- Study design: RCT individual participant level randomisation

- Study location (WHO income taxonomy): Austrailia (high)

- Funding source: National Breast Cancer Foundation for funding Dr. Hayes' fellowship

- Inclusion criteria: women younger than 76 years, who had completed treatment for unilateral breast cancer at least six months before, subsequently had unilateral upper limb lymphoedema diagnosed by a healthcare professional and were prepared to travel to the exercise clinic for 12 weeks (if randomly allocated to the intervention group (IG)) were eligible. All participants were doing $<90$ minutes/week of moderate intensity exercise (intensity was assessed by RPE) 
Hayes 2009 (Continued)

- Exclusion criteria: no other exclusion criteria were applied

- CONSORT diagram included: no

- Study recruitment rate: $32 / 138$

- Length of follow-up: length of intervention = 12 weeks, length of follow-up from baseline $=24$ weeks

\begin{tabular}{ll}
\hline Participants & - Primary cancer diagnosis: unilateral breast cancer \\
- Metastatic disease: no \\
- Age, years: mean (SD): control: 60 (11), intervention 59 (7) \\
- Sex: women \\
- BMl: unclear \\
- Ethnicity: unclear \\
- Comorbidities reported: all had lymphoedema
\end{tabular}

Interventions

- Sample size: intervention ( $n=16)$, control $(n=16)$

- Group or individual intervention: a mix of supervised and non-supervised. Supervised sessions were group based (up to 10 women)

- Weeks 1 to 4: three times per week (two supervised)

- Weeks 5 to 8: four times per week (two supervised)

- Weeks 9 to 12: at least four times per week (one supervised)

- Setting: unclear

- Exercise prescription components

- Weeks 1 to 2: aerobic only (floor-based aerobic exercise to music and walking)

- Weeks 3 to 4: aerobic (floor-based aerobic exercise to music, water-based aerobic exercise and walking) and water-based resistance exercises

- Weeks 5 to 8: aerobic (mix of all types) and water-based and free-weight resistance exercises

- Weeks 9 to 12: aerobic (mix of all types) and machine-weight resistance exercise

- Theoretical basis: not stated

- CALO-RE taxonomy components: \#9, \#26

- Frequency of contact with researchers or exercise professionals: 20 supervised exercise sessions over 12 weeks

- Instructions to controls: the control group was instructed to continue habitual activities

\begin{tabular}{ll}
\hline Outcomes & - Change in fitness reported: none \\
& - Free-living energy expenditure: unclear
\end{tabular}

Process measures

- Method of measuring exercise behaviour: together, exercise adherence rates and qualitative comments were used to provide insight into the acceptability of the programme

- Aerobic exercise frequency: three to four or more times per week

- Aerobic exercise duration: 20 to $45+$ minutes

- Aerobic exercise intensity: 3 to 7 on a modified Borg scale

- Description aerobic exercise mode: floor-based aerobic exercise to music, water-based aerobic exercise and walking

- Resistance exercise frequency: three to four or more times per week

- Resistance exercise sets: unclear

- Resistance exercise repetitions: 20 to 10

- Resistance exercise intensity: approximately 15 to 10 repetition max

- Description of resistance exercise: unclear

\section{Compliance}

- Intervention uptake: $16 / 16$

- Adherence: most women (88\%) allocated to the intervention group participated in $70 \%$ or more of scheduled supervised exercise sessions. The intervention was scheduled over winter, and missed sessions were most often related to respiratory illness $(n=10)$. Other reasons included having a skin le- 
Hayes 2009 (Continued)

sion removed $(n=1)$, undergoing gynaecological surgery $(n=1)$ and having work commitments $(n=$

2). One participant missed $50 \%$ of supervised sessions. Unsupervised exercise adherence is unclear

Qualitative quotes:

- "Without having you to guide me, there is no way I would have ever done the things I've done as part of this program"

- "You gave me the confidence to know what I and my arm can do"

- "I would not have tried the things I've done if not for the study. I now feel capable of joining an aqua class"

- "You've shown me what I can do rather then tell me what I shouldn't do"

- Attrition: one participant in each group at 24 weeks

- Adverse effects: none reported

- Achieves Rock et al guidelines: unclear

Description of usual care Physiotherapy, massage, compression, lymphatic drainage or laser therapy for lymphoedema

Notes Resistance aspect of this intervention will be excluded from analysis because of unclear exercise metrics

\section{Risk of bias}

Bias Authors' judgement Support for judgement

Random sequence genera- Low risk Participants were randomly allocated using a computer-generated table of tion (selection bias) random numbers

Allocation concealment Unclear risk Insufficient information to permit a 'low' or 'high' risk judgement

(selection bias)

\begin{tabular}{lll}
$\begin{array}{l}\text { Blinding of outcome as- } \\
\begin{array}{l}\text { sessment (detection bias) } \\
\text { All outcomes }\end{array}\end{array}$ & Low risk & $\begin{array}{l}\text { All measures were assessed pre-intervention (time 1; T1), immediately postin- } \\
\text { tervention (time 2; } \mathrm{T} 2 \text { ) and at 12-week follow-up (time 3; T3) and were con- } \\
\text { ducted by the same assessor, who was blinded to participant group allocation }\end{array}$ \\
\hline $\begin{array}{l}\text { Incomplete outcome data } \\
\text { (attrition bias) }\end{array}$ & Low risk & $\begin{array}{l}\text { All participants }(\mathrm{n}=32 \text { ) participated in T1 and T2, whereas data were unavail- } \\
\text { able for two participants (one in the IG and one in the CG) at T3. To ensure that } \\
\text { missing data did not contribute to the results found, data analysis was repeat- } \\
\text { ed with these two participants excluded, and no differences in results were ob- } \\
\text { served (data not shown) }\end{array}$
\end{tabular}

Selective reporting (re- Low risk All outcomes reported
porting bias)

Other bias High risk Adherence data on home-based aspect of the intervention not clear

Irwin 2015

- Study design: RCT individual participant level randomisation
- Study location: Yale and Connecticut
- Funding source: National Cancer Insitute
- Inclusion criteria: inclusion criteria required participating in less than 90 minutes/week of physical
activity in the past 6 months and no strength training in the past year. Additionally, participants had
to be experiencing at least mild arthralgias (as defined by a score of 3 out of 10 on the worst pain item
of the Brief Pain Inventory (BPI)) for at least 2 months before enrolment.
- Exclusion criteria: see inclusion criteria.


Irwin 2015 (Continued)

- CONSORT diagram included: yes

- Study recruitment rate: $121 / 1016$

- Length of follow-up: length of intervention = 12 months, length of follow-up from baseline $=12$ months.

\begin{tabular}{ll}
\hline Participants & Primary cancer diagnosis: breast cancer \\
- & Current cancer treatment: chemotherapy, radiotherapy and none. \\
- & Metastatic disease: unclear \\
- & Age, years, mean (SD): intervention $=62.0(7.0)$, control = $60.5(7.0)$. \\
- BMl: intervention $=30.0(6.8)$, control $=28.7(5.5)$ \\
- Ethnicity: intervention $=85 \%$ Non-Hispanic white, $2 \%$ Hispanic, $10 \%$ African American, $2 \%$ Asian $/$ Pa- \\
cific Islander. Control $=84 \%$ Non-Hispanic white, $5 \%$ Hispanic, $7 \%$ African American, $2 \%$ Asian $/$ Pacific \\
Islander, $2 \%$ American Indian. \\
- Comorbidities reported: unclear
\end{tabular}

Interventions

- Sample size: intervention ( $n=61)$, control $(n=60)$

- Group or individual intervention: individual

- Setting: local health club and home-based.

- Exercise prescription components: aerobic and resistance.

- Theoretical basis: none

- CALO-RE taxonomy components: programme set goal, \#9

- Frequency of contact with researcher or exercise professional:

- Frequency of contact with healthcare professional: twice-weekly supervised resistance training programme, supervised by a certified cancer exercise trainer. Assessments were carried out at baseline, 6 months and 12 months

- Instructions to controls: women in the usual care group were instructed to continue with their usual activities. Participants in both groups were provided with a breast cancer specific educational booklet developed for the HOPE study, which discussed topics such as lymphoedema and fatigue. This booklet was individually discussed during the exercise training for the exercise group and in a monthly phone call for the usual care group.

Outcomes

- Change in fitness reported: cardiorespiratory fitness was measured at baseline and at 12 months with a standard maximal oxygen consumption (VO2 max) treadmill test.

- Free-living energy expenditure: measured using a physical activity questionnaire.

Process measures

- Method of measuring exercise behaviour: heart rate monitors, exercise log books and adherence to exercise programme

- Aerobic exercise frequency: twice weekly

- Aerobic exercise duration: 150 minutes per week.

- Aerobic exercise intensity: 50\% HRMax and increased to 60-80\% HRMax

- Description aerobic exercise mode: brisk walking, cycle ergometers and elliptical trainers

- Resistance exercise frequency: twice weekly

- Resistance exercise sets: 3

- Resistance exercise repetitions: 8-12 reps

- Resistance exercise intensity: participants progressed up to three sets per exercise over the first month. After two sessions during which a participant lifted the same weight 12 times during each set, the weight was increased by the smallest possible increment. One rep max was measured at baseline and 12 months.

- Description of resistance exercise: lower and upper body, leg press, leg extension, leg curl, bench press and seated row. *from linked paper, Thomas 2017*

Compliance

- Intervention uptake: 61

- Adherence: women randomly assigned to exercise also reported their exercise prospectively in daily activity logs and reported an average 119 minutes per week of aerobic exercise, with an average of 
Irwin 2015 (Continued)

$70 \%$ of strength-training sessions completed. Women randomly assigned to exercise increased their physical activity by an average 159 minutes per week, compared with 49 minutes per week in the usual-care group. Additionally, $53 \%$ of women adhered to monthly telephone calls.

- Attrition: $88.5 \%$ remained after 6 months, $69 \%$ at 12 months.

- Adverse effects: five participants had to discontinue the use of Atromatise inhibitors

- Achieves Rock et al guidelines: yes, six weeks of resistance exercise.

Description of usual care

Women in the usual care group were instructed to continue with their usual activities. Participants in both groups were provided with a breast cancer specific educational booklet developed for the HOPE study, which discussed topics such as lymphoedema and fatigue. This booklet was individually discussed during the exercise training for the exercise group and in a monthly phone call for the usual care group.

\section{Notes}

\section{Risk of bias}

\begin{tabular}{lll}
\hline Bias & Authors' judgement & Support for judgement \\
\hline $\begin{array}{l}\text { Random sequence genera- } \\
\text { tion (selection bias) }\end{array}$ & Low risk & $\begin{array}{l}\text { Participants were grouped according to the intention-to-treat principle. Per- } \\
\text { muted block randomisation (at 1:1 ratio) with random block size was per- } \\
\text { formed, stratified by joint pain before Al therapy and current bisphosphonate } \\
\text { use (related to our secondary aim of bone mass). }\end{array}$ \\
& &
\end{tabular}

\begin{tabular}{|c|c|c|}
\hline $\begin{array}{l}\text { Allocation concealment } \\
\text { (selection bias) }\end{array}$ & Unclear risk & Insufficient information to permit a 'low' or 'high' risk judgement \\
\hline $\begin{array}{l}\text { Blinding of outcome as- } \\
\text { sessment (detection bias) } \\
\text { All outcomes }\end{array}$ & Unclear risk & Insufficient information to permit a 'low' or 'high' risk judgement \\
\hline $\begin{array}{l}\text { Incomplete outcome data } \\
\text { (attrition bias) } \\
\text { All outcomes }\end{array}$ & Low risk & Balanced across both groups and intention to treat applied to the analysis/ \\
\hline $\begin{array}{l}\text { Selective reporting (re- } \\
\text { porting bias) }\end{array}$ & Low risk & All outcomes reported. \\
\hline Other bias & Low risk & None. \\
\hline
\end{tabular}

\section{Kaltsatou 2011}

\section{Methods}

- Study design: RCT individual participant level randomisation

- Study location (WHO income taxonomy): Greece (high)

- Funding source: unclear

- Inclusion criteria: participating only in the dancing exercising programme; none of the participants had prior physical practise or experience in traditional Greek dances or were participating in regular moderate intensity exercise. All participants had been diagnosed and surgically treated for breast cancer. They had completed cancer therapies, including surgery, radiotherapy and chemotherapy and had stopped all medical treatments at least three months before the beginning of the study (mean time post-treatment: 2.2 years)

- Exclusion criteria: included poorly controlled hypertension and any health condition that would deter the participant from performing the exercises

- CONSORT diagram included: no

- Study recruitment rate: unclear 
- Primary cancer diagnosis: all participants had been diagnosed and surgically treated for breast cancer

- Current cancer treatment: participants had completed cancer therapies, including surgery, radiotherapy and chemotherapy and had stopped all medical treatments at least three months before the beginning of the study (mean time post-treatment: 2.2 years)

- Metastatic disease: unclear

- Age, years: mean (SD): intervention: 56.6 (4.2), control: 57.1 (4.1)

- Sex: women

- BMI: unclear

- Ethnicity: unclear

- Comorbidities reported: unclear

- Sample size: intervention ( $n=14)$, control $(n=13)$

- Group or individual intervention: group

- Setting: supervised

- Exercise prescription components: aerobic training with Greek traditional dances, upper body training and cool-down

- Theoretical basis: not stated

- CALO-RE taxonomy components: \#9, \#21, \#22, \#26

- Frequency of contact with researchers or exercise professionals: three supervised exercise sessions per week

- Instructions to controls: asked to refrain from any form of recreational activity during the study period

Outcomes Change in fitness reported: aerobic exercise tolerance assessed by 6-minute walk test

- Free-living energy expenditure: unclear

Process measures

- Method of measuring exercise behaviour: unclear

- Aerobic exercise frequency: three times per week

- Aerobic exercise duration: the aerobic training phase lasted 25 minutes and included learning and practising Greek traditional dances

- Aerobic exercise intensity: all dances, practised throughout the intervention, were of moderate intensity (between $65 \%$ and $80 \%$ of maximum heart rate). Heart rate was estimated by palpation by participants for four 15-second periods. Participants also rated their perceived exertion on a Borg scale. They were encouraged to reach perceived exertion 13 to 14 on the Borg 6 to 20 category scale. Intensity of exercise was prescribed on an individual basis, and the workload was progressively increased

- Description aerobic exercise mode: Greek traditional dances

- Resistance exercise frequency: three times per week

- Resistance exercise sets: unclear

- Resistance exercise repetitions: unclear

- Resistance exercise intensity: unclear

- Description of resistance exercise: upper body exercise training and cool-down lasted 25 minutes and emphasised stretching and resistance training with the use of various resistance machines

$\begin{array}{ll}\text { Compliance } & \text { - Intervention uptake: unclear } \\ \text { - Adherence: unclear } \\ \text { - Attrition: unclear } \\ \text { - Adverse effects: none reported } \\ \text { - Achieves Rock et al guidelines: unclear }\end{array}$

\footnotetext{
Description of usual care Unclear
} 
Kaltsatou 2011 (Continued)

Risk of bias

\begin{tabular}{|c|c|c|}
\hline Bias & Authors' judgement & Support for judgement \\
\hline $\begin{array}{l}\text { Random sequence genera- } \\
\text { tion (selection bias) }\end{array}$ & Unclear risk & Insufficient information to permit a 'low' or 'high' risk judgement \\
\hline $\begin{array}{l}\text { Allocation concealment } \\
\text { (selection bias) }\end{array}$ & Unclear risk & Insufficient information to permit a 'low' or 'high' risk judgement \\
\hline $\begin{array}{l}\text { Blinding of outcome as- } \\
\text { sessment (detection bias) } \\
\text { All outcomes }\end{array}$ & Unclear risk & Insufficient information to permit a 'low' or 'high' risk judgement \\
\hline $\begin{array}{l}\text { Incomplete outcome data } \\
\text { (attrition bias) } \\
\text { All outcomes }\end{array}$ & Unclear risk & Insufficient information to permit a 'low' or 'high' risk judgement \\
\hline $\begin{array}{l}\text { Selective reporting (re- } \\
\text { porting bias) }\end{array}$ & Low risk & All outcomes reported \\
\hline Other bias & High risk & Method of measuring exercise behaviour and adherence not reported \\
\hline
\end{tabular}

Kim 2006

\begin{tabular}{|c|c|}
\hline Methods & $\begin{array}{l}\text { - Study design: RCT individual participant level randomisation } \\
\text { - Study location (WHO income taxonomy): USA (high) } \\
\text { - Funding source: supported by an R01 grant from the National Institutes of Health, National Institute } \\
\text { of Nursing Research and a Postdoctoral Fellowship Award from the Korea Science and Engineering } \\
\text { Foundation KOSEF). } \\
\text { - Inclusion criteria: women newly diagnosed with breast cancer; no history of cancer; all stages of breast } \\
\text { cancer; age } 40 \text { years and above; and receiving cancer treatment } \\
\text { - Exclusion criteria: women with known bony metastasis; high risk of fracture; known psychiatric illness; } \\
\text { uncontrolled cardiopulmonary or other serious medical condition; and regular exercise at least two } \\
\text { to three times a week of moderate intensity (less than } 90 \text { minutes total) within the past two months } \\
\text { - CONSORT diagram included: no } \\
\text { - Study recruitment rate: unclear } \\
\text { - Length of follow-up: length of intervention = } 8 \text { weeks, length of follow-up from baseline = } 24 \text { weeks }\end{array}$ \\
\hline Participants & $\begin{array}{l}\text { - Primary cancer diagnosis: women with newly diagnosed breast cancer were stratified by the stage of } \\
\text { breast cancer (Stages I to IIB vs locally advanced) } \\
\text { - Current cancer treatment: undergoing treatment-chemotherapy was the most common type of ad- } \\
\text { juvant therapy }(48.8 \%) \text {, followed by radiotherapy }(34.1 \%) \text { and a combination of chemotherapy and } \\
\text { radiotherapy ( } 17.1 \%) \\
\text { - Metastatic disease: none } \\
\text { - Age, years: mean (SD): intervention: } 51.3(6.7) \text {, controls: } 48.3(8.8) \\
\text { - Sex: women } \\
\text { - BMI: unclear; } 33 \text { women who had significantly higher BMI }(34.3 \pm 10.2) \text { excluded from analysis } \\
\text { - Ethnicity: } 78 \% \text { white reported } \\
\text { - Comorbidities reported: unclear }\end{array}$ \\
\hline
\end{tabular}

Interventions

- Sample size: intervention ( $n=22)$, control $(n=19)$

- Group or individual intervention: unclear 
Kim 2006 (Continued)

- Setting: cardiac rehabilitation unit with cardiac monitoring until participants were released to be safe ( for $n=2$ ) and an exercise facility within the School of Nursing. Although most participants continued their exercise intervention in this exercise facility, a few opted to exercise at home on their own treadmill or to do fast walking

- Exercise prescription components: aerobic

- Theoretical basis: not stated

- CALO-RE taxonomy components: \#1, \#21, \#26, \#36

- Frequency of contact with researchers or exercise professionals: supervised exercise sessions three times per week for the 'majority'

- Instructions to controls: Usual care participants were instructed to refrain from starting a regular or structured exercise programme while participating in the study

Outcomes

- Change in fitness reported: changes in $\mathrm{VO}_{2}$ peak at baseline at 8 weeks (although it is not clear how $\mathrm{VO}_{2}$ was measured)

- Free-living energy expenditure: estimate of energy expenditure reported

Process measures

- Method of measuring exercise behaviour: frequency, intensity and duration of exercise during the 8week intervention period were monitored using Polar HR monitors, which were provided to all participants. All participants in both groups received a seven-day physical activity log to track their levels of exercise/physical activity over 16 weeks after the eight-week intervention. The seven-day physical activity log included five categories of the exercise/physical activity level, ranging from vigorous to sleeping/reclining, with explicit examples given for each level, which made monitoring feasible for participants. During 16 weeks of the postintervention follow-up period, the exercise physiologist research member called participants regularly to collect exercise/physical activity data from the log biweekly for participants in the intervention group and monthly for participants in the control group. Participants in the control group received less-frequent calls to minimise unintentional motivation or a reminder for exercise, but data were recorded at 2-week intervals for both groups

- Aerobic exercise frequency: three days per week

- Aerobic exercise duration: 30 minutes of aerobic exercise and 5 minutes for warm-up or cool-down

- Aerobic exercise intensity: moderate intensity to produce an HR corresponding to $60 \%$ to $70 \%$ of the individual's $\mathrm{HR}$ reserve and/or $\mathrm{VO}_{2}$ peak achieved on a graded exercise test at baseline

- Description aerobic exercise mode: cycling, walking, jogging or running on a treadmill or track

- Resistance exercise frequency: N/A

- Resistance exercise sets: N/A

- Resistance exercise repetitions: N/A

- Resistance exercise intensity: N/A

- Description of resistance exercise: N/A

- Intervention uptake: not clear

- Adherence: average weekly frequency of exercise was $2.4 \pm 0.6$ sessions, and average duration of exercise was $42.7 \pm 8.0$ minutes per session, including warm-up and cool-down periods. Average duration of exercise within prescribed target HRs was $27.8 \pm 8.1$ minutes per session. Overall adherence to exercise intervention was $78.3 \% \pm 20.1 \%$, but week-to-week variations over the 8 -week intervention period ranged from $68.3 \%$ at week 7 to $95.0 \%$ at week 3

- Attrition: of 74 women recruited, 11 women ( 6 control, 5 intervention) withdrew from the study. Reasons for withdrawal included personal problems $(n=2)$, problems at home $(n=2)$, problems related to chemotherapy $(n=3)$, thrombophlebitis in the lower leg $(n=2)$, non-exercise-related injuries ( $n$ $=1$ ) and death $(n=1)$. Twenty-two women (12 control and 10 intervention) missed either a pre-intervention or a postintervention graded exercise test (GXT), mainly because of scheduling conflicts, not keeping GXT appointments more than twice or unwillingness to perform the GXT. Forty-one women completed both pre-intervention and postintervention GXTs (i.e. 41/74)

- Adverse effects: see above

- Achieves Rock et al guidelines: no

Description of usual care

Usual cancer care included general information on the benefits of exercise but did not include specific instructions or further guidance for exercise. Seventy-eight per cent of women had Stage I and Stage 
Kim 2006 (Continued)

II breast cancer, and chemotherapy was the most common type of adjuvant therapy (48.8\%), followed by radiotherapy $(34.1 \%)$ and a combination of chemotherapy and radiotherapy (17.1\%). Regimens of adjuvant therapy most often consisted of Adriamycin $60 \mathrm{mg} / \mathrm{m}^{2}$ and cytoxan $600 \mathrm{mg} / \mathrm{m}^{2}$ every 2 to 3 weeks for 3 doses with or without Taxol $145 \mathrm{mg} / \mathrm{m}^{2}$ every 2 to 3 weeks for 3 to 4 doses. Radiotherapy was typically composed of delivering a total of 45 to 65 Gy over 6 to 7 weeks with booster doses of 20 Gy

Notes

\section{Risk of bias}

\begin{tabular}{lll}
\hline Bias & Authors' judgement & Support for judgement \\
\hline $\begin{array}{l}\text { Random sequence genera- } \\
\text { tion (selection bias) }\end{array}$ & Low risk & Computer-generated randomisation \\
\hline $\begin{array}{l}\text { Allocation concealment } \\
\text { (selection bias) }\end{array}$ & Unclear risk & Insufficient information to permit a 'low' or 'high' risk judgement \\
\hline $\begin{array}{l}\text { Blinding of outcome as- } \\
\text { sessment (detection bias) } \\
\text { All outcomes }\end{array}$ & Unclear risk & Insufficient information to permit a 'low' or 'high' risk judgement \\
\hline $\begin{array}{l}\text { Incomplete outcome data } \\
\text { (attrition bias) }\end{array}$ & High risk & Data on only 41 of 74 randomly assigned participants reported \\
\hline $\begin{array}{l}\text { Selective reporting (re- } \\
\text { porting bias) }\end{array}$ & Low risk & All outcomes reported \\
\hline $\begin{array}{l}\text { Other bias } \\
\text { High risk }\end{array}$ & $\begin{array}{l}\text { Women randomly assigned but excluded had higher BMI and more advanced } \\
\text { stages of cancer }\end{array}$ \\
\hline
\end{tabular}

Kim 2017

\begin{tabular}{|c|c|}
\hline Methods & $\begin{array}{l}\text { - Study design: RCT individual participant level randomisation } \\
\text { - Study location: Central Korea } \\
\text { - Funding source: no funding } \\
\text { - Inclusion criteria: participants were eligible to participate in this study if they met the following cri- } \\
\text { teria, with medical clearance from their oncologist: (1) diagnosed with stage I } \pm \text { III breast cancer, }(2) \\
6 \text { months after treatments with radio- and/or chemotherapy subsequent to surgery, (3) absence of } \\
\text { metastatic diseases and other cancers, }(4)<60 \text { minutes per week of physical activity including resis- } \\
\text { tance exercise in the past } 6 \text { months, }(5) \text { absence of cardiovascular and respiratory diseases, and (6) } \\
\text { no contraindicated medications and co morbidities that prohibit participation in a moderate exercise } \\
\text { programme. } \\
\text { - Exclusion criteria: history of chronic disease including diabetes, uncontrolled hypertension or thyroid } \\
\text { disease, Weight reduction >= } 10 \% \text { within past } 6 \text { months, Metastatic disease, Participate in more than } \\
60 \text { minutes of exercise per week in the past } 6 \text { months, Cardiovascular, respiratory or musculoskeletal } \\
\text { disease or joint problems that preclude moderate physical activity } \\
\text { - CONSORT diagram included: yes } \\
\text { - Study recruitment rate: unclear } \\
\text { - Length of follow-up: length of intervention = } 12 \text { weeks, length of follow-up from baseline = } 12 \text { weeks. }\end{array}$ \\
\hline Participants & $\begin{array}{l}\text { - Primary cancer diagnosis: breast cancer } \\
\text { - Current cancer treatment: none }\end{array}$ \\
\hline
\end{tabular}


Kim 2017 (Continued)

- Metastatic disease: none

- Age, years, mean (SD): intervention $=56.0$ (6.5), control = $49.3(4.8)$

- Gender: female

- BMI: intervention = 23.9 (2.7), control $=25.0$ (4.7)

- Ethnicity: unclear

- Comorbidities reported: unclear

- Sample size: intervention $(\mathrm{n}=15)$, control $(\mathrm{n}=15)$
- Group or individual intervention: unclear
- Setting: unclear
- Theorcise prescription components: aerobic and resistance
- CALO-RE taxonomy components: programme set goal, \#9
- Frequency of contact with researcher or exercise professional: baseline and follow-up assessments
by research staff. 180 minutes per week of supervision from (3 sessions) exercise trainer
- Frequency of contact with healthcare professional: medical clearance from oncologist before taking
part in trial.
Instructions to controls: instructed to maintain their routine physical activities and not to participate
any new exercise programmes during 12 weeks. After the final assessments, they had the option of
participation.

\section{Outcomes}

- Change in fitness reported: unclear

- Free-living energy expenditure: unclear

- Method of measuring exercise behaviour: adherence to exercise protocol and health-related fitness tests.

- Aerobic exercise frequency: three supervised sessions per week

- Aerobic exercise duration: 20 minutes per session.

- Aerobic exercise intensity: RPE range 11-13, that was gradually increased at 4-week intervals until reaching a rate of $13-15$.

- Description aerobic exercise mode: step aerobics on $17 \mathrm{~cm}$ platforms for 20 minutes

- Resistance exercise frequency: three supervised sessions per week.

- Resistance exercise sets: 20 minutes per session.

- Resistance exercise repetitions: the strength training was designed to begin with one set for the first two weeks, and the set number was increased every two weeks to finally achieve three sets of each exercise performing 12-16 repetitions to volitional fatigue per set.

- Resistance exercise intensity: volitional fatigue per set. The exercise intensity and the resistance of elastic band were progressively increased to maintain this range of repetition.

- Description of resistance exercise: the strength training using body weight and elastic bands consisting of shoulder press, black burn exercise, wall push-up, biceps curl-up, plank exercise, leg bridge, squat, and calf raise for 20 minutes.

- Intervention uptake: $85.7 \%$

- Adherence: two participants did not fulfil the required exercise

- Attrition: $7.23 \%$

- Adverse effects: unclear

- Achieves Rock et al guidelines: yes, six weeks of resistance exercise training

Description of usual care Instructured to maintain their routine physical activities and not to participate any new exercise programmes during 12 weeks. After the final assessments, they had the option of participation.

\section{Notes}

\section{Risk of bias}


Kim 2017 (Continued)

\section{Bias Authors' judgement Support for judgement}

Random sequence genera- Low risk tion (selection bias)

Allocation concealment $\quad$ Low risk
(selection bias)
(selection bias)

Blinding of outcome as- Low risk sessment (detection bias)

All outcomes

\begin{tabular}{lll}
\hline $\begin{array}{l}\text { Incomplete outcome data } \\
\text { (attrition bias) } \\
\text { All outcomes }\end{array}$ & Low risk & $\begin{array}{l}\text { Dropouts similar in both groups and reasons given. Reasons given for lack of } \\
\text { inclusion in final analysis. }\end{array}$ \\
\hline $\begin{array}{l}\text { Selective reporting (re- } \\
\text { porting bias) }\end{array}$ & Low risk & All outcomes reported. \\
\hline Other bias & High risk & $\begin{array}{l}\text { Age differences between groups in baseline demographics were present. Ad- } \\
\text { herence data is vague. }\end{array}$ \\
\hline
\end{tabular}

Following baseline assessments, 30 participants were randomly assigned to either an exercise intervention group or a control group using a sealed, computer random number generator with an allocation ratio of 1 to 1

Following baseline assessments, 30 participants were randomly assigned to either an exercise intervention group or a control group using a sealed, computer random number generator with an allocation ratio of 1 to 1

Four research staff members who were unaware of group assignment performed all outcome assessments

\section{McKenzie 2003}

\begin{tabular}{|c|c|}
\hline Methods & $\begin{array}{l}\text { - Study design: RCT individual participant level randomisation } \\
\text { - Study location (WHO income taxonomy): Canada (high) } \\
\text { - Funding source: supported by the Canadian Breast Cancer Research Initiative } \\
\text { - Inclusion criteria: participants were eligible for the study if they had undergone breast cancer treat- } \\
\text { ment for Stage I or II breast cancer that had been completed more than six months before enrolling in } \\
\text { the study and had subsequently developed unilateral lymphoedema that was greater than } 2 \mathrm{~cm} \text { and } \\
\text { less than } 8 \mathrm{~cm} \text { on at least one measurement point. Participants were not participating in }>90 \text { minutes } \\
\text { per week of moderate intensity exercise } \\
\text { - Exclusion criteria: stage III lymphoedema, bilateral disease or cases for which medication was re- } \\
\text { - quired that might affect upper extremity swelling } \\
\text { - NonSORT diagram included: no } \\
\text { - Study recruitment rate: unclear } \\
\text { - Length of follow-up: length of intervention }=8 \text { weeks, length of follow-up from baseline }=8 \text { weeks }\end{array}$ \\
\hline Participants & $\begin{array}{l}\text { - Primary cancer diagnosis: stage I or II breast cancer } \\
\text { - Current cancer treatment: all completed treatment six months before starting the study } \\
\text { - Metastatic disease: no } \\
\text { - Age, years: mean (SD): intervention: } 56.4 \text { (10.4), control: } 56.9(8.2) \\
\text { - Sex: women } \\
\text { - BMI: mean (SD): intervention: } 29.1(6.6), \text { control: } 25.6(3.3) \\
\text { - Ethnicity: unclear } \\
\text { - Comorbidities reported: unclear }\end{array}$ \\
\hline Interventions & $\begin{array}{l}\text { - Sample size: intervention }(n=7) \text {, control }(n=7) \\
\text { - Group or individual intervention: unclear } \\
\text { - Setting: supervised }\end{array}$ \\
\hline
\end{tabular}


McKenzie 2003 (Continued)

- Exercise prescription components: aerobic and resistance

- Theoretical basis: not stated

- CALO-RE taxonomy components: \#9, \#26

- Frequency of contact with researchers or exercise professionals: supervised exercise sessions three times per week

- Instructions to controls: Control participants were given no specific exercise instruction until after they completed the study but were specifically asked to refrain from initiating any new activity

\begin{tabular}{|c|c|}
\hline Outcomes & $\begin{array}{l}\text { - Change in fitness reported: no } \\
\text { - Free-living energy expenditure: unclear }\end{array}$ \\
\hline Process measures & $\begin{array}{l}\text { - Method of measuring exercise behaviour: work in kilo joules was calculated for each session for every } \\
\text { participant, and this was used to calculate cumulative work done over the course of the programme } \\
\text { - Aerobic exercise frequency: three days per week (initiated after week } 2 \text { ) } \\
\text { - Aerobic exercise duration: } 5 \text { to } 20 \text { minutes } \\
\text { - Aerobic exercise intensity: arm cycling at a resistance of } 8.3 \mathrm{~W} \text { to } 25 \mathrm{~W} \text {. Intensity was also assessed } \\
\text { with Polar HR monitors. Target HR was } 60 \% \text { to } 80 \% \text { of maximum predicted by age } \\
\text { - Description aerobic exercise mode: arm cycling } \\
\text { - Resistance exercise frequency: three days per week } \\
\text { - Resistance exercise sets: two sets of } 10 \text { repetitions for each exercise were done for the first week, three } \\
\text { - } \text { Rets of } 10 \text { were done thereafter } \\
\text { - Resistance exercise repetitions: see above } \\
\text { - Description of resistance exercise: seated row, bench press, latissimus dorsi pull-down, one arm bent- } \\
\text { over rowing, triceps extension, and biceps curl }\end{array}$ \\
\hline
\end{tabular}

$\begin{array}{ll}\text { Compliance } & \text { - Intervention uptake: unclear } \\ \text { - Adherence: unclear } \\ \text { - Attrition: no attrition reported } \\ \text { - Adverse effects: none reported } \\ \text { - Achieves Rock et al guidelines: no }\end{array}$

\begin{tabular}{ll}
\hline Description of usual care & Unclear \\
\hline Notes & $\begin{array}{l}\text { Resistance aspect of this intervention will be excluded from analysis because of unclear exercise met- } \\
\text { rics }\end{array}$ \\
\hline
\end{tabular}

\section{Risk of bias}

\begin{tabular}{lll}
\hline Bias & Authors' judgement & Support for judgement \\
\hline $\begin{array}{l}\text { Random sequence genera- } \\
\text { tion (selection bias) }\end{array}$ & Unclear risk & Insufficient information to permit a 'low' or 'high' risk judgement \\
\hline $\begin{array}{l}\text { Allocation concealment } \\
\text { (selection bias) }\end{array}$ & Unclear risk & Insufficient information to permit a 'low' or 'high' risk judgement \\
\hline $\begin{array}{l}\text { Blinding of outcome as- } \\
\text { sessment (detection bias) } \\
\text { All outcomes }\end{array}$ & Unclear risk & Insufficient information to permit a 'low' or 'high' risk judgement \\
\hline $\begin{array}{l}\text { Incomplete outcome data } \\
\text { (attrition bias) } \\
\text { All outcomes }\end{array}$ & Unclear risk & Insufficient information to permit a 'low' or 'high' risk judgement \\
\hline
\end{tabular}


McKenzie 2003 (Continued)

Selective reporting (re- Low risk $\quad$ All outcomes reported
porting bias)

Other bias High risk Adherence to prescribed exercise not reported

\section{Mohamady 2017}

\begin{tabular}{|c|c|}
\hline Methods & $\begin{array}{l}\text { - Study design: RCT individual participant level randomisation } \\
\text { - Study location: Cairo University } \\
\text { - Funding source: unclear } \\
\text { - Inclusion criteria: patients were selected to be enrolled into this study after they had fulfilled the in- } \\
\text { clusion criteria of the study; female patients with breast cancer undergoing chemotherapy, they were } \\
\text { medically stable and not receiving Erythropoietin therapy, their BMI ranged from } 30 \text { to } 35 \text {, and they } \\
\text { had an inactive lifestyle for at least the previous } 6 \text { months. } \\
\text { - Exclusion criteria: BMI more than } 35 \text {, age older than } 70 \text { or younger than } 60 \text { years. Patients who received } \\
\text { erythropoietin treatments, suffered uncorrected visual problems, had scars under their feet, and had } \\
\text { a history of serious cerebrovascular or cardiovascular diseases, or severe musculoskeletal problems } \\
\text { restricting physical activity. } \\
\text { - CONSORT diagram included: no } \\
\text { - Study recruitment rate: unclear } \\
\text { - Length of follow-up: length of intervention = } 12 \text { weeks, length of follow-up from baseline = } 12 \text { weeks. }\end{array}$ \\
\hline Participants & $\begin{array}{l}\text { - Primary cancer diagnosis: breast cancer } \\
\text { - Current cancer treatment: chemotherapy } \\
\text { - Metastatic disease: unclear } \\
\text { - Age, years, mean (SD): intervention = } 54.6(4.23) \text {, control = } 58.25 \text { (2.65) } \\
\text { - Gender: female } \\
\text { - BMI: intervention = } 34.7(3.44) \text {, control = } 35.2(3.36) \\
\text { - Ethnicity: unclear } \\
\text { - Comorbidities reported: unclear }\end{array}$ \\
\hline
\end{tabular}

Interventions

- Sample size: intervention $(n=15)$, control $(n=15)$

- Group or individual intervention: unclear

- Setting: lab

- Exercise prescription components: aerobic

- Theoretical basis: none

- CALO-RE taxonomy components: programme set goal, \#9

- Frequency of contact with researcher or exercise professional: initial assessment before baseline with oncologist. Assessments at baseline and 12 weeks. 3 times per week for 25 to 40 minutes at exercise sessions.

- Frequency of contact with healthcare professional: initial assessment before baseline assessment with oncologist.

- Instructions to controls: the control group, who performed the usual daily living activities in addition to administration of their medication and nutritional support.

$\begin{array}{ll}\text { Outcomes } & \text { - Change in fitness reported: none reported } \\ & \text { - Free-living energy expenditure: none reported }\end{array}$

Process measures

- Method of measuring exercise behaviour: heart rate monitor

- Aerobic exercise frequency: three sessions per week for 12 weeks

- Aerobic exercise duration: 3 25-40 minute sessions per week 
- Aerobic exercise intensity: $50 \%$ to $70 \%$ Maximal HR. Aerobic exercise intensity was determined using the Karvonen formula in which Target Heart Rate $=\left[\left(\operatorname{max~HR} \_\right.\right.$resting HR ${ }_{-} \%$ intensity $]+$ resting HR, where maximum heart rate $=220$-age .

- Description aerobic exercise mode: treadmill

- Resistance exercise frequency: $\mathrm{N} / \mathrm{A}$

- Resistance exercise sets:N/A

- Resistance exercise repetitions:N/A

- Resistance exercise intensity:N/A

- Description of resistance exercise:N/A

$\begin{array}{ll}\text { Compliance } & \text { - Intervention uptake: unclear } \\ \text { - Adherence: unclear } \\ \text { - Attrition: unclear } \\ \text { - Adverse effects: unclear } \\ \text { - Achieves Rock et al guidelines: unclear }\end{array}$

Description of usual care

The control group, who performed the usual daily living activities in addition to administration of their medication and nutritional support.

Notes

\section{Risk of bias}

\begin{tabular}{|c|c|c|}
\hline Bias & Authors' judgement & Support for judgement \\
\hline $\begin{array}{l}\text { Random sequence genera- } \\
\text { tion (selection bias) }\end{array}$ & Low risk & $\begin{array}{l}\text { Randomisation was done via random number generator and opening opaque } \\
\text { envelopes prepared by an independent individual. }\end{array}$ \\
\hline $\begin{array}{l}\text { Allocation concealment } \\
\text { (selection bias) }\end{array}$ & Low risk & $\begin{array}{l}\text { Randomisation was done via random number generator and opening opaque } \\
\text { envelopes prepared by an independent individual. }\end{array}$ \\
\hline $\begin{array}{l}\text { Blinding of outcome as- } \\
\text { sessment (detection bias) } \\
\text { All outcomes }\end{array}$ & Unclear risk & Insufficient information to permit a 'low' or 'high' risk judgement. \\
\hline $\begin{array}{l}\text { Incomplete outcome data } \\
\text { (attrition bias) } \\
\text { All outcomes }\end{array}$ & Unclear risk & Insufficient information to permit a 'low' or 'high' risk judgement. \\
\hline $\begin{array}{l}\text { Selective reporting (re- } \\
\text { porting bias) }\end{array}$ & Low risk & Reported on all outcomes. \\
\hline Other bias & High risk & No adherence data. \\
\hline
\end{tabular}

\section{Musanti 2012}

\section{Methods}

- Study design: RCT individual participant level randomisation

- Study location (WHO income taxonomy): New Jersey, USA (high)

- Funding source: supported by an award from the Greater NYC Affiliate of the Susan G. Komen Breast Cancer Foundation, Inc., New York, NY

- Inclusion criteria: eligible survivors were English-speaking women diagnosed with Stage I to IIIB breast cancer who had completed adjuvant chemotherapy at least three months or radiation therapy at least 6 weeks before entry, and who were no more than 24 months beyond their last treatment. Hormonal therapy could be ongoing 
- Exclusion criteria: women were excluded if medical history or physical examination revealed evidence of anaemia (haemoglobin $<10 \mathrm{mg} / \mathrm{dL}$ ), uncontrolled hypertension, congestive heart failure, pulmonary disease, diabetes and thyroid or musculoskeletal disease. Additional exclusion criteria included current enrolment in a weight loss or exercise programme or a positive response to any question on the Physical Activity Readiness Questionnaire, thus indicating the need for medical clearance before starting an exercise programme

- CONSORT diagram included: no

- Study recruitment rate: $55 / 231$

- Length of follow-up: length of intervention $=12$ weeks, length of follow-up from baseline $=12$ weeks

Participants

- Primary cancer diagnosis: completed adjuvant chemotherapy at least three months or radiation therapy at least six weeks before entry and were no more than 24 months beyond their last treatment

- Current cancer treatment: hormonal therapy could be ongoing: $56 \%$ on hormone therapy

- Metastatic disease: none

- Age: overall mean $(\mathrm{SD})=50.5(7.5)$

- Sex: women

- BMI: unclear

- Ethnicity: unclear

- Comorbidities reported: unclear

- Sample size: flexibility group $(n=13)$, aerobic group $(n=12)$, resistance group $(n=17)$, aerobic and resistance group $(n=13)$.

- Group or supervised intervention: individual

- Setting: home-based

- Exercise prescription components: aerobic and resistance exercise

- Theoretical basis: exercise and self-esteem model

- CALO-RE taxonomy components: \#9, \#16, \#17, \#21, \#22, \#26

- Frequency of contact with researchers or exercise professionals: weekly contact via phone or e-mail. Content included exercise programme adherence, the need for progression of the exercise prescription and adverse effect reporting

- Instructions to controls: all participants were prescribed flexibility exercise. In-person verbal instruction plus demonstration was used to teach participants how to do their assigned exercises. In addition, each participant received a written guidebook that included general information about exercise participation, such as clothing and safety tips, as well as their individualised exercise prescription, exercise instructions and an exercise log sheet

Outcomes

- Change in fitness reported: prediction of $\mathrm{VO}_{2}$ max from submaximal treadmill testing using the Bruce protocol; change in upper body weight lifted and endurance reported

- Free-living energy expenditure: unclear

Process measures

- Method of measuring exercise behaviour: Adherence to the exercise prescription was calculated as a proportion of completed sessions over the total possible number of sessions in the assigned exercise programme. Mean percentage scores were as follows: flexibility $=85$, aerobic $=81$, resistance $=91$ and aerobic plus resistance $=86$. Although participants were encouraged to complete their exercise log, only $50 \%$ of participants successfully did so

- Aerobic exercise frequency: three times per week. Women who participated in the aerobic and resistance group followed instructions similar to those given to the aerobic and resistance only groups; however, the frequency of aerobic exercise progressed to four to five days per week, and resistance was maintained at two times per week

- Aerobic exercise duration: 15 to 30 minutes

- Aerobic exercise intensity: $40 \%$ to $65 \%$ of the calculated heart rate max

- Description aerobic exercise mode: walking

- Resistance exercise frequency: times per week. A+R group performed resistance exercise twice per week

- Resistance exercise sets: one 
Musanti 2012 (Continued)

- Resistance exercise repetitions: women started with one set of 10 to 12 repetitions. Progression through more resistive bands occurred so that RPE rose to around seven to eight at the completion of 12 repetitions

- Resistance exercise intensity: women in the resistance group were prescribed a Thera-Band that produced an RPE of 3 to 5 on a scale of 0 to 10. Progression through more resistive bands occurred so that RPE rose to around seven to eight at the completion of 12 repetitions

- Description of resistance exercise: Women started with one set of 10 to 12 repetitions of the following exercises: shoulder flexion, shoulder press, latissimus pull-down, seated row, chest press, elbow press (triceps), elbow curl (biceps), hip flexion, hip extension, abdominal crunches, leg press and squat

\section{Compliance}

- Intervention uptake: 13/13,12/12,17/17,13/13 for flexibility, aerobic, resistance and combined groups, respectively

- Adherence: adherence to the exercise prescription was calculated as a proportion of completed sessions over the total possible number of sessions in the assigned exercise programme. Mean percentage scores were as follows: flexibility $=85$, aerobic $=81$, resistance $=91$ and aerobic plus resistance $=$ 86 . Although participants were encouraged to complete their exercise log, only $50 \%$ successfully did so

- Attrition: 42/55. Forty-two women completed the study; however, five of these women returned the survey data form but refused final fitness testing because of time constraints related to work and family obligations. Thirteen women (24\%) did not complete their assigned 12 -week programme. All dropped out by week 6 , except one woman, who developed appendicitis after the 12-week exercise programme but before she could complete the postintervention testing. No post study assessments were obtained from these women. The most frequently cited reason given for discontinuing the exercise programme was perceived difficulty fitting the exercise into their lives because of work and/ or family responsibilities (seven women). One woman had her breast reconstruction surgery rescheduled so that completion became impossible, one did not give a reason, and one could not complete the initial fitness testing because of an elevated HR. Two women cited the need for additional supervised exercise sessions because they could not maintain motivation on their own

- Adverse effects: adverse effects were reported in two women during the study. In both cases, the women developed tendonitis: one in the shoulder and the other in the foot. Both had a history of tendonitis, and both received standard treatment (i.e. rest, anti-inflammatory medication, and gentle movement). Both women resumed exercise at a lesser intensity, progressed their exercise over time and completed the study without further incident

- Achieves Rock et al guidelines: 12 weeks of resistance exercise at two or three times per week. Aerobic prescription: unclear

\section{Risk of bias}

\begin{tabular}{lll}
\hline Bias & Authors' judgement & Support for judgement \\
\hline $\begin{array}{l}\text { Random sequence genera- } \\
\text { tion (selection bias) }\end{array}$ & Low risk & Computer-generated randomisation table \\
\hline $\begin{array}{l}\text { Allocation concealment } \\
\text { (selection bias) }\end{array}$ & Low risk & $\begin{array}{l}\text { Computer-generated randomisation table maintained by office staff in the } \\
\text { clinical research office }\end{array}$ \\
\hline $\begin{array}{l}\text { Blinding of outcome as- } \\
\text { sessment (detection bias) } \\
\text { All outcomes }\end{array}$ & Low risk & $\begin{array}{l}\text { Physical fitness testing was performed at a hospital-based fitness centre. The } \\
\text { same research assistant, blinded to participant group allocation, performed } \\
\text { these measurements at pre-intervention and postintervention measurement } \\
\text { time points }\end{array}$ \\
\hline
\end{tabular}

Incomplete outcome data High risk
(attrition bias)


Musanti 2012 (Continued)

Selective reporting (re- High risk Waist, upper and mid and lower arm circumference measures not reported porting bias)

Other bias

High risk
- A significant number of the dropouts belonged to the resistance exercise group $(n=8 / 13)$. These women did not verbalise any discontent with this specific modality of exercise; their reasons for dropping out were as previously described. Of note, these women had significantly stronger muscular endurance measurements than were reported in the non-dropout group

- Second, significant differences were noted in baseline levels of fatigue $(P=$ $0.003)$, with the dropout group perceiving a greater level of fatigue. Baseline leisure time activity was also markedly different. Women in the completion group reported a significantly greater weekly volume of low to moderate physical activity. In the dropout group, however, scores ranged from 0 to 12 , indicating very little general activity

- Only $50 \%$ of activity logs were returned

Perna 2010

- Study design: RCT individual participant level randomisation

- Study location (WHO income taxonomy): Maryland, USA (high)

- Funding source: funded by the National Cancer Institute (CA R01-78801)

- Inclusion criteria: (a) English speaking, (b) between 21 and 75 years of age, (c) sedentary lifestyle (i.e. exercise fewer than three times per week for greater than 30 minutes/session, at a moderate intensity, in last six months), (d) average or below average fitness as determined by a graded exercise test (GXT) and (e) recent diagnosis of breast cancer (Stage $0, \mathrm{I}, \mathrm{II}$ or IIIa)

- Exclusion criteria: (a) non - cancer-related contraindications to aerobic walking exercise (e.g. symptomatic coronary artery disease, psychotic spectrum mental illness, orthopaedic problems), (b) preexisting metabolic disease (e.g. diabetes, uncontrolled hypertension) and (c) a contraindication to exercise discovered on the exercise stress test

- CONSORT diagram included: no

- Study recruitment rate: $51 / 57$

- Length of follow-up: length of intervention $=3$ months, length of follow-up from baseline $=3$ months

Participants

- Primary cancer diagnosis: breast cancer (Stage 0, I, II or IIIa)

- Current cancer treatment: most (52.9\%) women had Stage I breast cancer and underwent lumpectomy surgery (74.1\%). Many (44.1\%) women received both radiation and chemotherapy, $26.5 \%$ received radiation only, $8.8 \%$ received chemotherapy only and $20.6 \%$ received no adjuvant therapy

- Metastatic disease: none

- Age, years: overall mean $(S D)=50.8(11.8)$

- Sex: female

- BMI: overall mean (SD): 28.8 (6.1)

- Ethnicity: a large percentage of women were black (44.1\%), and total ethnic minority group membership was high $(45.1 \%)$

- Comorbidities reported: $23.5 \%$ of women had CESD depression scores above the clinical cut-off

- Sample size: intervention ( $\mathrm{n}=51$ in total), numbers randomly assigned to each arm are unclear

- Group or supervised intervention: unclear

- Setting: supervised hospital-based and subsequently home-based intervention

- Exercise prescription components: aerobic and resistance

- Theoretical basis: trans theoretical model

- CALO-RE taxonomy components: \#1, \#5, \#8, \#9, \#10, \#12, \#15, \#16, \#19, \#20, \#21, \#22, \#23, \#24, \#25, \#26, \#29, \#35 
- Frequency of contact with researchers or exercise professionals: supervised exercise sessions three times a week for 4 weeks during hospital phase. Thereafter, intervention participants received weekly contact by telephone or electronic mail according to participant preference

- Instructions to controls: women in the information control group received a 45-minute session covering their fitness, strength and flexibility assessment results and an informational brochure. The session specifically excluded discussion of strategies addressing exercise barriers, and participants who asked about exercise were told to "do the best you can". To facilitate participant retention, the control group was contacted once per month, and one week before follow-up assessment, they were given a pedometer for data collection purposes (Note: Pedometer data were not part of the article)

Outcomes

- Change in fitness reported: no

- Free-living energy expenditure: unclear

Process measures

- Method of measuring exercise behaviour: participants were provided with monthly calendars to record their exercise activity and were contacted weekly by telephone or electronic mail according to their preference. Godin Leisure Time Exercise Questionnaire and the LTEQ self-report instrument surveys were also used

- Aerobic exercise frequency

- Hospital-based phase (first 4 weeks): three times per week

- Home-based phase: at least three days per week

- Aerobic exercise duration

- Hospital-based phase (first 4 weeks): 15 to 45 minutes

- Home-based phase: 30 minutes or longer

- Aerobic exercise intensity

- Hospital-based phase: $50 \%$ to $85 \%$ max HR

- Home-based phase: moderate intensity, RPE 11 to 16

- Description aerobic exercise mode: home or treadmill walking

- Resistance exercise frequency

- Hospital-based phase: three per week

- Home-based phase: participants were asked to continue resistance training three times a week

- Resistance exercise sets

- Hospital-based phase: 1 to 2 sets

- Home-based phase: maintaining the same numbers of sets and repetitions

- Resistance exercise repetitions

- Hospital-based phase: 12 to 15

- Home-based phase: maintaining the same numbers of sets and repetitions

- Resistance exercise intensity

- Hospital-based phase: 12 repetitions at the lightest weight, and, as tolerated, repetitions were increased to 15 after the first week. After a participant could perform 15 repetitions of an exercise, another set was added. Upper body exercises were performed with a padded weight belt with interchangeable $1.0 \mathrm{lb}$ bars used to adjust the total weight up to a maximum of $20 \mathrm{lb}$. Participant body weight was used for lower body exercises

- Home-based phase: maintain

- Description of resistance exercise: The resistance programme consisted of upper body (biceps curl, triceps extension, chest fly, military press, upright row and shoulder shrug) and lower body (leg squat and lunge) exercises

- Intervention uptake: unclear

- Adherence: women assigned to the structured intervention completed an average of $83 \%$ of their scheduled hospital-based exercise sessions (mean $=9.9, \mathrm{SD}=3.3$ sessions), and $76.9 \%$ completed all 12 sessions. LTEQ scores increased from baseline by $157 \%$ (from $M=9.7, S D=8.1$ to $M=25.0, S D=13.1$ ) in the intervention group and by $32.7 \%$ among the control group (from $M=10.7, S D=12.8$ to $M=14.2$, $\mathrm{SD}=11.8$ ). Home-based adherence is not clear

- Attrition: unclear. No details on numbers randomly assigned to each arm. An overall study completion figure of $80.4 \%$ is cited (i.e. participants completing follow-up assessments)

- Adverse effects: unclear 
Perna 2010 (Continued)

- Achieves Rock et al guidelines: unclear

Description of usual care unclear

Notes

\section{Risk of bias}

\begin{tabular}{|c|c|c|}
\hline Bias & Authors' judgement & Support for judgement \\
\hline $\begin{array}{l}\text { Random sequence genera- } \\
\text { tion (selection bias) }\end{array}$ & Low risk & $\begin{array}{l}\text { Participants were stratified by cancer stage and were randomly assigned to } \\
\text { groups }\end{array}$ \\
\hline $\begin{array}{l}\text { Allocation concealment } \\
\text { (selection bias) }\end{array}$ & Low risk & $\begin{array}{l}\text { Participant assignment to groups at enrolment was concealed from the } \\
\text { project director }\end{array}$ \\
\hline $\begin{array}{l}\text { Blinding of outcome as- } \\
\text { sessment (detection bias) } \\
\text { All outcomes }\end{array}$ & Low risk & $\begin{array}{l}\text { Physicians monitoring graded exercise tests were blinded to participant group } \\
\text { assignment. Similarly, a physical therapist or an exercise physiologist, blinded } \\
\text { to participant assignment, performed strength assessments }\end{array}$ \\
\hline
\end{tabular}

Incomplete outcome data Low risk Intent-to-treat analysis done and multiple imputation used (attrition bias)

All outcomes

\begin{tabular}{lll}
\hline $\begin{array}{l}\text { Selective reporting (re- } \\
\text { porting bias) }\end{array}$ & Low risk \\
\hline Other bias & High risk & $\begin{array}{l}\text { Numbers randomly assigned to intervention and control groups are unclear, } \\
\text { as are numbers completing in each arm }\end{array}$ \\
\hline
\end{tabular}

Pinto 2003

\begin{tabular}{ll}
\hline Methods & Study design: RCT individual participant level randomisation \\
- Study location (WHO income taxonomy): Rhode Island, USA (High) \\
- Funding source: this study was supported by Grant RO3 MH55570 from the National Institute of Mental \\
Health to Dr Pinto \\
- Inclusion criteria: sedentary women (exercised fewer than three times per week for 20 minutes per \\
session) who had been diagnosed with breast cancer (Stage 0, I or II) over the past 3 years. Post-surgery \\
patients who had completed chemotherapy or radiation treatment were invited to participate in a 12- \\
week exercise programme or a wait-list control group (CG) \\
- Exclusion criteria: medical or current psychiatric illness that would make compliance with the study \\
protocol difficult or dangerous (e.g. coronary artery disease, hypertension, diabetes), orthopaedic \\
problems or neuropathies that would limit exercise training. Medications that would alter training re- \\
sponses (e.g. beta blockers) or affect distress outcomes (e.g. antidepressants) were also reasons for \\
exclusion \\
- CONSORT diagram included: no \\
- Study recruitment rate: $24 / 53^{*}$ \\
- Length of follow-up: length of intervention = 12 weeks, length of follow-up from baseline $=12$ weeks \\
- Primary cancer diagnosis: stage 0 to II breast cancer, postsurgery participants who had completed \\
chemotherapy or radiation treatment \\
- Current cancer treatment: none \\
- Agetastatic disease: none \\
- Gender: women
\end{tabular}


Pinto 2003 (Continued)

- BMI: overall mean (SD): 26.8 (4.1)

- Ethnicity: all white

- Comorbidities reported: unclear

- Sample size: intervention $(\mathrm{n}=12)$, waiting list control $(\mathrm{n}=12)$
- Group or supervised intervention: unclear
- Setting: supervised and home-based exercise
- Exercise prescription components: aerobic and resistance exercise (resistance exercise was intro-
duced only for last 4 weeks of the 12 -week programme)
- Theoretical basis: none
- CALO-RE taxonomy components: programme set goal, \#9, \#15, \#16, \#21, \#26
- Frequency of contact with researchers or exercise professionals: an exercise physiologist monitored
participants' blood pressure and heart rate once a week before, during and after exercise. Individual
exercise prescriptions were updated before each session. Unclear whether physiologist was present
at each exercise session
- Instructions to controls: asked not to change their current level of physical activity

Outcomes

- Change in fitness reported: aerobic exercise tolerance test performed but no control group comparison data reported

- Free-living energy expenditure: unclear

Process measures
- Method of measuring exercise behaviour: attendance at supervised exercise sessions. Individual exercise prescriptions were updated before each session

- Aerobic exercise frequency: three times per week

- Aerobic exercise duration: over the 12 weeks, the exercise session developed into 10 minutes of warmup (cardiovascular and flexibility), 10 minutes of cool-down (cardiovascular and flexibility) and 30 minutes of cardiovascular activity within an individual's target heart rate zone

- Aerobic exercise intensity: $60 \%$ to $70 \%$ of peak heart rate by the end of the 12 -week intervention

- Description aerobic exercise mode: Cardiovascular activities included treadmill walking, arm and leg ergometers, arm cycling, stationary cycling and rowing. To tailor the programme for women who had undergone breast surgery and to improve upper body endurance, investigators encouraged arm cycling and rowing during the sessions. Participants used at least three modes of physical activity per session that would ensure at least one cardiovascular arm activity

- Resistance exercise frequency: N/A less than 6 weeks

- Resistance exercise sets: N/A less than 6 weeks

- Resistance exercise repetitions: N/A less than 6 weeks.

- Resistance exercise intensity: N/A less than 6 weeks

- Description of resistance exercise: N/A less than 6 weeks

\section{Compliance}

- Intervention uptake: unclear-Quote: "Three women discontinued participation within the first four weeks of the 12-week programme"

- Adherence: Of the 12 participants in the exercise group, three women discontinued participation within the first four weeks of the 12-week programme (reasons included child care responsibilities and inconvenience of travelling to the hospital). These individuals provided questionnaire data at post assessments but did not complete post-treatment exercise tolerance tests. The remaining participants attended a mean of $88 \%$ of the 36 -session exercise programme and completed the exercise tolerance test and questionnaire assessments at post-treatment. Adherence rate to the home-based component of the exercise prescription was unclear

- Attrition: nine participants were lost to follow-up (three in the exercise group, six in the control group)

- Adverse effects: not reported; however, it is unclear why the six controls dropped out

- Achieves Rock et al guidelines: unclear 
Pinto 2003 (Continued)

Notes

*We estimated study recruitment rate on the basis of numbers randomly assigned of those approached and eligible

\section{Risk of bias}

\begin{tabular}{lll}
\hline Bias & Authors' judgement & Support for judgement \\
\hline $\begin{array}{l}\text { Random sequence genera- } \\
\text { tion (selection bias) }\end{array}$ & Unclear risk & Insufficient information to permit a 'low' or 'high' risk judgement \\
\hline $\begin{array}{l}\text { Allocation concealment } \\
\text { (selection bias) }\end{array}$ & Unclear risk & Insufficient information to permit a 'low' or 'high' risk judgement \\
\hline $\begin{array}{l}\text { Blinding of outcome as- } \\
\text { sessment (detection bias) } \\
\text { All outcomes }\end{array}$ & Unclear risk & Insufficient information to permit a 'low' or 'high' risk judgement \\
\hline $\begin{array}{l}\text { Incomplete outcome data } \\
\text { (attrition bias) } \\
\text { All outcomes }\end{array}$ & High risk & $\begin{array}{l}\text { Exercise tolerance test performed but no control group comparison data re- } \\
\text { ported. 38\% lost to follow-up }\end{array}$ \\
\hline $\begin{array}{l}\text { Selective reporting (re- } \\
\text { porting bias) }\end{array}$ & High risk & $\begin{array}{l}\text { None of the physiological assessments were performed for the control group } \\
\text { at 12 weeks }\end{array}$ \\
\hline $\begin{array}{l}\text { Other bias } \\
\text { High risk }\end{array}$ & $\begin{array}{l}\text { A statistically significant difference was noted between groups for body es- } \\
\text { teem at baseline (weight concerns and physical } \\
\text { condition sub scales) }\end{array}$ \\
\hline
\end{tabular}

\section{Pinto 2005}

\section{Methods}

- Study design: RCT individual participant level randomisation

- Study location (WHO income taxonomy): Rhode Island, USA (high)

- Funding source: supported by National Cancer Institute Grant No. CA 75452 (BMP)

- Inclusion criteria: eligibility criteria included age 18 years; currently sedentary (exercised one time per week for 20 minutes at vigorous intensity or two times per week for 30 minutes at moderate intensity for the past six months) ${ }^{\star}$; diagnosed with Stage 0 to II breast cancer over the past 5 years; completed surgery, chemotherapy and/or radiation; ambulatory (able to walk a mile without assistive devices); and willing to be randomly assigned

- Exclusion criteria: participants were excluded if they had a prior history of cancer (exception: nonmelanoma skin cancer), or if they had a medical or current psychiatric illness that could make compliance with the study protocol difficult or dangerous (e.g. cardiovascular disease, diabetes, orthopaedic problems that limit exercise training)

- CONSORT diagram included: yes

- Study recruitment rate: $86 / 123$

- Length of follow-up: 12 weeks of 'treatment' with nine months of follow-up from baseline

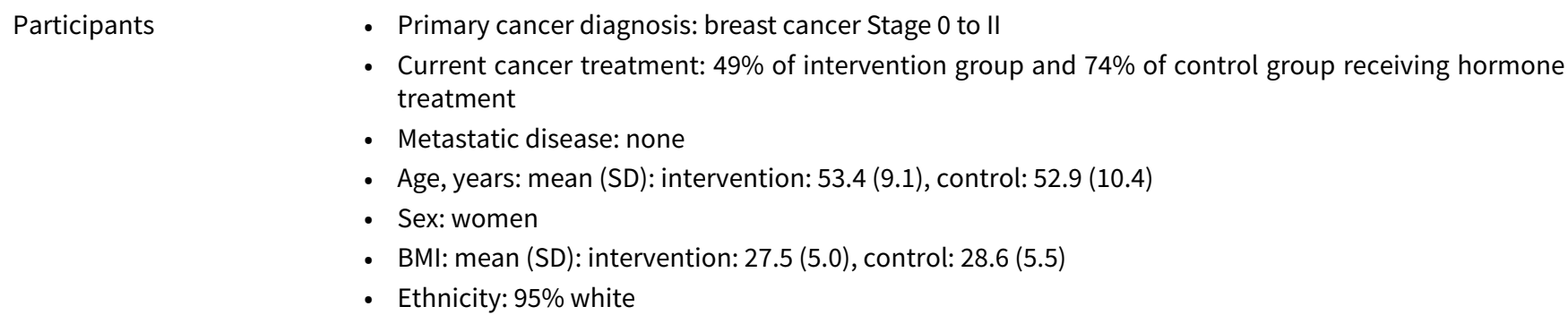

- Current cancer treatment: $49 \%$ of intervention group and $74 \%$ of control group receiving hormone treatment

- Metastatic disease: none

- Age, years: mean (SD): intervention: 53.4 (9.1), control: $52.9(10.4)$

- Sex: women

- BMI: mean (SD): intervention: 27.5 (5.0), control: 28.6 (5.5)

- Ethnicity: 95\% white 
Pinto 2005 (Continued)

- Comorbidities reported: unclear

- Sample size: intervention $(n=43)$, control $(n=43)$
- Group or supervised intervention: individual
- Setting: home-based
- Exercise prescription components: aerobic
- CALO-RE taxonomy components: \#5, \#8, \#12, \#16, \#17, \#19
- Frequency of contact with researchers or exercise professionals: after randomisation, each interven-
tion participant received in-person instructions on how to exercise at a moderate-intensity level, how
to monitor heart rate, and how to warm up before exercise and cool down after exercise. Also, interven-
tion participants received weekly phone calls for 12 weeks, then calls every month for three months
- Instructions to controls: control participants were asked to refrain from changing their current level
of activity during the 12 weeks. They received a weekly phone call from research staff for 12 weeks to
match the frequency of contact with the intervention group. These women received the same cancer
survivorship tip sheets as the PA group

Outcomes - Change in fitness reported: aerobic exercise tolerance assessed by a timed one-mile walk test

- Free-living energy expenditure: total weekly energy expenditure (kcal/kg/week) calculated from the seven-day physical activity recall questionnaire

Process measures

- Method of measuring exercise behaviour: seven-day physical activity recall questionnaire and accelerometer data providing kcal/hour

- Aerobic exercise frequency: two to five days per week

- Aerobic exercise duration: 10 to 30 minutes

- Aerobic exercise intensity: The programme promoted moderate intensity activities at $55 \%$ to $65 \%$ of maximum heart rate

- Description of aerobic exercise mode: brisk walking, biking, swimming or use of home exercise equipment

- Resistance exercise frequency: N/A

- Resistance exercise sets: N/A

- Resistance exercise repetitions: N/A

- Resistance exercise intensity: N/A

- Description of resistance exercise: N/A

Compliance Intervention uptake: $43 / 43$

- Adherence:

- Pinto 2005: 15 of 43 in the intervention group and 0 of 41 in the control group accumulated at least 30 minutes of moderate intensity physical activity (e.g., walking briskly, heavy house work) on most, ideally all, days of the week as reported by seven-day recall questionnaires. No changes were reported in accelerometer data in the intervention group (change score $=-0.33 \mathrm{kcal} / \mathrm{hour}$ ).

- Pinto 2009: from heart rate data: At week 1, participants reported an average of 43.12 minutes of exercise (SD 44.32) and at week 12, a mean of 128.53 minutes/week of exercise (SD 76.82), at between $55 \%$ and $65 \%$ of predicted max heart rate. However, less than $75 \%$ of the intervention group were meeting the prescribed goal after week 4.

- Attrition: Four dropped out in the intervention arm and did not provide data at the post-treatment assessment. Reasons for dropout included no time $(n=1)$; could not be contacted to determine reasons $(n=2)$; and participation terminated $(n=1)$ (the study team terminated one woman's participation because of symptoms of chest pain during exercise and her refusal to have these symptoms evaluated by her physician)

- Adverse effects: not clear whether chest pain was related to exercise in dropout whose participation was terminated

- Achieves Rock et al guidelines: no 
Pinto 2005 (Continued)

Notes
*Data from baseline questionnaires indicated that two participants in the intervention group were active at baseline (i.e. a discrepancy was noted between telephone screening and assessment). However, the author has advised that outliers were removed during data analysis of study outcomes. Author advised that accelerometer data should have been reported as kcal/hour)

\section{Risk of bias}

\begin{tabular}{|c|c|c|}
\hline Bias & Authors' judgement & Support for judgement \\
\hline $\begin{array}{l}\text { Random sequence genera- } \\
\text { tion (selection bias) }\end{array}$ & Unclear risk & Insufficient information to permit a 'low' or 'high' risk judgement \\
\hline $\begin{array}{l}\text { Allocation concealment } \\
\text { (selection bias) }\end{array}$ & Unclear risk & Insufficient information to permit a 'low' or 'high' risk judgement \\
\hline $\begin{array}{l}\text { Blinding of outcome as- } \\
\text { sessment (detection bias) } \\
\text { All outcomes }\end{array}$ & Unclear risk & Insufficient information to permit a 'low' or 'high' risk judgement \\
\hline $\begin{array}{l}\text { Incomplete outcome data } \\
\text { (attrition bias) } \\
\text { All outcomes }\end{array}$ & Low risk & Intention-to-treat approach used and low attrition reported (5\%) \\
\hline $\begin{array}{l}\text { Selective reporting (re- } \\
\text { porting bias) }\end{array}$ & Low risk & All outcomes reported \\
\hline Other bias & High risk & $\begin{array}{l}\text { Significantly more control group participants were receiving hormone treat- } \\
\text { ment: } 49 \% \text { versus } 74 \% \text { in the intervention and control groups, respectively ( } P= \\
0.015) \text {. Objective accelerometer data do not support the self-reported physical } \\
\text { activity behaviour }\end{array}$ \\
\hline
\end{tabular}

\section{Pinto 2011}

Methods

- Study design: RCT individual participant level randomisation

- Study location (WHO income taxonomy): Rhode Island, USA (high)

- Funding source: this study was funded by the National Cancer Institute (CA 101770 to Dr Pinto)

- Inclusion criteria: (i) men and women aged $\geq 18$ years; (ii) completed primary and adjuvant treatments for colon or rectal cancer (Stages I to III); (iii) $\leq 5$ years since treatment completion; (iv) able to read and speak English; (v) provided consent for medical chart review; (vi) able to walk unassisted; (vii) sedentary, which was defined as exercising $<60$ minutes/week at moderate intensity PA or $<20$ minutes/week of vigorous intensity PA over the past six months; and (viii) had access to a telephone

- Exclusion criteria: patients with a prior history of cancer were excluded. Another exclusion criterion was a medical or current psychiatric illness (e.g. orthopaedic problems) that could make compliance with the study protocol difficult or unsafe. Patients with cardiovascular disease and/or diabetes were included if their treating physicians approved of their study participation

- CONSORT diagram included: yes

- Study recruitment rate: $46 / 66$

- Length of follow-up: 12 weeks of counselling with 12 months of follow-up from baseline

$\begin{array}{ll}\text { Participants } & \text { Primary cancer diagnosis: } 57 \% \text { colon cancer, } 43 \% \text { rectal cancer } \\ \text { - Current cancer treatment: none } \\ \text { - Metastatic disease: none } \\ \text { - Age, years: mean (SD): control: } 55.6 \text { (8.24), intervention: } 59.5 \text { (11.2) } \\ \text { - Gender: } 56 \% \text { female }\end{array}$


Pinto 2011 (Continued)

- BMI: mean (SD): control: 29.4 (6.1), intervention: 27.9 (6.0)

- Ethnicity: 1 of 46 non white

- Comorbidities reported: unclear

\begin{tabular}{|c|c|}
\hline Interventions & $\begin{array}{l}\text { - Sample size: intervention }(\mathrm{n}=20) \text {, control }(\mathrm{n}=26) \\
\text { - Group or supervised intervention: individual } \\
\text { - Setting: home-based and facilitated with phone calls } \\
\text { - Exercise prescription components: aerobic } \\
\text { - Theoretical basis: trans theoretical model, social cognitive theory } \\
\text { - CALO-RE taxonomy components: } \# 5, \# 8, \# 9, \# 12, \# 16, \# 17, \# 19, \# 21, \# 23, \# 24, \# 26 \\
\text { - Frequency of contact with researchers or exercise professionals: after an initial one-to-one consulta- } \\
\text { tion, each participant received a weekly call over } 12 \text { weeks from research staff to monitor physical } \\
\text { activity participation, identify relevant health problems, solve any barriers to physical activity and re- } \\
\text { inforce participants for their efforts } \\
\text { - Instructions to controls: were asked not to change their usual level of activity }\end{array}$ \\
\hline Outcomes & $\begin{array}{l}\text { - Change in fitness reported: timed one-mile walk with estimation of } \mathrm{VO}_{2} \text { peak } \\
\text { - Free-living energy expenditure: calories per week estimated from } \mathrm{CHAMPS} \text { questionnaire }\end{array}$ \\
\hline Process measures & $\begin{array}{l}\text { - Method of measuring exercise behaviour: questionnaires-seven-day physical activity recall; com- } \\
\text { munity healthy activities model programme for seniors (CHAMPS); stage of motivational readiness for } \\
\text { physical activity. Accelerometer data also collected } \\
\text { - Aerobic exercise frequency: two to five times per week } \\
\text { - Aerobic exercise duration: } 10 \text { to } 30 \text { minutes } \\
\text { - Aerobic exercise intensity: the programme promoted moderate intensity aerobic activities at } 64 \% \text { to } \\
76 \% \text { of estimated maximum heart rate } \\
\text { - Description aerobic exercise mode: Brisk walking, biking, or use of home exercise equipment was rec- } \\
\text { ommended } \\
\text { - Resistance exercise frequency: N/A } \\
\text { - Resistance exercise sets: N/A } \\
\text { - Resistance exercise repetitions: N/A } \\
\text { - Resistance exercise intensity: N/A } \\
\text { - Description of resistance exercise: N/A }\end{array}$ \\
\hline
\end{tabular}

Compliance - Intervention uptake: 20/20

- Adherence:

- Goal of 150 minutes/week of physical activity was met or exceeded by $64.7 \%$ of the intervention group versus $40.9 \%$ of the control group at three months, by $38.9 \%$ of the intervention group versus $27.3 \%$ of the control group at six months and by $31.6 \%$ of the intervention group versus $21.7 \%$ of the control group at 12 months

- Physical activity of moderate intensity (recorded using the three-day PAR questionnaire) was compared with the corresponding accelerometer data over three days. Spearman rank correlations were weak at baseline $(r=0.12)$ because of a high proportion of sedentary participants. Correlation at the three-month follow-up showed the only significant between-group change reported in exercise minutes: $r=0.32$

- Attrition: $1 / 20$ at three, six and 12 months in the intervention arm; $2 / 26$ at three, $3 / 26$ at six and 12 months in the control group

- Adverse effects: one cancer recurrence in the control group at three months

- Achieves Rock et al guidelines: self-report indicates that $64.7 \%$ of the intervention group and $40.9 \%$ of the control group were achieving the guidelines. However, accelerometer data are not provided to support this. Further, only a weak correlation was reported between self-report and accelerometer data at three months

Description of usual care Unclear 
Pinto 2011 (Continued)

Notes

\section{Risk of bias}

\begin{tabular}{|c|c|c|}
\hline Bias & Authors' judgement & Support for judgement \\
\hline $\begin{array}{l}\text { Random sequence genera- } \\
\text { tion (selection bias) }\end{array}$ & Unclear risk & Insufficient information to permit a 'low' or 'high' risk judgement \\
\hline $\begin{array}{l}\text { Allocation concealment } \\
\text { (selection bias) }\end{array}$ & Unclear risk & Insufficient information to permit a 'low' or 'high' risk judgement \\
\hline $\begin{array}{l}\text { Blinding of outcome as- } \\
\text { sessment (detection bias) } \\
\text { All outcomes }\end{array}$ & Unclear risk & Insufficient information to permit a 'low' or 'high' risk judgement \\
\hline $\begin{array}{l}\text { Incomplete outcome data } \\
\text { (attrition bias) } \\
\text { All outcomes }\end{array}$ & Low risk & $<10 \%$ attrition reported \\
\hline $\begin{array}{l}\text { Selective reporting (re- } \\
\text { porting bias) }\end{array}$ & High risk & Accelerometer data not reported \\
\hline Other bias & High risk & $\begin{array}{l}\text { Accelerometer correlation with self-report questionnaires is weak at follow-up } \\
\text { points when significant differences between groups in physical activity are } \\
\text { reported (i.e. } r=0.32 \text { at } 3 \text { months). Substantial contamination in the control } \\
\text { group }\end{array}$ \\
\hline
\end{tabular}

\section{Rogers 2015}

\section{Methods}

- Study design: RCT individual participant level randomisation

- Study location: Springfield, IL, USA *from linked to study Rogers $2012^{*}$

- Funding source: this project was supported by the National Cancer Institute R01CA136859. Kerry S. Courneya is supported by the Canada Research Chairs Program.

- Inclusion criteria: women (ages 18-70) with history of ductal carcinoma in situ (DCIS) or stage I-IIIA breast cancer who self-reported engaging in B30 minutes of vigorous or B60 minutes of moderate intensity physical activity per week on average over the past 6 months were enrolled. Participants had to be postprimary treatment, C8 weeks post surgery, English speaking, and medically cleared by their physician. *from linked to study Rogers 2012*

- Exclusion criteria: women (ages 18-70) with history of ductal carcinoma in situ (DCIS) or stage I-IIIA breast cancer who self-reported engaging in less than 30 minutes of vigorous or less 0 minutes of moderate intensity physical activity per week on average over the past 6 months were enrolled. Participants had to be postprimary treatment, C8 weeks post surgery, English speaking, and medically cleared by their physician. *from linked to study Rogers $2012^{*}$

- CONSORT diagram included: yes

- Study recruitment rate: $222 / 288$

- Length of follow-up: length of intervention $=12$ weeks, length of follow-up from baseline $=6$ months.

Participants

- Primary cancer diagnosis: breast cancer

- Current cancer treatment: post primary treatment and/or hormone treatment

- Metastatic disease: unclear

- Age, years, mean (SD): intervention = 54.9 (9.3), control = $53.9(7.7)$

- Gender: female

- BMI: intervention $=30.8$ (6.9), control $=30.5(6.8){ }^{*}$ from linked paper Rogers $2016^{\star}$ 
Rogers 2015 (Continued)

- Ethnicity: $1.8 \%$ Hispanic and $98.2 \%$ non-Hispanic

- Comorbidities reported: unclear

\begin{tabular}{|c|c|}
\hline Interventions & 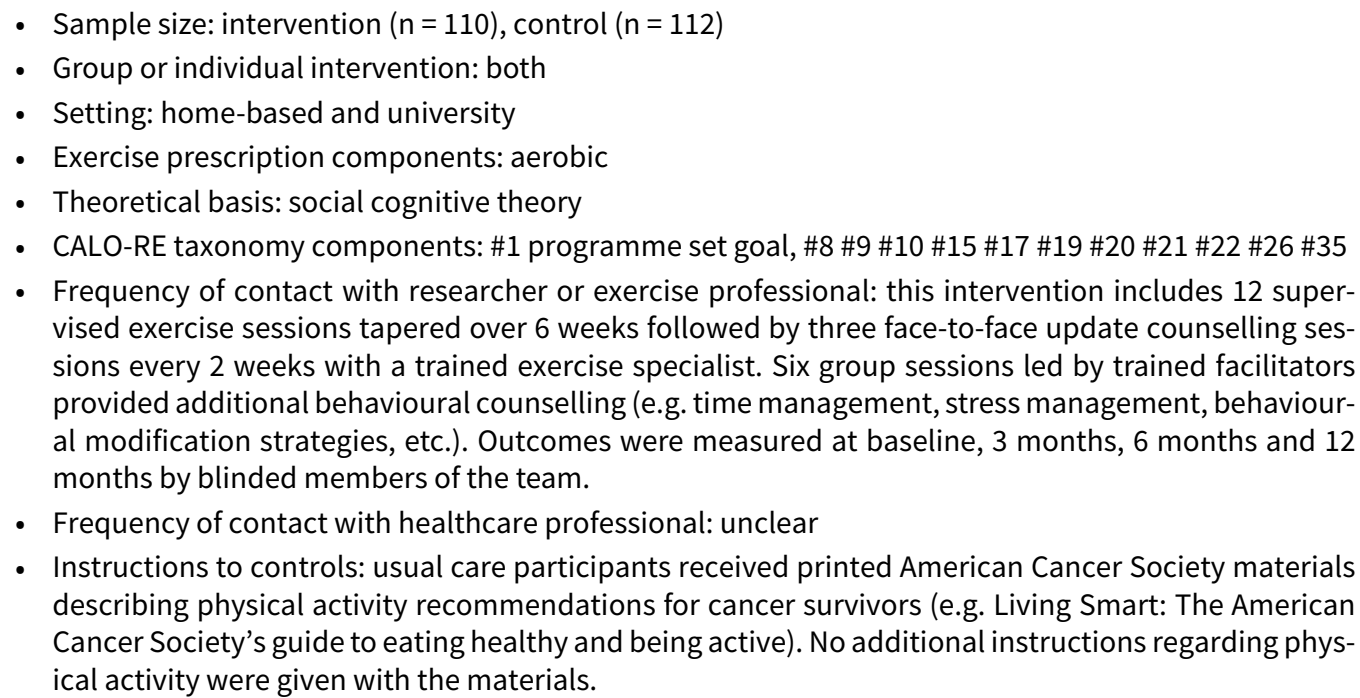 \\
\hline
\end{tabular}

Outcomes

- Change in fitness reported: aerobic fitness was measured using a submaximal treadmill test and modified Naughton protocol

- Free-living energy expenditure: assessed using self-report and accelerometers.

Process measures

- Method of measuring exercise behaviour: HR monitor, Accelerometers, use of Godin questionnaire and activity log.

- Aerobic exercise frequency: 150 minutes per week.

- Aerobic exercise duration: 20-30 minutes per session, three times per week.

- Aerobic exercise intensity: the programme used the rating of perceived exertion, progressing from 1.5-5.5 over the programme.

- Description aerobic exercise mode: walking on a treadmill in supervised sessions, after supervised sessions other aerobic exercises could be chosen by the participant as long as target intensity and duration was met

- Resistance exercise frequency: N/A

- Resistance exercise sets: N/A

- Resistance exercise repetitions: N/A

- Resistance exercise intensity: N/A

- Description of resistance exercise: N/A

- Intervention uptake: $222 / 288$

- Adherence: adherence to the intervention was $98 \%$ for supervised exercise sessions, $96 \%$ for update sessions, and $91 \%$ for discussion group sessions. Only five intervention participants did not receive the allocated intervention (i.e. did not complete $\mathrm{C} 75 \%$ of all intervention components combined).

- Attrition: $3 \%$ at month 3, $4 \%$ at month 6 .

- Adverse effects: related expected adverse events in the intervention group included back or lower extremity musculoskeletal pain or injury $(n=14)$, heart rate monitor rash $(n=1)$, fall while walking ( $n$ $=1$ ), breast reconstruction $(n=3)$, and chest pain during treadmill fitness test $(n=1)$

- Achieves Rock et al guidelines: yes, 150 minutes per week was the total aim of moderate intensity exercise per week, $96 \%$ to $98 \%$ achieved this.

Description of usual care

Usual care participants received printed American Cancer Society materials describing physical activity recommendations for cancer survivors (e.g. Living Smart: The American Cancer Society's guide to eating healthy and being active). No additional instructions regarding physical activity were given with the materials 
Rogers 2015 (Continued)

Notes

\section{Risk of bias}

Bias Authors' judgement Support for judgement

Random sequence genera- Low risk
tion (selection bias)

Randomisation to one of the two study group conditions was completed using computer-generated numbers in blocks of 4 within each recruiting site to facilitate an even distribution between study conditions during each recruitment wave.

\begin{tabular}{ll}
\hline $\begin{array}{l}\text { Allocation concealment } \\
\text { (selection bias) }\end{array}$ & Low risk
\end{tabular}

\begin{tabular}{ll}
\hline $\begin{array}{l}\text { Blinding of outcome as- } \\
\text { sessment (detection bias) }\end{array} \quad$ Low risk & $\begin{array}{l}\text { Outcomes were measured at baseline, } 3 \text { months, } 6 \text { months and } 12 \text { months by } \\
\text { blinded members of the team. }\end{array}$
\end{tabular}

All outcomes blinded members of the team.

\begin{tabular}{lll}
\hline $\begin{array}{l}\text { Incomplete outcome data } \\
\text { (attrition bias) } \\
\text { All outcomes }\end{array}$ & Low risk & Dropouts similar in both groups with reasons given. \\
\hline $\begin{array}{l}\text { Selective reporting (re- } \\
\text { porting bias) }\end{array}$ & Low risk & All outcomes were reported. \\
\hline Other bias & High risk & $\begin{array}{l}\text { Physical activity reported at baseline, differed between objective and subjec- } \\
\text { tive measures. }\end{array}$ \\
\hline
\end{tabular}

\section{Scott 2013}

\begin{tabular}{|c|c|}
\hline Methods & $\begin{array}{l}\text { - Study design: RCT individual participant level randomisation } \\
\text { - Study location: Sheffield, UK } \\
\text { - Funding source: American Institue for cancer research grant } \\
\text { - Inclusion criteria: this study recruited } 90 \text { overweight women with a BMI > } 25 \mathrm{~kg} / \mathrm{m}^{2} \\
\text { - Exclusion criteria: included concomitant hormone replacement therapy (HRT) or oral contraceptives; } \\
\text { metastatic or active loco-regional disease; physical or psychiatric impairment limiting physical mo- } \\
\text { bility; severe nausea, anorexia or other conditions precluding participation in exercise, the consump- } \\
\text { tion of alternative/complementary diets or use of high-dose antioxidant supplements; and those al- } \\
\text { ready engaged in regular exercise. } \\
\text { - CONSORT diagram included: yes } \\
\text { - Study recruitment rate: } 47,43 \text { (intervention vs control) } \\
\text { - Length of follow-up: length of intervention = } 24 \text { weeks, length of follow-up from baseline = } 24 \text { weeks. }\end{array}$ \\
\hline Participants & $\begin{array}{l}\text { - Primary cancer diagnosis: breast cancer } \\
\text { - Current cancer treatment: none or receiving adjuvant endocrine treatment } \\
\text { - Metastatic disease: unclear } \\
\text { - Age, years, mean (SD): intervention = } 55.8(10.0) \text {, control = } 55.3(8.8) \text {. } \\
\text { - Gender: female } \\
\text { - BMl: intervention = } 29.7(3.5) \text {, control = } 31.1(5.7) \\
\text { - Ethnicity: } \text { white } \\
\text { - Comorbidities reported: } \text { unclear }\end{array}$ \\
\hline Interventions & $\begin{array}{l}\text { - Sample size: intervention }(n=47) \text {, control }(n=43) \\
\text { - Group or individual intervention: individually tailored but in groups of 1-3. }\end{array}$ \\
\hline
\end{tabular}


Scott 2013 (Continued)

- Setting: university exercise research facility

- Exercise prescription components: aerobic and resistance

- Theoretical basis: none

- CALO-RE taxonomy components: programme set goal, \#21

- Frequency of contact with researcher or exercise professional: assessments at baseline and 24 weeks by a trained technician blinded to the group allocation. Three weekly supervised sessions and an additional weekly small-group nutrition education seminar.

- Frequency of contact with healthcare professional: unclear

- Instructions to controls: in the control group contact with researchers was limited to assessment sessions. Participants in the control group were offered three exercise sessions at the university exercise research facility and general exercise and dietary advice after the final follow-up.

- Change in fitness reported: aerobic exercise tolerance was tested using a submaximal, 8-minute single
stage walking test on a treadmill.
- Free-living energy expenditure: unclear

Process measures

- Method of measuring exercise behaviour: heart rate monitor and adherence to exercise protocol.

- Aerobic exercise frequency: three sessions per week.

- Aerobic exercise duration: thirty minutes per session.

- Aerobic exercise intensity: $65 \%$ to $85 \%$ age predicted maximum heart rate

- Description aerobic exercise mode: treadmill, cross-trainer, cycle-ergometer and/or rowing ergometer

- Resistance exercise frequency: three sessions per week. Resistance exercise sets: 3 sets

- Resistance exercise repetitions: 12 reps

- Resistance exercise intensity: resistance training was individually tailored to the women's ability at the time (strength, range of motion). For upper body, we initially worked on range of motion then built up to 3 sets of 12 reps using light hand weights ( $1 \mathrm{~kg}, 2 \mathrm{~kg}$ or $3 \mathrm{~kg}$ ) or resistance bands (according to patient preference) for a range of exercises focusing on the arms, chest and back. We also used the exercise balls for core stability work and some upper body work (e.g. press ups against the wall). Did not do much leg strengthening as they were using the exercise bike, treadmill, cross-trainer for the aerobic section of the session, but some women progressed to using the exercise balls for assisted squats against the wall. Women with lymphoedema did the same as the others but stuck to very light weights, e.g. $1 \mathrm{~kg}$. The focus was light weights and lots of reps, as per the lymphoedema avoidance/ management guidance at the time.

- Description of resistance exercise: resistance bands, hand weights and stability balls.

\begin{tabular}{ll}
\hline Compliance & - Intervention uptake: $47 / 238$ \\
- Adherence: $80 \%$ of all sessions. \\
- Attrition: $10 \%$ \\
- Adverse effects: none reported. \\
- Achieves Rock et al guidelines: yes, 6 weeks of resistance exercise.
\end{tabular}

Description of usual care The control group received a healthy eating booklet (Eat well), which also included brief advice on keeping active.

Notes

\section{Risk of bias}

Bias Authors' judgement Support for judgement

Random sequence genera- Low risk tion (selection bias)
Patients were randomised using minimisation (on the advice of statistician at the Leeds CTU [we used their distant randomisation service]) to balance the potential confounding variables of chemotherapy, hormone treatment or no hormone treatment. Using this approach, the first participant is allocated a treatment at random. For each subsequent participant a decision has to 
Scott 2013 (Continued)

be made about which treatment would lead to better balance between the groups in the variables of interest. The randomisation ratio was 1:1.

\begin{tabular}{|c|c|c|}
\hline $\begin{array}{l}\text { Allocation concealment } \\
\text { (selection bias) }\end{array}$ & Low risk & $\begin{array}{l}\text { Randomisation conducted by and independent researcher and not revealed } \\
\text { until baseline assessment was complete }\end{array}$ \\
\hline $\begin{array}{l}\text { Selective reporting (re- } \\
\text { porting bias) }\end{array}$ & Low risk & All outcomes reported. \\
\hline
\end{tabular}

Thomas 2013

\begin{tabular}{|c|c|}
\hline Methods & $\begin{array}{l}\text { - Study design: RCT individual participant level randomisation } \\
\text { - Study location: Yale } \\
\text { - Funding source: National Cancer Institue } \\
\text { - Inclusion criteria: the inclusion criteria required participating in less than } 90 \text { minutes of physical activ- } \\
\text { ity per week prior to enrolment; participants were nonsmokers and were free of other serious health } \\
\text { problems. Only those women who were sedentary or reported less than } 90 \text { minutes of moderate to vig- } \\
\text { orous physical activity per week and were not currently participating in a weight loss diet programme } \\
\text { were eligible. } \\
\text { - Exclusion criteria: exclusion criteria for the study included women younger than } 40 \text { years of age due } \\
\text { to potential differences in disease aetiology and women over } 75 \text { years of age due to likelihood of sig- } \\
\text { nificant co morbidities and safety concerns for elderly exercise participants. } \\
\text { - CONSORT diagram included: yes *from linked study Irwin } 2008^{*} \\
\text { - Study recruitment rate: } 75 / 788^{*} \text { from linked study Irwin } 2008^{*} \text {. } \\
\text { - Length of follow-up: length of intervention }=6 \text { months, length of follow-up from baseline }=6 \text { months. }\end{array}$ \\
\hline Participants & $\begin{array}{l}\text { - Primary cancer diagnosis: breast cancer } \\
\text { - Current cancer treatment: previous chemotherapy, radiotherapy, hormone therapy and none } \\
\text { - Metastatic disease: unclear } \\
\text { - Age, years, mean (SD): intervention = } 56.5(9.8) \text {, control = } 55.1(7.6) \text {. } \\
\text { - Gender: female } \\
\text { - BMI: intervention }=30.8(5.9) \text {, control = } 29.4(7.4) \text {. } \\
\text { - Ethnicity: intervention }=83 \% \text { white, } 17 \% \text { African American, control = } 90 \% \text { white, } 7 \% \text { African-American, } \\
3 \% \text { Asian/Pacific islander. } \\
\text { - Comorbidities reported: unclear }\end{array}$ \\
\hline Interventions & $\begin{array}{l}\text { - Sample size: intervention }(\mathrm{n}=35) \text {, control }(\mathrm{n}=30) \\
\text { - Group or individual intervention: individual } \\
\text { - Setting: local health club } \\
\text { - Exercise prescription components: aerobic } \\
\text { - Theoretical basis: none } \\
\text { - CALO-RE taxonomy components: \#5 \#9\#17 } \\
\text { - Frequency of contact with researcher or exercise professional: } 3 \text { weekly supervised sessions with a } \\
\text { certified exercise trainer. }\end{array}$ \\
\hline
\end{tabular}


- Frequency of contact with healthcare professional: unclear

- Instructions to controls: women in the usual care group were instructed to continue with their usual activities. If a participant wanted to exercise, she was told she could, but the exercise programme and training materials would not be offered to her until the end of the study. At the end of the study, women in the usual care condition were offered three supervised training sessions, a pedometer, exercise handouts, and the results of their clinical tests. Additionally, all study participants received quarterly newsletters that highlighted issues relevant to breast cancer survivorship.

\begin{tabular}{ll}
\hline Outcomes & Change in fitness reported: unclear \\
& - Free-living energy expenditure: unclear
\end{tabular}

Process measures

- Method of measuring exercise behaviour: physical activity questionnaire, 7-day physical activity log and heart rate monitors.

- Aerobic exercise frequency: five weekly sessions, three supervised and two unsupervised.

- Aerobic exercise duration: 30 minutes per session

- Aerobic exercise intensity: 50\% HRMax and increased to $60 \%$ to $80 \%$ HRMax

- Description aerobic exercise mode:

- Resistance exercise frequency: N/A

- Resistance exercise sets: N/A

- Resistance exercise repetitions: N/A

- Resistance exercise intensity:N/A

- Description of resistance exercise: N/A

Compliance - Intervention uptake: 75/88

- Adherence: the goal of the intervention was for participants to achieve 150 minutes of moderate intensity exercise per week; $33 \%$ of the intervention group achieved 150 minutes per week, $56 \%$ of the intervention group achieved 120 minutes per week and $75 \%$ achieved 90 minutes per week.

- Attrition: among the 75 women randomised, complete 6-month data were available for 67 women (89\%); 34 women randomised to exercise and 33 women randomised to usual care. * from linked study Irwin 2008*

- Adverse effects: five of the 37 women randomised to exercise experienced an adverse event; 2 events were related to the study (plantar fascitis), and 3 were unrelated (swollen achilles, stress fracture in foot, and plantar fascitis) to the study. No women developed lymphoedema during the study. *from linked study Irwin 2008*

- Achieves Rock et al guidelines: no

Description of usual care

Women in the usual care group were instructed to continue with their usual activities. If a participant wanted to exercise, she was told she could, but the exercise programme and training materials would not be offered to her until the end of the study. At the end of the study, women in the usual care condition were offered three supervised training sessions, a pedometer, exercise handouts, and the results of their clinical tests. Additionally, all study participants received quarterly newsletters that highlighted issues relevant to breast cancer survivorship.

Notes

\section{Risk of bias}

\begin{tabular}{lll}
\hline Bias & Authors' judgement & Support for judgement \\
\hline $\begin{array}{l}\text { Random sequence genera- } \\
\text { tion (selection bias) }\end{array}$ & Low risk & $\begin{array}{l}\text { After completion of all baseline measures, each participant was randomly as- } \\
\text { signed with equal probability to either the exercise or usual-care group. }\end{array}$ \\
\hline $\begin{array}{l}\text { Allocation concealment } \\
\text { (selection bias) }\end{array}$ & Low risk & $\begin{array}{l}\text { Randomisation was performed by using a random number generation, and } \\
\text { group assignment was placed in a sealed envelope, which was opened by the } \\
\text { study coordinator at the time of randomisation. }\end{array}$ \\
\hline
\end{tabular}


Thomas 2013 (Continued)

\begin{tabular}{|c|c|c|}
\hline $\begin{array}{l}\text { Blinding of outcome as- } \\
\text { sessment (detection bias) } \\
\text { All outcomes }\end{array}$ & Low risk & $\begin{array}{l}\text { For each participant, the same data that were collected at the baseline vis- } \\
\text { it were collected in a similar manner at } 6 \text { months postrandomisation by staff } \\
\text { blinded to the participant's group, "from linked study Irwin } 2008^{*}\end{array}$ \\
\hline
\end{tabular}

\begin{tabular}{lll}
\hline $\begin{array}{l}\text { Incomplete outcome data } \\
\text { (attrition bias) } \\
\text { All outcomes }\end{array}$ & Low risk & Outcome data were present for $89 \%$ of the participants at 6 months. \\
\hline $\begin{array}{l}\text { Selective reporting (re- } \\
\text { porting bias) }\end{array}$ & High risk & No body fat or lean mass values given. \\
\hline Other bias & High risk & No data given from food frequency questionnaire. \\
\hline
\end{tabular}

ADP: androgen-deprivation therapy; BMI: body mass index; BPI: Brief Pain Inventor; yHR: heart rate; m: metre; MRI: magnetic resonance imaging; NSCLC: non-small cell lung cancer; PAR: Physical Activity Recall; QoL: quality of life; RPE: Rating of Perceived Exertion; SD: standard deviation; VAS: visual analogue scale;

\section{Characteristics of excluded studies [ordered by study ID]}

\begin{tabular}{|c|c|}
\hline Study & Reason for exclusion \\
\hline Adams 2016 & Participants were not sedentary at baseline \\
\hline Ahmed 2006 & Sedentary status at baseline is unclear \\
\hline Alibhai 2014 & Participants were not sedentary at baseline \\
\hline Ames 2011 & Exercise prescription metrics are unclear \\
\hline Anderson 2012 & Sedentary status at baseline is unclear \\
\hline Anderson 2013 & Not a homogenous cancer cohort \\
\hline Anderson 2015 & Report - not a full-text paper \\
\hline Anulika 2015 & Unable to access full text \\
\hline Arbane 2011 & Author advised that baseline sedentary status was not assessed \\
\hline Arbane 2014 & Patients were hospitalised \\
\hline Arikawa 2013 & Not a cancer cohort \\
\hline Banerjee 2013 & Poster \\
\hline Baruth 2015 & Unclear if participants were meeting the baseline moderate exercise sedentary criteria \\
\hline Battaglini 2007 & Author advised that baseline sedentary status was not assessed \\
\hline Battaglini 2008 & Linked to Battaglini 2007 \\
\hline Bloom 2013 & Poster \\
\hline Bracha 2012 & Unclear of duration and intensity of prescribed exercise \\
\hline
\end{tabular}




\begin{tabular}{|c|c|}
\hline Study & Reason for exclusion \\
\hline Brdareski 2012 & No usual care comparison \\
\hline Brown 2012 & Linked to Schmitz 2009 and Schmitz 2010 \\
\hline Bruno 2018 & Participants were not sedentary at baseline \\
\hline Buchan 2016 & No usual care comparison \\
\hline Buffart 2013 & Poster \\
\hline Buffart 2014a & Not a homogenous cancer cohort \\
\hline Buffart 2014b & Not a homogenous cancer cohort \\
\hline Campbell 2005 & Unclear if participants were meeting the baseline moderate exercise sedentary criteria \\
\hline Cantaero-Villanueva 2013 & Participants were not sedentary \\
\hline Cantaero-Villanueva 2016 & Unclear if participants were meeting the baseline moderate exercise sedentary criteria \\
\hline Cantarero-Villanueva 2011 & Intervention exercise prescription metrics unclear \\
\hline Cantarero-Villanueva 2012a & Linked to Cantarero-Villanueva 2011 \\
\hline Carmack Taylor 2004 & Linked to Carmack Taylor 2006 \\
\hline Carmack Taylor 2006 & Exercise prescription metrics are unclear \\
\hline Carmack Taylor 2007 & Linked to Carmack Taylor 2006 \\
\hline Carson 2009 & Author advised that baseline sedentary status was not assessed \\
\hline Casla 2015 & Participants were not sedentary at baseline \\
\hline Cerulli 2014 & Unknown exercise prescription \\
\hline Chen 2015 & Baseline exercise activity inclusion criteria is greater then 90 minutes \\
\hline Chen 2016 & Baseline exercise activity inclusion criteria is greater then 90 minutes \\
\hline Cho 2006 & Sedentary status at baseline is unclear \\
\hline Christensen 2014 & Participants not sedentary at baseline \\
\hline Chuang 2017 & Exercise prescription is not clear \\
\hline Coleman 2003 & Exercise prescription metrics are unclear \\
\hline Cornette 2016 & Exercise prescription is not clear \\
\hline Cornie 2013a & Participants not sedentary at baseline \\
\hline Cornie 2013b & Sedentary status at baseline is unclear \\
\hline Cornie 2014 & Protocol paper \\
\hline
\end{tabular}




\begin{tabular}{|c|c|}
\hline Study & Reason for exclusion \\
\hline Cornie 2015 & Participants not sedentary at baseline \\
\hline Courneya 2012 & Participants not sedentary at baseline \\
\hline Courneya 2013 & Participants not sedentary at baseline \\
\hline Courneya $2014 a$ & Author advised us that the participants were not sedentary at baseline \\
\hline Courneya 2014b & Author advised us that the participants were not sedentary at baseline \\
\hline Courneya 2015 & Participants not sedentary at baseline \\
\hline Courneya 2016a & Participants not sedentary at baseline \\
\hline Courneya 2016b & Linked to Courneya 2013 paper \\
\hline Culos Reed 2010 & Exercise prescription metrics are unclear \\
\hline Danhauer 2009 & Sedentary status at baseline is unclear \\
\hline Daubenmier 2006 & Linked to Ornish 2005 \\
\hline De Jesus 2013 & Poster \\
\hline Demark-Wahnefried 2015 & No usual care comparison \\
\hline DeNysschen 2011 & Sedentary status at baseline is unclear \\
\hline Dieli-Conwright 2014 & Protocol paper \\
\hline Dieperink 2017 & Authors confirmed that participants were not sedentary at baseline \\
\hline Diepold 2016 & The participants were in palliative care \\
\hline Do 2015 & Cross-over trial \\
\hline Dolan 2010 & START trial includes non-sedentary participants \\
\hline Dolan 2014 & Poster \\
\hline Dolan 2016 & Participants not sedentary at baseline \\
\hline Donmez 2017 & Exercise prescription is not clear \\
\hline Donnelly 2011 & Author advised that cohort was not sedentary at baseline \\
\hline Edvarsen 2015 & Sedentary status at baseline is unclear \\
\hline Emslie 2007 & Linked to Mutrie 2007 \\
\hline Eriksen 2017 & Participants were not sedentary at baseline \\
\hline Fan-Ko 2017 & Exercise prescription is not clear \\
\hline Fernandez-Lao 2012 & Intervention exercise prescription metrics unclear \\
\hline
\end{tabular}




\begin{tabular}{|c|c|}
\hline Study & Reason for exclusion \\
\hline Fields 2015 & Poster \\
\hline Fields 2017 & Participants were not sedentary at baseline \\
\hline Forbes 2017 & Mixed cancer cohort \\
\hline Frattaroli 2008 & Linked to Ornish 2005 \\
\hline Friedenrich 2016 & Participants were not cancer patients \\
\hline Furzer 2016 & Not a homogenous cancer cohort \\
\hline Galiano-Castillo 2017 & Unclear whether the participants were sedentary at baseline \\
\hline Galvão 2010 & Sedentary status at baseline is unclear \\
\hline Galvão 2011 & Linked to Galvão 2010 \\
\hline Galvão 2017 & Participants were not sedentary at baseline \\
\hline Gaskin 2016 & Participants were not sedentary at baseline \\
\hline Gehring 2014 & Poster \\
\hline Gehring 2015 & Poster \\
\hline Gehring 2018 & Authors confirmed participants were not sedentary at baseline \\
\hline Gerland 2012 & Abstract \\
\hline Giallauria 2014 & Sedentary behaviour was not assessed \\
\hline Gokal 2016 & Participants were not sedentary at baseline \\
\hline Granger 2013 & Participants were hospitalised \\
\hline Greenlee 2013 & Cross-over trial \\
\hline Gruenigen 2012a & Participants were not sedentary at baseline \\
\hline Gruenigen $2012 b$ & Linked to Gruenigen 2012a \\
\hline Guinan 2013 & Participants were not sedentary at baseline \\
\hline Guinan 2017 & Authors confirmed participants were not sedentary at baseline. \\
\hline Gómez 2011 & Cohort not sedentary at baseline \\
\hline Haines 2010 & Sedentary status at baseline is unclear \\
\hline Hanssens 2012 & Abstract \\
\hline Hartman 2015 & Protocol paper \\
\hline Hatchett 2013 & Intensity of exercise is unclear \\
\hline
\end{tabular}




\begin{tabular}{|c|c|}
\hline Study & Reason for exclusion \\
\hline Hayes 2011 & Author advised that baseline sedentary status was not assessed \\
\hline Hayes 2012 & Paper not published yet \\
\hline Hayes 2013 & Author clarified that the participants were not sedentary at baseline \\
\hline Hayes 2014 & Trial still ongoing, paper not published yet \\
\hline Headley 2004 & Sedentary status at baseline is unclear \\
\hline Heim 2007 & Sedentary status at baseline is unclear \\
\hline Herbert 2012 & Participants were not sedentary at baseline. \\
\hline Herrero 2006 & Sedentary status at baseline is unclear \\
\hline Ho 2016 & No intensity reported \\
\hline Hoffman 2013 & Poster \\
\hline Hoffman 2017 & Unclear whether the participants were sedentary at baseline \\
\hline Hojan 2016 & Unable to gain copy of paper \\
\hline Hojan 2017 & Unsure whether participants were sedentary at baseline \\
\hline Huang 2015 & Participants were not sedentary at baseline \\
\hline Hubbard 2016 & Participants were not sedentary at baseline \\
\hline Husebo 2014 & Participants were not sedentary at baseline \\
\hline Hwang 2012 & Not all participants were randomised \\
\hline James 2012 & Poster \\
\hline Jarden 2013 & Study protocol \\
\hline Jeffs 2013 & intensity of the exercise is unclear \\
\hline Jensen $2015 a$ & Abstract \\
\hline Jensen $2015 b$ & Participants were hospitalised \\
\hline Jensen 2016 & Length of follow-up is less than 6 weeks \\
\hline Jones 2014a & Participants were not sedentary at baseline \\
\hline Jones 2014b & Participants were not sedentary at baseline \\
\hline Kalter 2015 & Moderator paper on previous excluded study \\
\hline Kampshoff 2015 & Not homogenous cancer cohort \\
\hline Kampshoff 2016 & Mixed cancer cohort \\
\hline
\end{tabular}




\begin{tabular}{|c|c|}
\hline Study & Reason for exclusion \\
\hline Kanera 2016 & Mixed cancer cohort \\
\hline Kanera 2017 & Mixed cancer cohort \\
\hline Kavanagh 2009 & Sedentary status at baseline is unclear \\
\hline Kilbreath 2006 & Sedentary status at baseline is unclear \\
\hline Kilbreath 2012 & Sedentary status at baseline is unclear \\
\hline Kim 2010 & Sedentary status at baseline is unclear \\
\hline Klepin 2015 & Abstract \\
\hline Klinkhammer-Schalke 2012 & Sedentary status at baseline is unclear \\
\hline Kwiatkowski 2013 & Participants were not sedentary at baseline \\
\hline Lahart 2016 & Participants were not sedentary at baseline \\
\hline Lai 2017 & Follow-up is less than 6 weeks \\
\hline Lee $2012 a$ & Study protocol \\
\hline Lee $2012 b$ & Study protocol \\
\hline Lee 2014 & Participants were not sedentary at baseline \\
\hline Leone 2016 & No frequency/duration/intensity of exercise reported \\
\hline Ligibel 2008 & Author advised that exercise intensity was not clear \\
\hline Ligibel 2009 & Linked to Ligibel 2008 \\
\hline Ligibel 2016 & Exercise intensity was unclear \\
\hline Lin 2014 & Not randomised controlled trial \\
\hline Litterini 2013 & Not homogenous cancer cohort \\
\hline Livingston 2015 & Participants were not sedentary at baseline \\
\hline Lynch 2014 & No frequency/duration/intensity data \\
\hline Lyons 2016 & Exercise is carried out for couples \\
\hline MacVicar 1989 & Sedentary status at baseline is unclear \\
\hline Manassero 2007 & Exercise prescription metrics are unclear \\
\hline Martin 2013 & Unclear if the participants were sedentary at baseline \\
\hline Mayo 2014 & Not homogenous cancer cohort \\
\hline McClure 2010 & Sedentary status at baseline is unclear \\
\hline
\end{tabular}




\begin{tabular}{|c|c|}
\hline Study & Reason for exclusion \\
\hline McGowan 2013 & No frequency/duration/intensity data \\
\hline McGuire 2011 & Linked to Waltman 2010 \\
\hline McNeely 2004 & Author advised that cohort was not sedentary \\
\hline Milecki 2013 & Participants were not sedentary at baseline \\
\hline Mina 2013 & No usual care comparison \\
\hline Mock 1994 & Sedentary status at baseline is unclear \\
\hline Mock 1997 & Sedentary status at baseline is unclear \\
\hline Mock 2005 & Sedentary status at baseline is unclear \\
\hline Molassiotis 2015 & Inspiratory muscle training \\
\hline Moller 2015 & Unable to source copy of full-text paper \\
\hline Monga 2007 & Sedentary status at baseline is unclear \\
\hline Morielli 2018 & Not a randomised controlled trial \\
\hline Mustian 2008 & Exercise prescription metrics are unclear \\
\hline Mustian 2015 & Poster \\
\hline Mutrie 2007 & Author advised that cohort was not sedentary at baseline \\
\hline Naumann 2012 & Not a randomised controlled trial \\
\hline Newton 2014 & Poster \\
\hline Nieman 1995 & Sedentary status at baseline is unclear \\
\hline Nikander 2007 & Sedentary status at baseline is unclear \\
\hline Nikander 2012 & Participants were not sedentary at baseline. \\
\hline Nilsen 2015 & Unclear whether participants were sedentary at baseline or not \\
\hline Nobes 2012 & Poster \\
\hline Nuri 2012 & Unclear on inclusion or exclusion criteria \\
\hline Nuri 2016 & Unclear whether participants were sedentary at baseline or not. \\
\hline Nyrop 2017 & Not sedentary at baseline \\
\hline O'Neil 2015 & Unclear on intensity of prescribed exercise \\
\hline Ohira 2006 & Linked to Schmitz 2005 \\
\hline Ornish 2005 & Sedentary status at baseline is unclear \\
\hline
\end{tabular}




\begin{tabular}{|c|c|}
\hline Study & Reason for exclusion \\
\hline Ornish 2008a & Linked to Ornish 2005 \\
\hline Ornish 2008b & Linked to Ornish 2005 \\
\hline Park 2012 & The interventions were prescribed continence exercises rather than aerobic/resistance exercise \\
\hline Park 2016 & Author confirmed participants were not sedentary at baseline \\
\hline Payne 2008 & Sedentary status at baseline is unclear \\
\hline Philips 2012 & Not a homogenous cancer cohort \\
\hline Pickett 2002 & Sedentary status at baseline is unclear \\
\hline Pinto 2013a & No usual care comparison \\
\hline Pinto 2013b & No usual care comparison \\
\hline Pinto 2015 & No usual care comparison \\
\hline Porserud 2014 & Intensity of prescribed exercise was unclear \\
\hline Portela 2008 & Author advised that baseline sedentary status was not assessed \\
\hline Rabin 2016 & The cancer cohort was not homogenous \\
\hline Rahnama 2010 & Author not able to confirm sedentary status \\
\hline Rao 2012 & Unclear whether participants were sedentary at baseline or not. \\
\hline Reis 2013 & Did not report or measure intensity \\
\hline Rogers 2009 & Author advised that cohort was not sedentary at baseline \\
\hline Rogers 2012 & Author advised that cohort was not sedentary at baseline \\
\hline Rogers 2013a & No usual care comparison \\
\hline Rogers 2013b & Participants were not sedentary at baseline \\
\hline Rogers 2014 & Participants were not sedentary at baseline \\
\hline Rogers 2015b & Linked to Rogers 2014 \\
\hline Saarto $2012 a$ & Participants were not sedentary at baseline \\
\hline Saarto $2012 b$ & Participants were not sedentary at baseline \\
\hline Sajid 2013 & No usual care comparison \\
\hline Samuel 2013 & Control was advised to keep physically active as possible \\
\hline Sandel 2005 & Sedentary status at baseline is unclear \\
\hline Schmidt 2015 & No usual care comparison \\
\hline
\end{tabular}




\begin{tabular}{|c|c|}
\hline Study & Reason for exclusion \\
\hline Schmidt 2017a & Linked to Schmidt 2015 \\
\hline Schmidt 2017b & Unclear whether participants were sedentary or not at baseline \\
\hline Schmitz 2009 & Author advised intensity not assessed \\
\hline Schmitz 2010 & Author advised intensity not assessed \\
\hline Schmitz 2015a & Linked to Schmitz 2015b \\
\hline Schmitz 2015b & Participants were not cancer survivors \\
\hline Schuler 2017 & Not homogenous cancer cohort \\
\hline Schwartz 2015 & Not homogenous cancer cohort \\
\hline Scruggs 2018 & Exercise prescription is not clear \\
\hline Sebio Garcia 2017 & Unclear if the participants were sedentary at baseline \\
\hline Segal 2001 & Author advised exercise behavior not formally assessed at baseline \\
\hline Segal 2003 & Author advised exercise behavior not formally assessed at baseline \\
\hline Segal 2009 & Author advised exercise behavior not formally assessed at baseline \\
\hline Sener 2017 & Intensity of exercise is not clear \\
\hline Sheppard 2016 & Intensity of exercise is not clear \\
\hline Shobeiri 2016 & Participants were not sedentary at baseline \\
\hline Short 2012 & Poster \\
\hline Short 2017a & Participants were not sedentary at baseline \\
\hline Short 2017b & Participants were not sedentary at baseline \\
\hline Singh 2015 & Cross-over trial \\
\hline Skinner 2016 & Participants were not sedentary at baseline \\
\hline Sohl 2016 & No usual care comparison \\
\hline Spahn 2013 & No usual care comparison \\
\hline Stacey 2016 & Mediator paper reporting on previous unsuitable randomised controlled trial \\
\hline Stefanelli 2013 & Unclear whether the participants were sedentary at baseline or not \\
\hline Stolley 2017 & Unclear whether participants were sedentary at baseline \\
\hline Streckman 2014 & Participants were hospitalised \\
\hline Sturgeon 2017 & Participants were not sedentary at baseline \\
\hline
\end{tabular}




\begin{tabular}{|c|c|}
\hline Study & Reason for exclusion \\
\hline Swisher 2015 & Participants were not sedentary at baseline \\
\hline Taafe 2017 & Usual care participants were active \\
\hline Taleghani 2012 & Participants were not adults \\
\hline Taso 2014 & Intensity not reported \\
\hline Terranova 2017 & Unclear whether participants were sedentary at baseline \\
\hline Tomasello 2017 & Compared with a 'healthy' control \\
\hline Tometich 2017 & Participants were not sedentary at baseline \\
\hline Travier 2015 & Participants were not sedentary at baseline \\
\hline Trinh 2014 & Linked to Mutrie 2007 \\
\hline Uth 2014 & Participants were not sedentary at baseline \\
\hline Uth 2016 & Participants were not sedentary at baseline \\
\hline Van Vulpen 2016 & Not a homogenous cancer cohort \\
\hline van Waart 2015 & Unclear whether participants were sedentary at baseline \\
\hline von Gruenigen 2008 & Author advised that cohort was not sedentary at baseline \\
\hline von Gruenigen 2009 & Linked to von Gruenigen 2008 \\
\hline von Gruenigen 2012 & Author advised that cohort was not sedentary \\
\hline Waltman 2010 & Author advised that cohort was not sedentary \\
\hline Wang 2012 & Sedentary status at baseline is unclear \\
\hline Wasley 2018 & Mixed cancer cohort \\
\hline Wiskemann 2017 & Participants were not sedentary at baseline \\
\hline Xu 2015 & Participants were not sedentary at baseline \\
\hline Yang 2011 & Sedentary status at baseline is unclear \\
\hline Yeo 2012 & Author not able to clarify exercise metrics \\
\hline Yuen 2007 & Author advised that cohort was not sedentary at baseline \\
\hline Yun 2013 & Not homogenous cancer cohort \\
\hline Zhang 2018 & Unclear whether participants were sedentary at baseline \\
\hline Zhao 2016 & Not a randomised controlled trial \\
\hline Zhou 2015 & Conference paper \\
\hline
\end{tabular}




\begin{tabular}{ll}
\hline Study & Reason for exclusion \\
\hline Zimmer 2014 & Compared with a 'healthy control' \\
\hline Zimmer 2016 & Protocol paper \\
\hline Zopf 2012 & Poster \\
\hline
\end{tabular}

Characteristics of studies awaiting assessment [ordered by study ID]

Bai 2004

Methods

\section{Participants}

Interventions

\section{Outcomes}

\section{Notes}

Study awaiting translation: Bai S-M, Ma C, Liu Y-M, Xue W-P, Luo M, Ou Z-H. Effects of cognitive behavior intervention and cinesiateics on the quality of life of patients with nasopharyngeal carcinoma after radiotherapy. Chinese Journal of Clinical Rehabilitation 2004;8(29):6312-3.

\section{Chen 2010}

\section{Methods}

\section{Participants}

Interventions

\section{Outcomes}

\begin{tabular}{ll}
\hline Notes & Study awaiting translation: Chen J, Luo A, He Y. Influence of postoperative rehabilitation ex- \\
ercises on functional recovery of ill limb of breast cancer patients. Chinese Nursing Research \\
$2010 ; 24(4 \mathrm{~A}): 875-7$.
\end{tabular}

\section{Cho 2004}

\section{Methods}

\section{Participants}

$$
\text { Interventions }
$$

\section{Outcomes}

\section{Notes}

Study awaiting translation: $\mathrm{Cho} \mathrm{OH}$. Effects of a comprehensive rehabilitation programme for mastectomy patients. Taehan Kanho Hakhoe Chi 2004;34(5):809-19. 
Choi 2012

\title{
Methods
}

Participants

\section{Interventions}

\section{Outcomes}

\begin{tabular}{ll}
\hline Notes & Still awaiting translation: Choi, J. Y. Kang, H. S. Effects of a home-based exercise program for pa- \\
tients with stomach cancer receiving oral chemotherapy after surgery. Journal of Korean Academy \\
of Nursing, 2012; 42(1):95-104
\end{tabular}

\section{Dong 2006}

\section{Methods}

Participants

\section{Interventions}

\section{Outcomes}

$$
\text { Notes }
$$

Study awaiting translation: Dong HY, Wang ZF, Cai L. Correlation between quality of life and rehabilitative guidance education in the postoperative patients with breast cancer. Chinese Journal of Clinical Rehabilitation 2006; 10(42), 28-30.

\section{Guo 2004}

\section{Methods}

Participants

\author{
Interventions
}

\section{Outcomes}

\begin{tabular}{ll}
\hline Notes & Study awaiting translation: Guo Y-M. Effects of moderate strength and endurance exercise on emo- \\
tion and quality of sleep in patients with malignant tumor. Chinese Journal of Clinical Rehabilita- \\
tion 2004;8(35):7896-7.
\end{tabular}

\section{Hu 2013}

\section{Methods}

\section{Participants}

Interventions 
Hu 2013 (Continued)

Outcomes

Notes

LeVu 1997

Methods

Participants

Interventions

Outcomes

Notes

Study awaiting translation: Le Vu B, Dumortier A, Guillaume MV, Mouriesse H, Barreau-Pouhaer L. Efficacy of massage and mobilization of the upper limb after surgical treatment of breast cancer.

Bulletin du Cancer 1997;80(10):957-61.

Oliveira 2010

\section{Methods}

Participants

Interventions

\section{Outcomes}

\section{Notes}

Study awaiting translation: Oliveira MM, Souza GA, Miranda Mde S, Okubo MA, Amaral MT, Silva MP, Gurgel MS. Upper limb exercises during radiotherapy for breast cancer and quality of life. Revista Brasileira de Ginecologia e Obstetrícia 2010;32(3):133-8.

Park 2006

\section{Methods}

\section{Participants}

Interventions

\section{Outcomes}

\section{Notes}

Study awaiting translation: Park HS, Cho GY, Park KY. The effects of a rehabilitation program on physical health, physiological indicator and quality of life in breast cancer mastectomy patients. Taehan Kanho Hakhoe Chi 2006;36(2):310-20. 
Wang 2005

Methods

\section{Participants}

Interventions

\section{Outcomes}

Notes

Study awaiting translation: Wang Y;Yao J-F;Yang J-Y. Effect of rehabilitation exercises on the recovery outcomes of lung function in postoperative patients with lung cancer. Zhongguo Linchuang Kangfu (Chinese Journal of Clinical Rehabilitation) 2005; 9(39):14-16.

\section{Zhang 2005}

Methods

\section{Participants}

Interventions

\section{Outcomes}

Notes

Study awaiting translation: Zhang T, Chang XM, He YG, Huang HX, Fan KS. Effects of rehabilitation therapy in relieving pain and improving quality of life in patients with advanced cancer. Zhongguo Linchuang Kangfu (Chinese Journal of Clinical Rehabilitation) 2005;40:59-61.

\section{DATA AND ANALYSES}

\section{Comparison 1. Aerobic exercise tolerance}

\begin{tabular}{|c|c|c|c|c|}
\hline Outcome or subgroup title & No. of studies & $\begin{array}{l}\text { No. of partici- } \\
\text { pants }\end{array}$ & Statistical method & Effect size \\
\hline $\begin{array}{l}1 \text { Aerobic exercise tolerance (all cancers: } 8 \\
\text { to } 12 \text { weeks of follow-up) }\end{array}$ & 10 & 604 & $\begin{array}{l}\text { Std. Mean Difference (IV, } \\
\text { Fixed, } 95 \% \mathrm{CI} \text { ) }\end{array}$ & $0.54[0.37,0.70]$ \\
\hline $\begin{array}{l}2 \text { Aerobic exercise tolerance (all cancers: } 8 \\
\text { to } 12 \text { weeks of follow-up sensitivity analysis) }\end{array}$ & 4 & 201 & $\begin{array}{l}\text { Std. Mean Difference (IV, } \\
\text { Fixed, } 95 \% \mathrm{CI} \text { ) }\end{array}$ & $0.85[0.56,1.14]$ \\
\hline $\begin{array}{l}3 \text { Aerobic exercise tolerance (all cancers: } 6 \\
\text { months of follow-up) }\end{array}$ & 7 & 591 & $\begin{array}{l}\text { Std. Mean Difference (IV, } \\
\text { Fixed, } 95 \% \mathrm{CI} \text { ) }\end{array}$ & $0.56[0.39,0.72]$ \\
\hline $\begin{array}{l}4 \text { Aerobic exercise tolerance (breast cancer: } \\
\text { 8-12 weeks of follow-up) }\end{array}$ & 6 & 441 & $\begin{array}{l}\text { Std. Mean Difference (IV, } \\
\text { Random, 95\% CI) }\end{array}$ & $0.57[0.22,0.93]$ \\
\hline $\begin{array}{l}5 \text { Aerobic exercise tolerance (all cancers: } \\
\text { combination of supervised and home-based } \\
\text { exercise: } 8 \text { to } 12 \text { weeks of follow-up) }\end{array}$ & 4 & 357 & $\begin{array}{l}\text { Std. Mean Difference (IV, } \\
\text { Random, } 95 \% \mathrm{CI} \text { ) }\end{array}$ & $0.53[0.01,1.04]$ \\
\hline
\end{tabular}




\begin{tabular}{|c|c|c|c|c|}
\hline Outcome or subgroup title & No. of studies & $\begin{array}{l}\text { No. of partici- } \\
\text { pants }\end{array}$ & Statistical method & Effect size \\
\hline $\begin{array}{l}6 \text { Aerobic exercise tolerance (all cancers: } \\
\text { home-based exercise: } 8 \text { to } 12 \text { weeks of fol- } \\
\text { low-up) }\end{array}$ & 3 & 155 & $\begin{array}{l}\text { Std. Mean Difference (IV, } \\
\text { Fixed, } 95 \% \mathrm{CI} \text { ) }\end{array}$ & $0.70[0.37,1.03]$ \\
\hline $\begin{array}{l}7 \text { Aerobic exercise tolerance (all cancer- } \\
\text { s:supervised exercise: } 8 \text { to } 12 \text { weeks of fol- } \\
\text { low-up) }\end{array}$ & 3 & 92 & $\begin{array}{l}\text { Std. Mean Difference (IV, } \\
\text { Random, 95\% CI) }\end{array}$ & $1.07[0.26,1.89]$ \\
\hline $\begin{array}{l}8 \text { Aerobic exercise tolerance (all cancers: un- } \\
\text { dergoing active treatment: } 8 \text { to } 12 \text { weeks fol- } \\
\text { low-up) }\end{array}$ & 6 & 313 & $\begin{array}{l}\text { Std. Mean Difference (IV, } \\
\text { Fixed, } 95 \% \mathrm{CI} \text { ) }\end{array}$ & $0.72[0.49,0.95]$ \\
\hline $\begin{array}{l}9 \text { Aerobic exercise tolerance (all cancers: no } \\
\text { active treatment: } 8 \text { to } 12 \text { weeks follow-up }\end{array}$ & 4 & 291 & $\begin{array}{l}\text { Std. Mean Difference (IV, } \\
\text { Random, } 95 \% \mathrm{Cl} \text { ) }\end{array}$ & $0.61[0.10,1.12]$ \\
\hline
\end{tabular}

Analysis 1.1. Comparison 1 Aerobic exercise tolerance, Outcome 1 Aerobic exercise tolerance (all cancers: 8 to 12 weeks of follow-up).

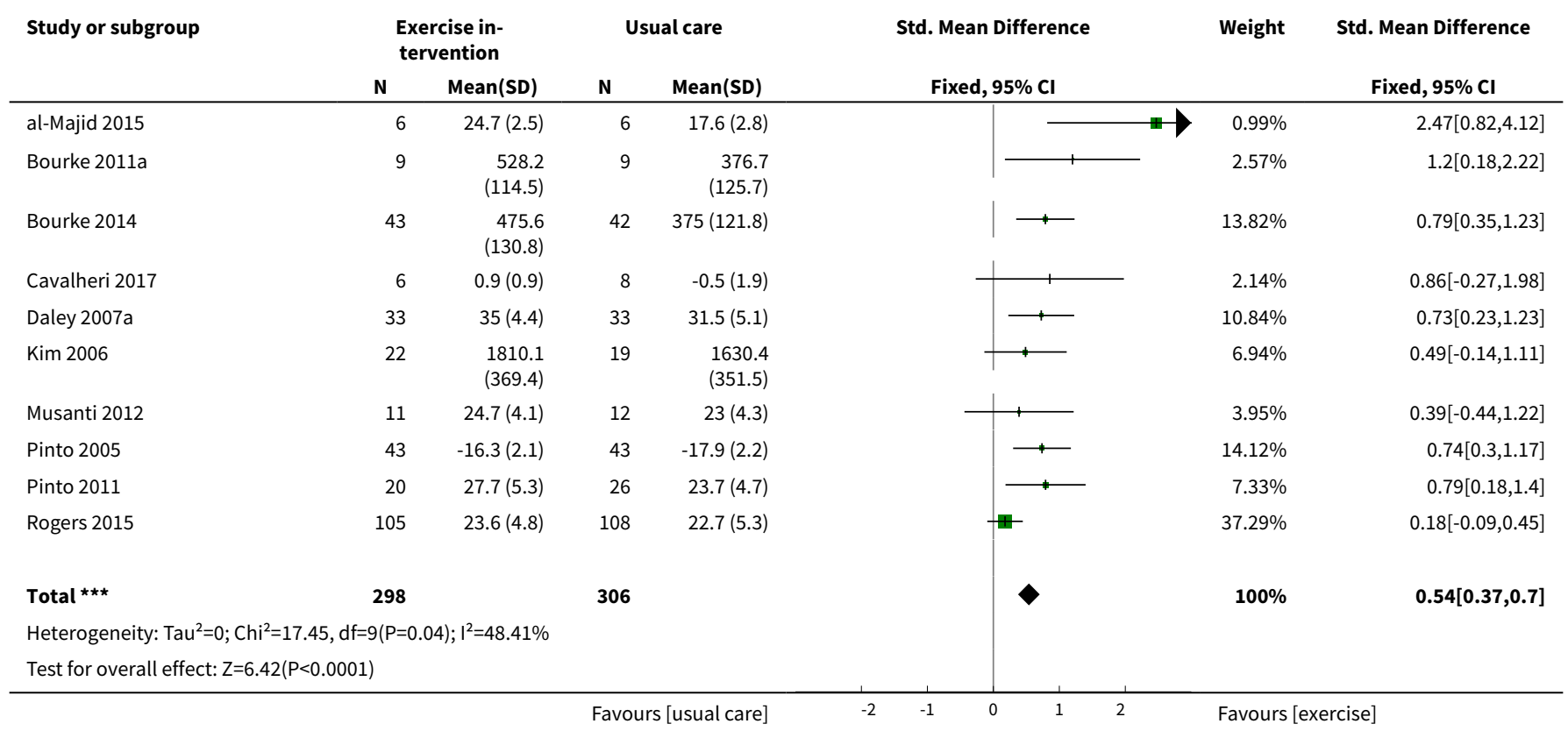

Analysis 1.2. Comparison 1 Aerobic exercise tolerance, Outcome 2 Aerobic exercise tolerance (all cancers: 8 to 12 weeks of follow-up sensitivity analysis).

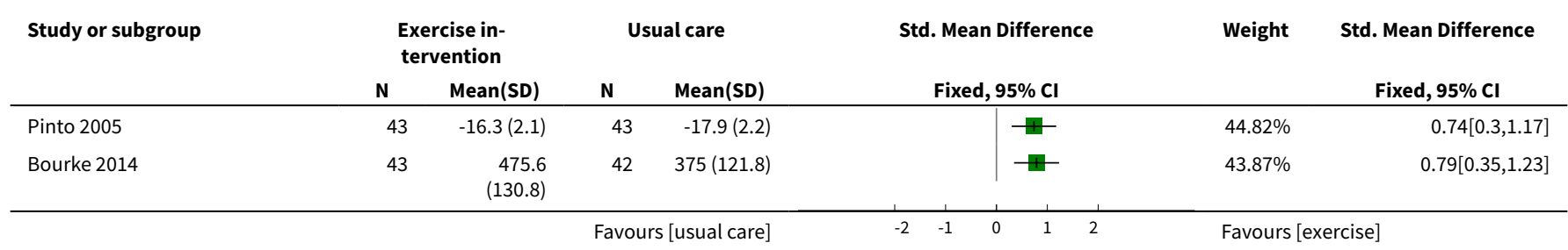




\begin{tabular}{|c|c|c|c|c|c|c|c|c|}
\hline \multirow{3}{*}{$\begin{array}{l}\text { Study or subgroup } \\
\text { Bourke } 2011 a\end{array}$} & \multicolumn{2}{|c|}{$\begin{array}{l}\text { Exercise in- } \\
\text { tervention }\end{array}$} & \multicolumn{2}{|c|}{ Usual care } & \multirow{2}{*}{\multicolumn{2}{|c|}{$\begin{array}{l}\text { Std. Mean Difference } \\
\text { Fixed, } 95 \% \mathrm{Cl} \\
\end{array}$}} & \multirow{3}{*}{$\begin{array}{l}\text { Weight } \\
8.17 \%\end{array}$} & \multirow{3}{*}{$\begin{array}{l}\text { Std. Mean Difference } \\
\qquad \text { Fixed, } 95 \% \text { Cl } \\
1.2[0.18,2.22]\end{array}$} \\
\hline & \multirow{2}{*}{$\frac{\mathbf{N}}{9}$} & \multirow{2}{*}{$\begin{array}{r}\text { Mean(SD) } \\
528.2 \\
(114.5)\end{array}$} & & \multirow{2}{*}{$\begin{array}{r}\text { Mean(SD) } \\
376.7 \\
(125.7)\end{array}$} & & & & \\
\hline & & & & & & $\longrightarrow$ & & \\
\hline al-Majid 2015 & 6 & $24.7(2.5)$ & 6 & $17.6(2.8)$ & & & $3.14 \%$ & $2.47[0.82,4.12]$ \\
\hline 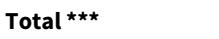 & 101 & & 100 & & & 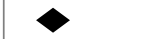 & $100 \%$ & $0.85[0.56,1.14]$ \\
\hline \multicolumn{9}{|c|}{ Heterogeneity: $\operatorname{Tau}^{2}=0 ; \mathrm{Chi}^{2}=4.46, \mathrm{df}=3(\mathrm{P}=0.22) ; \mathrm{I}^{2}=32.76 \%$} \\
\hline \multicolumn{3}{|c|}{ Test for overall effect: $Z=5.7(P<0.0001)$} & & & & & & \\
\hline
\end{tabular}

Analysis 1.3. Comparison 1 Aerobic exercise tolerance, Outcome 3 Aerobic exercise tolerance (all cancers: 6 months of follow-up).

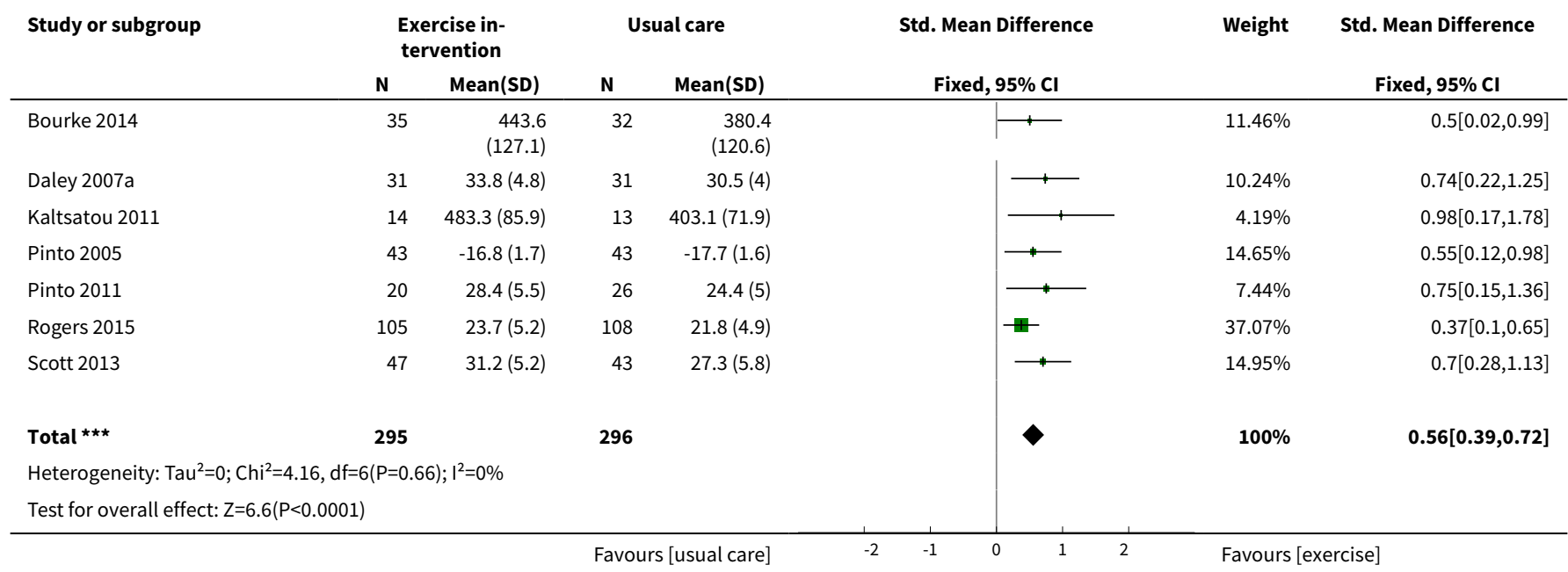

Analysis 1.4. Comparison 1 Aerobic exercise tolerance, Outcome 4 Aerobic exercise tolerance (breast cancer: 8-12 weeks of follow-up).

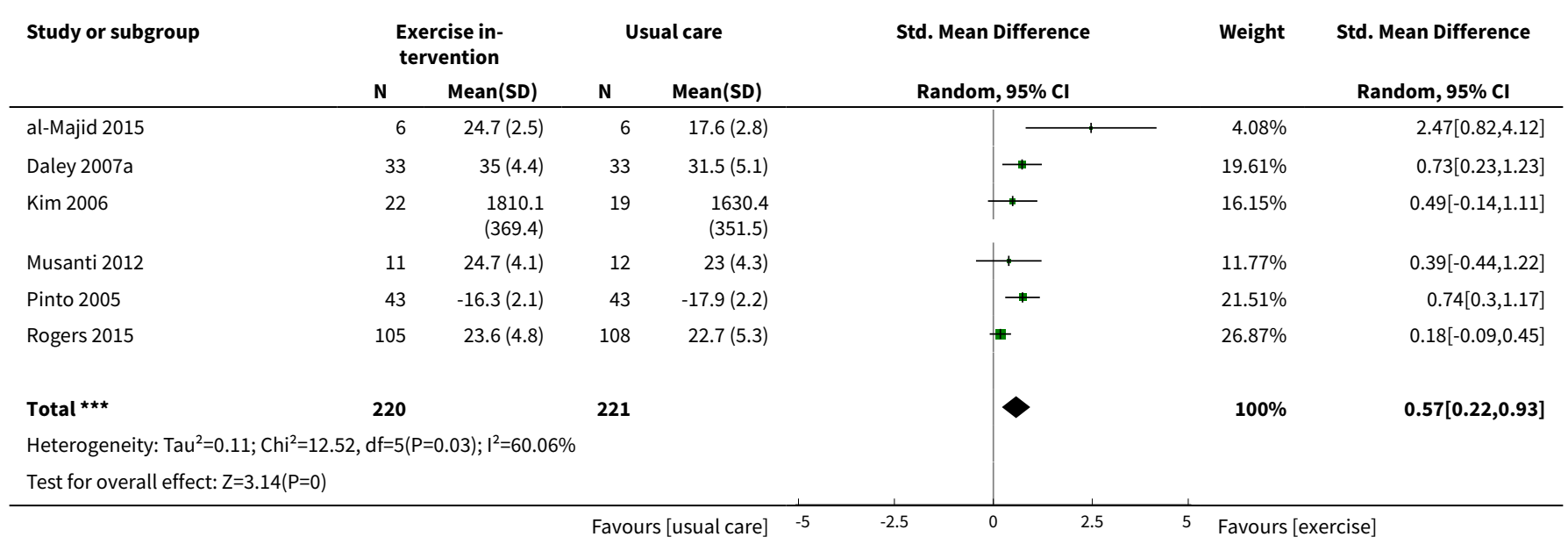


Analysis 1.5. Comparison 1 Aerobic exercise tolerance, Outcome 5 Aerobic exercise tolerance (all cancers: combination of supervised and home-based exercise: 8 to 12 weeks of follow-up).

\begin{tabular}{|c|c|c|c|c|c|c|c|}
\hline \multirow[t]{2}{*}{ Study or subgroup } & \multicolumn{2}{|c|}{$\begin{array}{l}\text { Exercise in- } \\
\text { tervention }\end{array}$} & \multicolumn{2}{|c|}{ Usual care } & \multirow{2}{*}{$\begin{array}{c}\text { Std. Mean Difference } \\
\text { Random, } 95 \% \mathrm{Cl} \\
\end{array}$} & \multirow{3}{*}{$\begin{array}{l}\text { Weight } \\
14.83 \%\end{array}$} & \multirow{3}{*}{$\begin{array}{c}\text { Std. Mean Difference } \\
\text { Random, 95\% Cl } \\
1.2[0.18,2.22]\end{array}$} \\
\hline & \multirow{2}{*}{$\frac{\mathbf{N}}{9}$} & \multirow{2}{*}{$\begin{array}{r}\text { Mean(SD) } \\
528.2 \\
(114.5)\end{array}$} & & \multirow{2}{*}{$\begin{array}{r}\text { Mean(SD) } \\
376.7 \\
(125.7)\end{array}$} & & & \\
\hline Bourke 2011a & & & & & $\longrightarrow$ & & \\
\hline Bourke 2014 & 43 & $\begin{array}{r}475.6 \\
(130.8)\end{array}$ & 42 & $375(121.8)$ & 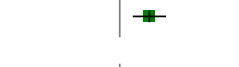 & $28.57 \%$ & $0.79[0.35,1.23]$ \\
\hline Kim 2006 & 22 & $\begin{array}{l}1810.1 \\
(369.4)\end{array}$ & 19 & $\begin{array}{l}1630.4 \\
(351.5)\end{array}$ & - & $23.62 \%$ & $0.49[-0.14,1.11]$ \\
\hline Rogers 2015 & 105 & $23.6(4.8)$ & 108 & $22.7(53)$ & \# & $32.98 \%$ & $0.02[-0.24,0.29]$ \\
\hline 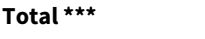 & 179 & & 178 & & & $100 \%$ & $0.53[0.01,1.04]$ \\
\hline \multicolumn{8}{|c|}{ Heterogeneity: $\operatorname{Tau}^{2}=0.19 ; \mathrm{Chi}^{2}=12.06, \mathrm{df}=3(\mathrm{P}=0.01) ; \mathrm{I}^{2}=75.13 \%$} \\
\hline \multicolumn{3}{|c|}{ Test for overall effect: $Z=2.01(P=0.04)$} & & & & & \\
\hline
\end{tabular}

Analysis 1.6. Comparison 1 Aerobic exercise tolerance, Outcome 6 Aerobic exercise tolerance (all cancers: home-based exercise: 8 to 12 weeks of follow-up).

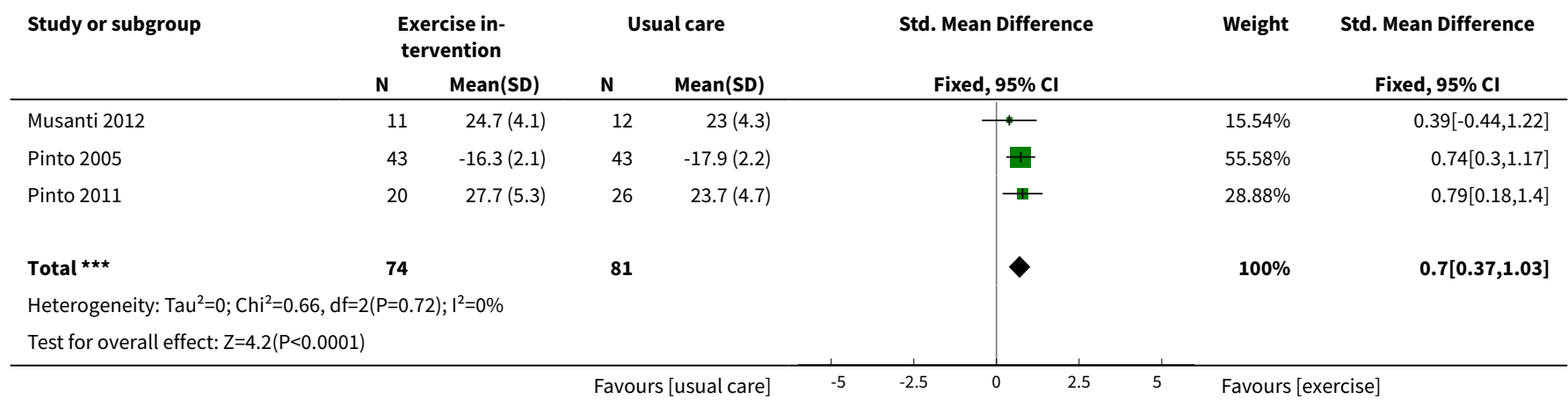

Analysis 1.7. Comparison 1 Aerobic exercise tolerance, Outcome 7 Aerobic exercise tolerance (all cancers:supervised exercise: 8 to 12 weeks of follow-up).

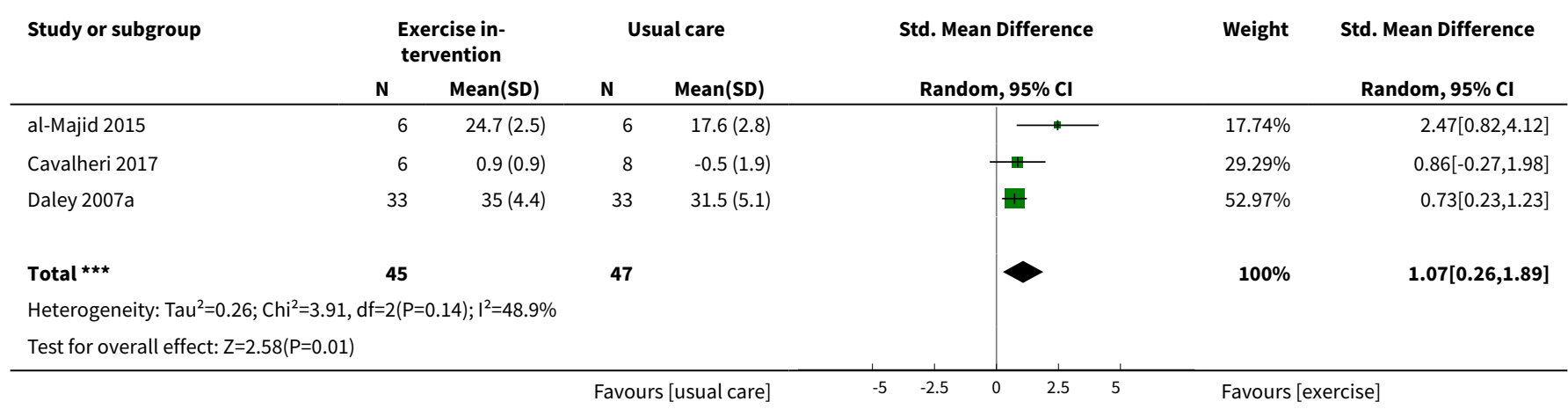


Analysis 1.8. Comparison 1 Aerobic exercise tolerance, Outcome 8 Aerobic exercise tolerance (all cancers: undergoing active treatment: 8 to 12 weeks follow-up).

\begin{tabular}{|c|c|c|c|c|c|c|c|}
\hline \multirow{3}{*}{$\begin{array}{l}\text { Study or subgroup } \\
\text { al-Majid } 2015\end{array}$} & \multicolumn{2}{|c|}{$\begin{array}{l}\text { Exercise in- } \\
\text { tervention }\end{array}$} & \multicolumn{2}{|c|}{ Usual care } & \multirow{2}{*}{$\begin{array}{l}\text { Std. Mean Difference } \\
\text { Fixed, } 95 \% \mathrm{Cl} \\
\end{array}$} & \multirow{3}{*}{$\begin{array}{r}\text { Weight } \\
1.95 \%\end{array}$} & \multirow{3}{*}{$\begin{array}{l}\text { Std. Mean Difference } \\
\text { Fixed, 95\% Cl } \\
2.47[0.82,4.12]\end{array}$} \\
\hline & \multirow{2}{*}{$\frac{\mathbf{N}}{6}$} & \multirow{2}{*}{$\begin{array}{r}\text { Mean(SD) } \\
24.7(2.5)\end{array}$} & \multirow{2}{*}{$\frac{\mathbf{N}}{6}$} & \multirow{2}{*}{$\frac{\text { Mean(SD) }}{17.6(2.8)}$} & & & \\
\hline & & & & & 1 & & \\
\hline Bourke 2014 & 43 & $\begin{array}{r}475.6 \\
(130.8)\end{array}$ & 42 & $375(121.8)$ & $\rightarrow$ & $27.28 \%$ & $0.79[0.35,1.23]$ \\
\hline Daley 2007a & 33 & $35(4.4)$ & 33 & $31.5(5.1)$ & $\rightarrow$ & $21.41 \%$ & $0.73[0.23,1.23]$ \\
\hline Kim 2006 & 22 & $\begin{array}{l}1810.1 \\
(369.4)\end{array}$ & 19 & $\begin{array}{l}1630.4 \\
(351.5)\end{array}$ & 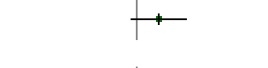 & $13.71 \%$ & $0.49[-0.14,1.11]$ \\
\hline Musanti 2012 & 11 & $24.7(4.1)$ & 12 & $23(4.3)$ & + & $7.79 \%$ & $0.39[-0.44,1.22]$ \\
\hline Pinto 2005 & 43 & $-16.3(2.1)$ & 43 & $-17.9(2.2)$ & 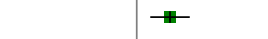 & $27.87 \%$ & $0.74[0.3,1.17]$ \\
\hline 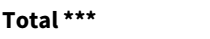 & 158 & & 155 & & 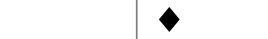 & $100 \%$ & $0.72[0.49,0.95]$ \\
\hline \multicolumn{8}{|c|}{ Heterogeneity: $\mathrm{Tau}^{2}=0 ; \mathrm{Chi}^{2}=5.54, \mathrm{df}=5(\mathrm{P}=0.35) ; \mathrm{I}^{2}=9.8 \%$} \\
\hline \multicolumn{3}{|c|}{ Test for overall effect: $Z=6.12(P<0.0001)$} & & & & & \\
\hline
\end{tabular}

Analysis 1.9. Comparison 1 Aerobic exercise tolerance, Outcome 9 Aerobic exercise tolerance (all cancers: no active treatment: 8 to 12 weeks follow-up.

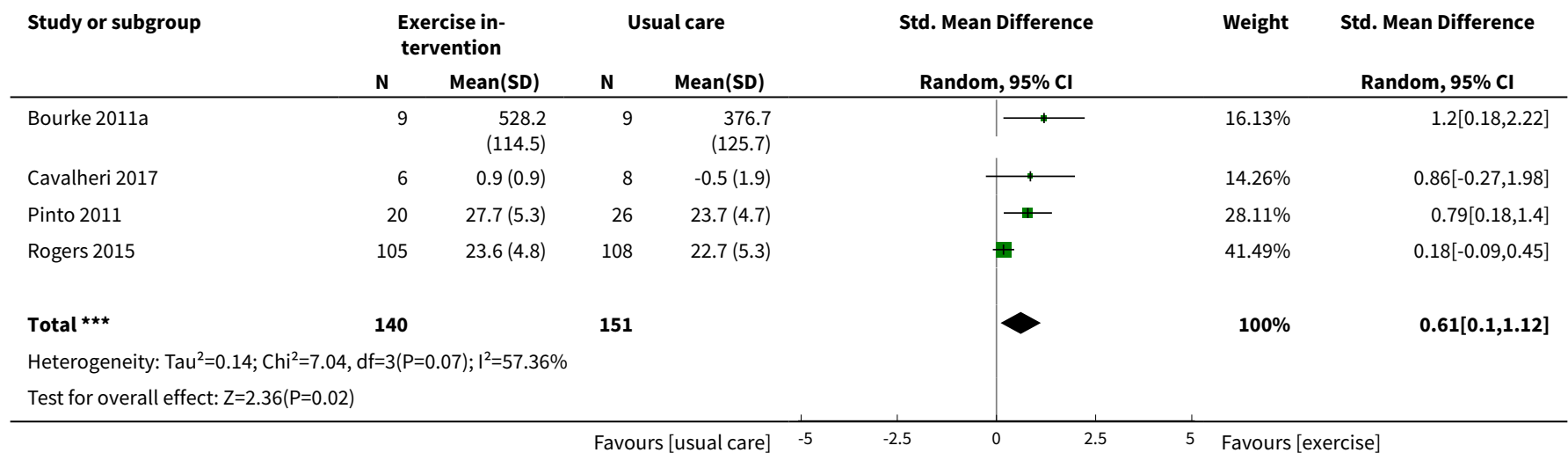

\section{Comparison 2. Strength tests (all cancers)}

\begin{tabular}{lllll}
\hline Outcome or subgroup title & No. of studies & $\begin{array}{l}\text { No. of partici- } \\
\text { pants }\end{array}$ & Statistical method & Effect size \\
\hline $\begin{array}{l}1 \text { Strength tests (all cancers, 12 weeks of } \\
\text { follow-up) }\end{array}$ & 4 & 278 & $\begin{array}{l}\text { Std. Mean Difference (IV, } \\
\text { Fixed, 95\% Cl) }\end{array}$ & $0.20[-0.03,0.44]$ \\
\hline $\begin{array}{l}\text { 2 Strength tests (all cancers: 12 weeks of } \\
\text { follow-up: sensitivity analysis) }\end{array}$ & 2 & 231 & $\begin{array}{l}\text { Std. Mean Difference (IV, } \\
\text { Fixed, 95\% CI) }\end{array}$ & 0.17 [-0.09, 0.43] \\
\hline
\end{tabular}


Analysis 2.1. Comparison 2 Strength tests (all cancers), Outcome 1 Strength tests (all cancers, 12 weeks of follow-up).

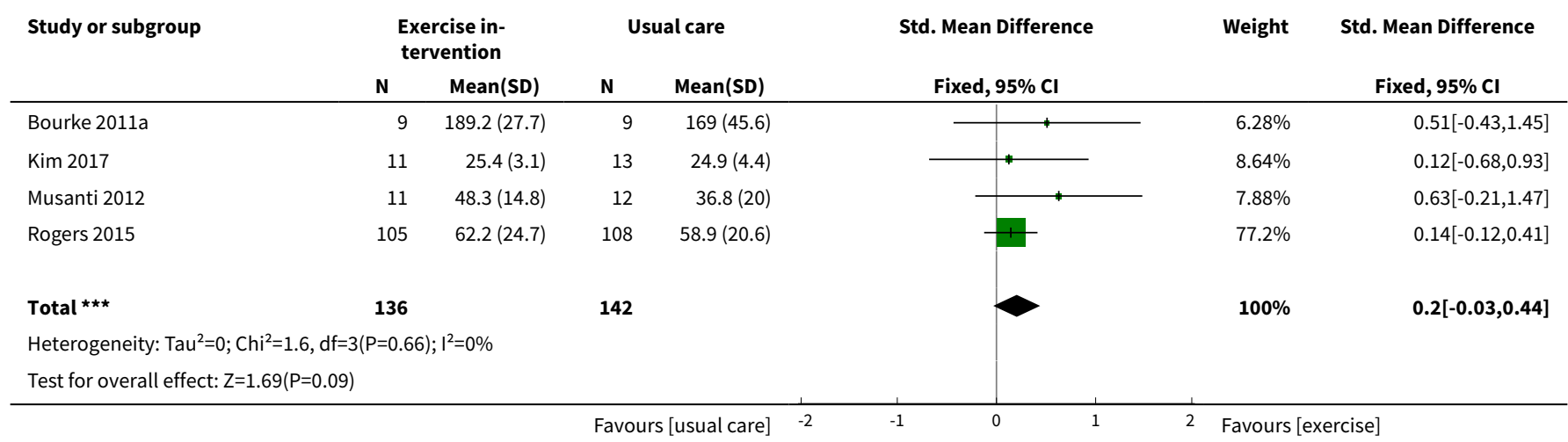

Analysis 2.2. Comparison 2 Strength tests (all cancers), Outcome 2 Strength tests (all cancers: 12 weeks of follow-up: sensitivity analysis).

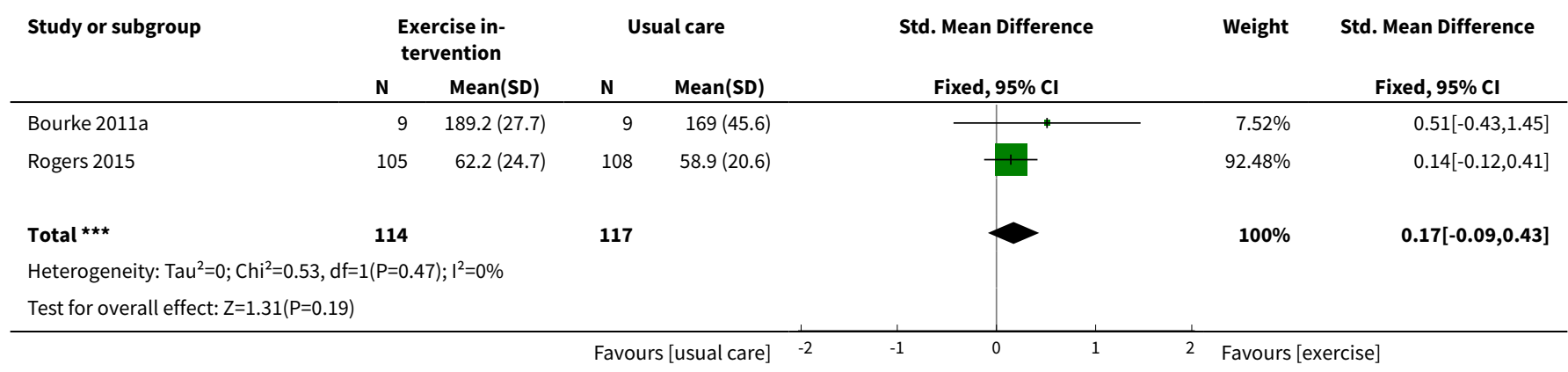




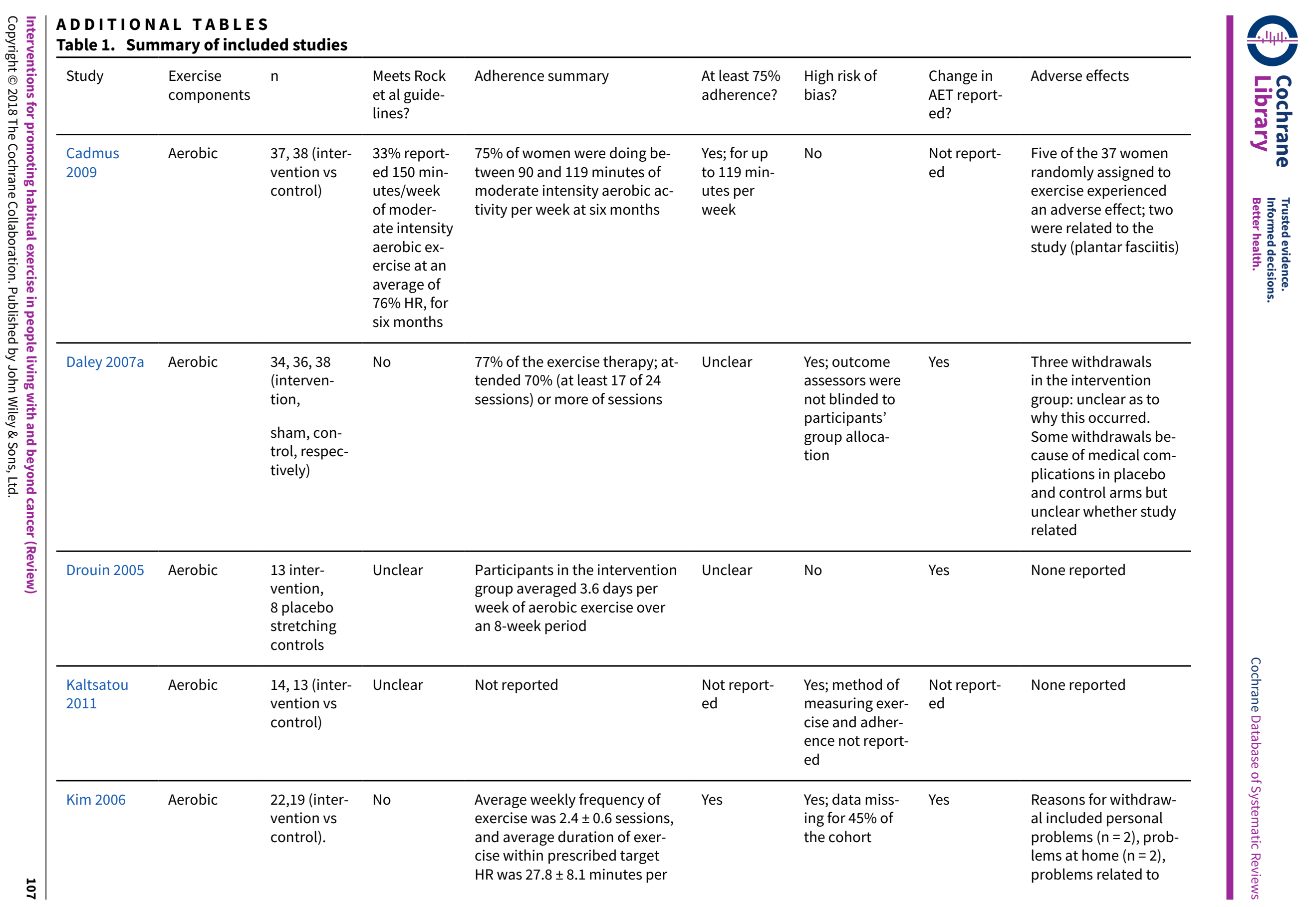




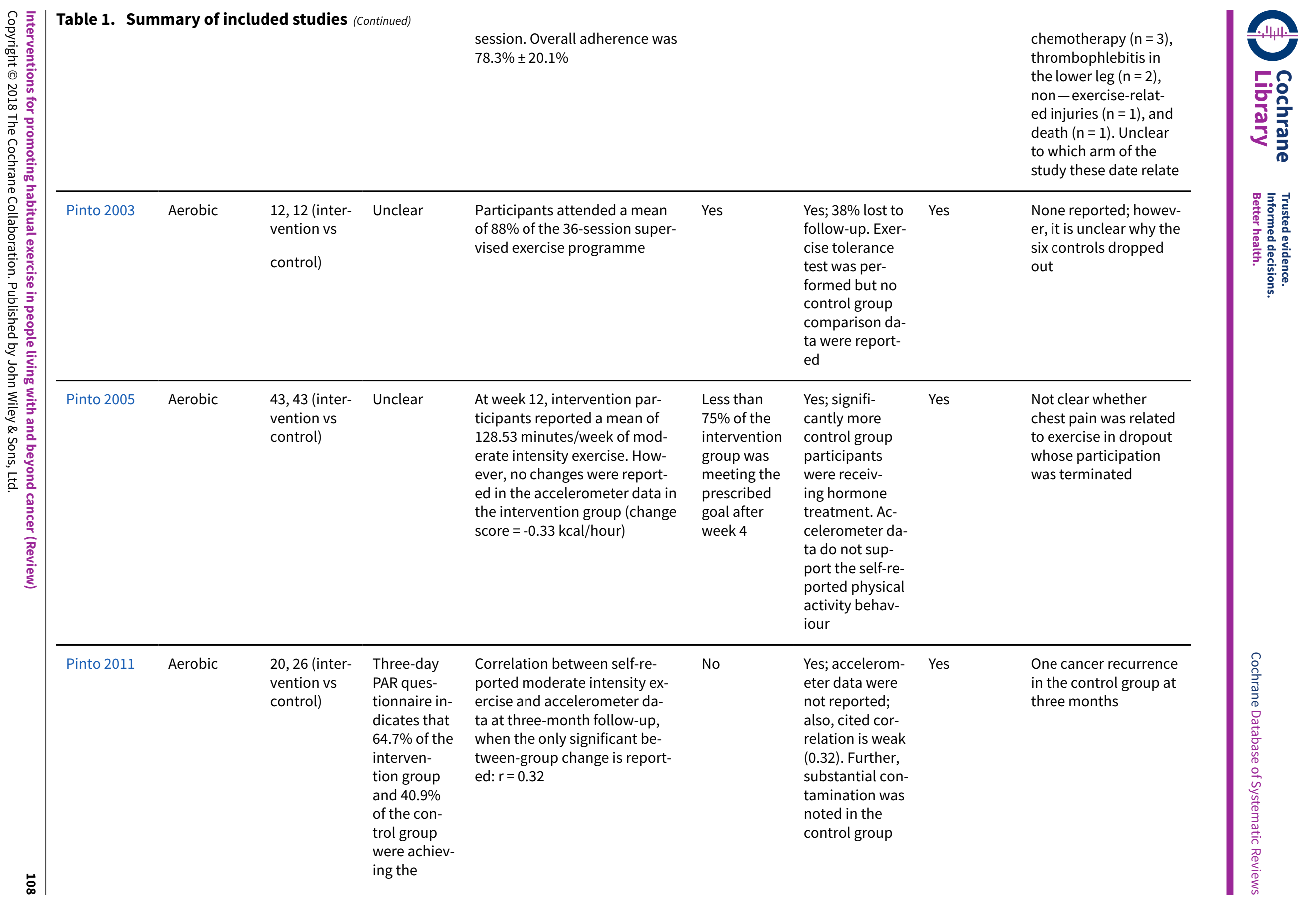




\begin{tabular}{|c|c|c|c|c|c|c|c|c|}
\hline & & & $\begin{array}{l}\text { guidelines } \\
\text { at three } \\
\text { months }\end{array}$ & & & & & \\
\hline $\begin{array}{l}\text { Bourke } \\
2011 a\end{array}$ & $\begin{array}{l}\text { Aerobic and } \\
\text { resistance }\end{array}$ & $\begin{array}{l}9,9 \text { (inter- } \\
\text { vention vs } \\
\text { control) }\end{array}$ & $\begin{array}{l}\text { Six weeks } \\
\text { of resis- } \\
\text { tance exer- } \\
\text { cise twice a } \\
\text { week }\end{array}$ & $\begin{array}{l}90 \% \text { attendance at the super- } \\
\text { vised sessions. } 94 \% \text { of indepen- } \\
\text { dent exercise sessions were } \\
\text { completed }\end{array}$ & Yes & No & Yes & $\begin{array}{l}\text { One stroke in the inter- } \\
\text { vention group, unrelat- } \\
\text { ed to the exercise pro- } \\
\text { gramme }\end{array}$ \\
\hline Hayes 2009 & $\begin{array}{l}\text { Aerobic and } \\
\text { resistance }\end{array}$ & $\begin{array}{l}16,16 \text { (inter- } \\
\text { vention vs } \\
\text { control) }\end{array}$ & Unclear & $\begin{array}{l}\text { Most women ( } 88 \%) \text { allocated to } \\
\text { the intervention group partici- } \\
\text { pated in } 70 \% \text { or more of sched- } \\
\text { uled supervised exercise ses- } \\
\text { sions }\end{array}$ & Unclear & $\begin{array}{l}\text { Yes; adherence } \\
\text { data on unsu- } \\
\text { pervised as- } \\
\text { pect of the in- } \\
\text { tervention are } \\
\text { not clear }\end{array}$ & No & None reported \\
\hline $\begin{array}{l}\text { McKenzie } \\
2003\end{array}$ & $\begin{array}{l}\text { Aerobic and } \\
\text { resistance }\end{array}$ & $\begin{array}{l}7,7 \text { (inter- } \\
\text { vention vs } \\
\text { control) }\end{array}$ & No & Unclear & Unclear & $\begin{array}{l}\text { Yes; adherence } \\
\text { to exercise not } \\
\text { reported }\end{array}$ & $\begin{array}{l}\text { Not report- } \\
\text { ed }\end{array}$ & None reported \\
\hline $\begin{array}{l}\text { Musanti } \\
2012\end{array}$ & $\begin{array}{l}\text { Aerobic and } \\
\text { resistance }\end{array}$ & $\begin{array}{l}\text { Flexibility } \\
\text { group ( } n= \\
13) \text {, aerobic } \\
\text { group ( } n= \\
\text { 12), resis- } \\
\text { tance group } \\
(n=17) \text {, aer- } \\
\text { obic and } \\
\text { resistance } \\
\text { group ( } n= \\
13)\end{array}$ & $\begin{array}{l}12 \text { weeks of } \\
\text { resistance } \\
\text { exercise } \\
\text { two or three } \\
\text { times per } \\
\text { week }\end{array}$ & $\begin{array}{l}\text { Mean percentages of adher- } \\
\text { ence were as follows: flexibili- } \\
\text { ty }=85 \% \text {, aerobic }=81 \% \text {, resis- } \\
\text { tance }=91 \% \text { and aerobic plus } \\
\text { resistance }=86 \%\end{array}$ & Unclear & $\begin{array}{l}\text { Yes; a signifi- } \\
\text { cant number } \\
\text { of dropouts be- } \\
\text { longed to the } \\
\text { resistance exer- } \\
\text { cise group ( } \mathrm{n}= \\
8 / 13 \text { ). Only } 50 \% \\
\text { of activity logs } \\
\text { were returned }\end{array}$ & Yes & $\begin{array}{l}\text { Adverse effects were } \\
\text { reported in two } \\
\text { women during the } \\
\text { study. In both cases, } \\
\text { the women developed } \\
\text { tendonitis: one in the } \\
\text { shoulder and the oth- } \\
\text { er in the foot. Both } \\
\text { had a history of ten- } \\
\text { donitis, and both re- } \\
\text { ceived standard treat- } \\
\text { ment }\end{array}$ \\
\hline Perna 2010 & $\begin{array}{l}\text { Aerobic and } \\
\text { resistance }\end{array}$ & $\begin{array}{l}51 \text { partici- } \\
\text { pants in to- } \\
\text { tal. Num- } \\
\text { bers ran- } \\
\text { domly as- } \\
\text { signed to } \\
\text { each arm } \\
\text { are unclear }\end{array}$ & $\begin{array}{l}\text { Three } \\
\text { months of } \\
\text { resistance } \\
\text { exercise } \\
\text { three times } \\
\text { per week }\end{array}$ & $\begin{array}{l}\text { Women assigned to the struc- } \\
\text { tured intervention complet- } \\
\text { ed an average of } 83 \% \text { of their } \\
\text { scheduled hospital-based exer- } \\
\text { cise sessions (only } 4 \text { weeks in } \\
\text { duration), and } 76.9 \% \text { complet- } \\
\text { ed all } 12 \text { sessions. Home-based } \\
\text { component ( } 8 \text { weeks in dura- } \\
\text { tion) }\end{array}$ & Unclear & $\begin{array}{l}\text { Yes; numbers } \\
\text { randomly as- } \\
\text { signed to in- } \\
\text { tervention and } \\
\text { control groups } \\
\text { are unclear, as } \\
\text { are numbers } \\
\text { completing in } \\
\text { each arm }\end{array}$ & $\begin{array}{l}\text { Not report- } \\
\text { ed }\end{array}$ & Unclear \\
\hline
\end{tabular}




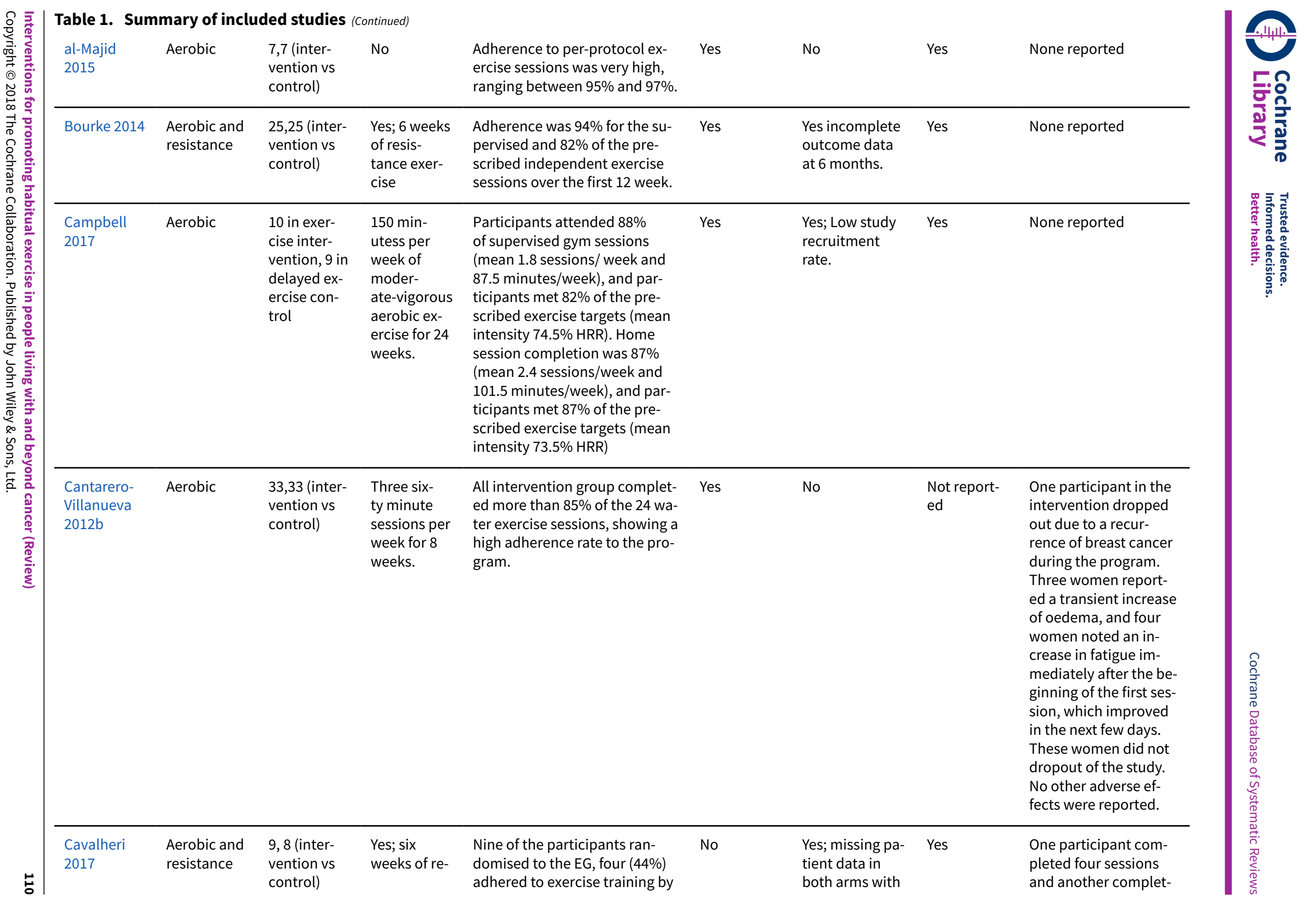




\begin{tabular}{|c|c|c|c|c|c|c|c|c|}
\hline & & & $\begin{array}{l}\text { sistance ex- } \\
\text { ercise. }\end{array}$ & $\begin{array}{l}\text { completing } 15 \text { or more training } \\
\text { sessions (i.e., } \geq 60 \% \text { ). }\end{array}$ & & $\begin{array}{l}\text { no reasons giv- } \\
\text { en. }\end{array}$ & & $\begin{array}{l}\text { ed six sessions. Both } \\
\text { stopped training as } \\
\text { they felt unwell. They } \\
\text { completed some of the } \\
\text { post-intervention as- } \\
\text { sessments and were } \\
\text { later diagnosed with a } \\
\text { primary cancer other } \\
\text { than lung cancer. }\end{array}$ \\
\hline Kim 2017 & $\begin{array}{l}\text { Aerobic and } \\
\text { resistance }\end{array}$ & $\begin{array}{l}15,15 \text { (inter- } \\
\text { vention vs } \\
\text { control) }\end{array}$ & $\begin{array}{l}\text { Three six- } \\
\text { ty minute } \\
\text { sessions per } \\
\text { week for } 12 \\
\text { weeks. }\end{array}$ & $\begin{array}{l}\text { Vague statement: Two partici- } \\
\text { pants did not fulfil the required } \\
\text { exercise }\end{array}$ & Unclear & $\begin{array}{l}\text { Yes; Age dif- } \\
\text { ferences be- } \\
\text { tween groups in } \\
\text { baseline demo- } \\
\text { graphics were } \\
\text { present. Ad- } \\
\text { herence data is } \\
\text { vague. }\end{array}$ & $\begin{array}{l}\text { Not report- } \\
\text { ed }\end{array}$ & None reported \\
\hline $\begin{array}{l}\text { Mohamady } \\
2017\end{array}$ & Aerobic & $\begin{array}{l}15,15 \text { (inter- } \\
\text { vention vs } \\
\text { control) }\end{array}$ & No & Unclear & Unclear & $\begin{array}{l}\text { Yes; No adher- } \\
\text { ence data. }\end{array}$ & Unclear & Unclear \\
\hline Rogers 2015 & Aerobic & $\begin{array}{l}110,112 \text { (in- } \\
\text { tervention } \\
\text { vs control) }\end{array}$ & Yes & $\begin{array}{l}\text { Adherence to the intervention } \\
\text { was } 98 \% \text { for supervised exer- } \\
\text { cise sessions, } 96 \% \text { for update } \\
\text { sessions, and } 91 \% \text { for discus- } \\
\text { sion group sessions. }\end{array}$ & Yes & $\begin{array}{l}\text { Yes; differences } \\
\text { in objective and } \\
\text { subjective mea- } \\
\text { sures of physi- } \\
\text { cal activity re- } \\
\text { ported }\end{array}$ & Yes & $\begin{array}{l}\text { Related expected ad- } \\
\text { verse events in the in- } \\
\text { tervention group in- } \\
\text { cluded back or low- } \\
\text { er extremity muscu- } \\
\text { loskeletal pain or in- } \\
\text { jury }(n=14) \text {, heart rate } \\
\text { monitor rash }(n=1) \text {, } \\
\text { fall while walking }(n= \\
1) \text {, breast reconstruc- } \\
\text { tion }(n=3) \text {, and chest } \\
\text { pain during treadmill } \\
\text { fitness test }(n=1)\end{array}$ \\
\hline Scott 2013 & $\begin{array}{l}\text { Aerobic and } \\
\text { resistance }\end{array}$ & $\begin{array}{l}47,43 \text { (inter- } \\
\text { vention vs } \\
\text { control) }\end{array}$ & $\begin{array}{l}\text { Yes, six } \\
\text { weeks of re- } \\
\text { sistance ex- } \\
\text { ercise. }\end{array}$ & $\begin{array}{l}\text { Adherence for the intervention } \\
\text { group was } 80 \%\end{array}$ & Yes & No & Yes & None reported. \\
\hline $\begin{array}{l}\text { Thomas } \\
2013\end{array}$ & Aerobic & $\begin{array}{l}35,30 \text { (inter- } \\
\text { vention vs } \\
\text { control) }\end{array}$ & Yes & $\begin{array}{l}\text { The exercise goal was } 150 \mathrm{~min} \text { - } \\
\text { utes/week of moderate inten- }\end{array}$ & No & $\begin{array}{l}\text { Yes; not all out- } \\
\text { comes were re- } \\
\text { ported and low }\end{array}$ & $\begin{array}{l}\text { Not report- } \\
\text { ed }\end{array}$ & None reported. \\
\hline
\end{tabular}




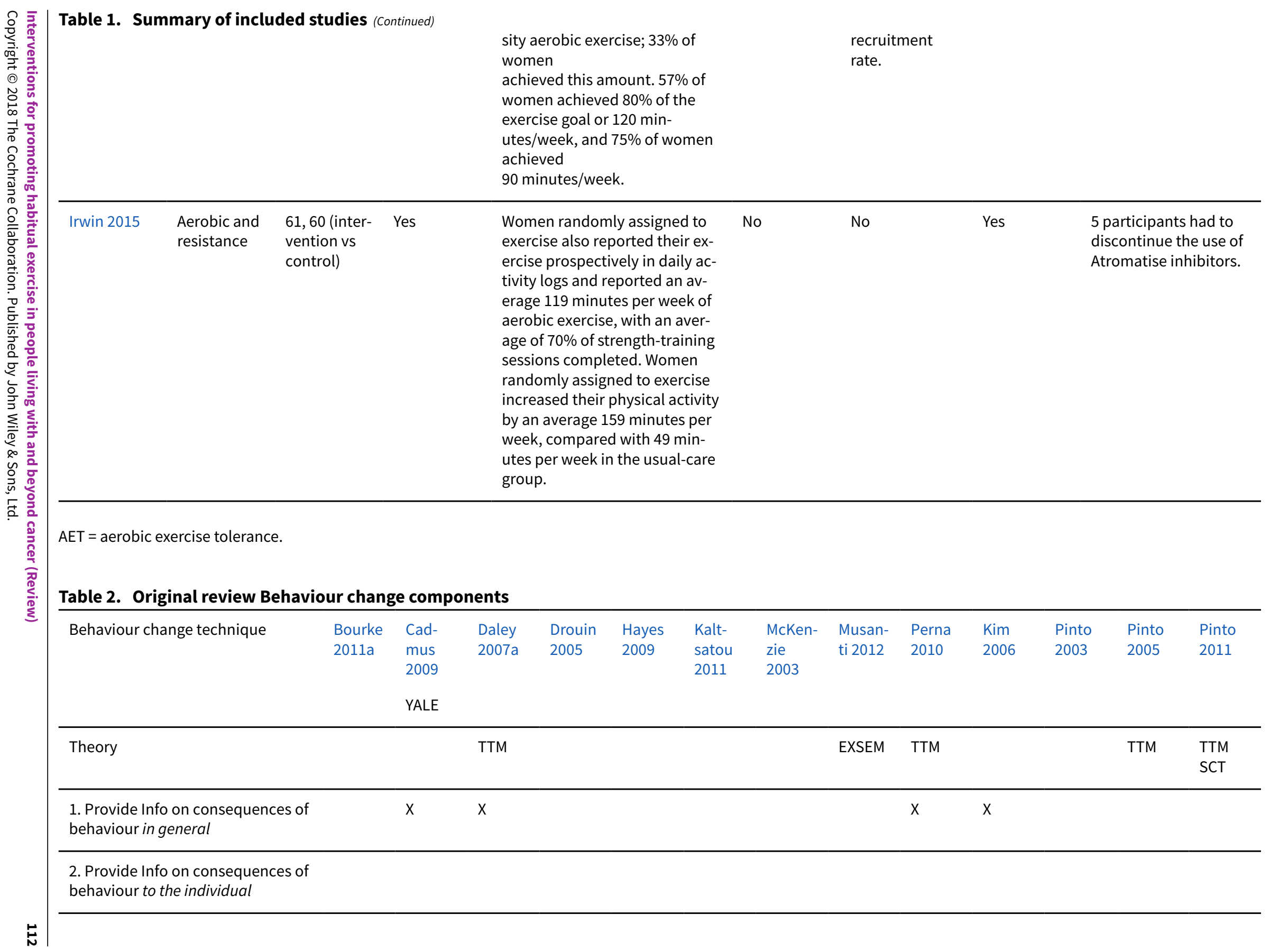




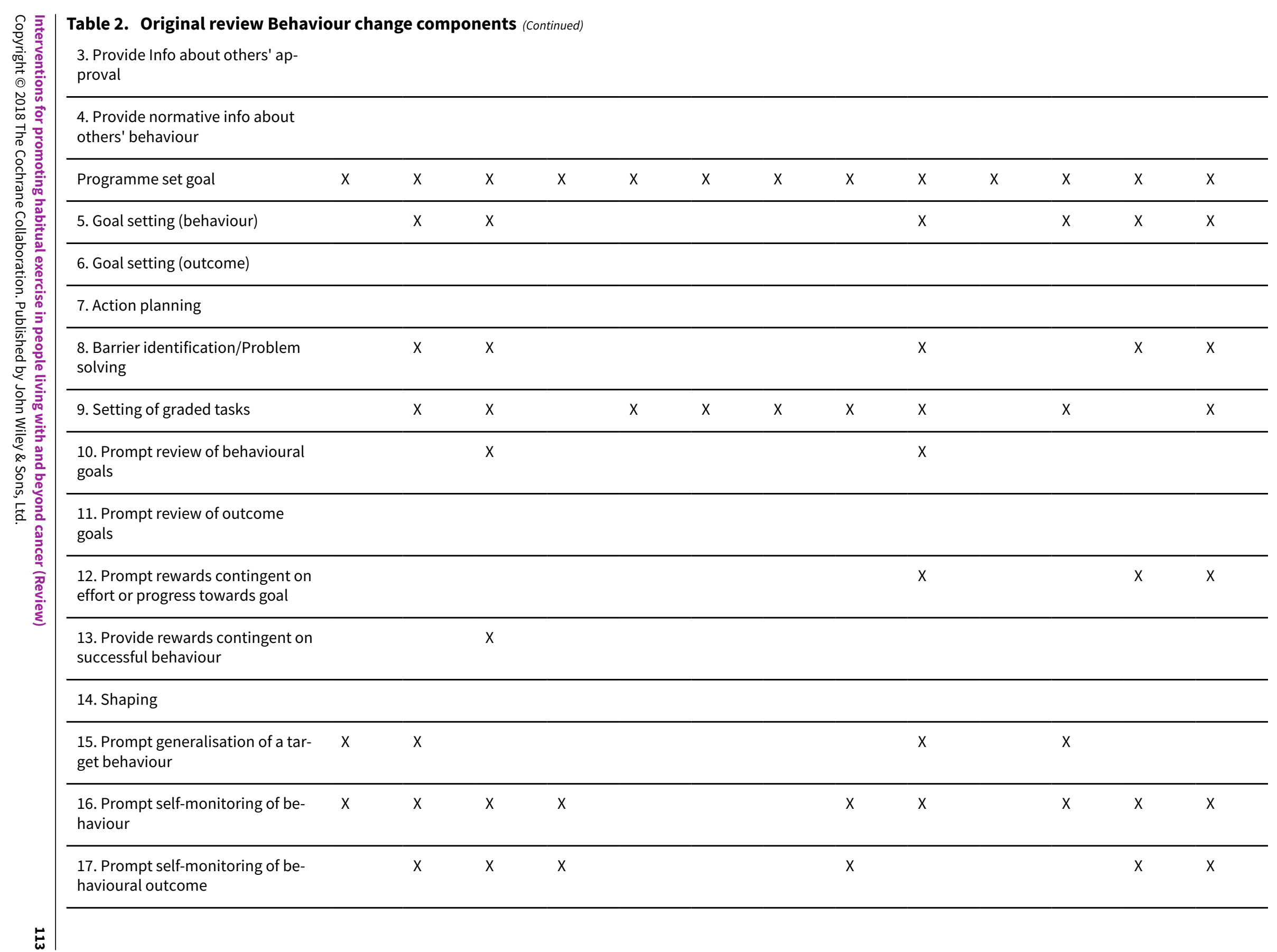




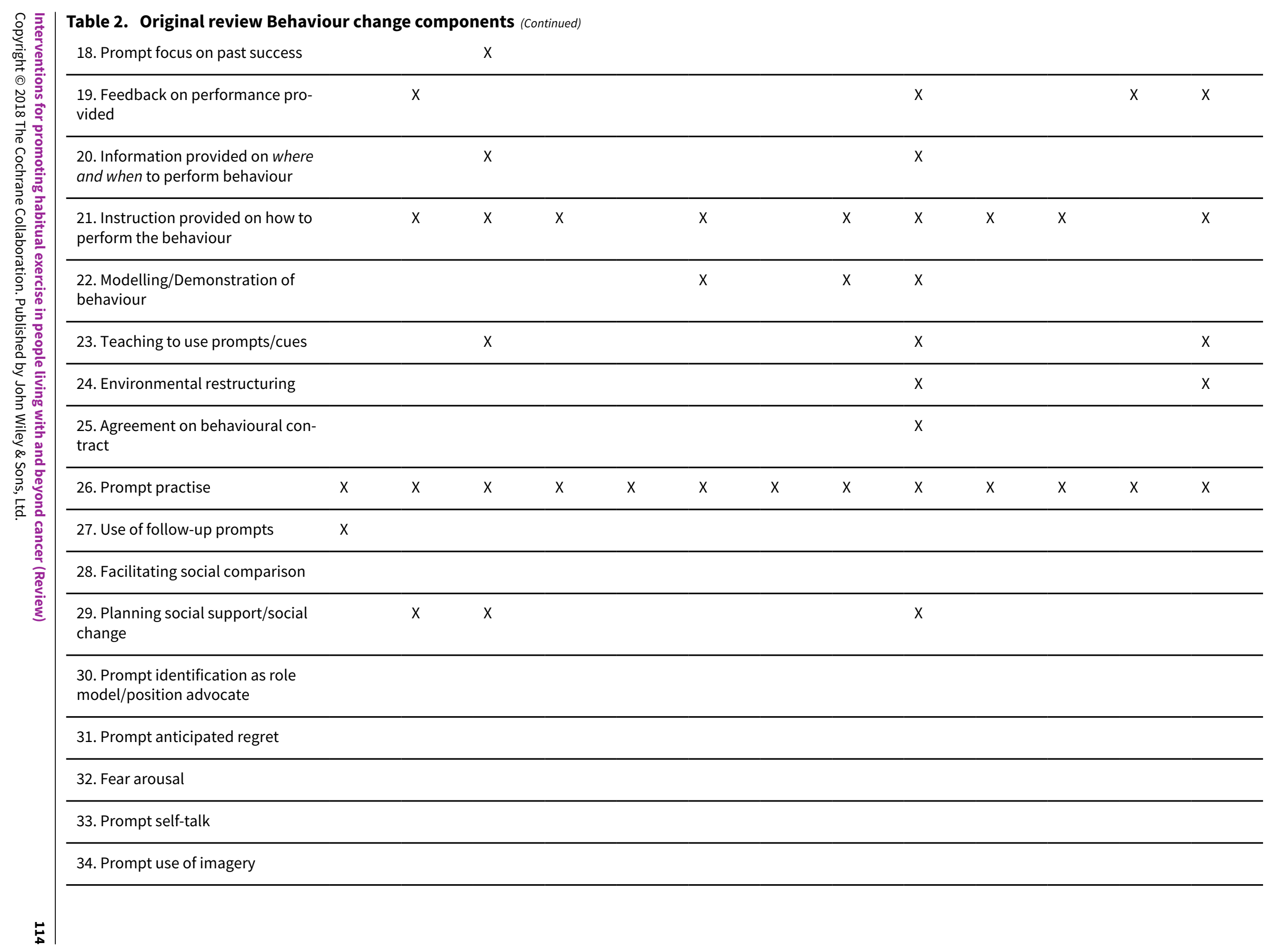




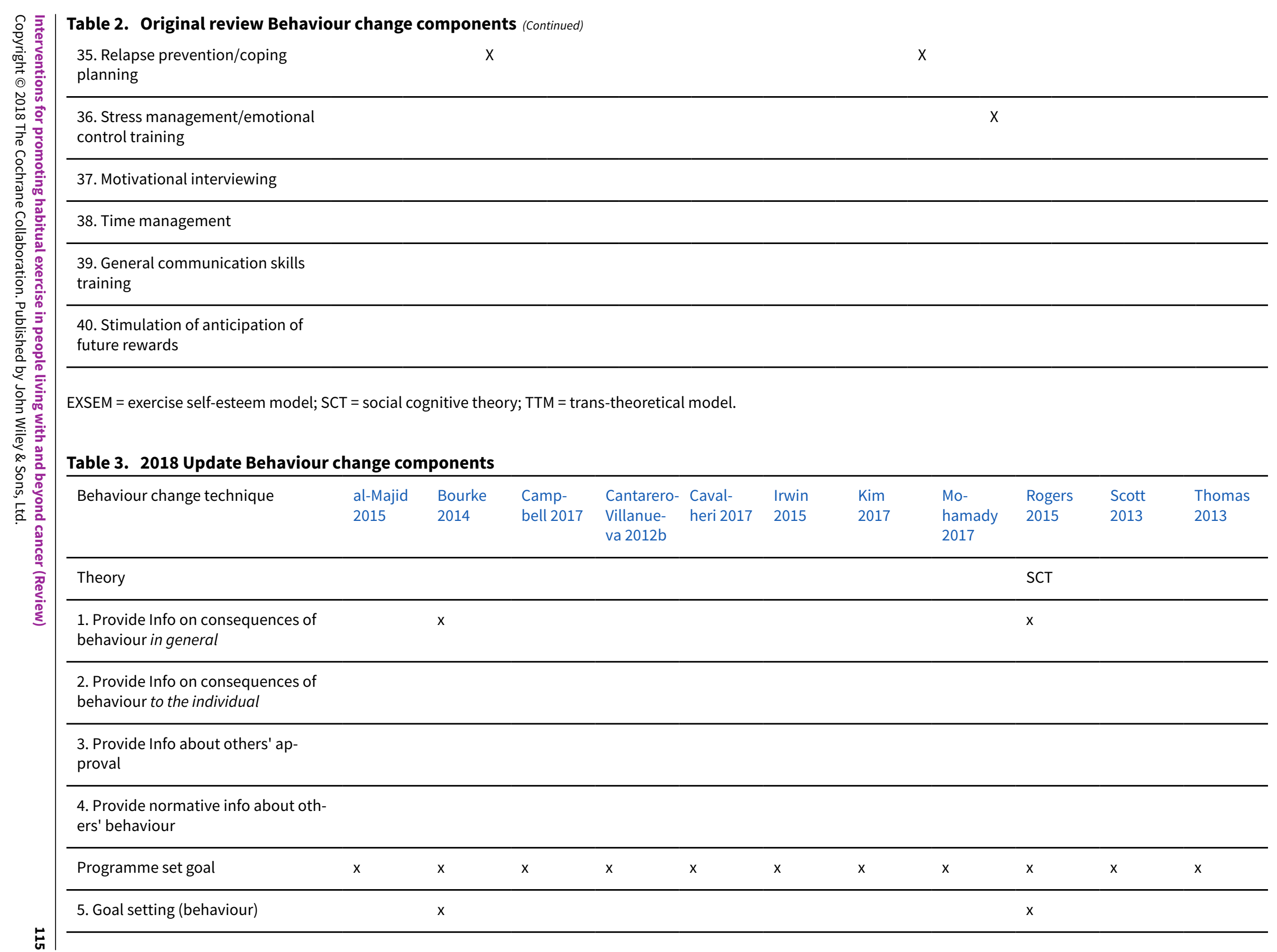




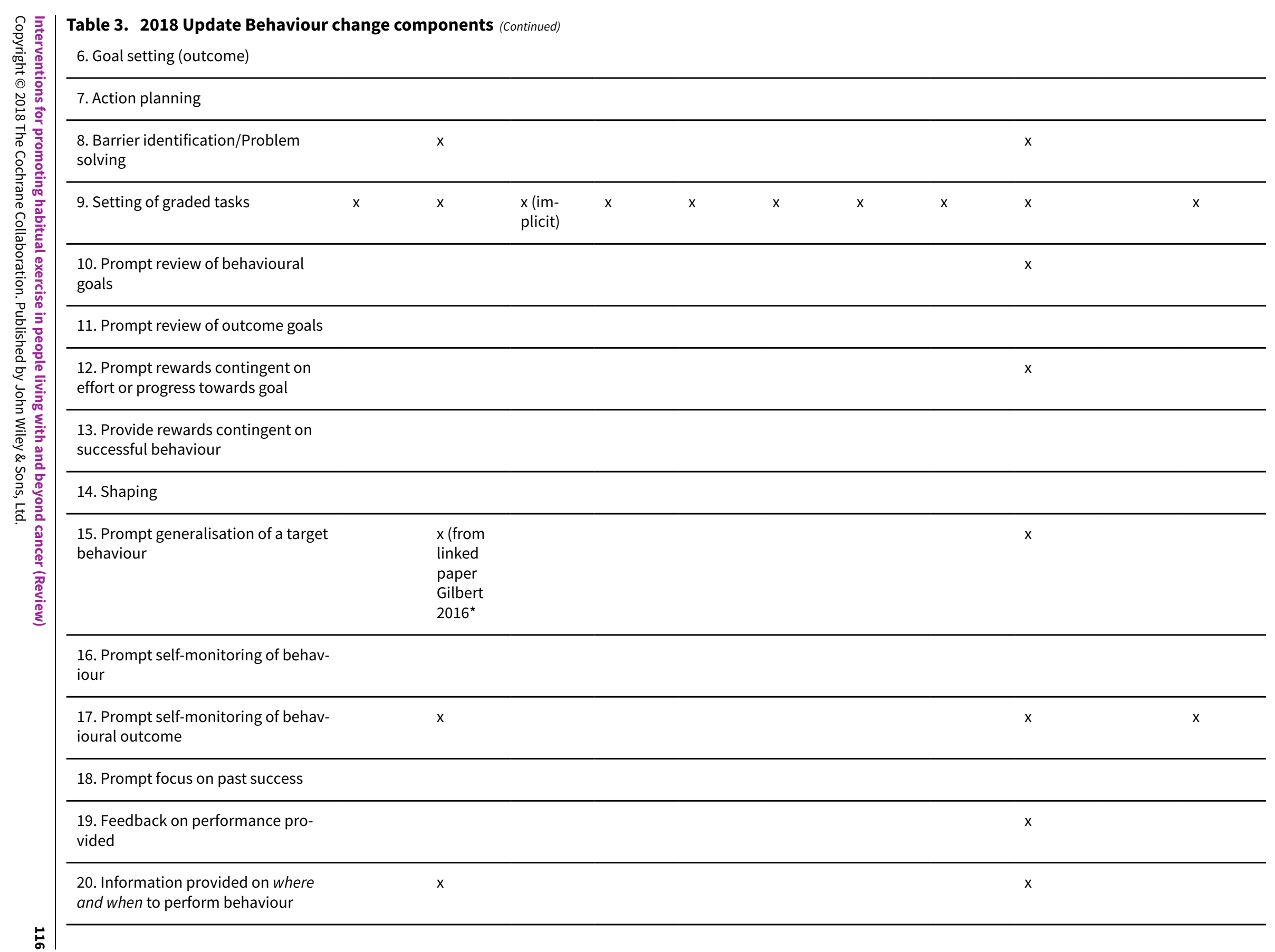




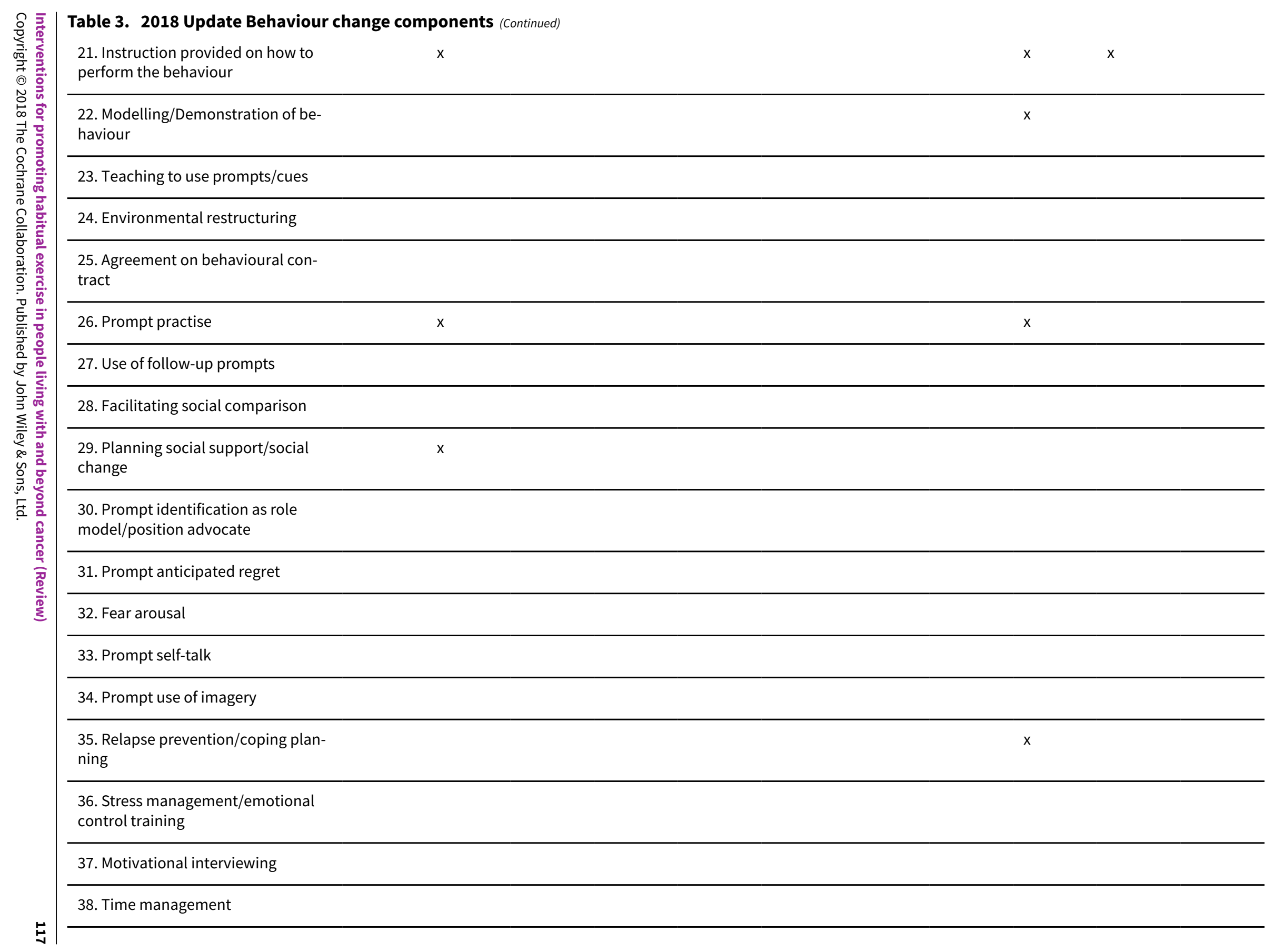




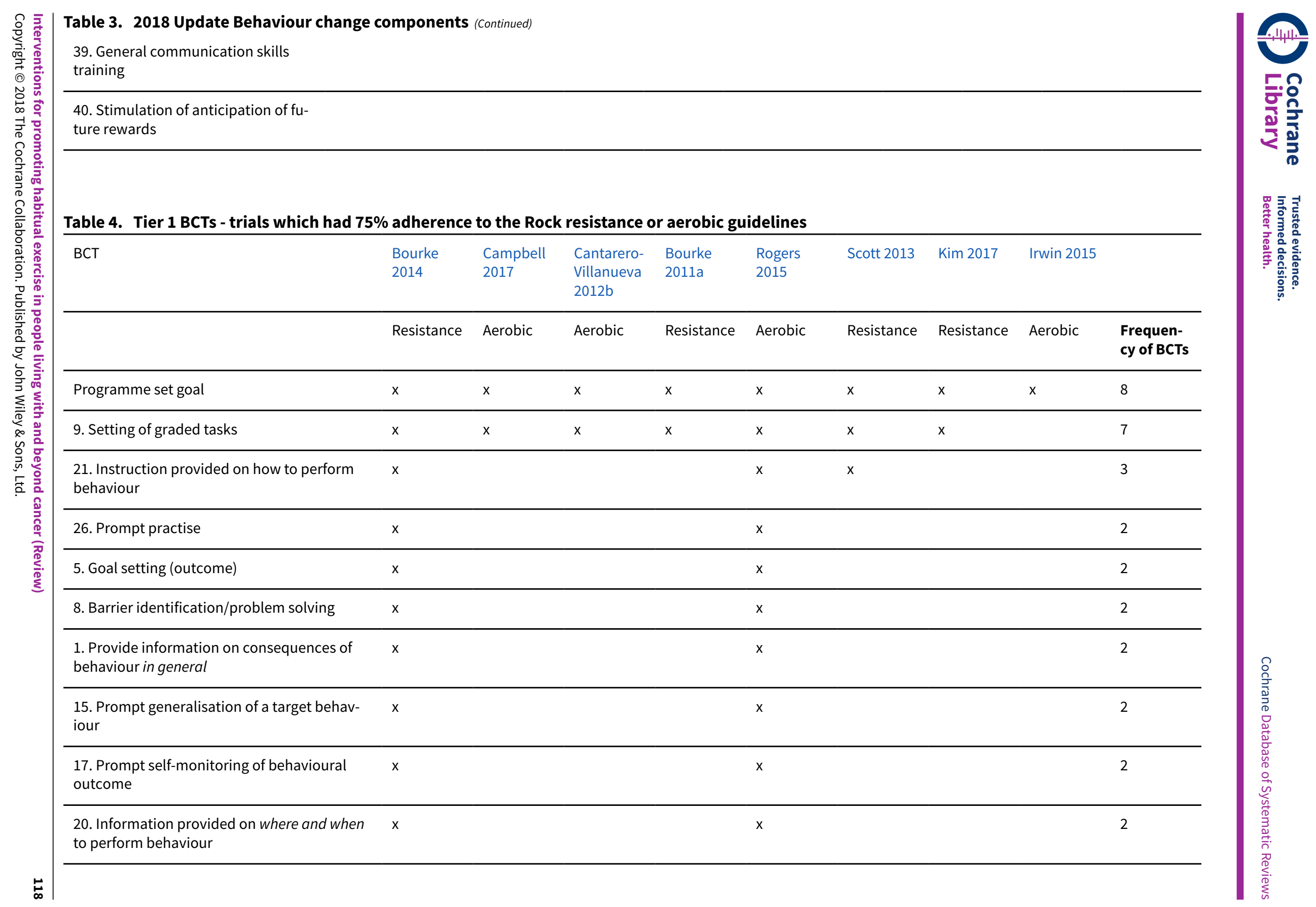

Table 4. Tier $1 \mathrm{BCTs}$ - trials which had $75 \%$ adherence to the Rock resistance or aerobic guidelines 


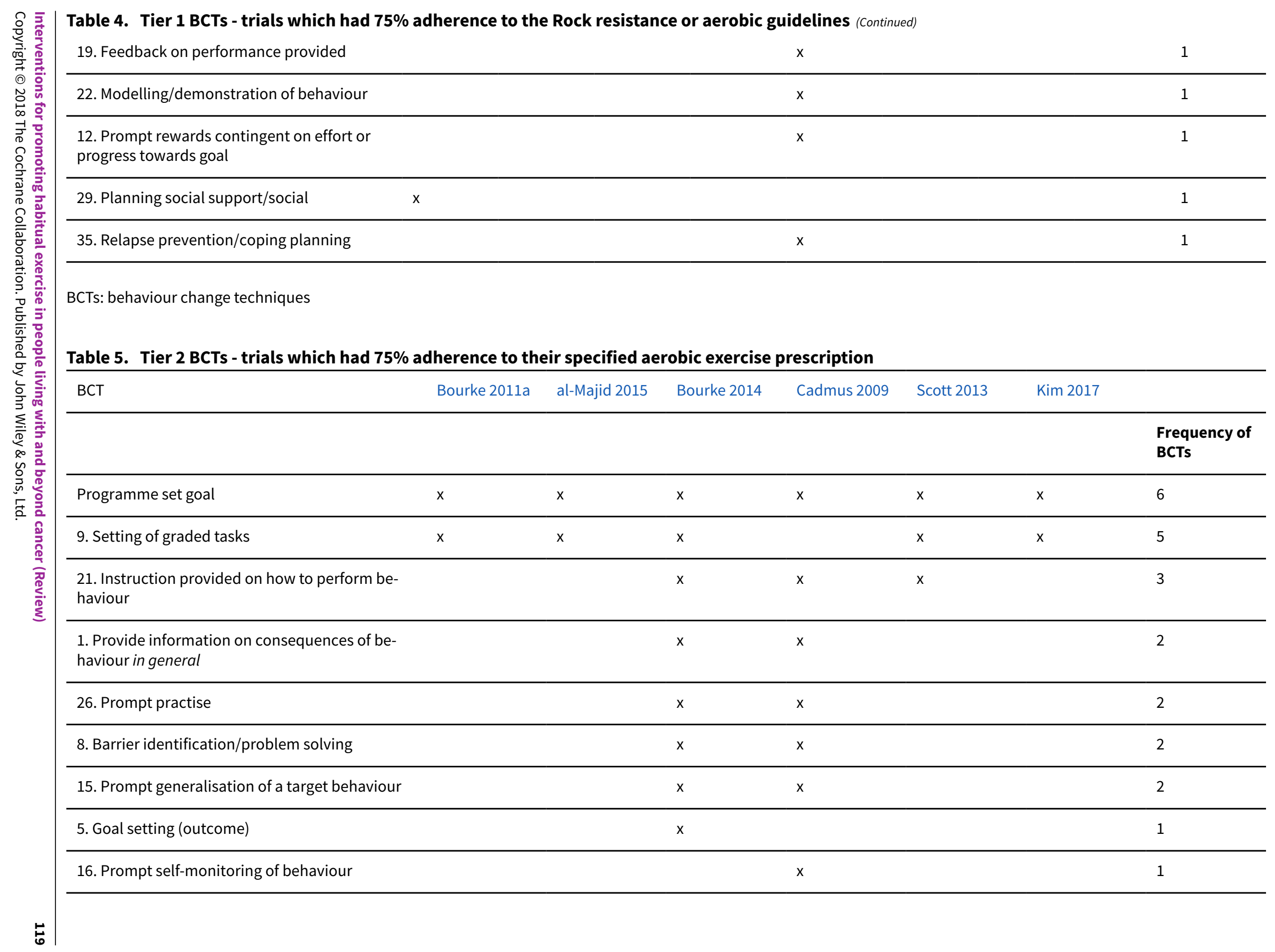




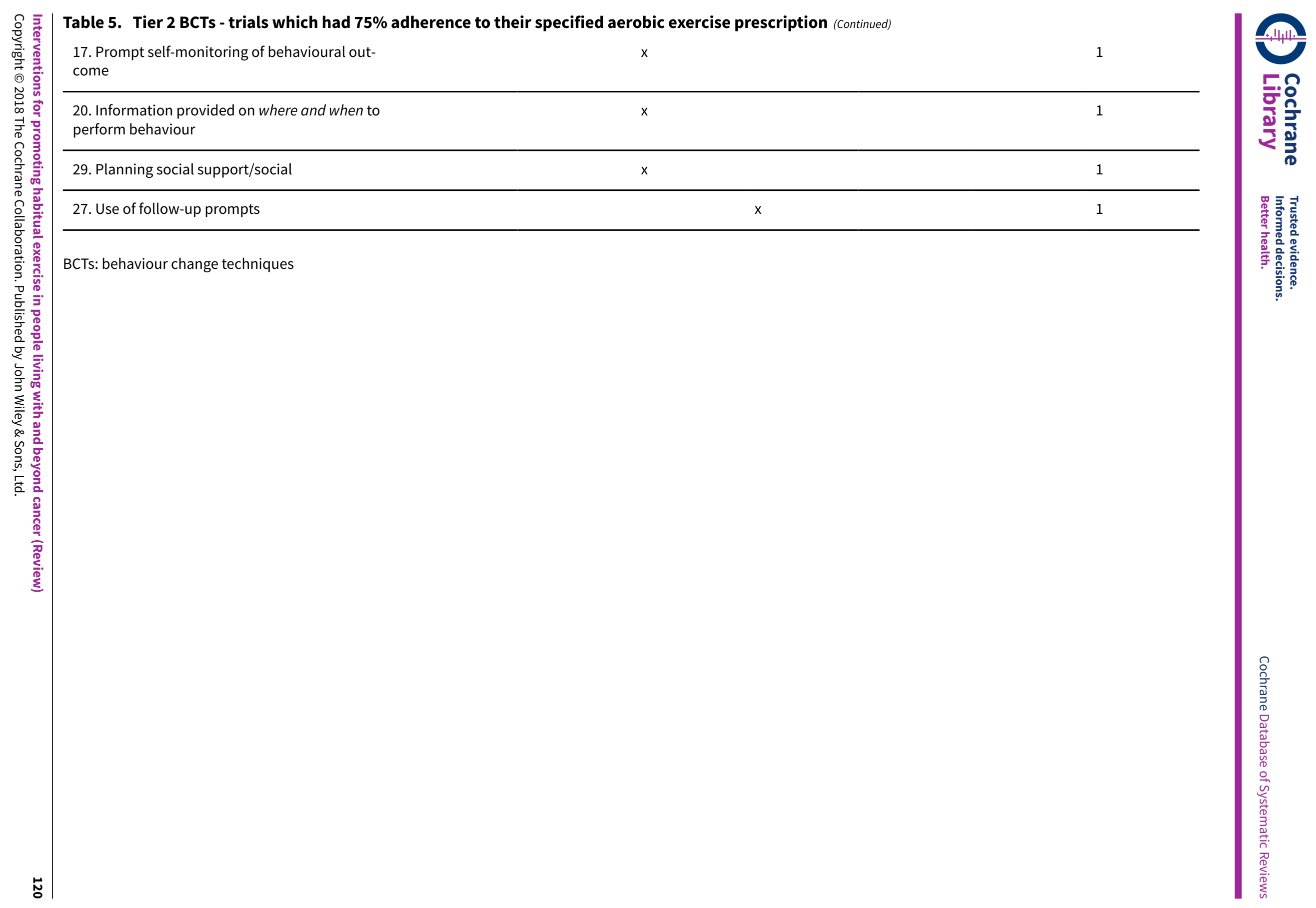




\section{APPENDICES}

\section{Appendix 1. CENTRAL search strategy}

\section{CENTRAL 2018 update search}

\#1 MeSH descriptor Neoplasms explode all trees

\#2 (cancer ${ }^{\star}$ or tumor ${ }^{\star}$ or tumour ${ }^{\star}$ or neoplas* or malignan* or carcinoma* or adenocarcinoma* or choriocarcinoma* or leukemia* or leukaemia* or metastat* or sarcoma* or teratoma*)

\#3 (\#1 OR \#2)

\#4 MeSH descriptor Exercise explode all trees

\#5 MeSH descriptor Exercise Movement Techniques explode all trees

\#6 MeSH descriptor Exercise Therapy explode all trees

\#7 MeSH descriptor Physical Fitness, this term only

\#8 (physical* ${ }^{\star}$ adj5 $\left(\right.$ fit $^{\star}$ or activ*))

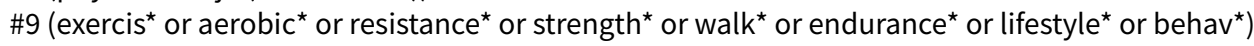

\#10 (\#4 OR \#5 OR \#6 OR \#7 OR \#8 OR \#9)

$\# 11$ \#3 and \#10

\#12 MeSH descriptor: [Health Behavior] explode all trees

\#13 MeSH descriptor: [Risk Reduction Behavior] this term only

\#14 ((promot ${ }^{\star}$ or motivat ${ }^{\star}$ or advis* or encourag* or assist* or develop* or stimulat* or help* or support ${ }^{\star}$ or organis* or aid ${ }^{\star}$ or assist $^{\star}$ or $^{\star}$ endors ${ }^{\star}$ or prompt ${ }^{\star}$ or driv* or inspire ${ }^{\star}$ or lead ${ }^{\star}$ or inspir ${ }^{\star}$ or further ${ }^{\star}$ or advocat ${ }^{\star}$ or recommend or endorse $^{\star}$ or foster $^{\star}$ or champion $^{\star}$ ) near $/ 5$ (exercis* or aerobic* or resistance* or strength* or walk $^{\star}$ or endurance $\left.{ }^{\star}\right)$ )

$\# 15 \# 12$ or \#13 or \#14

$\# 16$ \#11 and \#15

\section{CENTRAL 2012 search}

\#1 MeSH descriptor Neoplasms explode all trees

\#2 (cancer ${ }^{\star}$ or tumor ${ }^{\star}$ or tumour ${ }^{\star}$ or neoplas ${ }^{\star}$ or malignan* or carcinoma* or adenocarcinoma* or choriocarcinoma* or leukemia* or leukaemia* or metastat* or sarcoma* or teratoma*)

\#3 (\#1 OR \#2)

\#4 MeSH descriptor Exercise explode all trees

\#5 MeSH descriptor Exercise Movement Techniques explode all trees

\#6 MeSH descriptor Exercise Therapy explode all trees

\#7 MeSH descriptor Physical Fitness, this term only

\#8 (physical ${ }^{\star}$ adj5 $\left(\right.$ fit $^{\star}$ or $\left.\left.\operatorname{activ}^{\star}\right)\right)$

\#9 (exercis* or aerobic ${ }^{\star}$ or resistance ${ }^{\star}$ or strength* or walk $^{\star}$ or endurance ${ }^{\star}$ )

\#10 (\#4 OR \#5 OR \#6 OR \#7 OR \#8 OR \#9)

$\# 11$ MeSH descriptor Patient Education as Topic, this term only

$\# 12$ (educat ${ }^{\star}$ or inform ${ }^{\star}$ or teach ${ }^{\star}$ or supervis ${ }^{\star}$ or communicat ${ }^{\star}$ or leaflet ${ }^{\star}$ )

$\# 13 \mathrm{MeSH}$ descriptor Survivors, this term only

\#14 survivor ${ }^{\star}$

\#15 MeSH descriptor Behavior Therapy explode all trees

\#16 (behaviour* or behavior ${ }^{\star}$ or cognit* or CBT)

\#17 MeSH descriptor Motivation explode all trees

\#18 MeSH descriptor Interview, Psychological, this term only

$\# 19$ (motivat* ${ }^{*}$ or interview ${ }^{\star}$ )

\#20 (\#11 OR \#12 OR \#13 OR \#14 OR \#15 OR \#16 OR \#17 OR \#18 OR \#19)

\#21 (\#3 AND \#10 AND \#20)

\section{Appendix 2. MEDLINE search strategy}

\section{MEDLINE 2018 update search}

1. exp Neoplasms/

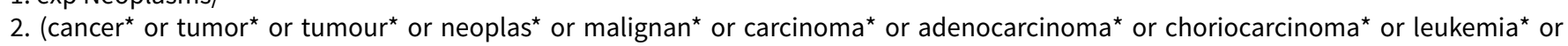
leukaemia* or metastat $^{\star}$ or sarcoma* or teratoma*).ti,ab.

3.1 or 2

4. exp Exercise/

5. exp Exercise Movement Techniques/

6. exp Exercise Therapy/

7. Physical Fitness/ 
8. $\left(\right.$ physical $^{\star}$ adj5 $\left(\right.$ fit $^{\star}$ or activ $\left.\left.{ }^{\star}\right)\right) \cdot$.ti,ab.

9. (exercis ${ }^{\star}$ or aerobic ${ }^{\star}$ or resistance or strength $^{\star}$ or walk* or endurance* or lifestyle* or behave*).mp.

10.4 or 5 or 6 or 7 or 8 or 9

11.3 and 10

12. exp Health Behavior/

13. risk reduction behavior/

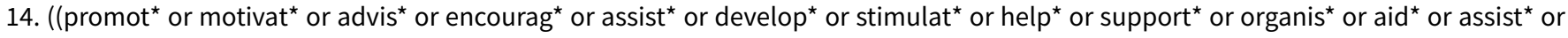
endors ${ }^{\star}$ or prompt or driv $^{\star}$ or inspire* or lead ${ }^{\star}$ or inspir* or further ${ }^{\star}$ or advocat ${ }^{\star}$ or recommend ${ }^{\star}$ or endorse* or foster ${ }^{\star}$ or champion $^{\star}$ ) adj5 (exercis* or aerobic* or resistance* or strength ${ }^{\star}$ or walk* or endurance*)).ti,ab.

15. 12 or 13 or 14

16. 11 and 15

17. randomized controlled trial.pt.

18. controlled clinical trial.pt.

19. randomized.ab.

20. placebo.ab.

21. clinical trials as topic.sh.

22. randomly.ab.

23. trial.ti.

24. 17 or 18 or 19 or 20 or 21 or 22 or 23

25. (animals not (humans and animals)).sh.

26. 24 not 25

27. 16 and 26

key:

$\mathrm{mp}=$ title, abstract, original title, name of substance word, subject heading word, protocol supplementary concept, rare disease supplementary concept, unique identifier

$\mathrm{pt}=$ publication type

$a b=a b s t r a c t$

ti=title

sh=subject heading

\section{MEDLINE 2012 search}

1. exp Neoplasms/

2. (cancer ${ }^{\star}$ or tumor ${ }^{\star}$ or tumour ${ }^{\star}$ or neoplas ${ }^{\star}$ or malignan* or carcinoma* or adenocarcinoma* or choriocarcinoma* or leukemia* or leukaemia* or metastat* or sarcoma* or teratoma*).mp.

3. 1 or 2

4. exp Exercise/

5. exp Exercise Movement Techniques/

6. exp Exercise Therapy/

7. Physical Fitness/

8. (physical* $\operatorname{adj}\left(\right.$ fit $^{\star}$ or $\left.\left.\operatorname{activ}^{\star}\right)\right) \cdot \mathrm{mp}$.

9. (exercis ${ }^{\star}$ or aerobic ${ }^{\star}$ or resistance ${ }^{\star}$ or strength* or walk $^{\star}$ or endurance $\left.{ }^{\star}\right)$.mp.

10. 4 or 5 or 6 or 7 or 8 or 9

11. Patient Education as Topic/

12. Patient education handout/

13. (educat ${ }^{\star}$ or inform ${ }^{\star}$ or teach* or supervis $^{\star}$ or communicat ${ }^{\star}$ or leaflet $\left.^{\star}\right)$.mp.

14. Survivors/ or survivor ${ }^{\star} . \mathrm{mp}$.

15. exp Behavior Therapy/

16. (behaviour ${ }^{\star}$ or behavior ${ }^{\star}$ or cognit* or CBT).mp.

17. exp Motivation/

18. Interview, Psychological/

19. (motivat ${ }^{\star}$ or interview*).mp.

20.11 or 12 or 13 or 14 or 15 or 16 or 17 or 18 or 19

21.3 and 10 and 20

22. randomized controlled trial.pt.

23. controlled clinical trial.pt.

24. randomized.ab.

25. placebo.ab.

26. clinical trials as topic.sh.

27. randomly.ab.

28. trial.ti. 
29. 22 or 23 or 24 or 25 or 26 or 27 or 28

30.21 and 29

31. exp animals/ not humans.sh.

32. 30 not 31

key:

$\mathrm{mp}=$ title, abstract, original title, name of substance word, subject heading word, protocol supplementary concept, rare disease supplementary concept, unique identifier

pt=publication type

$a b=a b s t r a c t$

ti=title

sh=subject heading

\section{Appendix 3. Embase search strategy}

\section{Embase 2018 update search}

1. exp neoplasm/

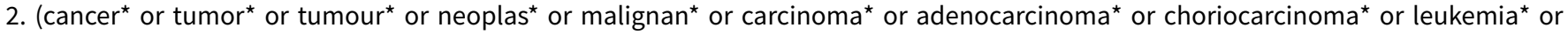
leukaemia* or metastat* ${ }^{\star}$ or sarcoma* or teratoma*).ti,ab.

3.1 or 2

4. exp exercise/

5. exp kinesiotherapy/

6. fitness/

7. (physical ${ }^{\star}$ adj5 $\left(\right.$ fit $^{\star}$ or $^{\star}$ activ $\left.\left.^{\star}\right)\right) . t i$, ab.

8. (exercis ${ }^{\star}$ or aerobic ${ }^{\star}$ or resistance ${ }^{\star}$ or strength ${ }^{\star}$ or walk* or endurance ${ }^{\star}$ or lifestyle* or behav $\left.{ }^{\star}\right) . \mathrm{mp}$.

9. 4 or 5 or 6 or 7 or 8

10. 3 and 9

11. exp health behavior/

12. risk reduction/

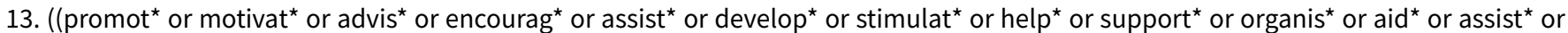
endors ${ }^{\star}$ or prompt ${ }^{\star}$ or driv ${ }^{\star}$ or inspire or lead $^{\star}$ or inspir* or further $^{\star}$ or advocat ${ }^{\star}$ or recommend ${ }^{\star}$ or endorse* or foster ${ }^{\star}$ or champion $^{\star}$ ) adj5 (exercis* or aerobic $^{\star}$ or resistance* or strength $^{\star}$ or walk* or endurance $\left.^{\star}\right)$ ).ti,ab.

14. 11 or 12 or 13

15. 10 and 14

16. crossover procedure/

17. double-blind procedure/

18. randomized controlled trial/

19. single-blind procedure/

20. random*.mp.

21. factorial ${ }^{\star} . \mathrm{mp}$.

22. (crossover ${ }^{\star}$ or cross over ${ }^{\star}$ or cross-over $\left.^{\star}\right) . \mathrm{mp}$.

23. placebo*.mp.

24. (double* adj blind $\left.{ }^{\star}\right) \cdot \mathrm{mp}$.

25. $\left(\right.$ singl ${ }^{\star}$ adj blind $\left.{ }^{\star}\right) \cdot m p$.

26. assign ${ }^{\star} \cdot \mathrm{mp}$.

27. allocat*.mp.

28. volunteer ${ }^{\star}$.mp.

29.16 or 17 or 18 or 19 or 20 or 21 or 22 or 23 or 24 or 25 or 26 or 27 or 28

30.15 and 29

31. (exp animal/ or nonhuman/ or exp animal experiment/) not human/

32. 30 not 31

key:

[mp=title, abstract, subject headings, heading word, drug trade name, original title, device manufacturer, drug manufacturer, device trade name, keyword]

\section{Embase 2012 search}

1 exp neoplasm/

2 (cancer $^{\star}$ or tumor ${ }^{\star}$ or tumour ${ }^{\star}$ or neoplas ${ }^{\star}$ or malignan ${ }^{\star}$ or carcinoma* or adenocarcinoma* or choriocarcinoma* or leukemia* or leukaemia* or metastat $^{\star}$ or sarcoma* or teratoma*).mp.

31 or 2 
4 exp exercise/

5 exp kinesiotherapy/

6 fitness/

7 (physical $^{\star}$ adj5 $\left(\right.$ fit $^{\star}$ or activ $\left.\left.^{\star}\right)\right)$.mp.

8 (exercis ${ }^{\star}$ or aerobic ${ }^{\star}$ or resistance ${ }^{\star}$ or strength $^{\star}$ or walk* or endurance $\left.{ }^{\star}\right) . \mathrm{mp}$.

94 or 5 or 6 or 7 or 8

10 patient education/

11 (educat $^{\star}$ or inform ${ }^{\star}$ or teach ${ }^{\star}$ or supervis ${ }^{\star}$ or communicat ${ }^{\star}$ or leaflet $\left.{ }^{\star}\right)$.mp.

12 survivor/ or survivor ${ }^{\star} . \mathrm{mp}$.

13 behavior therapy/

14 cognitive therapy/

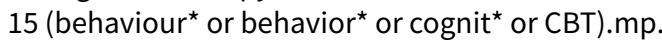

16 motivation/

17 interview/

18 (motivat* $^{\star}$ or interview ${ }^{\star}$ ).mp.

1910 or 11 or 12 or 13 or 14 or 15 or 16 or 17 or 18

203 and 9 and 19

21 crossover procedure/

22 double-blind procedure/

23 randomized controlled trial/

24 single-blind procedure/

25 random*.mp.

26 factorial $^{*} . \mathrm{mp}$.

27 (crossover ${ }^{\star}$ or cross over ${ }^{\star}$ or cross-over ${ }^{\star}$ ).mp.

28 placebo*.mp.

29 (double $^{\star}$ adj blind $\left.{ }^{\star}\right) \cdot \mathrm{mp}$.

30 (singl $^{\star}$ adj blind ${ }^{\star}$ ).mp.

31 assign $^{\star}$.mp.

32 allocat $^{\star} . \mathrm{mp}$

33 volunteer ${ }^{\star} . \mathrm{mp}$.

3421 or 22 or 23 or 24 or 25 or 26 or 27 or 28 or 29 or 30 or 31 or 32 or 33

3520 and 34

36 (exp animal/ or nonhuman/ or exp animal experiment/) not human/

3735 not 36

key:

[mp=title, abstract, subject headings, heading word, drug trade name, original title, device manufacturer, drug manufacturer, device trade name, keyword]

\section{Appendix 4. AMED search strategy}

\section{Amed Ovid 2018 update search}

1 exp neoplasms/

2 (cancer ${ }^{\star}$ or tumor ${ }^{\star}$ or tumour ${ }^{\star}$ or neoplas ${ }^{\star}$ or malignan* or carcinoma* or adenocarcinoma* or choriocarcinoma* or leukemia* or

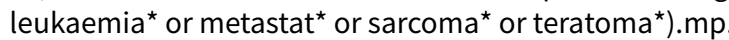

31 or 2

4 exp exercise/

5 exp exercise therapy/

6 physical fitness/

7 (physical* ${ }^{\star} \operatorname{adj} 5\left(\right.$ fit $^{\star}$ or $\left.\left.\operatorname{activ}^{\star}\right)\right) \cdot \mathrm{mp}$.

8 (exercis $^{\star}$ or aerobic ${ }^{\star}$ or resistance ${ }^{\star}$ or strength ${ }^{\star}$ or walk ${ }^{\star}$ or endurance or lifestyle $^{\star}$ or behav $\left.{ }^{\star}\right) . \mathrm{mp}$.

94 or 5 or 6 or 7 or 8

10 exp Health behavior/

11 ((promot ${ }^{\star}$ or motivat ${ }^{\star}$ or advis* or encourag* or assist* or develop* or stimulat ${ }^{\star}$ or help or support $^{\star}$ or organis $^{\star}$ or aid $^{\star}$ or assist $^{\star}$ or $^{\star}$

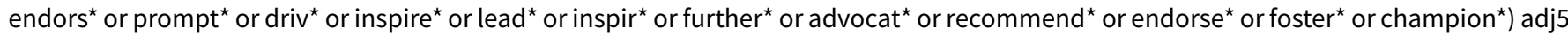
(exercis ${ }^{\star}$ or aerobic ${ }^{\star}$ or resistance* or strength* or walk $^{\star}$ or endurance*)).ti,ab.

1210 or 11

133 and 9 and 12

key:

$\mathrm{mp}=$ abstract, heading words, title 


\section{Amed Ovid 2012 search}

1 exp neoplasms/

2 (cancer ${ }^{\star}$ or tumor ${ }^{\star}$ or tumour ${ }^{\star}$ or neoplas ${ }^{\star}$ or malignan* or carcinoma* or adenocarcinoma* or choriocarcinoma* or leukemia* or

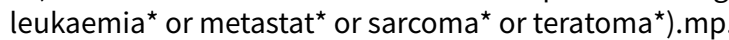

31 or 2

4 exp exercise/

5 exp exercise therapy/

6 physical fitness/

7 (physical* ${ }^{\star} \operatorname{adj} 5\left(\right.$ fit $^{\star}$ or $\left.\left.\operatorname{activ}^{\star}\right)\right) \cdot \mathrm{mp}$.

8 (exercis ${ }^{\star}$ or aerobic ${ }^{\star}$ or resistance ${ }^{\star}$ or strength ${ }^{\star}$ or walk ${ }^{\star}$ or endurance $\left.{ }^{\star}\right) . \mathrm{mp}$.

94 or 5 or 6 or 7 or 8

10 exp patient education/

11 (educat $^{\star}$ or inform $^{\star}$ or teach ${ }^{\star}$ or supervis ${ }^{\star}$ or communicat ${ }^{\star}$ or leaflet $^{\star}$ ).mp.

12 survivors/ or survivor ${ }^{\star}$.mp.

13 exp behavior therapy/

14 (behaviour* or behavior ${ }^{\star}$ or cognit ${ }^{\star}$ or CBT).mp.

15 exp motivation/

16 interviews/

17 (motivat $^{\star}$ or interview ${ }^{\star}$ ).mp.

1810 or 11 or 12 or 13 or 14 or 15 or 16 or 17

193 and 9 and 18

key:

$\mathrm{mp}=$ abstract, heading words, title

\section{Appendix 5. CINAHL search strategy}

\section{CINAHL 2018 update search}

1 exp NEOPLASMS/

2 (cancer* OR tumor* OR tumour ${ }^{\star}$ OR neoplas* OR malignan* OR carcinoma* OR adenocarcinoma* OR choriocarcinoma* OR leukemia* OR leukaemia* OR metastat* OR sarcoma* OR teratoma*).af

31 OR 2

4 exp EXERCISE/

5 exp THERAPEUTIC EXERCISE/

6 exp PHYSICAL FITNESS/

7 (physical $^{\star}$ AND $\left(\right.$ fit $^{\star}$ OR activ $\left.\left.^{\star}\right)\right)$.af

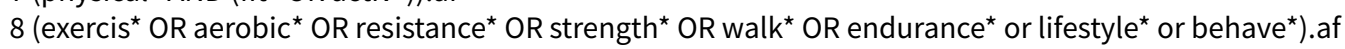

94 OR 5 OR 6 OR 7 OR 8

103 and 9

11 exp BEHAVIOR THERAPY/

12. (risk reduction*) AND (behav*)

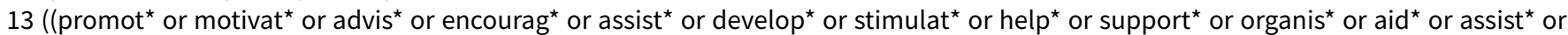
endors ${ }^{\star}$ or prompt or driv $^{\star}$ or inspire* or lead ${ }^{\star}$ or inspir ${ }^{\star}$ or further ${ }^{\star}$ or advocat ${ }^{\star}$ or recommend ${ }^{\star}$ or endorse* or foster ${ }^{\star}$ or champion*) adj5 (exercis* or aerobic ${ }^{\star}$ or resistance* or strength $^{\star}$ or walk* or endurance $\left.^{\star}\right)$ ).ti,ab.

1411 or 12 or 13

1510 AND 14

16 Randomized controlled trials

17 Randomised controlled trials

1816 or 17

1915 AND 18

key

af=any field

\section{CINAHL 2012 search}

1 exp NEOPLASMS/

2 (cancer* OR tumor* OR tumour* OR neoplas* OR malignan* OR carcinoma* OR adenocarcinoma* OR choriocarcinoma* OR leukemia* OR leukaemia* OR metastat* OR sarcoma* OR teratoma*).af

31 OR 2

4 exp EXERCISE/

5 exp THERAPEUTIC EXERCISE/

Interventions for promoting habitual exercise in people living with and beyond cancer (Review) 
6 exp PHYSICAL FITNESS/

7 (physical* AND (fit* OR activ $\left.{ }^{\star}\right)$ ).af

8 (exercis* OR aerobic* OR resistance* OR strength* OR walk* OR endurance ${ }^{\star}$ ).af

94 OR 5 OR 6 OR 7 OR 8

10 exp PATIENT EDUCATION/

11 (educat $^{\star}$ OR inform ${ }^{\star}$ OR teach ${ }^{\star}$ OR supervis ${ }^{\star}$ OR communicat ${ }^{\star}$ OR leaflet ${ }^{\star}$ ).af

12 CANCER SURVIVORS/

13 survivor ${ }^{*}$.af

14 exp BEHAVIOR THERAPY/

15 (behaviour* OR behavior* OR cognit* OR CBT).af

16 exp MOTIVATION/

17 MOTIVATIONAL INTERVIEWING/

18 (motivat ${ }^{\star}$ OR interview ${ }^{\star}$ ).af

1910 OR 11 OR 12 OR 13 OR 14 OR 15 OR 16 OR 17 OR 18

203 AND 9 AND 19

21 RANDOMIZED CONTROLLED TRIALS/

2220 and 21

\section{Appendix 6. PsycINFO search strategy}

\section{PsycINFO 2018 update search}

1 neoplasms.af

2 ((cancer ${ }^{\star}$ OR tumor ${ }^{\star}$ OR tumour ${ }^{\star}$ OR neoplas ${ }^{\star}$ OR malignan* OR carcinoma* OR adenocarcinoma* OR choriocarcinoma* OR leukemia* OR leukaemia* OR metastat* OR sarcoma* OR teratoma*)).ti,ab

3 exercise.af

4 (physical AND fitness).af

5 ((physical* $\operatorname{adj5}\left(\right.$ fit $^{\star}$ OR activ $\left.\left.\left.^{\star}\right)\right)\right) \cdot$ ti,ab

6 ((exercis ${ }^{\star}$ OR aerobic ${ }^{\star}$ OR resistance* OR strength* OR walk* OR endurance* OR lifestyle* OR behave $\left.\left.{ }^{\star}\right)\right)$.af

71 OR 2

83 OR 4 OR 5 OR 6

9 (health AND behaviour).af

10 (risk AND reduction AND behaviour).af

11 (((promot* OR motivat* OR advis* OR encourag* OR assist* OR develop* OR stimulat* OR help* OR support* OR organis* OR aid* OR assist ${ }^{\star}$ OR endors ${ }^{\star}$ OR prompt ${ }^{\star}$ OR driv ${ }^{\star}$ OR inspire* OR lead ${ }^{\star}$ OR inspir ${ }^{\star}$ OR further ${ }^{\star}$ OR advocat ${ }^{\star}$ OR recommend OR endorse $^{\star}$ OR foster ${ }^{\star}$ OR champion ${ }^{\star}$ ) adj5 (exercis ${ }^{\star}$ OR aerobic ${ }^{\star}$ OR resistance ${ }^{\star}$ OR strength* OR walk $^{\star}$ OR endurance $\left.\left.^{\star}\right)\right)$ ).ti,ab

129 OR 10 OR 11

137 AND 8 AND 12

\section{PsycINFO Ovid 2012 search}

1 exp neoplasms/

2 (cancer* or tumor $^{\star}$ or tumour ${ }^{\star}$ or neoplas* or malignan* or carcinoma* or adenocarcinoma* or choriocarcinoma* or leukemia* or leukaemia* or metastat* or sarcoma* or teratoma*).mp.

31 or 2

4 exp exercise/

5 physical fitness/

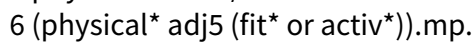

7 (exercis $^{\star}$ or aerobic ${ }^{\star}$ or resistance ${ }^{\star}$ or strength ${ }^{\star}$ or walk ${ }^{\star}$ or endurance $\left.{ }^{\star}\right) . m p$.

84 or 5 or 6 or 7

9 client education/

10 (educat $^{\star}$ or inform ${ }^{\star}$ or teach* ${ }^{\star}$ or supervis ${ }^{\star}$ or communicat* ${ }^{\star}$ or leaflet ${ }^{\star}$ ).mp.

11 survivors/ or survivor*.mp.

12 exp cognitive behavior therapy/

13 exp behavior therapy/

14 (behaviour* or behavior* or cognit* or CBT).mp.

15 exp motivation/

16 motivational interviewing/

17 (motivat* ${ }^{\star}$ or interview ${ }^{\star}$ ).mp.

189 or 10 or 11 or 12 or 13 or 14 or 15 or 16 or 17

193 and 8 and 18

20 clinical trials/ 
21 (random $^{\star}$ or trial $^{\star}$ or group ${ }^{\star}$ or placebo $\left.{ }^{\star}\right) . m p . m p=t i t l e$, abstract, heading word, table of contents, key concepts, original title, tests \& measures

2220 or 21

2319 and 22

key:

[mp=title, abstract, heading word, table of contents, key concepts, original title, tests \& measures]

\section{Appendix 7. PEDro search strategy}

\section{PEDro 2012 search}

- Title and abstract: "cancer"

- Therapy: fitness training (selected)

- Sub discipline: oncology (selected)

- Method: clinical trial (selected)

\section{Appendix 8. SPORTS DISCUS search strategy (EBSCO host)}

\section{Sports discus update 2018 search}

1. TX cancer ${ }^{\star}$ OR tumor ${ }^{\star}$ OR tumour ${ }^{\star}$ OR neoplas ${ }^{\star}$ OR malignan ${ }^{\star}$ OR carcinoma* OR adenocarcinoma* OR choriocarcinoma* OR leukemia* $^{\star}$ OR leukaemia* OR metastat* OR sarcoma* OR teratoma* $(26,616)$

2. TX randomi*ed controlled trial $(12,682)$

3. (TX randomi*ed controlled trial) AND (S4 AND S5) (636)

4. Limiters - Published Date: 20120101-20171231 (411)

\section{Appendix 9. Cochrane Collaboration's tool for assessing risk of bias}

\section{Random sequence generation}

- Low risk of bias (e.g. participants assigned to treatments on basis of a computer-generated random sequence or a table of random numbers)

- High risk of bias (e.g. participants assigned to treatments on basis of date of birth, clinic ID number or surname, or no attempt to randomly assign participants)

- Unclear risk of bias (e.g. not reported, information not available)

\section{Allocation concealment}

- Low risk of bias (e.g. when the allocation sequence could not be foretold)

- High risk of bias (e.g. allocation sequence could be foretold by participants, investigators or treatment providers)

- Unclear risk of bias (e.g. not reported)

\section{Blinding of participants and personnel}

- Low risk of bias, if participants and personnel were adequately blinded

- High risk of bias, if participants were not blinded to the intervention that the participant received

- Unclear risk of bias, if this was not reported or was unclear

\section{Blinding of outcome assessors}

- Low risk of bias, if outcome assessors were adequately blinded

- High risk of bias, if outcome assessors were not blinded to the intervention that the participant received

- Unclear risk of bias, if this was not reported or was unclear

\section{Incomplete outcome data}

We recorded the proportions of participants whose outcomes were not reported at the end of the study. We coded a satisfactory level of loss to follow-up for each outcome as follows

- Low risk of bias, if fewer than $20 \%$ of participants were lost to follow-up and reasons for loss to follow-up were similar in both treatment arms

- High risk of bias, if more than $20 \%$ of participants were lost to follow-up or reasons for loss to follow-up differed between treatment arms 
- Unclear risk of bias, if loss to follow-up was not reported

\section{Selective reporting of outcomes}

- Low risk of bias (e.g. review reports all outcomes specified in the protocol)

- High risk of bias (e.g. if it is suspected that outcomes have been selectively reported)

- Unclear risk of bias (e.g. if it is unclear whether outcomes were selectively reported)

\section{Other bias}

- Low risk of bias, if no other source of bias is suspected and the trial appears to be methodologically sound

- High risk of bias, if it is suspected that the trial was prone to an additional bias

- Unclear risk of bias, if uncertainty exists about whether an additional bias may have been present

\section{WHAT'S NEW}

\begin{tabular}{lll}
\hline Date & Event & Description \\
\hline 24 September 2018 & Amended & Text amendment. \\
\hline
\end{tabular}

\section{H I S T O R Y}

Protocol first published: Issue 11, 2012

Review first published: Issue 9, 2013

\begin{tabular}{lll}
\hline Date & Event & Description \\
\hline 3 May 2018 & New search has been performed & Literature searches updated to 3 May 2018. \\
\hline 3 May 2018 & $\begin{array}{l}\text { New citation required but conclusions } \\
\text { have not changed }\end{array}$ & $\begin{array}{l}\text { Review updated with the inclusion of 10 additional studies but } \\
\text { conclusions remain unchanged. }\end{array}$ \\
\hline
\end{tabular}

\section{CONTRIBUTIONS OF AUTHORS}

All authors contributed to the design, development and drafting of the protocol for this review. RT, LS, RG and HQ conducted screening and data extraction, with assistance from LB. LS and RT conducted analysis of the studies according to the CALO-RE taxonomy. MAT, LS, DJR, KAR, SJCT and JMS assisted with interpretation of results and drafting of the final report. RT led the final report.

\section{DECLARATIONSOF INTEREST}

Rebecca Turner:

Liz Steed: None known

Helen Quirk: None known

Rosa Greasley: None known

John Saxton: None known

Stephanie Taylor: None known

Derek Rosario: None known

Mohamed Thaha: None known

Liam Bourke: received honoraria for lecturing from Sanofi and Astellas and research funding from the NIHR and CRUK.

\section{SOURCES OF SUPPORT}

\section{Internal sources}

- None, Other. 


\section{External sources}

- None, Other.

\section{DIFFERENCES BETWEEN PROTOCOLANDREVIEW}

- We have highlighted reasons why we contacted corresponding authors and have quantified how many times we attempted to do this by email (please see Selection of studies; Excluded studies).

- We did not examine funnel plots because too few studies were identified (please see Assessment of risk of bias in included studies).

- We carried out a GRADE assessment on the quality of our meta-analysis data and included a 'Summary of findings' table (Summary of findings for the main comparison) with this information.

- We were not able to find any studies describing 'pattern' of resistance exercise (i.e. the period of rest in between sets) and hence did not discount any studies for not reporting this. We judged that it would be more informative to include the studies that we found than to not report on resistance exercise interventions at all.

- In the 2018 update, we added contact with healthcare professionals to our secondary objectives. Healthcare professionals have a role to play in the integration of exercise in the cancer care pathway and therefore it would be useful to understand if the exercise studies incorporate healthcare professionals in the role of recruitment or behavioural support during the intervention.

- In the 2018 update, we did not search Metaregister (http://www.controlled-trials.com/rct) website as it is now unavailable.

\section{INDEX TERMS}

\section{Medical Subject Headings (MeSH)}

${ }^{\star}$ Cancer Survivors; “Exercise; *Habits; *Sedentary Behavior; Breast Neoplasms [rehabilitation]; Colorectal Neoplasms [rehabilitation]; Exercise Tolerance [physiology]; Health Promotion; Muscle Strength; Neoplasms [^rehabilitation]; Patient Compliance [statistics \& numerical data]; Prostatic Neoplasms [rehabilitation]; Randomized Controlled Trials as Topic; Time Factors

\section{MeSH check words}

Female; Humans; Male 